\title{
Epigenetic regulation of BDNF-TrkB signaling in the pathophysiology and treatment of mood disorders
}

Citation for published version (APA):

Boulle, F. (2013). Epigenetic regulation of BDNF-TrkB signaling in the pathophysiology and treatment of mood disorders. [Doctoral Thesis, Maastricht University]. Uitgeverij BOXPress. https://doi.org/10.26481/dis.20131129fb

Document status and date:

Published: 01/01/2013

DOI:

10.26481/dis.20131129fb

Document Version:

Publisher's PDF, also known as Version of record

\section{Please check the document version of this publication:}

- A submitted manuscript is the version of the article upon submission and before peer-review. There can be important differences between the submitted version and the official published version of record.

People interested in the research are advised to contact the author for the final version of the publication, or visit the DOI to the publisher's website.

- The final author version and the galley proof are versions of the publication after peer review.

- The final published version features the final layout of the paper including the volume, issue and page numbers.

Link to publication

\footnotetext{
General rights rights.

- You may freely distribute the URL identifying the publication in the public portal. please follow below link for the End User Agreement:

www.umlib.nl/taverne-license

Take down policy

If you believe that this document breaches copyright please contact us at:

repository@maastrichtuniversity.nl

providing details and we will investigate your claim.
}

Copyright and moral rights for the publications made accessible in the public portal are retained by the authors and/or other copyright owners and it is a condition of accessing publications that users recognise and abide by the legal requirements associated with these

- Users may download and print one copy of any publication from the public portal for the purpose of private study or research.

- You may not further distribute the material or use it for any profit-making activity or commercial gain

If the publication is distributed under the terms of Article $25 \mathrm{fa}$ of the Dutch Copyright Act, indicated by the "Taverne" license above, 
Epigenetic regulation of BDNF/TrkB signaling in the pathophysiology and treatment of mood disorders

Fabien BOULLE 
Copyright (C): Fabien Boulle 2013,

All rights reserved. No part of this book may be reproduced or transmitted in any form or by any means, without permission in writing, from the copyright holder.

Cover design: Proefschriftmaken.nl || Uitgeverij BOXPress

Printing and layout: Proefschriftmaken.nl || Uitgeverij BOXPress

Published by Uitgeverij BOXPress, Hertogenbosch 


\section{Epigenetic regulation of BDNF/TrkB signaling in the pathophysiology and treatment of mood disorders}

\section{DISSERTATION}

To obtain the degree of Doctor at

Maastricht University and Université Paris-Descartes, on the authority of the Rector Magnifici,

Prof. Dr. L.L.G Soete and Prof. Dr. F. Dardel, in accordance with the decision of the Board of Deans, to be defended in public

on Friday $29^{\text {th }}$ of November 2013 at 12.00 hrs

$$
\text { by }
$$

Fabien BOULLE 


\section{Supervisors:}

Prof. Dr. H.M.W. Steinbusch

Prof. Dr. L. Lanfumey

\section{Co-supervisors:}

Dr. D.L.A Van den Hove

Dr. G.R.L Kenis

\section{Assessment committee:}

Prof. Dr. M. De Baets (Chairman)

Prof. Dr. K.P. Lesch (University of Wuerzburg)

Prof. Dr. P. Gorwood (University of Paris-Descartes)

Dr. R. Mongeau (University of Paris-Descartes)

Dr. A. Romano

Dr. A. Korosi (University of Amsterdam) 
"Be realistic, demand the impossible"

Ernesto Quevara (1968) 


\section{CONTENTS}

\section{Chapter I}

General introduction, aim and outlines

\section{Chapter II}

Epigenetic regulation of the BDNF gene: implications for psychiatric diseases

\section{Chapter III}

Growth factors and neuroplasticity pathways in the pathophysiology and treatment of mood disorders

\section{Chapter IV}

TrkB inhibition as a therapeutic target for CNS-related disorders

\section{Chapter V}

Blockade of the BDNF receptor TrkB downregulates the expression of plasticity genes concomitant with epigenetic changes in differentiated human neuroblastoma cells

\section{Chapter VI}

Long-term behavioral and neurobiological consequences of developmental exposure to fluoxetine in a rodent model of maternal adversity

\section{Chapter VII}

Behavioral and neurochemical characterization of TrkB-dependent mechanisms of agomelatine in glucocorticoid receptor-impaired mice

\section{Chapter VIII}

Agomelatine normalizes hippocampal and behavioral dysfunction in a mouse model of environmental stress 


\section{Chapter IX}

General discussion

Summary

Acknowledgements

About the author

List of publications 


\section{CHAPTER I}

General Introduction

Fabien BOULLE 
Mood disorders, also referred as affective disorders, belong to a group of diagnoses from the Diagnostic and Statistical Manual of Mental Disorder (DSM-IV TR) classification where a disturbance of an individual's mood is the main feature of the disorder (Nettle et al., 2012). Among mood disturbances, depression and mania can be seen as opposite ends of the affective spectrum. Classically, mania refers to the $u p$ pole of the spectrum, where patients experience elevated and irritable mood often associated with distractibility, racing thoughts and agitation (e.g. a manic or hypomanic episode). In contrast, depression refers to the down pole, where patients suffer from low mood, loss of interest, fatigue, feelings of worthlessness and/or suicidal ideation (e.g. major depressive episode). Mania and depression can occur simultaneously (e.g. mixed episodes or bipolar disorder). Epidemiological research indicates that mood disorders are among the major health problems worldwide due to the high prevalence and recurrence in the general population, and the significant burden for individual life quality and the repercussion on healthcare systems and society (WHO, 2001). Today, depression is estimated to affect 350 millions people, with a lifetime prevalence ranging from 3 percent in Japan to 17 percent in the United states most of the countries showing a prevalence between 8 to 12 percent in the general population - (WHO, 2012). On the other side, the occurrence of manic episodes during a lifetime has been estimated to only 1 to 2 percent (Soldani et al., 2005; Merikangas et al., 2004). Moreover, co-morbidity between mood disorders and somatic or other psychiatric diseases is often observed in patients. For instance, depression frequently co-occurs with anxiety or neuropathic pain, and increases the risk for cardio-vascular problems (Kessler et al., 1996; Bair et al., 2003). In addition, major depression represents a considerable risk factor for suicide, which has been estimated to lead to more than 1 million deaths every year (WHO, 2012). By 2030, major depression is expected to become the largest contributor to disease burden (WHO, 2008).

\section{I - The pathophysiology of mood disorders}

Neurotransmitters and circuits in mood disorders: The etiology of mood disorders is still poorly understood, and the complexity and heterogeneity of the diseases hamper adequate diagnosis and treatment (Phillips et al., 2013; Zajecka et al., 2013). Up to date, three principal neurotransmitters have been associated to the pathophysiology and treatment of mood disorders (Krishnan et al., 2008). They are dopamine (DA), noradrenaline (NA) and serotonin (5-HT), the so-called monoamine neurotransmitter systems, and often act in concert to regulate mood. The mesolimbic dopamine pathway comprises neurons projecting from the ventral tegmental area (VTA) in the brainstem to the nucleus accumbens (NAc) in the ventral striatum, and is believed to be involved in behavioral expressions like pleasure, euphoria, delusions or hallucinations. The mesocortical dopamine pathway projects from the VTA to the prefrontal cortex, which is mostly implicated in mediating cognitive and affective functions. Noradrenaline has both ascending and descending pathways. The ascending pathway projects from the locus coeruleus in the brainstem to multiple brain regions including the amydala, thalamus, striatum, hypothalamus, hippocampus and prefrontal cortex. The ascending noradrenergic projections are mainly 
involved in the regulation of attention, decision-making, arousal and the fight or flight response. Serotonin, like noradrenaline, has both ascending and descending projections. The ascending pathway arises from the raphe nucleus in the brainstem, and projects to the amydala, thalamus, striatum, hypothalamus, hippocampus and prefrontal cortex. In the brain, serotonin is mostly involved in sleep, anxiety, appetite and mood. However, clean-cut evidences for changes of monoamine levels in the brain of mood disorders patients are still lacking.

Pharmacological treatments: Although there is no clear evidence that dysregulation of the monoamine neurotransmitter systems significantly contributes to the etiology of mood disorders, most antidepressant drugs mainly act via the monoaminergic pathways by increasing the levels of the neurotransmitters in the synaptic cleft, either by blocking the reuptake or by inhibiting the breakdown of the neurotransmitters. Tricyclic antidepressants (TCAs) for example, the first class of psychotropic drugs to be clinically used at a large scale, mainly act by blocking serotonin and norepinephrine transporters (SERT and NAT). The downside of these types of antidepressants is the relatively high toxicity and the numerous side effects. Later, more specific reuptake blockers have been developed, like the selective serotonin reuptake inhibitors (SSRIs), the serotonin-norepinephrine reuptake inhibitors (SNRIs) and the norepinephrine reuptake inhibitors (NARIs) that more specifically act on their respective target transporters and generally have fewer side effects. Another way to increase monoaminergic signaling is by inhibiting the breakdown of the neurotransmitters in the synaptic cleft. For example, the monoamine oxidase inhibitors (MAOIs) have shown to reduce the breakdown of monoamines, by inhibiting the monoamine oxidase enzyme family. Thus, MAOIs enhance serotonergic, noradrenergic and dopaminergic transmission.

However, all currently available antidepressants encounter notable limitations including a delayed therapeutic effict (from weeks to months), a low response rate (only two third of the patients respond well) and a high relapse rate after treatment termination (Trivedi et al., 2006).

Stress, neurotrophins and depression: Stress has been proposed as a major risk factor to develop affective disorders. Stressful stimuli generally activate the hypothalamus resulting in the production of corticotropin-releasing factor (CRF), which in turn stimulates the release of adenocorticotropic hormone (ACTH) from the pituitary. Finally, ACTH causes the secretion of glucocorticoids, i.e. cortisol (corticosterone in rodents), from the adrenal gland. Cortisol in turn terminated the hormonal stress response by inhibiting the CRF release from the hypothalamus. However, under pathological conditions, such as chronic or excessive stress exposure, the HPA axis fails to exert this negative feedback, resulting in abnormally high glucocorticoid levels. Thus, chronic hypercortisolemia can significantly impact on structural and functional plasticity in various brain areas (Berton et al., 2006). In particular, prolonged stress exposure has been shown to affect the production of growth factors, and among many candidates, brain-derived neurotrophic factor (BDNF) has been reported as a key-role player in the deleterious effects of stress on the brain (see Figure 1). BDNF is a small neurotrophin secreted by neuronal and glial cells in 
various regions of the brain, especially in the areas controlling mood and emotions. Upon binding to its tropomyosin-related kinase receptor (TrkB), BDNF induces proliferation, differentiation, survival and neurite extension, which are essential process in the normal development and functioning of brain cells. However, under situations of chronic stress, BDNF gene expression can be repressed. The resulting decrease in BDNF protein has been suspected to cause cell loss and synaptic dysfunction in the hippocampus and prefrontal cortex of depressed patients (Duman et al., 2012). Antidepressant treatments, via monoamine-related signal transduction cascades, have been shown to increase BDNF and other trophic factors, and potentially restore neuronal loss and atrophy in hippocampal and cortical areas via BDNF (Castren et al., 2008).

\section{II - BDNF/TrkB signaling}

Neurotrophins in the brain: Neurotrophins are a family of small-secreted proteins that play a key role in the development and maintenance of the vertebrate nervous system (Chao, 2003). To mediate their effects, neurotrophins can bind to two distinct classes of receptors, displaying opposite effects. The high affinity interaction with the "tropomyosin-related kinase" receptor family (Trks) is usually associated with cell survival, differentiation and synaptic plasticity, whereas the low affinity interaction with the p75 (p75NTR) promotes proteolysis and apoptosis ( $\mathrm{Lu}$ et al., 2005). The neurotrophin tyrosine kinase receptor 2 (NTRK2), also known as TrkB, is specifically activated by several neurotrophins including BDNF, neurotrophin 3 (NT 3) and neurotrophin 4/5 (NT 4/5), thereby exerting their trophic effects (Klein et al., 1991; Klein et al., 1992; Soppet et al., 1991). Among all the neurotrophins, the interaction of BDNF with TrkB has been characterized most thoroughly. The expression of BDNF, as well as of TrkB, is very abundant in the cortico-limbic structures of the brain and both are also present at lower levels in different peripheral tissues (Maisonpierre et al., 1990; Pruunsild et al., 2007). BDNF/TrkB signaling has been reported as critical in various physiological processes such as learning, memory and reward. In particular, BDNF is required for the maturation, differentiation and survival of neural progenitor cells, e.g. neurogenesis, in the dentate gyrus (DG) of the hippocampus. Abnormal BDNF-mediated activation of TrkB has been reported in various neurological and psychiatric disorders (Pezet and Malcangio, 2004).

BDNF-mediated activation of TrkB: The activation of TrkB by BDNF generally follows the common pattern associated with tyrosine kinase receptor activation (Friedman and Greene, 1999). Neurotrophins exist preferentially as homodimer complexes, and bind to the extracellular interface of a TrkB monomer resulting in receptor dimerisation (Jing et al., 1992). The dimerisation increases the catalytic activity of the intracellular domain of the receptor enabling the phosphorylation of tyrosine residues inside the activation loop (tyrosine Y701, Y705 and Y706) and subsequently the autophosphorylation of tyrosine residues situated outside of the activation loop (tyrosine Y515 and Y816) (Cunningham and Greene, 
1998). Then, activation and recruitment of partner proteins and adaptators to the different tyrosine sites will lead to activation of three main intracellular signaling pathways that are strongly interconnected (Huang and Reichardt, 2003). Briefly, phosphorylation of tyrosine Y515 activates 1) the Ras-mitogenactivated protein kinase (MAPK) signaling cascade, which promotes neuronal differentiation and growth, and 2) the phosphatidylinositol 3-kinase (PI3-K) signaling cascade, which promotes neuronal survival and growth. Phosphorylation of tyrosine Y816 activates 3) the phospholipase $\mathrm{C} \gamma$ (PLC $\gamma$ ) pathway generally associated with synaptic plasticity and neurotransmission (Minichiello, 2009). The neurotrophin/Trk complex is internalized by endocytosis and the intracellular domain of the receptor, present on the outside of the endosome, is still phosphorylated and susceptible to binding of signaling molecules (Howe et al., 2001). However, the exact mechanism underlying TrkB internalization and recycling is still poorly understood. In addition, different alternative TrkB mRNA splice variants can lead to the translation of different TrkB isoforms including two truncated forms (Middlemas et al., 1991). It has been described that the two truncated forms of TrkB (TrkB-T1 and TrkB-T2) lacking the intrinsic tyrosine kinase activity, were able to inhibit full-length TrkB (TrkB-FL) signaling via the binding of a truncated form with a full form (Dorsey et al., 2006). 


$$
\text { A - Normal state } \quad \text { B - Depressed state } \quad \text { C - Remitted state }
$$

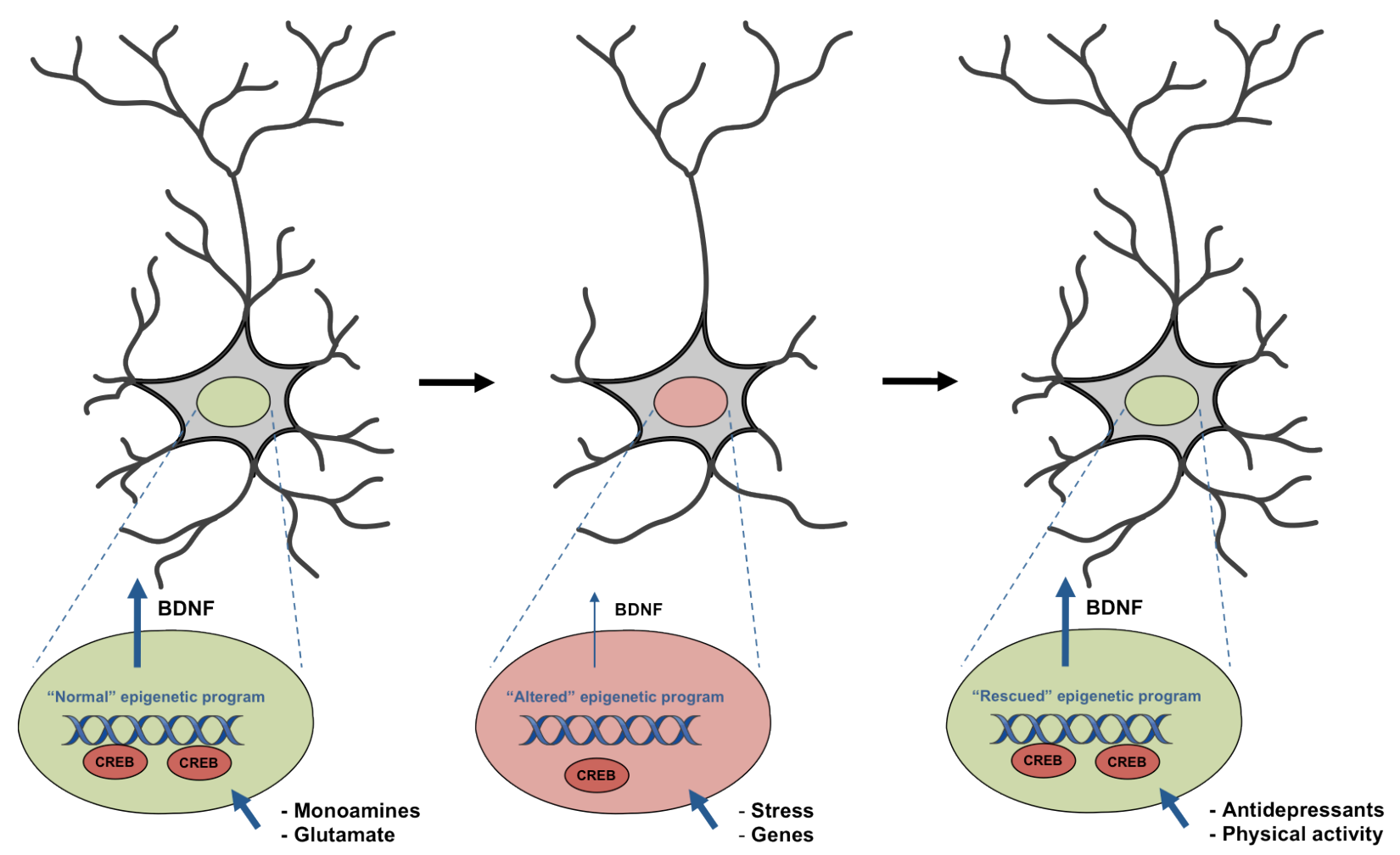

Figure 1: Schematic representation of epigenetic and neuroplastic mechanisms in the hippocampus of depressed patients and antidepressant action.

(A) Stimulation of hippocampal pyramidal neurons by glutamate or monoaminergic neurotransmitters, possibly via the activation of cAMP responsive element binding (CREB), is critical for the regulation of BDNF expression. In addition, epigenetic mechanisms control the expression of BDNF, and an appropriate epigenetic programming during development and adulthood ensures an adequate expression and function of BDNF. (B) Chronic stress exposure, as well as genetic variations, can interfere with epigenetic regulation and reduce BDNF-mediated plasticity in the hippocampus. (C) Interestingly, it has been shown that antidepressant treatments and physical activity can reverse epigenetic alterations and restore a normal expression of BDNF and enhance neuroplasticity in hippocampal neurons. Adapted from Berton et al (2006). 


\section{III - Epigenetic regulation in mood disorders}

Definition and basic principles: Epigenetics refers to mechanisms that regulate gene expression independently of the DNA sequence. Hence, the modulation of gene expression by epigenetic mechanisms is essential during development, where a "cellular memory" is created enabling an appropriate pattern of gene expression and a specific cellular phenotype (Probst et al., 2009). Diverse stimuli such as life events, behavioral experience or circadian rhythms can induce cellular responses that involve epigenetic remodeling, and it is believed that stable epigenetic imprints at particular genetic loci may shape neuronal plasticity and thereby influence behavior. The two best-described molecular mechanisms of epigenetic regulation are DNA methylation and post-translational histone modifications in the cell nucleus.

DNA methylation is the process of chemical addition of a methyl group to the carbon atom at position 5 of a cytosine residue, which typically occurs at $\mathrm{CpG}$ nucleotides (i.e. where a cytosine nucleotide occurs next to a guanine nucleotide in the linear sequence of bases, separated by a phosphate). In general, DNA methylation in promoter regions disables transcription factors to bind to their recognition sites, thereby silencing gene expression. DNA methylation needs the recruitment of specific enzymes called DNA methyltransferases (DNMTs), which mediate the addition of the methyl group on cytosine residues. In addition to DNMTs, some proteins are able to interact with methyl-CpG sites and increase the repressive potential of methylated DNA. These molecules can carry a methyl-CpG binding domain (MBD proteins) or other specific domains that recognise methylated DNA. Several pathways leading to DNA demethylation have been proposed involving the growth arrest and DNA-damage-inducible protein 45 alpha (GADD45a) (Barreto et al., 2007). In addition, ten-eleven-translocation (TET) enzymes can oxidize the 5-methylcytosine into a 5-hydroxymethylcytosine, which can be further oxidized into 5formylcytosine and 5-carboxylcytosine (Tahiliani et al., 2009; Ito et al., 2011).

In the eukaryotic nucleus, DNA is compacted and wrapped around histone and non-histone proteins to form a dynamic structure called chromatin. The nucleosome consists of an octamer of core histones (two copies of histone $\mathrm{H} 2 \mathrm{~A}, \mathrm{H} 2 \mathrm{~B}, \mathrm{H} 3$ and $\mathrm{H} 4$ ) around which DNA is wounded, and represents the basic repeated unit of chromatin. Two types of chromatin can be distinguished based upon their condensation states. Heterochromatin is inactive and condensed, which means that transcription factors are not able to approach and recognise their specific DNA-binding sites to activate gene transcription. On the other hand, euchromatin reflects an "open" state of chromatin, and is associated with active transcription. Chromatin remodelling enables the transition between a permissive and a repressive state, and vice versa, enabling a temporal and spatial modulation of gene expression. Post-translational changes encompass covalent modification of histones at distinct amino acid residues on their amino-terminal tails, including lysine acetylation, methylation, SUMOylation and ubiquitinylation; arginine methylation; serine 
phosphorylation and proline isomerisation (Berger et al., 2007). The effect of these chemical alterations on gene transcription depends on the type of histone modification but also on the amino acid residue being modified. Generally, histone acetylation is associated with euchromatin, while histone methylation is linked to heterochromatin. The enzymes responsible for acetylation or deacetylation are histone acetyltransferases (HATs) and histone deacetylases (HDACs), respectively. Regarding methylation, histone methyltransferases (HMTs) catalyse the addition of the methyl group, whereas histone demethylases (HDMs) reverse the methylated state. Interestingly, it has been shown that HDACs and HMTs were associated with MBDs and act as co-repressor molecules to form complexes that further repress gene transcription (Jones et al., 1998). All these findings support a link between DNA methylation and chromatin remodelling in transcriptional regulation.

Clinical and preclinical evidence of epigenetic mechanisms in mood disorders: The episodic nature of mood disorders suggests that they are unlikely to be pure genetic diseases, which generally are responsible for the genesis of life-long illnesses. Genome-wide association studies have revealed hundreds of potential candidates for severe mental illness, but the effective contribution of each individual gene appears to be very small. Epidemiological evidence also links environmental factors, especially early life events, with an increased risk for mood disorders (Hammen et al., 2005; Kessler et al., 1997). Hence, the notion of gene $\mathrm{x}$ environment (GxE) interaction has emerged as a prevalent theory to explain the inter-individual variations underlying susceptibility and resilience to mental disorders. As a possible mediator of GxE interactions, epigenetic reprogramming during brain development may be of critical importance. A multitude of clinical studies have investigated epigenetic signatures in bloodderived lymphocytes and post-mortem brain tissues from mood disorder patients. For example, postmortem brain analysis revealed a decreased expression of G9a histone methyltransferase, HDAC2 and H3K9 methylation, all pointing toward a permissive state of chromatin, in the NAc of depressed patients (Covington et al., 2009; Covington et al., 2011). In the periphery, mRNA profiling in white blood cells revealed a decrease of HDAC2 and HDAC5 in the depressive state of major depressive disorder (MDD), and a decrease of HDAC6 and HDAC8 in the depressive state of bipolar disorder (BPD) (Hobara et al., 2010). Interestingly, the alterations at HDAC2 and HDAC5 were normalized in the remitted state. Similarly, the mRNA expression in peripheral white blood cells of the HDACs Sirt1, Sirt2 and Sirt6 was decreased in the depressed state of MDD and BPD, whereas no differences were observed in the remitted state (Abe et al., 2011). In addition, a recent study showed that monozygotic twins affected with MDD have greater variance in methylation in white blood cells as compared to their unaffected siblings (Byrne et al., 2013). Next to the above-mentioned clinical evidence, various animal studies have brought further support for the involvement of epigenetics in the vulnerability to stress and mood disorders. Meaney and colleagues were the first to demonstrate a mechanism of epigenetic regulation for stress vulnerability in rodents. They found that variation in maternal care could regulate the expression of the glucocorticoid receptor (GR) in the hippocampus by inducing changes in DNA methylation and histone acetylation, an 
effect that seemed to be stable into adulthood. Offspring who received higher levels of maternal care showed less anxiety-like behavior and better recovery from stressful situations (Weaver et al., 2004). This result was the first to indicate the importance of early life events in epigenetic programming and susceptibility for mood disorders later in life. Moreover, using a model of adult stressful life events, Nestler and colleagues showed that an inbred population of mice could be separated into susceptible and unsusceptible subpopulations after exposure to social defeat stress (Krishnan et al., 2007), and that the molecular signature underlying the resistance to stress seems to reside in epigenetic regulations. Direct evidence for a possible role of epigenetic mechanisms in the development of mood disorders is further supported by the work on the Circadian Locomotor Output Cycles Kaput (Clock) gene. Clock has been shown to display histone acetyl transferase properties, and is critical in regulating circadian rhythms (Nakahata et al., 2008). Interestingly, mutations in the Clock gene resulted in manic-like behavior in mice (Roybal et al., 2007), and strongly support the implication of circadian rhythms and associated epigenetic regulations in the pathophysiology of BPD (Milhiet el al., 2011). Altogether, clinical and preclinical studies suggest that the interplay between life events and genetic variation might play a critical role in epigenetic reprogramming, and may be one of the most plausible explanations underlying differential susceptibility towards mood disorders.

Epigenetic mechanisms in the treatment of mood disorders: Antidepressants are known to increase levels of monoamine neurotransmitters at the synapse, and, after prolonged exposure, to induce neuroplastic changes. Hence, the modulation of monoamine-related signaling cascades might trigger various cellular events involving epigenetic remodeling and subsequent gene transcription. Fluoxetine, one of the most prescribed SSRI antidepressants, was shown to directly induce the expression of MBDs (MeCP2 and MBD2) in adult rat brain (Cassel et al., 2006). In addition, chronic treatment with fluoxetine could significantly upregulate $\mathrm{H} 3$ acetylation at the BDNF gene in the hippocampus of a mouse model of depression (Onishchenko et al., 2008). Similarly, escitalopram - another SSRI antidepressant - could decrease DNMT expression and reduce the excessive DNA methylation at the P11 gene in the frontal cortex of the Flinders Sensitive Line genetic rodent model of depression (Melas et al., 2011). Imipramine, a TCA, was shown to reverse the decreased $\mathrm{H} 3$ acetylation levels in the hippocampus induced by chronic stress in rodents (Covington et al., 2011; Hollis et al., 2011; Hollis et al., 2010). Furthermore, imipramine treatment reversed the large majority of histone methylation changes in the NAc induced by social defeat stress in mice (Wilkinson et al., 2009). Additional experiments further supported the notion that imipramine exerts its therapeutic effects by increasing BDNF levels, at least partly through downregulation of HDAC5 (Tsankova et al., 2006). Moreover, electroconvulsive shock therapy (ECT), still the most effective treatment for refractory depressed patients, has been shown to increase $\mathrm{H} 3$ acetylation at the BDNF gene in naïve rats (Tsankova et al., 2004). Regarding mood stabilizers, valproate, an effective treatment for mania and bipolar disorders, was shown to act as an HDAC inhibitor (Phiel et al., 2001). Interestingly, administration of HDAC inhibitors directly into the NAc exerted antidepressant 
properties in mice (Covington et al., 2009). This same study showed that HDAC inhibiton produced a similar pattern of gene expression in the NAc as compared to fluoxetine (Covington et al., 2009). Moreover, infusion of DNMT inhibitors such as RG108 and zebularine into the NAc could reverse the depressive-like behaviors induced by chronic stress in mice (LaPlant et al., 2010).

Altogether, the current literature indicates that epigenetic remodeling might be necessary for the therapeutic action of antidepressants.

\section{IV - Aim and outline of the thesis}

The research presented in this thesis aims to explore the role of BDNF signaling and its downstream epigenetic regulations in the pathophysiology and treatment of mood disorders.

First of all, an overview of current literature is provided in the first part of this dissertation. Chapter 2 gives an overview about epigenetic regulations at the BDNF gene in psychiatric phenotypes, and discusses potential implications for psychiatric neuroscience and development of novel psychotropic drugs. Further, Chapter 3 summarizes the literature about the impairment of neuroplasticity in depression and potential implications for the development of novel antidepressant drugs. In particular, a detailed overview of the different trophic factors (including BDNF) and intracellular signaling pathways implicated in the pathophysiology of depression is presented. In addition, the neurotrophic actions of current antidepressant medications are reviewed. Finally, Chapter 4 describes the upregulation of TrkB signaling in brain disorders and proposes different methods and approaches to model BDNF/TrkB interaction and develop novel TrkB modulators.

Further, the original research of this thesis explored the involvement of BDNF/TrkB signaling and epigenetic regulations in the pathophysiology and treatments of mood disorders. Chapter 5 provides further insights into the epigenetic and neuroplastic regulations of a novel TrkB inhibitor cyclotraxin-B. In Chapter 6, the effect of developmental exposure to fluoxetine was investigated using a model of prenatal stress in rats. In particular, the effects of maternal fluoxetine on affective behavior and epigenetic regulations at BDNF/TrkB signaling were addressed. Chapter 7 brings further evidence on the requirement of $\operatorname{TrkB}$ in the anxiolytic effects of the new generation antidepressant agomelatine in a transgenic mouse model of depression, while Chapter $\boldsymbol{8}$ focusses on the effects of agomelatine in a mouse model of hyperactivity and manic-like behavior. More specifically, the ability of agomelatine to restore stress-induced alterations at histone modifications, intracellular signaling cascades and plasticity-related gene expression was investigated.

Finally, Chapter 9 summarizes and discusses the main findings of this dissertation, while also providing future directions and perspectives. 


\section{References}

Abe, N., Uchida, S., Otsuki, K., Hobara, T., Yamagata, H., Higuchi, F., Shibata, T. and Watanabe, Y. (2011) Altered sirtuin deacetylase gene expression in patients with a mood disorder. J Psychiatr Res 45, 1106-1112.

Bair, M. J., Robinson, R. L., Katon, W. and Kroenke, K. (2003) Depression and pain comorbidity: a literature review. Arch Intern Med 163, 2433-2445.

Barreto, G., Schafer, A., Marhold, J., Stach, D., Swaminathan, S. K., Handa, V., Doderlein, G., Maltry, N., Wu, W., Lyko, F. and Niehrs, C. (2007) Gadd45a promotes epigenetic gene activation by repair-mediated DNA demethylation. Nature 445, 671-675.

Berger, S. L. (2007) The complex language of chromatin regulation during transcription. Nature 447, 407-412.

Berton, O. and Nestler, E. J. (2006) New approaches to antidepressant drug discovery: beyond monoamines. Nat Rev Neurosci 7, 137-151.

Byrne, E. M., Carrillo-Roa, T., Henders, A. K., Bowdler, L., McRae, A. F., Heath, A. C., Martin, N. G., Montgomery, G. W., Krause, L. and Wray, N. R. (2013) Monozygotic twins affected with major depressive disorder have greater variance in methylation than their unaffected co-twin. Transl Psychiatry 3, e269.

Cassel, S., Carouge, D., Gensburger, C., Anglard, P., Burgun, C., Dietrich, J. B., Aunis, D. and Zwiller, J. (2006) Fluoxetine and cocaine induce the epigenetic factors MeCP2 and MBD1 in adult rat brain. Mol Pharmacol 70, 487492.

Castren, E. and Rantamaki, T. (2008) Neurotrophins in depression and antidepressant effects. Novartis Found Symp 289, 43-52; discussion 53-49, 87-93.

Chao, M. V. (2003) Neurotrophins and their receptors: a convergence point for many signalling pathways. Nat Rev Neurosci 4, 299-309.

Covington, H. E., 3rd, Maze, I., LaPlant, Q. C., Vialou, V. F., Ohnishi, Y. N., Berton, O., Fass, D. M., Renthal, W., Rush, A. J., 3rd, Wu, E. Y., Ghose, S., Krishnan, V., Russo, S. J., Tamminga, C., Haggarty, S. J. and Nestler, E. J. (2009) Antidepressant actions of histone deacetylase inhibitors. J Neurosci 29, 11451-11460.

Covington, H. E., 3rd, Maze, I., Sun, H., Bomze, H. M., DeMaio, K. D., Wu, E. Y., Dietz, D. M., Lobo, M. K., Ghose, S., Mouzon, E., Neve, R. L., Tamminga, C. A. and Nestler, E. J. (2011) A role for repressive histone methylation in cocaine-induced vulnerability to stress. Neuron 71, 656-670.

Cunningham, M. E., Greene, L. A., 1998. A function-structure model for NGF-activated TRK. EMBO J. 17, 72827293.

Dorsey, S. G., Renn, C. L., Carim-Todd, L., Barrick, C. A., Bambrick, L., Krueger, B. K., Ward, C. W., Tessarollo, L., 2006. In vivo restoration of physiological levels of truncated TrkB.T1 receptor rescues neuronal cell death in a trisomic mouse model. Neuron. 51, 21-28.

Duman, R. S. and Aghajanian, G. K. (2012) Synaptic dysfunction in depression: potential therapeutic targets. Science 338, 68-72.

Friedman, W. J., Greene, L. A., 1999. Neurotrophin signaling via Trks and p75. Exp. Cell. Res. 253, 131-142.

Hammen, C. (2005) Stress and depression. Annu Rev Clin Psychol 1, 293-319.

Hobara, T., Uchida, S., Otsuki, K., Matsubara, T., Funato, H., Matsuo, K., Suetsugi, M. and Watanabe, Y. (2010) Altered gene expression of histone deacetylases in mood disorder patients. J Psychiatr Res 44, 263-270.

Hollis, F., Duclot, F., Gunjan, A. and Kabbaj, M. (2011) Individual differences in the effect of social defeat on anhedonia and histone acetylation in the rat hippocampus. Horm Behav 59, 331-337. 
Hollis, F., Wang, H., Dietz, D., Gunjan, A. and Kabbaj, M. (2010) The effects of repeated social defeat on long-term depressive-like behavior and short-term histone modifications in the hippocampus in male Sprague-Dawley rats. Psychopharmacology (Berl) 211, 69-77.

Howe, C. L., Valletta, J. S., Rusnak, A. S., Mobley, W. C., 2001. NGF signaling from clathrin-coated vesicles: evidence that signaling endosomes serve as a platform for the Ras-MAPK pathway. Neuron. 32, 801-814.

Ito, S., Shen, L., Dai, Q., Wu, S. C., Collins, L. B., Swenberg, J. A., He, C. and Zhang, Y. (2011) Tet proteins can convert 5-methylcytosine to 5-formylcytosine and 5-carboxylcytosine. Science 333, 1300-1303.

Jing, S., Tapley, P., Barbacid, M., 1992. Nerve growth factor mediates signal transduction through trk homodimer receptors. Neuron. $9,1067-1079$.

Jones, P. L., Veenstra, G. J., Wade, P. A., Vermaak, D., Kass, S. U., Landsberger, N., Strouboulis, J. and Wolffe, A. P. (1998) Methylated DNA and MeCP2 recruit histone deacetylase to repress transcription. Nat Genet 19, $187-191$.

Kessler, R. C., Nelson, C. B., McGonagle, K. A., Liu, J., Swartz, M. and Blazer, D. G. (1996) Comorbidity of DSMIII-R major depressive disorder in the general population: results from the US National Comorbidity Survey. Br J Psychiatry Suppl, 17-30.

Kessler, R. C., Zhao, S., Blazer, D. G. and Swartz, M. (1997) Prevalence, correlates, and course of minor depression and major depression in the National Comorbidity Survey. J Affect Disord 45, 19-30.

Klein, R., Lamballe, F., Bryant, S. and Barbacid, M. (1992) The trkB tyrosine protein kinase is a receptor for neurotrophin-4. Neuron 8, 947-956.

Klein, R., Nanduri, V., Jing, S. A., Lamballe, F., Tapley, P., Bryant, S., Cordon-Cardo, C., Jones, K. R., Reichardt, L. F. and Barbacid, M. (1991) The trkB tyrosine protein kinase is a receptor for brain-derived neurotrophic factor and neurotrophin-3. Cell 66, 395-403.

Krishnan, V., Han, M. H., Graham, D. L., Berton, O., Renthal, W., Russo, S. J., Laplant, Q., Graham, A., Lutter, M., Lagace, D. C., Ghose, S., Reister, R., Tannous, P., Green, T. A., Neve, R. L., Chakravarty, S., Kumar, A., Eisch, A. J., Self, D. W., Lee, F. S., Tamminga, C. A., Cooper, D. C., Gershenfeld, H. K. and Nestler, E. J. (2007) Molecular adaptations underlying susceptibility and resistance to social defeat in brain reward regions. Cell 131, 391-404.

LaPlant, Q., Vialou, V., Covington, H. E., 3rd, Dumitriu, D., Feng, J., Warren, B. L., Maze, I., Dietz, D. M., Watts, E. L., Iniguez, S. D., Koo, J. W., Mouzon, E., Renthal, W., Hollis, F., Wang, H., Noonan, M. A., Ren, Y., Eisch, A. J., Bolanos, C. A., Kabbaj, M., Xiao, G., Neve, R. L., Hurd, Y. L., Oosting, R. S., Fan, G., Morrison, J. H. and Nestler, E. J. (2010) Dnmt3a regulates emotional behavior and spine plasticity in the nucleus accumbens. Nat Neurosci 13, 1137-1143.

Lu, B., Pang, P. T. and Woo, N. H. (2005) The yin and yang of neurotrophin action. Nat Rev Neurosci 6, 603-614.

Maisonpierre, P. C., Belluscio, L., Friedman, B., Alderson, R. F., Wiegand, S. J., Furth, M. E., Lindsay, R. M. and Yancopoulos, G. D. (1990) NT-3, BDNF, and NGF in the developing rat nervous system: parallel as well as reciprocal patterns of expression. Neuron 5, 501-509.

Melas, P. A., Rogdaki, M., Lennartsson, A., Bjork, K., Qi, H., Witasp, A., Werme, M., Wegener, G., Mathe, A. A., Svenningsson, P. and Lavebratt, C. (2011) Antidepressant treatment is associated with epigenetic alterations in the promoter of P11 in a genetic model of depression. Int J Neuropsychopharmacol 15, 669-679.

Merikangas, K. R. and Low, N. C. (2004) The epidemiology of mood disorders. Curr Psychiatry Rep 6, 411-421.

Middlemas, D. S., Lindberg, R. A., Hunter, T., 1991. TrkB, a neural receptor protein-tyrosine kinase: evidence for a full-length and two truncated receptors. Mol. Cell. Biol. 11, 143-153.

Milhiet, V., Etain, B., Boudebesse, C. and Bellivier, F. (2011) Circadian biomarkers, circadian genes and bipolar disorders. J Physiol Paris 105, 183-189.

Minichiello, L., 2009. TrkB signalling pathways in LTP and learning. Nat. Rev. Neurosci. 10, 850-860. 
Nakahata, Y., Kaluzova, M., Grimaldi, B., Sahar, S., Hirayama, J., Chen, D., Guarente, L. P. and Sassone-Corsi, P. (2008) The NAD+-dependent deacetylase SIRT1 modulates CLOCK-mediated chromatin remodeling and circadian control. Cell 134, 329-340.

Nettle, D. and Bateson, M. (2012) The evolutionary origins of mood and its disorders. Curr Biol 22, R712-721.

Onishchenko, N., Karpova, N., Sabri, F., Castren, E. and Ceccatelli, S. (2008) Long-lasting depression-like behavior and epigenetic changes of BDNF gene expression induced by perinatal exposure to methylmercury. J Neurochem 106, 1378-1387.

Pezet, S. and Malcangio, M. (2004) Brain-derived neurotrophic factor as a drug target for CNS disorders. Expert Opin Ther Targets 8, 391-399.

Phiel, C. J., Zhang, F., Huang, E. Y., Guenther, M. G., Lazar, M. A. and Klein, P. S. (2001) Histone deacetylase is a direct target of valproic acid, a potent anticonvulsant, mood stabilizer, and teratogen. J Biol Chem 276, 3673436741 .

Phillips, M. L., Kupfer, D. J. (2013) Bipolar disorder diagnosis: challenges and future direction. Lancet May 11; 381(9878): 1663-71

Probst, A. V., Dunleavy, E. and Almouzni, G. (2009) Epigenetic inheritance during the cell cycle. Nat Rev Mol Cell Biol 10, 192-206.

Pruunsild, P., Kazantseva, A., Aid, T., Palm, K. and Timmusk, T. (2007) Dissecting the human BDNF locus: bidirectional transcription, complex splicing, and multiple promoters. Genomics 90, 397-406.

Roybal, K., Theobold, D., Graham, A., DiNieri, J. A., Russo, S. J., Krishnan, V., Chakravarty, S., Peevey, J., Oehrlein, N., Birnbaum, S., Vitaterna, M. H., Orsulak, P., Takahashi, J. S., Nestler, E. J., Carlezon, W. A., Jr. and McClung, C. A. (2007) Mania-like behavior induced by disruption of CLOCK. Proc Natl Acad Sci U S A 104, 6406-6411.

Soldani, F., Sullivan, P. F. and Pedersen, N. L. (2005) Mania in the Swedish Twin Registry: criterion validity and prevalence. Aust N Z J Psychiatry 39, 235-243.

Soppet, D., Escandon, E., Maragos, J., Middlemas, D. S., Reid, S. W., Blair, J., Burton, L. E., Stanton, B. R., Kaplan, D. R., Hunter, T., Nikolics, K. and Parada, L. F. (1991) The neurotrophic factors brain-derived neurotrophic factor and neurotrophin-3 are ligands for the trkB tyrosine kinase receptor. Cell 65, 895-903.

Souery, D., Papakostas, G. I. and Trivedi, M. H. (2006) Treatment-resistant depression. J Clin Psychiatry 67 Suppl 6, 16-22.

Tahiliani, M., Koh, K. P., Shen, Y., Pastor, W. A., Bandukwala, H., Brudno, Y., Agarwal, S., Iyer, L. M., Liu, D. R., Aravind, L. and Rao, A. (2009) Conversion of 5-methylcytosine to 5-hydroxymethylcytosine in mammalian DNA by MLL partner TET1. Science 324, 930-935.

Tsankova, N. M., Berton, O., Renthal, W., Kumar, A., Neve, R. L. and Nestler, E. J. (2006) Sustained hippocampal chromatin regulation in a mouse model of depression and antidepressant action. Nat Neurosci 9, 519-525.

Tsankova, N. M., Kumar, A. and Nestler, E. J. (2004) Histone modifications at gene promoter regions in rat hippocampus after acute and chronic electroconvulsive seizures. J Neurosci 24, 5603-5610.

Weaver, I. C., Diorio, J., Seckl, J. R., Szyf, M. and Meaney, M. J. (2004) Early environmental regulation of hippocampal glucocorticoid receptor gene expression: characterization of intracellular mediators and potential genomic target sites. Ann N Y Acad Sci 1024, 182-212.

Wilkinson, M. B., Xiao, G., Kumar, A., LaPlant, Q., Renthal, W., Sikder, D., Kodadek, T. J. and Nestler, E. J. (2009) Imipramine treatment and resiliency exhibit similar chromatin regulation in the mouse nucleus accumbens in depression models. J Neurosci 29, 7820-7832.

World Health Organization (WHO). (2001). The world health report 2001. Mental health. New understanding. New hope. Geneva WHO. 


\section{Chapter I}

World Health Organization (WHO). (2008). 2004 update. Geneva

World Health Organization (WHO). (2012). Depression, a global public health concern.

Zajecka, J., Kornstein, S. G., Blier, P. (2013). Residuals symptoms in major depressive disorder: prevalence, effects and management. J Clin Psychiatry Apr; 74(4): e321-41 


\title{
CHAPTER II
}

\section{Epigenetic regulation of the BDNF gene: implications for psychiatric diseases}

\author{
FABIEN BOULLE ${ }^{1,2}$, DANIEL L.A VAN DEN HOVE, ${ }^{1,3}$, SISSI B JAKOB ${ }^{3}$, BART P RUTTEN ${ }^{1}$, MiCHEL HAMON ${ }^{2}$, JIM \\ VAN OS ${ }^{1,4}$, KLAUS-PETER LESCH ${ }^{1,3}$, LAURENCE LANFUMEY ${ }^{2}$, HARRY W STEINBUSCH ${ }^{1}$, GUNTER KENIS ${ }^{1}$
}

${ }^{1}$ Department of Psychiatry and Neuropsychology, Maastricht University, European Graduate School for Neuroscience (EURON), Maastricht, The Netherlands

${ }^{2}$ Center for Psychiatry and Neuroscience, INSERM U894, Univ. Pierre \& Marie Curie, Paris, France

${ }^{3}$ Department of Psychiatry, Psychosomatics and Psychotherapy, University of Wurzburg, Wurzburg, Germany

${ }^{4}$ King's College London, King's Health Partner, Department of Psychosis Studies Institute of Psychiatry, London, $U K$

Molecular Psychiatry, 2012 Jun; 17 (6): 584-96 


\section{Abstract}

Abnormal brain-derived neurotrophic factor (BDNF) signaling seems to play a central role in the course and development of various neurological and psychiatric disorders. In addition, positive effects of psychotropic drugs are known to activate BDNF-mediated signaling. Although the BDNF gene has been associated with several diseases, molecular mechanisms other then functional genetic variations can impact on the regulation of $B D N F$ gene expression and lead to disturbed BDNF signaling and associated pathology. Thus, epigenetic modifications, representing key mechanisms by which environmental factors induce enduring changes in gene expression, are suspected to participate in the onset of various psychiatric disorders. More specifically, various environmental factors, particularly when occurring during development, have been claimed to produce long-lasting epigenetic changes at the $B D N F$ gene, thereby affecting availability and function of the BDNF protein. Such stabile imprints on the BDNF gene might explain, at least in part, the delayed efficacy of treatments as well as the high degree of relapses observed in psychiatric disorders. Moreover, $B D N F$ gene has a complex structure displaying differential exon regulation and usage, suggesting a subcellular- and brain region-specific distribution. As such, developing drugs that modify epigenetic regulation at specific $B D N F$ exons represents a promising strategy for the treatment of psychiatric disorders. Here, we present an overview of the current literature on epigenetic modifications at the $B D N F$ locus in psychiatric disorders and related animal models.

Keywords: $B D N F$ gene, environmental factors, epigenetic, psychiatric disorders, treatments 


\section{I - Introduction}

BDNF is a small secreted protein that is a member of the neurotrophin family of growth factors ${ }^{1}$. Its action depends on two distinct receptors differing in their respective downstream signaling pathways. The p75 neurotrophin receptor is activated by all neurotrophins and, upon activation, has various effects, which are dependent on e.g. the ligand bound to it and the type of cell it is expressed $\mathrm{in}^{2,3}$. Further, its action depends on the presence of the tropomyosin-related kinase receptor B (TrkB), the other receptor for BDNF, and neurotrophin-4/5 ${ }^{4}$. BDNF-dependent activation of $\operatorname{TrkB}$ is essential for the proper development of the vertebrate nervous system and impairment of its associated signaling pathways is likely to be at the origin of many neurological and psychiatric disorders ${ }^{5-7}$. Activation and subsequent phosphorylation of the different tyrosine residues in the catalytic domain of the TrkB receptor has been associated with at least three intracellular signaling cascades, which are widely interconnected ${ }^{8}$. Briefly, the mitogen-activated protein kinase (MAPK) pathway is primarily implicated in neuronal differentiation and neurite outgrowth, the phosphoinositide-3 kinase (PI3K) pathway mainly enables cell survival, and the phospholipase-gamma (PLC- $\gamma$ ) pathway is particularly involved in synaptic plasticity and facilitates neurotransmission ${ }^{9-12}$. As such, BDNF plays an important role in normal neural development ${ }^{13}$. BDNF is highly expressed in limbic structures and cerebral cortex, and is important for long-term potentiation (LTP) and neurogenesis, making this trophic factor a key player in learning and memory as well as in reward-related processes ${ }^{14-16}$. BDNF is meticulously regulated in the brain and modifications of neuronal BDNF expression or release are thought to induce abnormal functioning of some brain areas ${ }^{17,18}$. Recent interest has been directed to the epigenetic regulation of BDNF that mediates the effects of environmental factors on the $B D N F$ gene resulting in enduring changes of its expression ${ }^{19}$. Epigenetics refers to processes such as DNA methylation, histone acetylation or nucleosome sliding, which are dynamic events controlling the expression of genes without affecting the DNA sequence (for reviews, $\operatorname{see}^{20,21}$ ).

This review gives an overview of recent findings on epigenetic mechanisms associated with $B D N F$ gene regulation in psychiatric disorders and animal models. The origin of such modifications, i.e. risk factors such as neurodevelopmental stress exposure, in these pathologies is not under focus here because it has already been the matter of an extensive recent review elsewhere ${ }^{19}$. Our objective here is to provide an overview of new insights into the potential role of the epigenetic regulation of $B D N F$ in the pathophysiology of these disorders. Further, we will discuss some pharmacological perspectives, focusing on drugs that can modify $B D N F$ gene expression by affecting epigenetic regulation. 


\section{II - Regulation of the BDNF gene expression}

The BDNF gene: BDNF has a complex gene structure, which has been documented and revisited extensively ${ }^{22-28}$. A number of studies have presented substantial similarities in rodents and humans (Figure 1). Briefly, the human BDNF gene consists of several untranslated 5' exons with independent promoters. These can be connected to a 3' coding exon to form a bipartite or tripartite transcript providing different splice variants of $B D N F \mathrm{mRNA}^{24}$. The 3' coding exon (exon IX) contains the sequence that codes for the pro-BDNF protein. In addition, the 3' untranslated region (UTR) of exon IX is composed of two alternative polyadenylation (polyA) sites, so as to generate one short splice variant and one long splice variant ${ }^{22}$. The use of distinct $B D N F$ mRNA splice variants differing either by the 5' or 3' extremity allows for temporal and spatial regulation of BDNF expression which appears to be critical in the modulation of synaptic plasticity and spine development in dendrites ${ }^{29-31}$. This temporo-spatial regulation depends largely on the various promoters of the $B D N F$ gene, which are differentially targeted in response to diverse stimuli and signaling events ${ }^{32-34}$. In addition to regulation at the promoter level, $B D N F$ gene expression is also controlled at the posttranscriptional level. In particular, all $B d n f$ mRNAs are translated into pro-BDNF and are further cleaved into mature BDNF by several mechanisms ${ }^{35}$. The balance between pro-BDNF and mature BDNF levels in the synaptic cleft is controlled by tissue plasminogen activator (tPA) and is essential for neuronal plasticity ${ }^{36}$. While pro-BDNF binds specifically to $\mathrm{p} 75$ and primarily promotes cell death and long-term depression (LTD), mature BDNF binds more readily to TrkB, particularly enabling long-term potentiation and cell survival ${ }^{37,38}$. Therefore, the balance between proand mature BDNF on the one hand, and between the $\mathrm{p} 75$ and TrkB receptors on the other, is of critical importance in determining the functional characteristics of the BDNF signal ${ }^{39}$. Moreover, a common single nucleotide polymorphism (SNP) within the $B D N F$ gene causes a valine (Val) to methionine (Met) substitution at codon 66 of the prodomain. This SNP is thought to alter BDNF mRNA and protein trafficking, and has been widely implicated in psychiatric disorders ${ }^{40-43}$.

Epigenetic control of BDNF gene expression: Various epigenetic mechanisms have been associated with repression or activation of the rodent $B d n f$ gene (Figure 2). For example, the methyl-CpG binding protein 2 (MeCP2) is known for its repression of Bdnf gene transcription ${ }^{44}, 45 . \mathrm{MeCP} 2$ binds selectively to methylated DNA at the rat's $B d n f$ promoter IV, where it is associated with the co-repressor molecules Sin3a and histone deacetylase 1 (HDAC1) to form a complex that maintains the repressed state of the $B d n f$ gene $^{46}$. It has been shown that increased Bdnf transcription after membrane depolarization in cultured neurons correlates with the phosphorylation and dissociation of MeCP2 from Bdnf promoter

$\mathrm{IV}^{46,47}$. Other proteins such as the Growth arrest and DNA-damage-inducible protein b (Gadd45b) have been shown to be required for activity-induced DNA demethylation at Bdnf promoter IX, which is associated with increased hippocampal neurogenesis in mice ${ }^{48}$. In addition to changes in DNAmethylation, post-translational modifications of histones at distinct amino acid residues on their amino- 
terminal tails have been reported at the $B d n f$ gene. Some of these covalent modifications have been shown to modulate $B d n f$ gene expression. For example, methylation at lysine (K) 27 on histone H3 (H3K27) is usually associated with transcriptional repression, whereas acetylation on histone $\mathrm{H} 3$ and $\mathrm{H} 4$ is associated with transcriptional activation ${ }^{49}$. Rodent studies have revealed that some promoters are preferentially targeted by epigenetic regulation. This is notably the case for promoter IV, that contains a specific binding site for the cyclic-AMP responsive element binding protein (CREB) ${ }^{32,50,51}$. CREB is known to have a specific binding domain for CREB binding protein (CBP), which plays a central role in the regulation of gene activity and influences chromatin remodeling due to its histone acetyl-transferase (HAT) properties $^{52}$.

\section{III - BDNF, epigenetics and psychiatric disorders}

A prevailing current theory posits that multiple genetic and environmental factors contribute to the development of most neurological and psychiatric disorders ${ }^{54,55}$. In particular, diverse environmental stressors have been shown to modulate BDNF availability and function in rodents ${ }^{56-58}$. Importantly, stressinduced changes in $B d n f$ mRNA expression have been shown to depend upon the timing, type, duration and frequency of the stressor ${ }^{59}$. Indeed, some risk factors may cause persisting changes in BDNF gene regulation, underlying a lasting epigenetic imprint on the genome, thereby increasing susceptibility to psychopathology. In this section, the epigenetic regulation of $B D N F$ in psychiatric disorders and related phenotypes will be discussed.

Epigenetic regulation of BDNF in learning and memorv: BDNF has been shown to mediate synaptic plasticity, known to be critically important in learning and memory processes ${ }^{60}$, in particular for the consolidation and extinction of fear memory ${ }^{61-63}$. It has been shown that the BDNF val66met polymorphism affects memory and extinction learning in rodents and humans, which may have its importance in anxiety-related behavior ${ }^{41}$, 42,64 . Recent data about BDNF protein levels led to the suggestion that this trophic factor is required for consolidation and extinction of fear memory in the prelimbic cortex as well as in the amygdala in rodents ${ }^{65}$, 66 . Expression of $B d n f$ exons I and III was significantly upregulated in the amygdala of fear-conditioned rats, whereas extinction of conditioned fear in the prefrontal cortex (PFC) was accompanied by a significant increase in $B d n f$ exons I and IV ${ }^{67,68}$. Interestingly, $B d n f$ exon IV upregulation was associated with hyperacetylation of histone $\mathrm{H} 4$ near its concurrent promoter, suggesting a relationship between long-lasting extinction learning and histone modifications at $B d n f$ gene promoters in the $\mathrm{PFC}^{68}$. Another study has shown that consolidation of fear learning was associated with a transcriptional upregulation of $B d n f$ exon IV, whereas context exposure alone leads to increased levels of $B d n f$ exons I and $\mathrm{VI}^{69}$. These data suggest differential exon usage in the hippocampus in response to distinct cognitive tasks such as learning a novel environment versus 
associating an emotion with that same environment. Interestingly, increased levels of $B d n f$ exon IVcontaining transcripts correlated with the decrease in DNA methylation at the corresponding promoter, which was directly linked to an overall increase in total $B d n f$ mRNA (exon IX) in the hippocampus during fear memory consolidation ${ }^{69}$. Moreover, there is increasing evidence that DNA methylation at the $B d n f$ gene represents a crucial mechanism that regulates associated changes in hippocampal synaptic plasticity $^{70}$. Regarding recognition memory, it has been shown that performance in the novel object recognition task correlates with increased $B d n f$ expression and methylation state at the $B d n f$ promoter I in the hippocampus of mice ${ }^{71}$. Nevertheless, although epigenetic regulation of the $B d n f$ gene seems to play a crucial role in the dynamic process of learning, memory and related pathological disorders, compelling evidence from human studies to support findings observed in animal models is lacking.

Epigenetic regulation of BDNF in depression: Some studies on human patients suffering from major depression have shown reduced hippocampal volumes ${ }^{72}$ and decreased circulating levels of BDNF, which normalize after chronic antidepressant treatment ${ }^{73,74}$. Post-mortem analyses have shown decreased BDNF levels in the brains of suicide victims and depressed patients ${ }^{75,76}$. Regarding rodent models of depression, mounting evidence indicates that BDNF is implicated in stress-induced hippocampal alterations ${ }^{77,} 78$. Reduced levels of BDNF have been shown to contribute to impaired neuronal differentiation in the dentate gyrus and depression-related behavior in rodents ${ }^{79}$. In contrast, infusion of BDNF into the hippocampus has antidepressant properties in rodent models of depression ${ }^{80}$. In addition, antidepressants such as selective serotonin reuptake inhibitors (SSRIs) are known to activate BDNF-mediated signaling and reverse neuronal atrophy and cell loss induced by chronic stress in rodents, whereas $B d n f+/$ - mice showed an impaired response to antidepressants ${ }^{81,82}$. Altogether, these findings have spurred researchers to further investigate the involvement of chromatin remodeling at the $B D N F$ gene in depression and antidepressant action. Indeed, in chronic social defeat stress, a rodent model of depression, levels of $B d n f$ mRNA IV and V were decreased in the hippocampus of stressed mice ${ }^{83}$. Interestingly, this robust decrease in expression was associated with long-lasting H3K27 hypermethylation at the corresponding promoters. A similar study, using perinatal exposure to methylmercury in mice as a model for depressivelike behavior has demonstrated that this developmental exposure was associated with long-lasting changes at $B d n f$ promoter IV in the hippocampus ${ }^{84}$. Onishchenko and colleagues ${ }^{84}$ showed that the observed decrease in hippocampal Bdnf mRNA levels was mediated by H3K27 hypermethylation and H3 hypoacetylation at this specific promoter.

Taken together, these studies underscore the importance of $B D N F$ gene expression in the pathophysiology of depression and in the mechanisms of antidepressant treatments. Further, animal models of stress and depression induce specific epigenetic changes at the Bdnf gene within the hippocampus, possibly contributing to the onset of associated behavioral disorders. However the role of epigenetic modifications of the $B D N F$ gene in depressed patients has yet to be investigated. 
Epigenetic regulation of BDNF in addiction: Both BDNF and the mesolimbic dopamine system are known to play a central role in addiction ${ }^{87-89}$. In the mesolimbic system, dopaminergic neurons in the ventral tegmental area (VTA) project to the nucleus accumbens (NAc). In this respect, BDNF has been shown to mediate long-term neuronal adaptation in pathological conditions by controlling dopamine receptor expression, thereby inducing behavioral sensitization ${ }^{90}$. Changes in $B d n f$ mRNA and protein have been examined in multiple brain regions such as the VTA and NAc following administration and/or withdrawal of many addictive compounds ${ }^{91-93}$. A recent study found that acute cocaine administration induces a transient increase in BDNF protein levels and activates TrkB-mediated signaling in the NAc of rats $^{94}$. Furthermore, BDNF infusions in the NAc are known to increase cocaine self-administration as well as relapse to cocaine seeking in withdrawal ${ }^{94}$. These authors suggest that BDNF release during cocaine use is important for the development and persistence of addictive behavior. In the VTA, an increase of BDNF induces a transition to an opiate-dependent motivational state in naïve rats ${ }^{95}$. Previous findings showed that changes in BDNF levels following cocaine administration are persistent ${ }^{96}$, suggesting that epigenetic modifications could be implicated in drug-induced modifications in gene expression. However, only few studies have focused on epigenetic regulation at the $B D N F$ gene in relation to addictive disorders. A recent study has revealed that chronic administration of cocaine increases $\mathrm{H} 3$ acetylation at $B d n f$ promoter II in the rat striatum, whereas no significant changes have been observed in $\mathrm{H} 4$ acetylation at the same promoter ${ }^{97}$. Interestingly, this hyperacetylation significantly increased after one week of withdrawal from cocaine. However the increase in $\mathrm{H} 3$ acetylation did not immediately correlate with an increase in $B d n f$ mRNA and protein levels, which progressively increased during cocaine withdrawal ${ }^{96}$. Similar results have shown that chronic administration of cocaine in rats caused a robust induction of $\mathrm{H} 3$, but not $\mathrm{H} 4$, acetylation at $B d n f$ promoters II and III in the NAc shell, which was reverted by HDAC4 overexpression in this same region ${ }^{102}$. Moreover, cocaine self-administration increased acetylation of histone $\mathrm{H} 3$ and reduced MeCP2 occupancy at Bdnf promoter IV in the PFC of rats, leading to decreased levels of $B d n f$ exon IV mRNA ${ }^{103}$. Another study has focused on the effects of cocaine abstinence on the endocrine and molecular response to stress, reporting that stress exposure resulted in an increase of $B d n f$ mRNA in the NAc only in mice subjected to prolonged cocaine abstinence ${ }^{104}$. The increase in $B d n f$ mRNA was associated with $\mathrm{H} 3$ hyperacetylation at BDNF promoter I. Regarding human findings, it has been shown that prenatal exposure to maternal smoking is associated with higher rates of DNA methylation at $B D N F$ promoter VI in white blood cells of adolescents, but only in those that are homozygous for the Val allele of the Val66Met polymorphism ${ }^{101}$. Interestingly, adolescents whose mothers smoked during pregnancy also showed an increase in drug experimentation ${ }^{101}$. Altogether, these studies support the notion that drug-induced plasticity may be partially caused by persistent epigenetically regulated changes in BDNF expression. 
Epigenetic regulation of BDNF in schizophrenia: Human studies have revealed that the val66met polymorphism within the $B D N F$ gene may be associated with schizophrenia and may be one of the major factors affecting brain volume reductions associated with this disorder ${ }^{105}$. Furthermore, analysis of human post-mortem brains has shown that $B D N F$ mRNA as well as BDNF protein synthesis and availability are significantly reduced in layer III, V and VI of the dorsolateral PFC (DLPFC) of schizophrenic patients ${ }^{106}$. In addition, it has been shown that levels of BDNF were significantly reduced in the serum of schizophrenic patients ${ }^{107,108}$. However, these findings should be interpreted with caution due to the heterogeneity across the different studies and the complex etiology of the schizophrenic spectrum. Further, the TrkB receptor is widely expressed in $\gamma$-aminobutyric acid (GABA) neurons, and impairment of BDNF/TrkB signaling might contribute to a change in GABAergic interneuron functioning observed in schizophrenic patients ${ }^{109}$. GABAergic neurons can be divided in different subpopulations including the parvalbumin-positive cells, which exert a powerful negative control on pyramidal cells, by high frequency firing and fast-spiking action potentials ${ }^{110}$. A recent study has demonstrated that mice mutant for $B d n f$ promoter IV show a significant deficit in GABAergic signaling by interneurons in the PFC, particularly those expressing parvalbumin ${ }^{111}$. These data suggest that decreased levels of BDNF in the brain may relate to alterations in the GABAergic system within the PFC of schizophrenic patients. Although that BDNF plays a crucial role in many neurodevelopmental processes and that schizophrenia is strongly linked to aberrant neurodevelopment ${ }^{112}$, only few studies have addressed epigenetic changes at $B D N F$ gene promoters induced by developmental perturbations ${ }^{113}{ }^{114}$. Whether epigenetic mechanisms are responsible of the abnormal levels of BDNF observed in post-mortem brains of schizophrenic patients remains unclear. A recent observation has suggested a link between the $B D N F$ Val66Met polymorphism and abnormal DNA methylation levels at $\mathrm{CpG}$ islands at the BDNF locus in the frontal cortex of schizophrenic patients ${ }^{100}$. More specifically, it was shown that there was a decrease in DNA methylation at exonic $\mathrm{CpG}$ islands of the $B D N F$ gene in the frontal cortex of individuals carrying the Met allele. All in all, these data support the notion that genetic variations in $B D N F$ are associated with a distinct epigenetic regulation of $B D N F$ gene expression, which may be important in the pathophysiology of schizophrenia.

\section{IV - Pharmaceutical drugs targeting $B D N F$ gene expression}

Since aberrant BDNF signaling might play a critical role in the pathophysiology and/or treatment of various psychiatric disorders, directly targeting epigenetic modifications at the BDNF gene promoters might represent a promising strategy to enduringly reverse abnormal BDNF expression and engender long-lasting clinical benefits. In the next section we will present recent findings demonstrating that common psychotropic drugs (such as antidepressants and mood stabilizers) interfere with epigenetic processes at the $B D N F$ gene, and discuss the potential use of other emerging drugs. 
Antidepressants: Chronic defeat stress is commonly used to model depressive-like behavior in rodents. Whereas chronic treatment with antidepressants is able to restore a normal phenotype in socially defeated animals $^{83,122}$, chronic imipramine administration could not reverse the enduring H3K27 hypermethylation at $B d n f$ promoters IV and $\mathrm{V}$ induced by chronic social defeat in mice. Interestingly, it did reverse the repression of $B d n f$ expression at promoter IV and $\mathrm{V}$ by inducing $\mathrm{H} 3-\mathrm{K} 9$ and $\mathrm{H} 3-\mathrm{K} 14$ acetylation resulting in an activation of $B d n f$ gene transcription ${ }^{83}$. Additional experiments further supported the notion that imipramine exerts its therapeutic effects by increasing BDNF levels, at least partly through downregulation of $\mathrm{HDAC}^{83}$. Another study showed that chronic treatment with fluoxetine did not alter the methylation state of H3K27 induced by perinatal exposure to methylmercury in mice, but significantly upregulated $\mathrm{H} 3$ acetylation at $B d n f$ promoter $\mathrm{IV}^{84}$. Moreover, electroconvulsive shock therapy (ECT), still the most effective treatment for refractory depressed patients ${ }^{85}$, is thought to be mediated by enduring changes in gene expression, including that of neurotrophic factors like BDNF. Acute ECT results in increased $\mathrm{H} 4$ acetylation at $B d n f$ promoter II and correlates with increases in total $B d n f$ mRNA in rats ${ }^{86}$. On the other hand, chronic ECT in healthy rats has been shown to increase H3 acetylation at Bdnf promoters IV and $\mathrm{V}$ and to result in an upregulation of the corresponding $B d n f$ mRNA ${ }^{86}$. These data suggest that antidepressant drugs as well as other antidepressant therapies reverse environmentally induced reductions in $B D N F$ expression through changes in covalent modifications at histones tails.

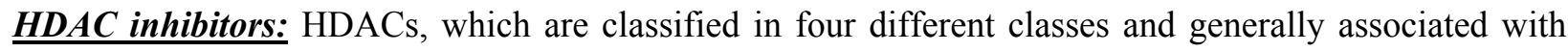
transcriptional repression ${ }^{123}$, represent interesting therapeutic targets for a wide range of human disorders $^{124,}{ }^{125}$. Many HDAC inhibitors are currently being tested in clinical trials and the FDA has already approved some of them for the treatment of specific types of cancer ${ }^{126}$. A possible role for HDAC inhibitors in treating certain mental disorders has emerged from the observation that valproic acid (VPA), a commonly used antiepileptic and mood stabilizing drug, is a non-specific inhibitor of class I and II HDACs $^{127}$. Interestingly, VPA has been shown to modulate the expression of BDNF protein and mRNA $^{128}$. Bdnf exon IV mRNA expression was increased within the PFC of mice treated with VPA during a fear extinction paradigm, the effect of which was mediated by $\mathrm{H} 4$ hyperacetylation at the corresponding gene promoter $^{68}$. Another interesting study has demonstrated that the VPA-induced increase in $B d n f$ expression depends upon a novel responsive region in the neighborhood of promoter $\mathrm{IV}^{128}$. In addition, other HDAC inhibitors such as sodium butyrate and trichostatin A (TSA) have been shown to induce an up-regulation of $B d n f$ gene transcription in both cortical neuronal and astrocyte cultures, although the exact mechanisms involved have not been elucidated yet ${ }^{128,129}$.

DNA methylation modulators: Several proteins belonging to the DNA methyltransferase (DNMT) family are implicated in regulating the maintenance methylation and de novo methylation at $\mathrm{CpG}$ dinucleotides ${ }^{21}$. Many clinical trials with DNMT inhibitors such as the nucleoside analogue 5-aza-cytidine (5-azaC) and its deoxy analogue 5-aza-deoxycytidine (5-aza-dC) have been investigated in the treatment of 
hematological malignancies ${ }^{130}$. Further, 5 -aza-dC has been shown to reduce the degree of methylation at $B d n f$ promoter I in mouse neuroblastoma cells ${ }^{131}$. Additionally, other DNMT inhibitors such as zebularine have been shown to induce a decrease in DNA methylation at the $B d n f$ gene $^{69,113}$. Infusion of zebularine in the hippocampus of mice significantly increased the levels of Bdnf exons I, IV and VI mRNA. In that study, demethylation at Bdnf promoters I, IV and VI was associated with enhanced consolidation of conditioned fear memories $^{69}$. Zebularine has been shown to decrease DNA methylation at $B d n f$ promoter IV in the PFC of rats subjected to early-life adversity ${ }^{113}$. Apart from targeting DNMTs, inhibition of $\mathrm{MeCP}$, which selectively binds to BDNF promoter IV to enhance DNA methylation ${ }^{47}$, could represent an interesting target to increase $B d n f$ expression.

\section{V - Preclinical and clinical perspectives}

There is growing evidence that BDNF plays a central role in psychiatric disorders owing to its action on neuronal and synaptic plasticity ${ }^{7}$. Various environmental factors, particularly when exposure occurs during early development, have been shown to produce disturbances in BDNF availability and function, thus increasing vulnerability to mental illness. As outlined in this review, long-lasting changes in epigenetic processes such as DNA methylation and histone modifications, thereby regulating $B D N F$ gene expression, seem to play a crucial role in this respect.

Relevance to psychiatric neuroscience: The proper regulation of $B D N F$ expression is critical for key regulatory processes related to e.g. learning, memory and reward. In addition, animal studies have revealed a major role for abnormal BDNF signaling in the pathophysiology of many psychiatric phenotypes. While memory formation and drugs of abuse are able to increase levels of $B d n f$ mRNA and protein in various brain areas, chronic stress exposure and associated negative emotional responses are generally linked to decreased levels of BDNF mainly in the hippocampus and PFC. In various animal models, different long-lasting epigenetic changes at the $B d n f$ gene are associated with abnormal $B d n f$ mRNA and protein levels.

While most studies have focused on chromatin remodeling, particularly involving histone tail modifications, relatively few studies have assessed DNA methylation changes. Interestingly, aberrant DNA methylation seems to be critically involved in developmental programming of adult health and disease. In fact, DNA methylation footprints are relatively stable and may even be transmitted to the next generation, suggesting an important role for BDNF in the transgenerational inheritance of emotional traits $^{113}$. Regarding human studies, it has been shown that DNA methylation at the BDNF gene was indeed increased in the Wernicke area of suicide patients as well as in the white blood cells of healthy adolescents prenatally exposed to maternal smoking ${ }^{99,101}$. On the other hand, decreased DNA methylation 
levels at the $B D N F$ gene were observed in the PFC of schizophrenic patients carrying the Met allele as compared to patients homozygous for the Val allele ${ }^{100}$.

Whereas both aberrant DNA methylation and histone modifications at the BDNF gene have been implicated in the pathophysiology of psychiatric disorders and related phenotypes, it is yet to be determined whether these epigenetic changes are the cause or the consequence of the associated pathology. The fact that epidemiologically relevant environmental risk factors for psychiatric disorders (e.g. chronic stress in major depression) modulate BDNF levels in animal models through epigenetic modifications, and that pharmacological interventions (e.g. antidepressants) are able to restore BDNF levels via changes in the epigenome, suggest that epigenetic changes at the $B D N F$ gene are rather causal in the pathology than merely being an epiphenomenon. Along similar lines, it is tempting to speculate that the effects of repetitive administration of drugs of abuse that modulate BDNF levels, thereby enduringly modifying the neuronal network and changing local plasticity in reward circuits, are mediated by epigenetic modifications.

Differential BDNF transcript regulation: BDNF expression is tightly regulated at the level of transcription with differential exon usage, resulting in the specific involvement of the various transcripts in different functions and related processes. Among other things, it has been reported that long and short $B d n f$ transcripts are differentially engaged in protein synthesis ${ }^{29}$. Furthermore, the use of distinct Bdnf mRNA splice variants differing in either their 5' or 3' extremity allows a temporal and spatial regulation of BDNF expression. For example, the various $B D N F$ transcripts display a tissue-specific expression pattern within the human body, as well as a region-specific distribution within the central nervous system $^{24}$. The expression of BDNF protein at local sites of action depends upon restricted regulation of $B d n f$ mRNA trafficking, which is controlled by the 5' non-coding exon, defining the distinct subcellular target areas of the different transcripts ${ }^{134}$. In rodent primary neuronal cultures, it has been shown that $B d n f$ exon IV was restricted to the soma, whereas Bdnf exon II and VII were predominantly observed in dendrites, and $B d n f$ exon I was distributed in both soma and dendrites ${ }^{40,135}$. It is suggested that transcripts localized in the dendrites are most likely to participate in local synthesis of BDNF protein and modulate morphological and biochemical changes related to synaptic plasticity ${ }^{136,137}$. Similarly, Bdnf transcripts primarily expressed in the soma would be particularly involved in processes related to the synthesis of neurotransmitters or hormones ${ }^{138}$. Bdnf exon II seems to be particularly involved in mediating synaptic plasticity within the reward circuitry, as well as in the molecular and cellular changes underlying drug abuse in the striatum $^{97,102}$. Furthermore, $B d n f$ exon VI is likely to be involved in cognitive processes related to learning and memory primarily in the hippocampus and PFC of rodents ${ }^{139}$. Bdnf exon IV, the promoter of which contains specific binding sites for CREB and $\mathrm{MeCP}$ 2, making it a preferential epigenetic target, displays a ubiquitous repartition in the brain and seems to play a key role in many processes related to mood, emotion, reward, learning and memory. Evidently, the exact role of the various 
BDNF transcripts and the complex regulation of $B D N F$ mRNA and protein processing await further research.

In relation to the differential functions of the various $B D N F$ transcripts, modulation of the expression of specific $B D N F$ exons in a targeted fashion may represent a promising strategy to restore enduring changes in gene expression induced by e.g. repeated environmental insults. In particular, HDAC inhibitors and DNMT inhibitors represent potentially powerful agents for the treatment of psychiatric disorders through regulation of e.g. BDNF gene expression. Conversely, these molecular agents are expected to exert their effects on a substantial proportion of the genome, thereby most likely inducing numerous negative side effects. More specifically, inhibitors of DNA methylation have been suggested to promote cancer metastasis, lupus or autoimmune diseases ${ }^{126}$. In view of the region-specific distribution of BDNF transcripts in the brain and their functionally distinct roles, developing compounds that modulate the transcription of specific $B D N F$ exons will provide considerable advantages and possibly avoid undesirable side effects.

Perspectives in psychiatric research: Another promising approach may be to directly target $\operatorname{TrkB}$ signaling, whose abnormal regulation may underlie lasting epigenetic changes influencing the transcription of many genes important in brain functioning. Directly targeting TrkB has the capacity to modulate the functional balance between $\mathrm{p} 75$ and TrkB signaling so as to avoid the possible negative effects mediated by the pro-apoptotic p75 receptor. Recent findings have described new specific TrkB agonists and antagonists ${ }^{140-144}$. Chronic administration of such agents might induce, through epigenetic modifications, lasting changes in the expression of TrkB target genes. Finding molecules that target specific brain regions and/or genetic loci, thus limiting their impact on non-specific adverse epigenetic processes in these areas, is a major challenge in psychiatric drug discovery.

In order to gain more insight into the exact role of epigenetic regulation at the $B D N F$ locus in psychiatric disorders, future studies should focus on human post-mortem brain material to assess whether epigenetic modifications in the human brain are comparable to those observed in rodent models. A recent study has suggested that DNA methylation patterns at gene promoters are preserved up to a post-mortem delay of at least 48 hours, enabling researchers to reliably study DNA methylation in human post-mortem brains ${ }^{145}$. Moreover, further studies should address the regulation of $B D N F$ gene expression in blood cells and assess whether and, if so, to what extent, changes observed within peripheral blood mononuclear cells (PBMCs) reflect those as observed within the brains of patients suffering from psychiatric disorders. This would indicate whether or not PBMCs represent a suitable surrogate tissue to examine epigenetic processes relevant to brain disorders ${ }^{146,147}$. Adverse environmental exposures occurring during the various stages of brain development are known risk factors for developing psychopathology, including affective disorders and schizophrenia ${ }^{112,148}$. To further elucidate the role of BDNF in this respect, the impact of 
such environmental factors on epigenetic changes at the $B d n f$ locus should be examined in animal models, both in relevant brain regions and peripheral blood cells, while simultaneously assessing possible associations between epigenetic states and intermediate behavioral phenotypes. Monitoring such changes in humans might be helpful to identify individuals at risk for pathology and/or predict transition from subclinical symptoms to disease. Finally, it is also important to understand the impact of the $B D N F$ val66met polymorphism on DNA methylation and/or histone modifications at the BDNF gene. If it is confirmed that this genetic variation indeed can influence DNA methylation at $\mathrm{CpG}$ islands within the human $B D N F$ promoter region ${ }^{64}$, this would add to the evidence of the $B D N F$ gene being a vulnerability substrate for psychiatric disorders, thus implicating a novel -epigenetic- mechanism in the effect of the polymorphism.

In conclusion, enduring epigenetic changes at the $B D N F$ gene seem to underlie various neurobiological and behavioral phenotypes in animal models of psychiatric disorders. Recent evidence suggests that such epigenetic modifications are also present in human patients. A better understanding of the exon-specific regulation of the $B D N F$ gene and associated epigenetic remodeling in psychiatric disorders and related phenotypes might open new therapeutic perspectives for these disorders.

\section{VI - References}

1. Leibrock J, Lottspeich F, Hohn A, Hofer M, Hengerer B, Masiakowski P et al. Molecular cloning and expression of brain-derived neurotrophic factor. Nature 1989 Sep 14; 341(6238): 149-152.

2. Casaccia-Bonnefil P, Carter BD, Dobrowsky RT, Chao MV. Death of oligodendrocytes mediated by the interaction of nerve growth factor with its receptor p75. Nature 1996 Oct 24; 383(6602): 716-719.

3. DeFreitas MF, McQuillen PS, Shatz CJ. A novel p75NTR signaling pathway promotes survival, not death, of immunopurified neocortical subplate neurons. J Neurosci 2001 Jul 15; 21(14): 5121-5129.

4. Chao MV. Neurotrophins and their receptors: a convergence point for many signalling pathways. Nat Rev Neurosci 2003 Apr; 4(4): 299-309.

5. Kalcheim C, Barde YA, Thoenen H, Le Douarin NM. In vivo effect of brain-derived neurotrophic factor on the survival of developing dorsal root ganglion cells. Embo J 1987 Oct; 6(10): 2871-2873.

6. Klein R, Smeyne RJ, Wurst W, Long LK, Auerbach BA, Joyner AL et al. Targeted disruption of the trkB neurotrophin receptor gene results in nervous system lesions and neonatal death. Cell 1993 Oct 8; 75(1): 113-122.

7. Pezet S, Malcangio M. Brain-derived neurotrophic factor as a drug target for CNS disorders. Expert Opin Ther Targets 2004 Oct; 8(5): 391-399.

8. Huang EJ, Reichardt LF. Trk receptors: roles in neuronal signal transduction. Annu Rev Biochem 2003; 72: 609-642.

9. Qian X, Riccio A, Zhang Y, Ginty DD. Identification and characterization of novel substrates of Trk receptors in developing neurons. Neuron 1998 Nov; 21(5): 1017-1029. 
10. Atwal JK, Massie B, Miller FD, Kaplan DR. The TrkB-Shc site signals neuronal survival and local axon growth via MEK and P13-kinase. Neuron 2000 Aug; 27(2): 265-277.

11. Minichiello L, Calella AM, Medina DL, Bonhoeffer T, Klein R, Korte M. Mechanism of TrkB-mediated hippocampal long-term potentiation. Neuron 2002 Sep 26; 36(1): 121-137.

12. Jeanneteau F, Deinhardt K, Miyoshi G, Bennett AM, Chao MV. The MAP kinase phosphatase MKP-1 regulates BDNF-induced axon branching. Nat Neurosci 2010 Nov; 13(11): 1373-1379.

13. Ernfors P, Kucera J, Lee KF, Loring J, Jaenisch R. Studies on the physiological role of brain-derived neurotrophic factor and neurotrophin-3 in knockout mice. Int J Dev Biol 1995 Oct; 39(5): 799-807.

14. Mao LM, Fibuch EE, Wang JQ. Decoding BDNF-LTP coupling in cocaine addiction. Neuron 2010 Sep 9; 67(5): 679-681.

15. Bekinschtein P, Cammarota M, Katche C, Slipczuk L, Rossato JI, Goldin A et al. BDNF is essential to promote persistence of long-term memory storage. Proc Natl Acad Sci U S A 2008 Feb 19; 105(7): 27112716 .

16. Pencea V, Bingaman KD, Wiegand SJ, Luskin MB. Infusion of brain-derived neurotrophic factor into the lateral ventricle of the adult rat leads to new neurons in the parenchyma of the striatum, septum, thalamus, and hypothalamus. $J$ Neurosci 2001 Sep 1; 21(17): 6706-6717.

17. Greenberg ME, Xu B, Lu B, Hempstead BL. New insights in the biology of BDNF synthesis and release: implications in CNS function. $J$ Neurosci 2009 Oct 14; 29(41): 12764-12767.

18. Martinowich K, Manji H, Lu B. New insights into BDNF function in depression and anxiety. Nat Neurosci 2007 Sep; 10(9): 1089-1093.

19. Roth TL, Sweatt JD. Epigenetic marking of the BDNF gene by early-life adverse experiences. Horm Behav 2010 May 17.

20. Felsenfeld G, Groudine M. Controlling the double helix. Nature 2003 Jan 23; 421(6921): 448-453.

21. Klose RJ, Bird AP. Genomic DNA methylation: the mark and its mediators. Trends Biochem Sci 2006 Feb; 31(2): 89-97.

22. Timmusk T, Palm K, Metsis M, Reintam T, Paalme V, Saarma M et al. Multiple promoters direct tissuespecific expression of the rat BDNF gene. Neuron 1993 Mar; 10(3): 475-489.

23. Aid T, Kazantseva A, Piirsoo M, Palm K, Timmusk T. Mouse and rat BDNF gene structure and expression revisited. J Neurosci Res 2007 Feb 15; 85(3): 525-535.

24. Pruunsild P, Kazantseva A, Aid T, Palm K, Timmusk T. Dissecting the human BDNF locus: bidirectional transcription, complex splicing, and multiple promoters. Genomics 2007 Sep; 90(3): 397-406.

25. Liu QR, Lu L, Zhu XG, Gong JP, Shaham Y, Uhl GR. Rodent BDNF genes, novel promoters, novel splice variants, and regulation by cocaine. Brain Res 2006 Jan 5; 1067(1): 1-12.

26. Liu QR, Walther D, Drgon T, Polesskaya O, Lesnick TG, Strain KJ et al. Human brain derived neurotrophic factor (BDNF) genes, splicing patterns, and assessments of associations with substance abuse and Parkinson's Disease. Am J Med Genet B Neuropsychiatr Genet 2005 Apr 5; 134B(1): 93-103.

27. Aoyama M, Asai K, Shishikura T, Kawamoto T, Miyachi T, Yokoi T et al. Human neuroblastomas with unfavorable biologies express high levels of brain-derived neurotrophic factor mRNA and a variety of its variants. Cancer Lett 2001 Mar 10; 164(1): 51-60.

28. Marini AM, Jiang X, Wu X, Tian F, Zhu D, Okagaki P et al. Role of brain-derived neurotrophic factor and NF-kappaB in neuronal plasticity and survival: From genes to phenotype. Restor Neurol Neurosci 2004; 22(2): $121-130$. 
29. An JJ, Gharami K, Liao GY, Woo NH, Lau AG, Vanevski F et al. Distinct role of long 3' UTR BDNF mRNA in spine morphology and synaptic plasticity in hippocampal neurons. Cell 2008 Jul 11; 134(1): 175187.

30. Timmusk T, Metsis M. Regulation of BDNF promoters in the rat hippocampus. Neurochem Int 1994 Jul; 25(1): 11-15.

31. Lau AG, Irier HA, Gu J, Tian D, Ku L, Liu G et al. Distinct 3'UTRs differentially regulate activitydependent translation of brain-derived neurotrophic factor (BDNF). Proc Natl Acad Sci U S A 2010 Sep 7; 107(36): 15945-15950.

32. Dias BG, Banerjee SB, Duman RS, Vaidya VA. Differential regulation of brain derived neurotrophic factor transcripts by antidepressant treatments in the adult rat brain. Neuropharmacology 2003 Sep; 45(4): 553563.

33. Tian F, Marini AM, Lipsky RH. NMDA receptor activation induces differential epigenetic modification of Bdnf promoters in hippocampal neurons. Amino Acids 2010 Apr; 38(4): 1067-1074.

34. Wong J, Hyde TM, Cassano HL, Deep-Soboslay A, Kleinman JE, Weickert CS. Promoter specific alterations of brain-derived neurotrophic factor mRNA in schizophrenia. Neuroscience 2010 Sep 1; 169(3): 1071-1084.

35. Barker PA. Whither proBDNF? Nat Neurosci 2009 Feb; 12(2): 105-106.

36. Pang PT, Teng HK, Zaitsev E, Woo NT, Sakata K, Zhen S et al. Cleavage of proBDNF by tPA/plasmin is essential for long-term hippocampal plasticity. Science 2004 Oct 15; 306(5695): 487-491.

37. Lu B, Pang PT, Woo NH. The yin and yang of neurotrophin action. Nat Rev Neurosci 2005 Aug; 6(8): 603614.

38. Jia Y, Gall CM, Lynch G. Presynaptic BDNF promotes postsynaptic long-term potentiation in the dorsal striatum. J Neurosci 2010 Oct 27; 30(43): 14440-14445.

39. Tang S, Machaalani R, Waters KA. Immunolocalization of pro- and mature-brain derived neurotrophic factor (BDNF) and receptor TrkB in the human brainstem and hippocampus. Brain Res 2010 Oct 1; 1354: $1-14$.

40. Chiaruttini C, Vicario A, Li Z, Baj G, Braiuca P, Wu Y et al. Dendritic trafficking of BDNF mRNA is mediated by translin and blocked by the G196A (Val66Met) mutation. Proc Natl Acad Sci U S A 2009 Sep 22; 106(38): 16481-16486.

41. Egan MF, Kojima M, Callicott JH, Goldberg TE, Kolachana BS, Bertolino A et al. The BDNF val66met polymorphism affects activity-dependent secretion of BDNF and human memory and hippocampal function. Cell 2003 Jan 24; 112(2): 257-269.

42. Chen ZY, Jing D, Bath KG, Ieraci A, Khan T, Siao CJ et al. Genetic variant BDNF (Val66Met) polymorphism alters anxiety-related behavior. Science 2006 Oct 6; 314(5796): 140-143.

43. Rybakowski JK. BDNF gene: functional Val66Met polymorphism in mood disorders and schizophrenia. Pharmacogenomics 2008 Nov; 9(11): 1589-1593.

44. Klose R, Bird A. Molecular biology. MeCP2 repression goes nonglobal. Science 2003 Oct 31; 302(5646): 793-795.

45. Im HI, Hollander JA, Bali P, Kenny PJ. MeCP2 controls BDNF expression and cocaine intake through homeostatic interactions with microRNA-212. Nat Neurosci 2010 Sep; 13(9): 1120-1127.

46. Martinowich K, Hattori D, Wu H, Fouse S, He F, Hu Y et al. DNA methylation-related chromatin remodeling in activity-dependent BDNF gene regulation. Science 2003 Oct 31; 302(5646): 890-893.

47. Chen WG, Chang Q, Lin Y, Meissner A, West AE, Griffith EC et al. Derepression of BDNF transcription involves calcium-dependent phosphorylation of MeCP2. Science 2003 Oct 31; 302(5646): 885-889. 
48. Ma DK, Jang MH, Guo JU, Kitabatake Y, Chang ML, Pow-Anpongkul N et al. Neuronal activity-induced Gadd45b promotes epigenetic DNA demethylation and adult neurogenesis. Science 2009 Feb 20; 323(5917): 1074-1077.

49. Tsankova N, Renthal W, Kumar A, Nestler EJ. Epigenetic regulation in psychiatric disorders. Nat Rev Neurosci 2007 May; 8(5): 355-367.

50. West AE, Chen WG, Dalva MB, Dolmetsch RE, Kornhauser JM, Shaywitz AJ et al. Calcium regulation of neuronal gene expression. Proc Natl Acad Sci U S A 2001 Sep 25; 98(20): 11024-11031.

51. Tao X, West AE, Chen WG, Corfas G, Greenberg ME. A calcium-responsive transcription factor, CaRF, that regulates neuronal activity-dependent expression of BDNF. Neuron 2002 Jan 31; 33(3): 383-395.

52. Chan HM, La Thangue NB. p300/CBP proteins: HATs for transcriptional bridges and scaffolds. J Cell Sci 2001 Jul; 114(Pt 13): 2363-2373.

53. Chang J, Zhang B, Heath H, Galjart N, Wang X, Milbrandt J. Nicotinamide adenine dinucleotide (NAD)regulated DNA methylation alters CCCTC-binding factor $(\mathrm{CTCF}) /$ cohesin binding and transcription at the BDNF locus. Proc Natl Acad Sci U S A 2010 Nov 24.

54. Caspi A, Moffitt TE. Gene-environment interactions in psychiatry: joining forces with neuroscience. Nat Rev Neurosci 2006 Jul; 7(7): 583-590.

55. Migliore L, Coppede F. Genetics, environmental factors and the emerging role of epigenetics in neurodegenerative diseases. Mutat Res 2009 Jul 10; 667(1-2): 82-97.

56. Duman RS, Monteggia LM. A neurotrophic model for stress-related mood disorders. Biol Psychiatry 2006 Jun 15; 59(12): 1116-1127.

57. Roceri M, Cirulli F, Pessina C, Peretto P, Racagni G, Riva MA. Postnatal repeated maternal deprivation produces age-dependent changes of brain-derived neurotrophic factor expression in selected rat brain regions. Biol Psychiatry 2004 Apr 1; 55(7): 708-714.

58. Roceri M, Hendriks W, Racagni G, Ellenbroek BA, Riva MA. Early maternal deprivation reduces the expression of BDNF and NMDA receptor subunits in rat hippocampus. Mol Psychiatry 2002; 7(6): 609616.

59. Nair A, Vadodaria KC, Banerjee SB, Benekareddy M, Dias BG, Duman RS et al. Stressor-specific regulation of distinct brain-derived neurotrophic factor transcripts and cyclic AMP response elementbinding protein expression in the postnatal and adult rat hippocampus. Neuropsychopharmacology 2007 Jul; 32(7): 1504-1519.

60. Chen LY, Rex CS, Pham DT, Lynch G, Gall CM. BDNF signaling during learning is regionally differentiated within hippocampus. J Neurosci 2010 Nov 10; 30(45): 15097-15101.

61. Bramham CR, Messaoudi E. BDNF function in adult synaptic plasticity: the synaptic consolidation hypothesis. Prog Neurobiol 2005 Jun; 76(2): 99-125.

62. Takei S, Morinobu S, Yamamoto S, Fuchikami M, Matsumoto T, Yamawaki S. Enhanced hippocampal BDNF/TrkB signaling in response to fear conditioning in an animal model of posttraumatic stress disorder. J Psychiatr Res 2010 Sep 20.

63. Peters J, Dieppa-Perea LM, Melendez LM, Quirk GJ. Induction of fear extinction with hippocampalinfralimbic BDNF. Science 2010 Jun 4; 328(5983): 1288-1290.

64. Soliman F, Glatt CE, Bath KG, Levita L, Jones RM, Pattwell SS et al. A genetic variant BDNF polymorphism alters extinction learning in both mouse and human. Science 2010 Feb 12; 327(5967): 863866.

65. Chhatwal JP, Stanek-Rattiner L, Davis M, Ressler KJ. Amygdala BDNF signaling is required for consolidation but not encoding of extinction. Nat Neurosci 2006 Jul; 9(7): 870-872. 
66. Choi DC, Maguschak KA, Ye K, Jang SW, Myers KM, Ressler KJ. Prelimbic cortical BDNF is required for memory of learned fear but not extinction or innate fear. Proc Natl Acad Sci U S A 2010 Feb 9; 107(6): 2675-2680.

67. Ou LC, Gean PW. Transcriptional regulation of brain-derived neurotrophic factor in the amygdala during consolidation of fear memory. Mol Pharmacol 2007 Aug; 72(2): 350-358.

68. Bredy TW, Wu H, Crego C, Zellhoefer J, Sun YE, Barad M. Histone modifications around individual BDNF gene promoters in prefrontal cortex are associated with extinction of conditioned fear. Learn Mem 2007 Apr; 14(4): 268-276.

69. Lubin FD, Roth TL, Sweatt JD. Epigenetic regulation of BDNF gene transcription in the consolidation of fear memory. J Neurosci 2008 Oct 15; 28(42): 10576-10586.

70. Levenson JM, Roth TL, Lubin FD, Miller CA, Huang IC, Desai P et al. Evidence that DNA (cytosine-5) methyltransferase regulates synaptic plasticity in the hippocampus. J Biol Chem 2006 Jun 9; 281(23): 15763-15773.

71. Munoz PC, Aspe MA, Contreras LS, Palacios AG. Correlations of recognition memory performance with expression and methylation of brain-derived neurotrophic factor in rats. Biol Res 2010; 43(2): 251-258.

72. Sheline YI, Gado MH, Kraemer HC. Untreated depression and hippocampal volume loss. Am J Psychiatry 2003 Aug; 160(8): 1516-1518.

73. Sen S, Duman R, Sanacora G. Serum brain-derived neurotrophic factor, depression, and antidepressant medications: meta-analyses and implications. Biol Psychiatry 2008 Sep 15; 64(6): 527-532.

74. Molendijk ML, Bus BA, Spinhoven P, Penninx BW, Kenis G, Prickaerts J et al. Serum levels of brainderived neurotrophic factor in major depressive disorder: state-trait issues, clinical features and pharmacological treatment. Mol Psychiatry 2010 Sep 21.

75. Dwivedi Y, Rizavi HS, Conley RR, Roberts RC, Tamminga CA, Pandey GN. Altered gene expression of brain-derived neurotrophic factor and receptor tyrosine kinase B in postmortem brain of suicide subjects. Arch Gen Psychiatry 2003 Aug; 60(8): 804-815.

76. Chen B, Dowlatshahi D, MacQueen GM, Wang JF, Young LT. Increased hippocampal BDNF immunoreactivity in subjects treated with antidepressant medication. Biol Psychiatry 2001 Aug 15; 50(4): 260-265.

77. Gourley SL, Kiraly DD, Howell JL, Olausson P, Taylor JR. Acute hippocampal brain-derived neurotrophic factor restores motivational and forced swim performance after corticosterone. Biol Psychiatry 2008 Nov 15; 64(10): 884-890.

78. Vollmayr B, Faust H, Lewicka S, Henn FA. Brain-derived-neurotrophic-factor (BDNF) stress response in rats bred for learned helplessness. Mol Psychiatry $2001 \mathrm{Jul}$; 6(4): 471-474, 358.

79. Taliaz D, Stall N, Dar DE, Zangen A. Knockdown of brain-derived neurotrophic factor in specific brain sites precipitates behaviors associated with depression and reduces neurogenesis. Mol Psychiatry 2010 Jan; 15(1): 80-92.

80. Shirayama Y, Chen AC, Nakagawa S, Russell DS, Duman RS. Brain-derived neurotrophic factor produces antidepressant effects in behavioral models of depression. J Neurosci 2002 Apr 15; 22(8): 3251-3261.

81. Monteggia LM, Barrot M, Powell CM, Berton O, Galanis V, Gemelli T et al. Essential role of brainderived neurotrophic factor in adult hippocampal function. Proc Natl Acad Sci U S A 2004 Jul 20; 101(29): 10827-10832.

82. Nibuya M, Morinobu S, Duman RS. Regulation of BDNF and trkB mRNA in rat brain by chronic electroconvulsive seizure and antidepressant drug treatments. $J$ Neurosci 1995 Nov; 15(11): 7539-7547. 
83. Tsankova NM, Berton O, Renthal W, Kumar A, Neve RL, Nestler EJ. Sustained hippocampal chromatin regulation in a mouse model of depression and antidepressant action. Nat Neurosci 2006 Apr; 9(4): 519525 .

84. Onishchenko N, Karpova N, Sabri F, Castren E, Ceccatelli S. Long-lasting depression-like behavior and epigenetic changes of BDNF gene expression induced by perinatal exposure to methylmercury. $J$ Neurochem 2008 Aug; 106(3): 1378-1387.

85. Lisanby SH. Electroconvulsive therapy for depression. N Engl J Med 2007 Nov 8; 357(19): 1939-1945.

86. Tsankova NM, Kumar A, Nestler EJ. Histone modifications at gene promoter regions in rat hippocampus after acute and chronic electroconvulsive seizures. J Neurosci 2004 Jun 16; 24(24): 5603-5610.

87. Koob GF, Volkow ND. Neurocircuitry of addiction. Neuropsychopharmacology 2010 Jan; 35(1): $217-238$.

88. Russo SJ, Mazei-Robison MS, Ables JL, Nestler EJ. Neurotrophic factors and structural plasticity in addiction. Neuropharmacology 2009; 56 Suppl 1: 73-82.

89. Lobo MK, Covington HE, 3rd, Chaudhury D, Friedman AK, Sun H, Damez-Werno D et al. Cell typespecific loss of BDNF signaling mimics optogenetic control of cocaine reward. Science 2010 Oct 15; 330(6002): 385-390.

90. Guillin O, Diaz J, Carroll P, Griffon N, Schwartz JC, Sokoloff P. BDNF controls dopamine D3 receptor expression and triggers behavioural sensitization. Nature 2001 May 3; 411(6833): 86-89.

91. Numan S, Lane-Ladd SB, Zhang L, Lundgren KH, Russell DS, Seroogy KB et al. Differential regulation of neurotrophin and trk receptor mRNAs in catecholaminergic nuclei during chronic opiate treatment and withdrawal. J Neurosci 1998 Dec 15; 18(24): 10700-10708.

92. Filip M, Faron-Gorecka A, Kusmider M, Golda A, Frankowska M, Dziedzicka-Wasylewska M. Alterations in BDNF and trkB mRNAs following acute or sensitizing cocaine treatments and withdrawal. Brain Res 2006 Feb 3; 1071(1): 218-225.

93. Lu H, Cheng PL, Lim BK, Khoshnevisrad N, Poo MM. Elevated BDNF after cocaine withdrawal facilitates LTP in medial prefrontal cortex by suppressing GABA inhibition. Neuron 2010 Sep 9; 67(5): 821-833.

94. Graham DL, Edwards S, Bachtell RK, DiLeone RJ, Rios M, Self DW. Dynamic BDNF activity in nucleus accumbens with cocaine use increases self-administration and relapse. Nat Neurosci 2007 Aug; 10(8): 1029-1037.

95. Vargas-Perez H, Ting AKR, Walton CH, Hansen DM, Razavi R, Clarke L et al. Ventral tegmental area BDNF induces an opiate-dependent-like reward state in naive rats. Science 2009 Jun 26; 324(5935): 17321734.

96. Grimm JW, Lu L, Hayashi T, Hope BT, Su TP, Shaham Y. Time-dependent increases in brain-derived neurotrophic factor protein levels within the mesolimbic dopamine system after withdrawal from cocaine: implications for incubation of cocaine craving. J Neurosci 2003 Feb 1; 23(3): 742-747.

97. Kumar A, Choi KH, Renthal W, Tsankova NM, Theobald DE, Truong HT et al. Chromatin remodeling is a key mechanism underlying cocaine-induced plasticity in striatum. Neuron 2005 Oct 20; 48(2): 303-314.

98. Chen ES, Ernst C, Turecki G. The epigenetic effects of antidepressant treatment on human prefrontal cortex BDNF expression. Int J Neuropsychopharmacol 2010 Dec 7: 1-3.

99. Keller S, Sarchiapone M, Zarrilli F, Videtic A, Ferraro A, Carli V et al. Increased BDNF promoter methylation in the Wernicke area of suicide subjects. Arch Gen Psychiatry 2010 Mar; 67(3): 258-267.

100. Mill J, Tang T, Kaminsky Z, Khare T, Yazdanpanah S, Bouchard L et al. Epigenomic profiling reveals DNA-methylation changes associated with major psychosis. Am J Hum Genet 2008 Mar; 82(3): 696-711. 
101. Toledo-Rodriguez M, Lotfipour S, Leonard G, Perron M, Richer L, Veillette S et al. Maternal smoking during pregnancy is associated with epigenetic modifications of the brain-derived neurotrophic factor- 6 exon in adolescent offspring. Am J Med Genet B Neuropsychiatr Genet 2010 Jun 25.

102. Wang L, Lv Z, Hu Z, Sheng J, Hui B, Sun J et al. Chronic cocaine-induced H3 acetylation and transcriptional activation of CaMKIIalpha in the nucleus accumbens is critical for motivation for drug reinforcement. Neuropsychopharmacology 2010 Mar; 35(4): 913-928.

103. Sadri-Vakili G, Kumaresan V, Schmidt HD, Famous KR, Chawla P, Vassoler FM et al. Cocaine-induced chromatin remodeling increases brain-derived neurotrophic factor transcription in the rat medial prefrontal cortex, which alters the reinforcing efficacy of cocaine. J Neurosci 2010 Sep 1; 30(35): 11735-11744.

104. Cleck JN, Ecke LE, Blendy JA. Endocrine and gene expression changes following forced swim stress exposure during cocaine abstinence in mice. Psychopharmacology (Berl) 2008 Nov; 201(1): 15-28.

105. Ho BC, Andreasen NC, Dawson JD, Wassink TH. Association between brain-derived neurotrophic factor Val66Met gene polymorphism and progressive brain volume changes in schizophrenia. Am J Psychiatry 2007 Dec; 164(12): 1890-1899.

106. Weickert CS, Hyde TM, Lipska BK, Herman MM, Weinberger DR, Kleinman JE. Reduced brain-derived neurotrophic factor in prefrontal cortex of patients with schizophrenia. Mol Psychiatry 2003 Jun; 8(6): 592610.

107. Ikeda Y, Yahata N, Ito I, Nagano M, Toyota T, Yoshikawa T et al. Low serum levels of brain-derived neurotrophic factor and epidermal growth factor in patients with chronic schizophrenia. Schizophr Res 2008 Apr; 101(1-3): 58-66.

108. Green MJ, Matheson SL, Shepherd A, Weickert CS, Carr VJ. Brain-derived neurotrophic factor levels in schizophrenia: a systematic review with meta-analysis. Mol Psychiatry 2010 Aug 24.

109. Hashimoto T, Bergen SE, Nguyen QL, Xu B, Monteggia LM, Pierri JN et al. Relationship of brain-derived neurotrophic factor and its receptor TrkB to altered inhibitory prefrontal circuitry in schizophrenia. $J$ Neurosci 2005 Jan 12; 25(2): 372-383.

110. Markram H, Toledo-Rodriguez M, Wang Y, Gupta A, Silberberg G, Wu C. Interneurons of the neocortical inhibitory system. Nat Rev Neurosci 2004 Oct; 5(10): 793-807.

111. Sakata K, Woo NH, Martinowich K, Greene JS, Schloesser RJ, Shen L et al. Critical role of promoter IVdriven BDNF transcription in GABAergic transmission and synaptic plasticity in the prefrontal cortex. Proc Natl Acad Sci U S A 2009 Apr 7; 106(14): 5942-5947.

112. van Os J, Kenis G, Rutten BP. The environment and schizophrenia. Nature 2010 Nov 11; 468(7321): 203212.

113. Roth TL, Lubin FD, Funk AJ, Sweatt JD. Lasting epigenetic influence of early-life adversity on the BDNF gene. Biol Psychiatry 2009 May 1; 65(9): 760-769.

114. Devlin AM, Brain U, Austin J, Oberlander TF. Prenatal exposure to maternal depressed mood and the MTHFR C677T variant affect SLC6A4 methylation in infants at birth. PLoS One 2010; 5(8): e12201.

115. Fuchikami M, Morinobu S, Kurata A, Yamamoto S, Yamawaki S. Single immobilization stress differentially alters the expression profile of transcripts of the brain-derived neurotrophic factor (BDNF) gene and histone acetylation at its promoters in the rat hippocampus. Int J Neuropsychopharmacol 2009 Feb; 12(1): 73-82.

116. Fuchikami M, Yamamoto S, Morinobu S, Takei S, Yamawaki S. Epigenetic regulation of BDNF gene in response to stress. Psychiatry Investig 2011 Dec; 7(4): 251-256.

117. Gomez-Pinilla F, Zhuang Y, Feng J, Ying Z, Fan G. Exercise impacts brain-derived neurotrophic factor plasticity by engaging mechanisms of epigenetic regulation. Eur J Neurosci 2011 Feb; 33(3): 383-390. 
118. Karpova NN, Rantamaki T, Di Lieto A, Lindemann L, Hoener MC, Castren E. Darkness Reduces BDNF Expression in the Visual Cortex and Induces Repressive Chromatin Remodeling at the BDNF Gene in Both Hippocampus and Visual Cortex. Cell Mol Neurobiol 2010 Jul 8.

119. Kuzumaki N, Ikegami D, Tamura R, Hareyama N, Imai S, Narita M et al. Hippocampal epigenetic modification at the brain-derived neurotrophic factor gene induced by an enriched environment. Hippocampus 2010 Mar 15.

120. Molteni R, Cattaneo A, Calabrese F, Macchi F, Olivier JD, Racagni G et al. Reduced function of the serotonin transporter is associated with decreased expression of BDNF in rodents as well as in humans. Neurobiol Dis 2010 Mar; 37(3): 747-755.

121. Roth TL, Zoladz PR, Sweatt JD, Diamond DM. Epigenetic modification of hippocampal Bdnf DNA in adult rats in an animal model of post-traumatic stress disorder. J Psychiatr Res 2011 Feb 8.

122. Krishnan V, Han MH, Graham DL, Berton O, Renthal W, Russo SJ et al. Molecular adaptations underlying susceptibility and resistance to social defeat in brain reward regions. Cell 2007 Oct 19; 131(2): 391-404.

123. Kazantsev AG, Thompson LM. Therapeutic application of histone deacetylase inhibitors for central nervous system disorders. Nat Rev Drug Discov 2008 Oct; 7(10): 854-868.

124. Urdinguio RG, Sanchez-Mut JV, Esteller M. Epigenetic mechanisms in neurological diseases: genes, syndromes, and therapies. Lancet Neurol 2009 Nov; 8(11): 1056-1072.

125. Wang L, de Zoeten EF, Greene MI, Hancock WW. Immunomodulatory effects of deacetylase inhibitors: therapeutic targeting of FOXP3+ regulatory T cells. Nat Rev Drug Discov 2009 Dec; 8(12): 969-981.

126. Szyf M. Epigenetics, DNA methylation, and chromatin modifying drugs. Annu Rev Pharmacol Toxicol 2009; 49: 243-263.

127. Gottlicher M, Minucci S, Zhu P, Kramer OH, Schimpf A, Giavara S et al. Valproic acid defines a novel class of HDAC inhibitors inducing differentiation of transformed cells. Embo J 2001 Dec 17; 20(24): 69696978.

128. Yasuda S, Liang MH, Marinova Z, Yahyavi A, Chuang DM. The mood stabilizers lithium and valproate selectively activate the promoter IV of brain-derived neurotrophic factor in neurons. Mol Psychiatry 2009 Jan; 14(1): 51-59.

129. Wu X, Chen PS, Dallas S, Wilson B, Block ML, Wang CC et al. Histone deacetylase inhibitors up-regulate astrocyte GDNF and BDNF gene transcription and protect dopaminergic neurons. Int $J$ Neuropsychopharmacol 2008 Dec; 11(8): 1123-1134.

130. Oki Y, Aoki E, Issa JP. Decitabine--bedside to bench. Crit Rev Oncol Hematol 2007 Feb; 61(2): 140-152.

131. Ishimaru N, Fukuchi M, Hirai A, Chiba Y, Tamura T, Takahashi N et al. Differential epigenetic regulation of BDNF and NT-3 genes by trichostatin A and 5-aza-2'-deoxycytidine in Neuro-2a cells. Biochem Biophys Res Commun Mar 26; 394(1): 173-177.

132. Ishimaru N, Fukuchi M, Hirai A, Chiba Y, Tamura T, Takahashi N et al. Differential epigenetic regulation of BDNF and NT-3 genes by trichostatin A and 5-aza-2'-deoxycytidine in Neuro-2a cells. Biochem Biophys Res Commun 2010 Mar 26; 394(1): 173-177.

133. Fukuchi M, Nii T, Ishimaru N, Minamino A, Hara D, Takasaki I et al. Valproic acid induces up- or downregulation of gene expression responsible for the neuronal excitation and inhibition in rat cortical neurons through its epigenetic actions. Neurosci Res 2009 Sep; 65(1): 35-43.

134. Chiaruttini C, Sonego M, Baj G, Simonato M, Tongiorgi E. BDNF mRNA splice variants display activitydependent targeting to distinct hippocampal laminae. Mol Cell Neurosci 2008 Jan; 37(1): 11-19.

135. Pattabiraman PP, Tropea D, Chiaruttini C, Tongiorgi E, Cattaneo A, Domenici L. Neuronal activity regulates the developmental expression and subcellular localization of cortical BDNF mRNA isoforms in vivo. Mol Cell Neurosci 2005 Mar; 28(3): 556-570. 
136. Tongiorgi E, Baj G. Functions and mechanisms of BDNF mRNA trafficking. Novartis Found Symp 2008; 289: 136-147; discussion 147-151, 193-135.

137. Kang H, Jia LZ, Suh KY, Tang L, Schuman EM. Determinants of BDNF-induced hippocampal synaptic plasticity: role of the Trk B receptor and the kinetics of neurotrophin delivery. Learn Mem 1996 Sep-Oct; 3(2-3): 188-196.

138. Loudes C, Petit F, Kordon C, Faivre-Bauman A. Distinct populations of hypothalamic dopaminergic neurons exhibit differential responses to brain-derived neurotrophic factor (BDNF) and neurotrophin-3 (NT3). Eur J Neurosci 1999 Feb; 11(2): 617-624.

139. Lubin FD. Epigenetic gene regulation in the adult mammalian brain: Multiple roles in memory formation. Neurobiol Learn Mem 2011 Mar 16.

140. Jang SW, Liu X, Yepes M, Shepherd KR, Miller GW, Liu Y et al. A selective TrkB agonist with potent neurotrophic activities by 7,8-dihydroxyflavone. Proc Natl Acad Sci U S A 2010 Feb 9; 107(6): 2687-2692.

141. Jang SW, Liu X, Pradoldej S, Tosini G, Chang Q, Iuvone PM et al. N-acetylserotonin activates TrkB receptor in a circadian rhythm. Proc Natl Acad Sci U S A 2010 Feb 23; 107(8): 3876-3881.

142. Massa SM, Yang T, Xie Y, Shi J, Bilgen M, Joyce JN et al. Small molecule BDNF mimetics activate TrkB signaling and prevent neuronal degeneration in rodents. J Clin Invest 2010 May 3; 120(5): 1774-1785.

143. Cazorla M, Jouvenceau A, Rose C, Guilloux JP, Pilon C, Dranovsky A et al. Cyclotraxin-B, the first highly potent and selective TrkB inhibitor, has anxiolytic properties in mice. PLoS One 2010; 5(3): e9777.

144. Cazorla M, Premont J, Mann A, Girard N, Kellendonk C, Rognan D. Identification of a low-molecular weight TrkB antagonist with anxiolytic and antidepressant activity in mice. J Clin Invest 2011 May 2; 121(5): 1846-1857.

145. Barrachina M, Ferrer I. DNA methylation of Alzheimer disease and tauopathy-related genes in postmortem brain. J Neuropathol Exp Neurol 2009 Aug; 68(8): 880-891.

146. Yuferov V, Nielsen DA, Levran O, Randesi M, Hamon S, Ho A et al. Tissue-specific DNA methylation of the human prodynorphin gene in post-mortem brain tissues and PBMCs. Pharmacogenet Genomics 2011 Apr; 21(4): 185-196.

147. Ressler KJ, Mercer KB, Bradley B, Jovanovic T, Mahan A, Kerley K et al. Post-traumatic stress disorder is associated with PACAP and the PAC1 receptor. Nature 2011 Feb 24; 470(7335): 492-497.

148. Bale TL, Baram TZ, Brown AS, Goldstein JM, Insel TR, McCarthy MM et al. Early life programming and neurodevelopmental disorders. Biol Psychiatry 2010 Aug 15; 68(4): 314-319. 


\section{Chapter II}

\begin{tabular}{|c|c|c|c|c|c|}
\hline Authors & $\begin{array}{l}\text { Subjects / } \\
\text { Patients }\end{array}$ & Variables & $\begin{array}{l}\text { BDNF } \\
\text { expression }\end{array}$ & $\begin{array}{l}\text { Epigenetic changes } \\
\text { at Bdnf gene }\end{array}$ & Regions \\
\hline Chen et al & Depressed patient & $\begin{array}{l}\text { Antidepressant } \\
\text { treatment vs no } \\
\text { antidepressant } \\
\text { treatment }\end{array}$ & $\begin{array}{l}\text { Increased in } \\
\text { BDNF mRNA }\end{array}$ & $\begin{array}{l}\text { Decrease in } \mathrm{H} 3 \mathrm{~K} 27 \\
\text { trimethylation at promoter IV }\end{array}$ & $\begin{array}{l}\text { Prefrontal } \\
\text { cortex }\end{array}$ \\
\hline Keller et al & Suicide victims & $\begin{array}{l}\text { suicide vs non- } \\
\text { suicide death }\end{array}$ & $\begin{array}{l}\text { Decreased in } \\
\text { mRNA and } \\
\text { protein }\end{array}$ & $\begin{array}{l}\text { Increase in DNA methylation } \\
\text { at promoter IX }\end{array}$ & Wernicke area \\
\hline Mill et al & $\begin{array}{l}\text { Schizophrenic } \\
\text { patients }\end{array}$ & Bdnf val66met SNP & ND & $\begin{array}{l}\text { Decrease in DNA methylation } \\
\text { at CpG islands }\end{array}$ & $\begin{array}{l}\text { Prefrontal } \\
\text { cortex }\end{array}$ \\
\hline $\begin{array}{l}\text { Toledo-Rodriguez } \\
\text { et al }\end{array}$ & $\begin{array}{l}\text { Healthy } \\
\text { adolescents }\end{array}$ & $\begin{array}{l}\text { Prenatal maternal } \\
\text { smoking }\end{array}$ & ND & $\begin{array}{l}\text { Increase in DNA methylation } \\
\text { at promoter VI }\end{array}$ & Blood cells \\
\hline
\end{tabular}

Table 1. Major findings on epigenetic modifications at the $B D N F$ gene in humans 


\begin{tabular}{|c|c|c|c|c|c|}
\hline Authors & Species/strain & Variables & $\begin{array}{l}\text { BDNF } \\
\text { expression }\end{array}$ & $\begin{array}{l}\text { Epigenetic changes at } \\
\text { Bdnf gene }\end{array}$ & Regions \\
\hline Bredy et al & C57BL/J mice & Fear memory & $\begin{array}{l}\text { Increase in } \\
\text { exon I and VI } \\
\text { mRNA }\end{array}$ & $\begin{array}{l}\text { Increase in histone } \mathrm{H} 3 \\
\text { acetylation at promoter I and } \\
\text { VI, increase in histone } \mathrm{H} 4 \\
\text { acetylation at promoter VI }\end{array}$ & $\begin{array}{l}\text { Prefrontal } \\
\text { cortex }\end{array}$ \\
\hline Fuchikami et al & $\begin{array}{l}\text { Sprague Dawley } \\
\text { rats }\end{array}$ & $\begin{array}{l}\text { Single } \\
\text { immobilisation } \\
\text { stress }\end{array}$ & $\begin{array}{l}\text { Decrease in } \\
\text { exon I and IV } \\
\text { mRNA }\end{array}$ & $\begin{array}{l}\text { Decrease in histone } \mathrm{H} 3 \\
\text { acetylation at promoter I, IV } \\
\text { and VI }\end{array}$ & Hippocampus \\
\hline Fuchikami et al & $\begin{array}{l}\text { Sprague Dawley } \\
\text { rats }\end{array}$ & Fear conditioning & $\begin{array}{l}\text { Increase in } \\
\text { exon I and IV } \\
\text { mRNA }\end{array}$ & $\begin{array}{l}\text { Increase in histone } \mathrm{H} 3 \text { and } \\
\mathrm{H} 4 \text { acetylation at promoters I } \\
\text { and IV }\end{array}$ & Hipp \\
\hline Gomez-Pinilla et al & $\begin{array}{l}\text { Sprague Dawley } \\
\text { rats }\end{array}$ & Voluntary exercice & $\begin{array}{l}\text { Increse in total } \\
\text { mRNA and } \\
\text { protein }\end{array}$ & $\begin{array}{l}\text { Increase in histone } \mathrm{H} 3 \\
\text { acetylation at promoter IV }\end{array}$ & Hippocampus \\
\hline Karpova et al & Wistar rats & Darkness & $\begin{array}{l}\text { Decrease in } \\
\text { total mRNA and } \\
\text { protein }\end{array}$ & $\begin{array}{l}\text { Increase in histone } \mathrm{H} 3 \mathrm{~K} 27 \\
\text { methylation, increase in DNA } \\
\text { methylation at promoter IV }\end{array}$ & Visual cortex \\
\hline Kumar et al & $\begin{array}{l}\text { Sprague Dawley } \\
\text { rats }\end{array}$ & Cocaine use & ND & $\begin{array}{l}\text { Increase in histone } \mathrm{H} 3 \\
\text { acetylation at promoter II }\end{array}$ & Striatum \\
\hline Kuzumaki et al & C57BL/6J mice & $\begin{array}{l}\text { Enriched } \\
\text { environment }\end{array}$ & $\begin{array}{l}\text { Increase in } \\
\text { total mRNA }\end{array}$ & $\begin{array}{l}\text { Increase in histone } \mathrm{H} 3 \mathrm{~K} 4 \\
\text { methylation at promoter III } \\
\text { and VI, decrease in histone } \\
\mathrm{H} 3 \mathrm{~K} 9 \text { methylation at } \\
\text { promoter IV and H3K27 at } \\
\text { promoters III and IV }\end{array}$ & Hippocampus \\
\hline Lubin et al & $\begin{array}{l}\text { Sprague Dawley } \\
\text { rats }\end{array}$ & Fear memory & $\begin{array}{l}\text { Increase in } \\
\text { total mRNA }\end{array}$ & $\begin{array}{l}\text { Decrease in DNA methylation } \\
\text { at promoter IV }\end{array}$ & Hippocampus \\
\hline Molteni et al & $\begin{array}{l}\text { SERT knockout } \\
\text { rats }\end{array}$ & SERT dysfunction & $\begin{array}{l}\text { Decrease in } \\
\text { total mRNA }\end{array}$ & $\begin{array}{l}\text { Increase in DNA methylation } \\
\text { at promoter VI, decrease in } \\
\text { histone H3 acetylation at } \\
\text { promoter IV }\end{array}$ & $\begin{array}{l}\text { Prefrontal } \\
\text { cortex }\end{array}$ \\
\hline Onishcenko et al & C57BL/6/Bkl mice & $\begin{array}{l}\text { Perinatal toxin } \\
\text { exposure }\end{array}$ & $\begin{array}{l}\text { Decrease in } \\
\text { total mRNA }\end{array}$ & $\begin{array}{l}\text { Increase in DNA methylation, } \\
\text { increase in histone H3K27 } \\
\text { methylation and decrease in } \\
\text { histone } \mathrm{H} 3 \text { acetylation at } \\
\text { promoter IV }\end{array}$ & Hippocampus \\
\hline Roth et al & $\begin{array}{l}\text { Sprague Dawley } \\
\text { rats }\end{array}$ & Predator exposure & $\begin{array}{l}\text { Decrease in } \\
\text { exon IV mRNA }\end{array}$ & $\begin{array}{l}\text { Increase in DNA methylation } \\
\text { at promoter IV }\end{array}$ & $\begin{array}{l}\text { Dorsal } \\
\text { hippocampus }\end{array}$ \\
\hline Roth et al & Long-Evans rats & Early life adversity & $\begin{array}{l}\text { Decrease in } \\
\text { total mRNA }\end{array}$ & $\begin{array}{l}\text { Increase in DNA methylation } \\
\text { at promoter IV }\end{array}$ & $\begin{array}{l}\text { Prefrontal } \\
\text { cortex }\end{array}$ \\
\hline Sadri-Vakili et al & $\begin{array}{l}\text { Sprague Dawley } \\
\text { rats }\end{array}$ & Cocaine use & $\begin{array}{l}\text { Iincrease in } \\
\text { exon IV mRNA }\end{array}$ & $\begin{array}{l}\text { Increase in histone } \mathrm{H} 3 \\
\text { acetylation at promoter IV }\end{array}$ & $\begin{array}{l}\text { Prefrontal } \\
\text { cortex }\end{array}$ \\
\hline Tsankova et al & Bl6/C57 mice & $\begin{array}{l}\text { Social defeat } \\
\text { stress }\end{array}$ & $\begin{array}{l}\text { Decrease in } \\
\text { total mRNA }\end{array}$ & $\begin{array}{l}\text { Increase in histone } \mathrm{H} 3 \mathrm{~K} 27 \\
\text { methylation at promoter IV } \\
\text { and VI }\end{array}$ & Hippocampus \\
\hline Wang et al & $\begin{array}{l}\text { Sprague Dawley } \\
\text { rats }\end{array}$ & Cocaine use & ND & $\begin{array}{l}\text { Incease in histone } \mathrm{H} 3 \\
\text { acetylation at promoters II } \\
\text { and III }\end{array}$ & $\begin{array}{l}\text { Nucleus } \\
\text { accumbens }\end{array}$ \\
\hline
\end{tabular}

Table 2. Major factors influencing epigenetic regulation of the $B d n f$ gene in rodents 


\begin{tabular}{|c|c|c|c|c|c|}
\hline Authors & $\begin{array}{l}\text { Chronic } \\
\text { treatments }\end{array}$ & Models & $\begin{array}{l}\text { BDNF } \\
\text { expression }\end{array}$ & $\begin{array}{l}\text { Epigenetic changes } \\
\text { at Bdnf gene }\end{array}$ & Regions \\
\hline Bredy et al & Valproic acid & $\begin{array}{l}\text { Fear conditioned } \\
\text { rats }\end{array}$ & $\begin{array}{l}\text { Increase in exon } \\
\text { VI mRNA }\end{array}$ & $\begin{array}{l}\text { Increase in histone } \mathrm{H} 4 \\
\text { acetylation at promoter VI }\end{array}$ & $\begin{array}{l}\text { Prefrontal } \\
\text { cortex }\end{array}$ \\
\hline $\begin{array}{l}\text { Ishimaru } \\
\text { et al }\end{array}$ & 5-aza C & Neuro-2a cells & $\begin{array}{l}\text { Increase in exon } \\
\text { I and IV mRNA }\end{array}$ & $\begin{array}{l}\text { Decrease in DNA } \\
\text { methylation at promoter I }\end{array}$ & - \\
\hline $\begin{array}{l}\text { Ishimaru } \\
\text { et al }\end{array}$ & Trichostatin A & Neuro-2a cells & $\begin{array}{l}\text { Increase in exon } \\
\text { I and IV mRNA }\end{array}$ & $\begin{array}{l}\text { Increase in histone } \mathrm{H} 3 \text { and } \\
\mathrm{H} 4 \text { acetylation at promoter I }\end{array}$ & - \\
\hline Lubin et al & Zebularine & $\begin{array}{l}\text { Fear conditioned } \\
\text { rats }\end{array}$ & $\begin{array}{l}\text { Increase in total } \\
\text { mRNA }\end{array}$ & $\begin{array}{l}\text { Decrease in DNA } \\
\text { methylation at promoters I, } \\
\text { II, IV and VI }\end{array}$ & $\begin{array}{l}\text { Hippocampu } \\
\text { s }\end{array}$ \\
\hline $\begin{array}{l}\text { Onishcenko } \\
\text { et al }\end{array}$ & Fluoxetine & $\begin{array}{l}\text { Perinatal stressed } \\
\text { rats }\end{array}$ & $\begin{array}{l}\text { Increase in total } \\
\text { mRNA }\end{array}$ & $\begin{array}{l}\text { Increase in histone } \mathrm{H} 3 \\
\text { acetylation at promoter IV }\end{array}$ & $\begin{array}{l}\text { Hippocampu } \\
\text { s }\end{array}$ \\
\hline Roth et al & Zebularine & $\begin{array}{l}\text { Early-life } \\
\text { maltreated rats }\end{array}$ & $\begin{array}{l}\text { Increase in total } \\
\text { mRNA }\end{array}$ & $\begin{array}{l}\text { Decrease in DNA } \\
\text { methylation at promoter IV }\end{array}$ & $\begin{array}{l}\text { Prefrontal } \\
\text { cortex }\end{array}$ \\
\hline $\begin{array}{l}\text { Tsankova } \\
\text { et al }\end{array}$ & ECT & Healthy rats & $\begin{array}{l}\text { Increase in exon } \\
\text { IV and VI mRNA }\end{array}$ & $\begin{array}{l}\text { Increase in histone } \mathrm{H} 3 \\
\text { acetylation at promoters IV } \\
\text { and VI }\end{array}$ & $\begin{array}{l}\text { Hippocampu } \\
\text { s }\end{array}$ \\
\hline $\begin{array}{l}\text { Tsankova } \\
\text { et al }\end{array}$ & Imipramine & Social defeated rats & $\begin{array}{l}\text { Increase in total } \\
\text { mRNA }\end{array}$ & $\begin{array}{l}\text { Increase in histone } \mathrm{H} 3 \\
\text { acetylation at promoters IV } \\
\text { and VI, increase histone } \\
\text { H3K9 methylation at } \\
\text { promoter III }\end{array}$ & $\begin{array}{l}\text { Hippocampu } \\
\text { s }\end{array}$ \\
\hline Wang et al & Trichostatin A & $\begin{array}{l}\text { Cocaine self- } \\
\text { administrated rats }\end{array}$ & ND & $\begin{array}{l}\text { Increase in histone } \mathrm{H} 3 \\
\text { acetylation at promoters II } \\
\text { and III }\end{array}$ & $\begin{array}{l}\text { Nucleus } \\
\text { accumbens }\end{array}$ \\
\hline
\end{tabular}

Table 3. Treatments and medications modulating epigenetic regulation of the $B d n f$ gene 
Rodent Bdnf gene
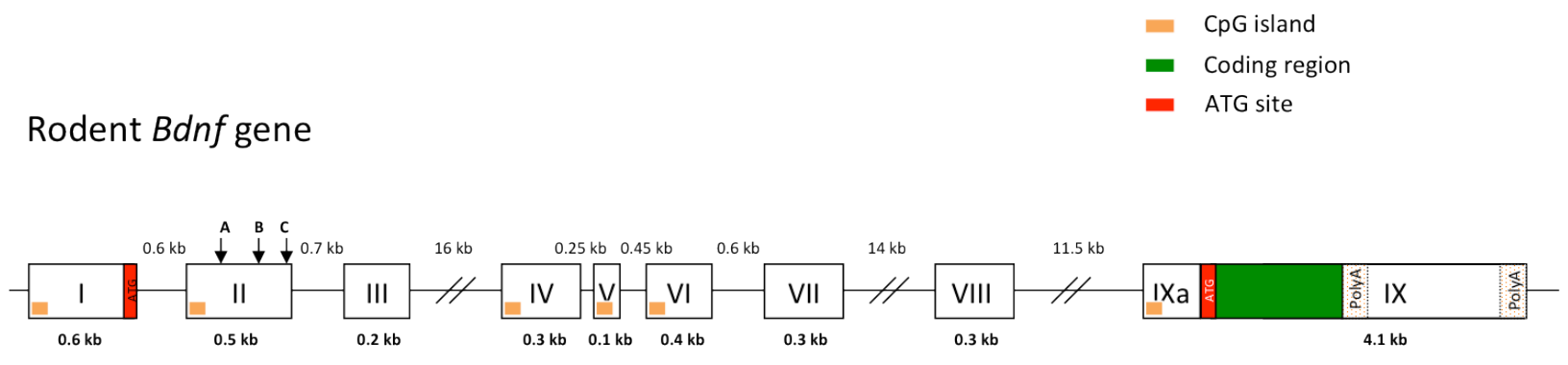

\section{Human BDNF gene}

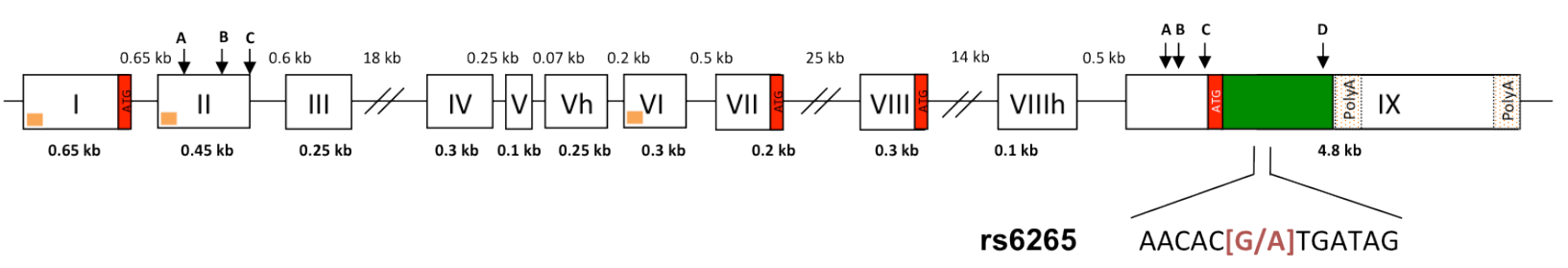

Fig 1. Structure of the human and rodent $B D N F$ gene.

Exons are represented as boxes and the introns as lines. Numbers of the exons are indicated in roman numerals and the size of exons and introns is indicated in Arabic numerals. The 3' coding exon (exon IX) contains 2 polyadenylation sites (poly A). The red boxes represent the start codon ATG that marks the initiation of transcription. The green box shows the region of exon IX coding for the pro-BDNF protein, including the rs6265 genetic variant implicated in the Val66Met polymorphism. Some exons, like exon II and IX, contain different transcript variants with alternative splice-donor sites (A, B, C, D). CpG islands were predicted with Methprimer software and determined as sequences of at least 200 pairs of bases with a GC percentage greater than $50 \%$. Adapted from Aid et al., $2007^{23}$, and Pruunsild et al., $2007^{24}$. 


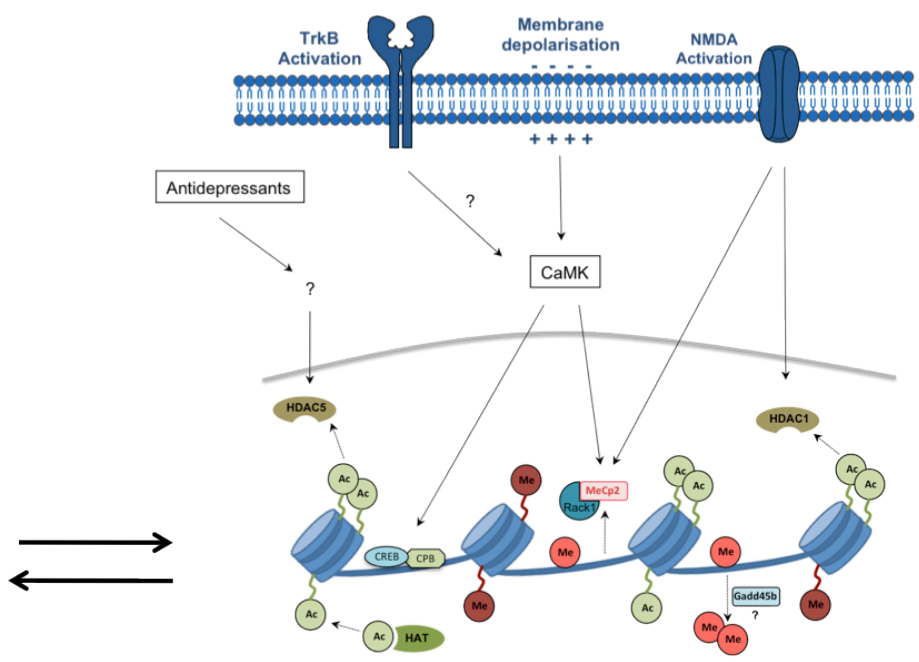

Repression of Bdnf IV

Activation of Bdnf IV

Fig 2. Epigenetic mechanism associated with repression and activation of $B d n f$ exon IV transcription.

The BDNF exon IV displays twelve distinct $\mathrm{CpG}$ sites, which can be methylated and interact selectively with $\mathrm{MeCP} 2$ to form complexes that repress gene transcription. Histone methyltransferases (HMTs) are responsible of adding methyl groups at histone tails (H3K27), whereas histone deacetylases (HDACs) remove acetylation at histone tails, both processes that repress gene transcription. Moreover, low levels of nicotinamine adenine dinucleotide (NAD) promote DNA methylation at BDNF locus ${ }^{53}$. Conversely, Bdnf gene activation is associated with an increased histone $\mathrm{H} 3$ and $\mathrm{H} 4$ acetylation, which is mediated by histone acetyl transferase (HAT) activity. Derepression of BDNF exon IV can be observed after membrane depolarization or NMDA receptor activation, both inducing the dissociation of MeCP2 from methylated $\mathrm{DNA}^{33,47}$. In addition, NMDA receptor stimulation has also been shown to reduce HDAC1 occupancy of BDNF promoter IV ${ }^{33}$. DNA demethylation might be facilitated by growth arrest and DNA damage proteins such as Gadd $45 b^{48}$. An increased binding of CREB to its specific binding protein CREB binding protein (CBP) is also associated with an increase in BDNF gene transcription. Membrane depolarization has been shown to increase this CBP-mediated regulation via calcium/calmodulin-dependent protein kinase (CaMK) signaling ${ }^{49}$. Hypothetically, TrkB, whose signaling is known to activate the CaMK pathway, might induce CREB phosphorylation and subsequent binding to $\mathrm{CPB}$, thereby increasing BDNF expression. See text for more details. 


\title{
CHAPTER III
}

Growth factors and neuroplasticity pathways in the pathophysiology and treatment of depression

\author{
FABIEN BOULlE ${ }^{1,2}$, Joost VAN HAASTEREN ${ }^{1}$,GUNTER KENIS ${ }^{2}$, Michel HAMON ${ }^{1}$, DANIEL L.A VAN DEN \\ HOVE $^{2,3}$, LAURENCE LANFUMEY ${ }^{1}$
}

${ }^{I}$ Centre de Psychiatrie et Neuroscience (INSERM U894), Universite Pierre et Marie Curie, Paris, France

${ }^{2}$ Department of Psychiatry and Neuropsychology, European Graduate School for Neuroscience (EURON), Maastricht University, Maastricht, The Netherlands

${ }^{3}$ Department of Psychiatry, Psychosomatics and Psychotherapy, University of Wuerzburg, Wuerzburg, Germany

\section{In preparation}




\begin{abstract}
Depression is considered as a major health problem with a high prevalence and a heavy economic burden in western societies. At the anatomical level, major depression corresponds to atrophy or impaired functioning of cortico-limbic regions involved in mood and emotions including the hippocampus and the prefrontal cortex. Especially, it is suspected that alterations in growth factors and associated signaling pathways might underlie neuronal loss and synaptic dysfunction in cortico-limbic structures, which may be causally related to the development and course of depression. Accordingly, mounting evidences suggest that antidepressant treatments may exert their therapeutic effects by enhancing trophic signalling and their downstream neuroplastic signaling. However, current therapies still have significant limitations including a delayed onset of action, as well as a considerable lack of efficacy. Hence, a deeper understanding about the molecular and cellular mechanisms involved in the pathophysiology, as well as in the action of antidepressants might lead to the identification of key-role effectors, and provide further insight into the development of novel fast-acting and more effective therapies. Here, we summarized the current literature about the involvement of growth factors and associated signalling in the pathophyisology and treatment of depression, and provide future directions for the development of novel antidepressant drugs.
\end{abstract}

Key words: growth factors, neurocircuits, plasticity, antidepressant, neurotrophic signalling, mood 


\section{I - Introduction}

Depression has emerged over the past decades as a major debilitating disease with a high prevalence in occidental populations, resulting in profound social and economic burden (Kessler et al., 2003; Lopez and Murray, 1998; Pincus and Pettit, 2001). The molecular and cellular mechanisms underlying the pathophysiology of depression remain poorly understood. Furthermore, the development and course of the illness are likely to be mediated by a complex interaction between genetic and environmental factors, and the associated heterogeneity of the disease makes it difficult to develop effective therapeutic treatments (Keers and Uher, 2012). So far, many classes of antidepressant medication have been discovered and marketed for the treatment of depression. However, currently available antidepressants display significant limitations, including low response rates and relapse after treatment cessation, which remain major drawbacks for a disease where suicide rate are relatively high (Angst et al., 2002). Up to date, clinical and preclinical studies have revealed that depression could be linked to alterations in cortico-limbic structures controlling mood and emotions, including neuronal loss and synaptic dysfunction (Duman and Aghajanian, 2012). Among many candidates, growth factors and related signalling pathways constitute major players in neuroplasticity, and current evidence indicate that impairment of such regulations might be associated with depressed mood (Pittenger and Duman, 2008). Interestingly, currently prescribed antidepressants, predominantly functioning via monoaminergic signalling cascades, have been shown to modulate neuroplastic signalling to exert their therapeutic effects (Tardito et al., 2006). Hence, a deeper understanding of the exact molecular and cellular mechanisms involved in antidepressant action might lead to the identification of key effectors, and provide further insight into the development of novel fast-acting and more effective therapies. Here, we summarized the current literature on the implication of trophic factors and associated signalling pathways in depression and antidepressant treatments. First, a brief overview of brain regions and circuits implicated in the pathophysiology of depression, and in the response to antidepressant is highlighted. Further, evidences for the involvement of growth factors and associated signalling pathways in depression and its treatment are described. Finally, perspectives and future directions for the development of new antidepressant drugs are suggested.

\section{II - Brain region and neurocircuits}

Neuroanatomical evidences: Many brain regions, especially within the limbic system, has been associated with mood and emotions, and the impairment in those areas might play a role in the pathophysiology of depression. For instance, the prefrontal cortex (PFC) has many functional connections within the brain, processing sensory input and mediating executive motor functions, and its links with the 
limbic system (e.g. hippocampus and amygdala) form an integral part of memory consolidation and retrieval (Ongur and Price, 2000; Price, 1999). Especially, the prefrontal cortex has been associated with decision-making, personality expression and social behaviour. Neuroimaging studies found a reduction in size of multiple areas of the PFC in subjects diagnosed with major depression (Bremner et al., 2002; Drevets, 2000). In line with those studies, post mortem brain analysis of depressed patients revealed reduced neural cell size and neural and glial cell densities in the dorsolateral and subgenual PFC (Cotter et al., 2002; Öngür et al., 1998; Rajkowska et al., 1999). In rodents, chronic restraint stress caused a significant reduction in number and length of apical dendritic branches in some areas of the PFC (Cook and Wellman, 2004). Similar results were observed after chronic administration of corticosterone, where drastic dendritic reorganization of pyramidal neurons was reported in the medial PFC (mPFC) (Wellman, 2001). Dendritic arborisation in the mPFC induced by stress in rats was found to be predictive of impaired attentional set-shifting performance, a measure of cognitive performance related to $\mathrm{mPFC}$ functioning (Liston et al., 2006).

Further, the amygdala is an integrant part of the limbic system implicated in cognitive and emotional processing, especially involving fear response (Aggleton, 1993; LeDoux, 2000). Volumetric MRI studies so far revealed contrasting results, with studies showing both an increase in volume (Frodl et al., 2003; Lange and Irle, 2004; Vassilopoulou et al., 2013) as well as a decrease in amygdala volume in depressed patients (Bellani et al., 2011; Kronenberg et al., 2009; Lorenzetti et al., 2009). Functional magnetic resonance imaging (fMRI) studies in depressed patients have shown exaggerated amygdala activity when confronted with emotional facial expressions (Canli et al., 2005; Sheline et al., 2001), and increased memory sensitivity to negative stimuli (Hamilton and Gotlib, 2008). Depressed patients also showed an overall increased activity of the left amygdala (Drevets et al., 1992). Similarly, Drevets and colleagues used PET imaging to find an increase in amygdala activation and metabolism in MDD patients (Drevets, 2003). A reduction in glial cell number, probably due to a decrease in oligodendrocytes, was discovered in post-mortem amygdala tissues of major depressive disorder (MDD) patients (Bowley et al., 2002; Hamidi et al., 2004). Increased fractional anisotropy suggesting improved connectivity was observed mainly from the left amygdala to the brain stem, cerebellum and hippocampus (Arnold et al., 2012). Accordingly, experiments using rats exposed to chronic stress showed enhanced dendritic arborisation, elongation and spine density, providing evidence for increased synaptic connectivity in this brain region (Vyas et al., 2006; Vyas et al., 2002). However, functional coupling was reduced between the amygdala and the supragenual PFC (Matthews et al., 2008). The heterogeneity of the depressed subjects used in the aforementioned studies is likely to be the cause of the contrasting results with factors such as medication, gender and onset and disease development. The data however strongly support the notion that disease severity correlates with more pronounced neurological alterations (Bellani et al., 2011; Lorenzetti et al., 2009), so there is no doubt that amygdala functioning is of particular interest in view of major depression. 
Next to the PFC and amygdala, a preponderant role for the ventral striatum has been reported in major depression. The basic fundamentals of the natural reward system are attributed to the dopaminergic connections between the ventral tegmental area (VTA) and the nucleus accumbens (NAc). In this respect, the NAc and the VTA may play a role in the hedonic symptoms of depression (Nestler and Carlezon Jr, 2006; Yadid and Friedman, 2008). Depressed patients show an attenuated activation of the VTA-NAc pathway or the NAc itself when compared to normal patients using fMRI analysis (Epstein et al., 2006; Furman et al., 2011; Pizzagalli et al., 2009; Smoski et al., 2009). Deep brain stimulation (DBS) targeting the NAc was shown to have antidepressant, anxiolytic and hedonic effects, most notably in treatment resistant depression (Bewernick et al., 2010; Giacobbe et al., 2009; Schlaepfer et al., 2008). These effects have been proven to be long lasting and stable up to four years (Bewernick et al., 2012; Malone Jr et al., 2009). Rat models indicate that NAc DBS influences the neurobiology of efferent projections of the NAc to the hippocampus. In response to NAc DBS, more neuronal precursors were found in the dentate gyrus of the hippocampus, hinting at an enhanced adult neurogenesis (Schmuckermair et al., 2013). DBS may also alter the morphology of the PFC, with increased apical and basilar dendrite length (Falowski et al., 2011). Both the alteration of the PFC and hippocampus in response of NAc DBS show the influence of the NAc in depression over the long term.

Finally, the hippocampus is a major part of the limbic system known to be highly vulnerable to stress and environmental variations. This region is critical in mood and cognition. MRI analyses revealed reduced hippocampal volumes in patients suffering from both recurrent and first episode depression (Bremner et al., 2000; Cole et al., 2011; Frodl et al., 2007), and a correlation between volume reductions and total duration of major depression has been reported (Sheline et al., 1996). It has also been proposed that reductions in hippocampal volume may not antedate illness onset, but volume may decrease at the greatest rate in the early years after illness onset (MacQueen et al., 2003). Post mortem analysis in MDD patients suggested an increase in the density of pyramidal, granule and glial cells combined with a decrease of soma size of pyramidal cells (Stockmeier et al., 2004). This might indicate a decrease in cellular neuropil which might provide an explanation for the reduced hippocampal volumes found in depressed subjects. In rodents, chronic stress caused atrophy of apical dendrites of pyramidal neurons in the CA3 region of the hippocampus (Magarinos et al., 1996; Vyas et al., 2002; Watanabe et al., 1992). Exposure to excess glucocorticoids in rats showed decreased apical branching numbers and apical dendrite length (Woolley et al., 1990), suggesting a role of the activation of the hypothalamic-pituitaryadrenal (HPA) axis in the remodelling of hippocampal morphology and neural cell loss associated with depression. Accordingly, various models of chronic stress exposure in rodents have indicated a decrease of neurogenesis in the dentate gyrus, involving a reduced proliferation, survival and differentiation of neural stem cells (Eisch and Petrik, 2012). Moreover, evidence that adult hippocampal neurogenesis is required for the behavioural effects of antidepressants (Sahay and Hen, 2007; Santarelli et al., 2003) provides further proof of the crucial role of the hippocampus in depression. 
Hippocampal plasticity and neurogenesis: Hippocampal neurogenesis is believed to be required in the therapeutic action of antidepressant drugs (David et al., 2009; Djavadian, 2004; Klempin et al., 2013; Santarelli et al., 2003). Accordingly, chronic treatment with the selective serotonin reuptake inhibitor (SSRI) fluoxetine increased hippocampal neurogenesis, involving the generation of newborn cells in the DG (Malberg et al., 2000; Santarelli et al., 2003; Surget et al., 2011) (Boldrini et al., 2009; Encinas et al., 2006). In addition, chronic fluoxetine administration increased the dentate connectivity and synaptic plasticity in naive rats (Stewart and Reid, 2000). A report proving that serotonin depletion reduced neurogenesis in the DG and SVZ in adult rats also supports the theory linking antidepressant treatment to neurogenesis (Brezun and Daszuta, 1999). The different serotonin receptors in the brain showed differential region specific neurogenesis patterns. Activation of 5- $\mathrm{HT}_{1 \mathrm{~A}}$ resulted in increased neurogenesis in the SGL and SVZ whereas activation of $5-\mathrm{HT}_{2 \mathrm{~A}}$ increased proliferation in the SGL but not the SVZ. The opposite was the case regarding 5- $\mathrm{HT}_{2 \mathrm{C}}$ activation, with an increased neurogenesis in the SVZ but not the SGL of the DG (Banasr et al., 2004). Further, serotonin and noradrenaline reuptake inhibitor (SNRI) antidepressants, like SSRIs, have been shown to modulate neurogenesis and plasticity. Neurogenesis in the DG of the hippocampus was increased following chronic venlafaxine administration to rats (Mostany et al., 2008). Similarly, chronic venlafaxine treatment proved to be efficient in preventing the deleterious effects of restraint stress on hippocampal neurogenesis and BDNF protein expression (Xu et al., 2006). However, a recent study reported that duloxetine treatment did not significantly increase the number of new cells in the hippocampus of mice (Marlatt et al., 2010). Finally, tricyclic antidepressants (TCA) have also proved to modulate hippocampal neurogenesis. Analysis of post-mortem brains of MDD patients treated with nortryptiline and clomipramine showed an increase of neural progenitor cells and dividing cells in the DG, as compared to healthy controls (Boldrini et al., 2009). In animal models, clomipramine was able to counteract the stress-induced inhibition of proliferation in the hippocampus (Liu et al., 2008). Chronic imipramine and desipramine treatment increased cell proliferation in multiple brain regions of the hippocampus of rodents (Pechnick et al., 2011; Santarelli et al., 2003; Schiavon et al., 2010). 5- $\mathrm{HT}_{1 \mathrm{~A}}$ knockout in mice abolished the antidepressant effects of fluoxetine but not desipramine and imipramine (Santarelli et al., 2003). In addition, imipramine could restore the decrease in neurogenesis caused by chronic stress and chronic corticosteroid upregulation (Diniz et al., 2013; Doi et al., 2010; Hitoshi et al., 2007; Kitamura et al., 2011; Van Bokhoven et al., 2011).

\section{III - Neurotrophins and growth factors}

$\underline{B D N F}:$ Brain-derived neurotrophic factor (BDNF) is involved in the growth, differentiation and survival of neurons (McAllister et al., 2001) and is also an important factor in the regulation of neurogenesis (Rossi et al., 2006) and synaptic plasticity (McAllister et al., 1999). BDNF is abundantly expressed in the mammalian brain, with the highest concentrations found in the hippocampus and cortex (Hofer et al., 
1990). Reduction of BDNF and its tropomyosin-related kinase receptor B (TrkB) expression in the hippocampus and PFC has been reported in post-mortem brain analysis of suicide victims (Dwivedi et al., 2003b; Pandey et al., 2008), and lowered serum concentration of BDNF has been associated with MDD (Karege et al., 2005; Karege et al., 2002; Sen et al., 2008). Interestingly, serum concentration could be largely restored with antidepressant treatment (Aydemir et al., 2005; Gonul et al., 2005; Piccinni et al., 2008; Sen et al., 2008; Shimizu et al., 2003), indicating that serum BDNF levels could perhaps provide an indication of antidepressant response (Gass and Hellweg, 2010). One of the most common functional single nucleotide polymorphism (SNP) in the BDNF gene is the val66met. This polymorphism affects the activity-dependent secretion of BDNF (Egan et al., 2003) and negatively influences hippocampal volume (Frodl et al., 2007), and may in this way increase susceptibility to MDD. Expression of BDNF was also increased in the post mortem brain of depressed patients treated with antidepressant drugs as compared to non-treated patients (Chen et al., 2001b; Dunham et al., 2009). In rodents, direct infusion of BDNF protein in the hippocampus (Deltheil et al., 2008; Deltheil et al., 2009; Shirayama et al., 2002; Sirianni et al., 2010) and midbrain (Siuciak et al., 1997) showed antidepressant-like effects. Contrastingly, the opposite effect was reported after infusion of BDNF in the VTA of the NAc (Eisch et al., 2003). The same disparity was present using region specific knockdown of BDNF expression. The impairment of BDNF signalling in the DG of the hippocampus (Taliaz et al., 2010) elicited pro-depressive behaviour whereas knockdown of BDNF in the NAc had an anti-depressive effect (Berton et al., 2006). Conditional knockout in the forebrain resulted in an increase in depressive behaviour in female but not male mice (Monteggia et al., 2007) and decreased the efficacy of the antidepressant desipramine (Monteggia et al., 2004). A conditional knockout of BDNF in the forebrain displayed the same gender-specific incongruity in stress-induced depressive-like behaviour (Autry et al., 2009). A different study using adeno-associated viral mediated knockout of BDNF in the DG and CA1 of the hippocampus proved that a loss of BDNF function in the hippocampus attenuated antidepressant drug treatment efficacy (Adachi et al., 2008). Lee and colleagues developed a val66met mouse analogue (Chen et al., 2006) and subsequent experiments showed that the val66met genetic variant decreased fluoxetine efficacy through impaired synaptic plasticity in the DG (Bath et al., 2012; Ninan et al., 2010) and PFC (Pattwell et al., 2012). In addition, BDNF expression in the brain of rats was upregulated after chronic antidepressant drug and electroconvulsive therapy (ECT) (Altar et al., 2003; Balu et al., 2008; Jacobsen and Mørk, 2004; Nibuya et al., 1995).

$\underline{F G F}$ : The fibroblast growth factor (FGF) family has been described as a major player in proliferation and maturation of neurons in the main neurogenic areas of the brain, the subgranular (SGZ) and subventricular (SVZ) zone of the dentate gyrus in the hippocampus. In addition, these growth factors (FGF1 and FGF2) were evidenced to play a critical role in the regulation of synaptic plasticity (Reuss et al., 2003). Post mortem brain analysis revealed a lowered expression of FGF1 and FGF2 in the dorsolateral PFC and the anterior cingulate cortex of patients with MDD (Evans et al., 2004). In addition, 
FGF2 was decreased in the hippocampus of depressed patients, whereas fibroblast growth factor receptor 1 (FGFR1) was increased (Gaughran et al., 2006). In rodents, Turner and colleagues reported reduced mRNA expression of FGF2 and its main receptor FGFR1 in the CA1, CA2, CA3 and DG following social defeat stress, a well-established model of depression (Turner et al., 2008a). Moreover, intracerebroventricular (ICV) injection of FGF2 induced neurogenesis in both the SVZ and SGZ (Jin et al., 2003; Mudo et al., 2009; Rai et al., 2007), and was also shown to improve depressive-like behaviour in rats (Turner et al., 2008b). A more recent study also reported that increased neural proliferation in the PFC following FGF2 infusions might also be involved in the antidepressant actions of FGF2 (Elsayed et al., 2012). Functional FGF2 knockout mice showed a significant decrease in newly generated neurons but no reduction in proliferating cells (Werner et al., 2011). The additional increase in cell death in the hippocampus indicated a faulty neurogenesis following FGF2 knockout (Werner et al., 2011). Conditional knockout experiments with FGFR1-null mice show defective long-term potentiation (LTP) and neurogenesis (Zhao et al., 2007), suggesting that the FGF2/FGFR1 interaction might represent an important foundation of neurogenesis.

$\underline{\boldsymbol{V E G F}}$ : Vascular endothelial growth factor (VEGF) is primarily known for its induction of angiogenesis and modulation of vascular permeability during embryogenesis and growth, as well as pathological events such as tumorigenesis (Ferrara et al., 2003). In addition, mounting evidence suggests that VEGF can be considered as a potent neurotrophic factor as well (Nowacka et al., 2012, Storkebaum et al., 2003). A multitude of studies have investigated the plasma concentrations of vascular endothelial growth factor (VEGF) in MDD patients, but the data and interpretation remain conflicting possibly due to the differences in study design (Clark-Raymond and Halaris, 2013). However, experimental studies showed that VEGF displayed robust neuroprotective effects in cell models of ischemia and hypoxia (Jin et al., 2000) as well as a positive effect on neuronal growth, maturation and proliferation under normoxic conditions (Khaibullina et al., 2004; Rosenstein et al., 2003; Silverman et al., 1999; Sondell et al., 1999; Zhu et al., 2003). A role in the development of dendrites and axons has also been described for VEGF (Khaibullina et al., 2004; Licht et al., 2010; Rosenstein et al., 2003; Sondell et al., 1999). Chronic stress in rats decreased the expression of VEGF and its receptor in the hippocampus (Heine et al., 2005). Moreover, ICV administration of VEGF increased neuroprotection and neurogenesis in the adult rat brain after ischemia (Sun et al., 2003). More specifically, ICV administration of VEGF increased neurogenesis in both the SVZ and the SGZ of the DG with enhanced proliferation of neurons, astroglia and endothelial cells (Jin et al., 2002), while VEGF-B knockout mice showed impaired neurogenesis (Sun et al., 2006). Hence, the overexpression of VEGF in the hippocampus using an adeno-associated viral vector in rats resulted in increased neurogenesis and was associated with improved learning and memory (Cao et al., 2004; During and Cao, 2006). Furthermore, VEGF is required for the proliferation of neural stem-like cells in the hippocampus following electroconvulsive therapy (ECT) treatments (Elfving and Wegener, 
2012; Segi-Nishida et al., 2008). In a similar manner, VEGF also seems to be required for the behavioural action of various antidepressants drugs in rodent models of depression (Greene et al., 2009; Sun et al., 2012; Warner-Schmidt and Duman, 2007; Warner-Schmidt and Duman, 2008).

GDNF: Glial cell line-derived neurotrophic factor (GDNF) is a neurotrophic factor first discovered in a glial cell line, and is expressed in many brain regions (Golden et al., 1998). It is a member of the transforming growth factor $\beta$ (TGF- $\beta$ ) superfamily and is important for neuronal survival (Pascual et al., 2008). Only a few clinical studies investigating the role of GDNF in depression have been reported, and contrasting findings between brain and blood expression remain. A recent post-mortem brain analysis showed an increased of (GDNF) expression in the parietal cortex of depressed patients (Michel et al., 2008). In contrast, decreased GDNF serum levels have been associated with depression (Diniz et al., 2012b; Pallavi et al., 2013; Zhang et al., 2008), and negatively correlated with disease severity in adolescents (Pallavi et al., 2013). Similarly, lowered expression of GDNF was also reported in peripheral white blood cells of depressed patients (Otsuki et al., 2008). Interestingly, antidepressant treatment significantly increased the serum concentration of GDNF in depressed patients (Zhang et al., 2008), as well as ECT in patients with drug-resistant depression (Zhang et al., 2009). Experimental studies in animal models evidenced a neuroprotective role of GDNF, and ICV infusion of GDNF increased progenitor cell proliferation in the DG (Dempsey et al., 2003) and SVZ (Kobayashi et al., 2006). Similarly, infusion of GDNF in the striatum of rats increased progenitor cell proliferation in the hippocampus and substantia nigra (Chen et al., 2005). Moreover, GDNF induced differentiation of DGderived neural precursors into astrocytes in vitro (Boku et al., 2013). Further, adeno-associated viral vector-induced overexpression of GDNF in the rat cortex provided neuroprotection against ischemiainduced injury (Tsai et al., 2000). In addition, antidepressant treatment increased GDNF release in a rat C6 glioblastoma cell line (Hisaoka et al., 2001), whereas lithium treatment in rats resulted in increased GDNF concentration in the PFC and occipital cortex but a decrease in the hippocampus (Angelucci et al., 2003b). Thus far, the exact involvement of GDNF in the aetiology of depression is not fully understood, but its neuroprotective capacity might make it an interesting future target for antidepressant treatment.

IGF-1: Insulin-like growth factor (IGF-1) has been designated as a potential therapeutic target for neurodegenerative disease such as depression (Carro et al., 2003, Paslakis et al., 2012). IGF-1 is a growth factor for many tissues and IGF-1 and its receptor IGF-1R are produced in many body tissues including the brain (Bondy et al., 1993). Decreased serum concentrations of IGF-1 have been associated with increased neurodegeneration (Busiguina et al., 2000). Studies using selective knockout mice showed that a decrease in both systemic and hippocampal IGF-1 levels could increase susceptibility to depression (Mitschelen et al., 2011). IGF-1 induced differentiation of neuronal precursors (Anderson et al., 2002; Arsenijevic and Weiss, 1998), and proved to be neuroprotective in cerebellar granule neurons in vitro (D'Mello et al., 1993). IGF-1 knockout mice showed a decrease in total brain size and DG granular cell 
layer volume, further supporting the importance of IGF-1 in neurodevelopment (Beck et al., 1995). Developmental research in mice has revealed the importance of IGF-1 in hippocampal neurogenesis and synaptogenesis (O'Kusky et al., 2000). ICV infusion of IGF-1 ameliorated the age-related decline in hippocampal neurogenesis (Lichtenwalner et al., 2001), and peripheral administration of this growth factor could selectively induce hippocampal neurogenesis in rat (Åberg et al., 2000). Interestingly, since IGF-1 can readily pass the blood brain barrier (Pan and Kastin, 2000), its effects on the brain can be achieved by direct injection in the blood circulation. Intranasal administration has been proposed in order to provide a shorter path for IGF-1 to enter the brain (Paslakis et al., 2012), avoiding unwanted effects of IGF-1 in peripheral tissues. In addition, increase of peripheral IGF-1 concentration by direct injection of IGF-1 or inhibition of IGF-1 binding protein displayed anxiolytic and antidepressant effect in rodents (Duman et al., 2009; Hoshaw et al., 2005; Malberg et al., 2007; Park et al., 2011), which might be attributed in part to increased serotonin levels in the brain (Hoshaw et al., 2008).

$\underline{V G F}:$ VGF nerve growth factor inducible (non-acronymic) is a small neuropeptide that plays a role in energy homeostasis, metabolism and synaptic plasticity. VGF expression is regulated by neurotrophin signalling. A recent study showed that depressed patients displayed lower expression of VGF in leukocytes, which could be reversed by antidepressant treatment (Cattaneo et al., 2010). Moreover, VGF expression in the hippocampus and PFC, like the neurotrophins described above, is decreased in animal models of depression (Cattaneo et al., 2010; Thakker-Varia and Alder, 2009). Interestingly, infusion of VGF in the hippocampus (Thakker-Varia et al., 2007) or lateral ventricle (Hunsberger et al., 2007) had an antidepressant behavioural effect in rats. This effect may be related to increased neurogenesis, which occurs after only 7 days of VGF administration to the hippocampus (Thakker-Varia and Alder, 2009). VGF expression can be increased by exogenous BDNF administration (Alder et al., 2003) and BDNF might even be a requirement for regional VGF expression (Eagleson et al., 2001). VGF is important in synaptic plasticity (Alder et al., 2003) and it is indicated that it increases synaptic plasticity in a BDNFdependent manner (Bozdagi et al., 2008). The requirement of BDNF in VGF expression and the necessity of BDNF in VGF-induced synaptic plasticity show that VGF is heavily intertwined in the BDNF pathway. In addition, VGF expression can be upregulated by exercise (Hunsberger et al., 2007) and ECT (Altar et al., 2004; Newton et al., 2003). Antidepressant treatment also increased VGF expression in the hippocampus and PFC of rats (Cattaneo et al., 2010).

$\underline{N G F}$ : Nerve growth factor (NGF) is a growth factor first described as a neurite outgrowth factor (Olson, 1967). Later, NGF proved to be involved in neuron repair and survival (Kromer, 1987; Shigeno et al., 1991; Sofroniew et al., 2001; Zhao et al., 2004). More recently, NGF has been implicated in neurogenesis in the striatum (Frielingsdorf et al., 2007; Zhu et al., 2011), hippocampal plasticity (Conner et al., 2009) and proliferation and differentiation of neuronal stem cells (Cattaneo and McKay, 1990). However, only 
few studies have investigated the role of this trophic factor in depression. Serum levels of NGF are lowered in elderly MDD patients (Diniz et al., 2012a). Interestingly, antidepressant treatment using duloxetine, a serotonin-norepinephrine reuptake inhibitor (SNRI), could restore altered levels of NGF in major depressed patients (Martino et al., 2013). However, this effect was not found in a clinical study using selective serotonin reuptake inhibitors (SSRI) antidepressant (Hellweg et al., 2008). In the Flinders Sensitive Line (FSL) rat model of depression, it was found that ECT increased NGF levels in the hippocampus (Angelucci et al., 2003a), and that NGF injections had antidepressant effects (Overstreet et al., 2010).

\section{IV - Intracellular signalling cascades}

MAPK/PI3K: The mitogen-activated protein kinase (MAPK) cascade is activated by a G-protein called Ras (Schaeffer and Weber, 1999). Ras is activated following ligand binding to tyrosine kinase receptors and neurotrophins may exert their proliferative and neurogenic action via the Trk/Ras/MAPK pathway (Chao, 2003; Guan, 1994; Kaplan and Miller, 2000). MAPK signalling, via the induction of extracellular signal-regulated kinase (ERK), has been implicated in neuronal survival (Cavanaugh, 2004; Hetman et al., 1999; Klesse et al., 1999; Xia et al., 1995) and neurotrophin induced survival (Creedon et al., 1996; Wang et al., 2007), in a way that most likely requires the involvement and activation of myocyteenhancer factor 2C (MEF2C) (Wang et al., 2007). Multiple lines of evidence point towards MAPK signalling as an important pathway in the action of neurotrophins in the brain (Kaplan and Miller, 2000). Several growth factors, including BDNF (Cavanaugh et al., 2001; Obrietan et al., 2002), NFG (Learish et al., 2000) and EGF (Learish et al., 2000) are known to increase the activity of MAPK. For example, MAPK activation was required for VEGF, EGF or FGF induced hippocampal proliferation (Abe and Saito, 2000a, b; Learish et al., 2000; Lu et al., 2011). In the PC12 cell line, p38 MAPK activation was required for the induction of neuronal differentiation by both NGF and epidermal growth factor EGF (Morooka and Nishida, 1998). BDNF promoted survival in neural cell cultures via a MAPK dependant activation of CREB (Bonni et al., 1999; Hetman et al., 2002). Decreased levels of ERK were found in the post-mortem brain of patients suffering from mood disorders (Yuan et al., 2010). Administration of mitogen-activated protein kinase kinase (MEK) inhibitors was associated with increased depressive-like behaviour, suggesting the participation of the MAPK signalling cascade in the pathophysiology of depression (Qi et al., 2009). Interestingly, a decrease of MAPK phosphorylation were found in the hippocampus and PFC of rats following chronic stress (First et al., 2011; Gourley et al., 2008; Qi et al., 2006), and could be normalized successfully by chronic antidepressant treatment (First et al., 2011; Gourley et al., 2008; Hisaoka et al., 2007). Furthermore, the Ras/MAPK pathway is known to be tightly intertwined with the phosphatidylinositide 3-kinase (PI3K) and its target kinase Akt (a serine/threonine kinase, also known as protein kinase B) in order to regulate neuronal survival (Klesse et al., 1999). The activation of the PI3K/Akt pathway seems to play a role in growth factor response, including NGF, BDNF and FGF (Chen et al., 2007; Peltier et al., 2007; Yao and Cooper, 1995), and is implicated in LTP 
and neurogenesis in the hippocampus (Bruel-Jungerman et al., 2009). The mammalian target of rapamycine (mTor) has also been described as a key-role mediator of the PI3K pathway, and many studies reported that the fast-acting and robust antidepressant-like properties of N-Methyl-D-aspartate (NMDA) antagonist might be assigned to the plasticity-related signalling underlying mTor activation (Autry et al., 2011; Li et al., 2010).

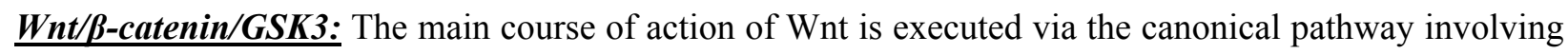
Frizzled receptors and dishevelled (Dsh) proteins, leading to the activation of $\beta$-catenin, possibly via the inhibition of glycogen synthase kinase 3 (GSK3) by phosphorylation (Miller et al., 1999). Wnt/ $\beta$-catenin signalling is involved in cerebral development and stimulates proliferation and neurogenesis in the telencephalon (Gulacsi and Anderson, 2008). Wnt2 has been shown to be a key-role regulator of dopaminergic neuron proliferation in the developing ventral midbrain (Sousa et al., 2010) and a conditional $\beta$-catenin knockout in the ventral midbrain of mice significantly reduced dopaminergic neurogenesis (Tang et al., 2009). The overexpression of Wnt3 was sufficient to increase hippocampal neurogenesis of adult hippocampal progenitor cells both in vitro and in vivo (Lie et al., 2005). Pharmacological blockade and genetic invalidation of Wnt pathway could attenuate adult hippocampal neurogenesis in rodents (Jessberger et al., 2009). Moreover, Dickkopf-1 (Dkk-1), an inhibitor of the Wnt canonical pathway, caused neuronal cell death when injected in rat brains (Scali et al., 2006), and a Dkk-1 knockout abolished the stress-related hippocampal atrophy in mice (Matrisciano et al., 2011). It is interesting to note that Wnt2, Wnt5a and Wnt7a are involved in the $\beta$-catenin dependant synaptic plasticity by increasing synaptogenesis and dendritic arborisation (Ciani et al., 2011; Sahores et al., 2010; Varela-Nallar et al., 2010; Varela-Nallar et al., 2012; Wayman et al., 2006; Yu and Malenka, 2003). Interestingly, post-mortem $\beta$-catenin levels were decreased in the ventral PFC of depressed patients as compared to healthy subjects (Karege et al., 2012) and conditional knockout of $\beta$-catenin resulted in an increase in depressive-like behaviour in mice (Gould et al., 2008). Further, BDNF proved to specifically increase the expression of Wnt1 and $\beta$-catenin in mouse neural stem cell cultures (Chen et al., 2013). Chronic ECT and antidepressant treatment increased $\beta$-catenin and Wnt2 expression in the hippocampus of rats (Madsen et al., 2003; Okamoto et al., 2010). In addition, viral-mediated overexpression of Wnt2 in the hippocampus of rat caused antidepressant-like effects (Okamoto et al., 2010). Viral-vector-induced knockdown of frizzled-6 resulted in increased depressive-like behaviour in rats (Voleti et al., 2012). On the other hand, chronic antidepressant treatment and ECT decreased frizzled-3 in the rat frontal cortex (Yamada et al., 2005). Furthermore, the inhibition of GSK3, an essential player is Wnt signalling, has been implicated as a potential therapeutic target for diabetes, neurodegenerative disease (Cohen and Goedert, 2004) and mood disorders such as depression (Li and Jope, 2010). Stimulation of neuroblastoma and cerebellar granule cells with BDNF led to increased phosphorylation of GSK3 $\beta$, resulting in the inhibition of its function (Foulstone et al., 1999; Mai et al., 2002). Similarly, NGF induced hippocampal axon growth required the inactivation of GSK3 $\beta$ (Kim et al., 2006; Zhou et al., 2004). A post-mortem 
study of depressed patients showed an increase in GSK3 kinase activity in the PFC of MDD patients, as compared to healthy controls (Karege et al., 2007). It is interesting to note that inhibitors of GSK3 augmented neurogenesis of neural progenitor cells via the $\mathrm{Wnt} / \beta$ catenin pathway in vitro (Lange et al., 2011; Valvezan and Klein, 2012), and deletion of GSK3 $\alpha$ and $\beta$ resulted in hyperproliferation of neural cells (Kim et al., 2009). On the other hand, overexpression of GSK3 $\beta$ induced neuronal death and atrophy of the DG (Sirerol-Piquer et al., 2011). In rats, intraperitoneal administration of GSK3 inhibitor produced antidepressant-like effects (Gould et al., 2004). Hence, the inhibition of GSK3 has been hypothesized as the mechanism by which lithium may exert influence on mood disorders such as depression (Wexler et al., 2007). Accordingly, administration of antidepressant drugs like fluoxetine and imipramine that increase extracellular serotonin concentrations resulted in increased phosphorylation on GSK3 $\beta$ in rodents (Beaulieu, 2007; Li et al., 2004).

CREB: The cyclic AMP response element binding protein (CREB) is activated by various kinase signalling pathways (Adams et al., 2000), and has been evidenced to participate in neural survival, as well as axon and dendrite outgrowth (Lonze et al., 2002; Redmond et al., 2002; Walton et al., 1999). Postmortem brain analysis of depressed suicide patients showed that CREB was decreased in the temporal cortex, hippocampus and PFC (Dowlatshahi et al., 1998; Dwivedi et al., 2003a). In addition, a decreased CRE-DNA binding activity in the hippocampus and PFC in suicide victims has been observed (Dwivedi et al., 2003a). Similarly, a reduction in CREB and a significantly larger decrease in phospho-CREB were reported in the orbitofrontal cortex of MDD patients (Yamada et al., 2003). In contrast, other studies indicated a higher expression of phospho-CREB in the PFC (Odagaki et al., 2001) and in the amygdala of patients suffering from mood disorders (Young et al., 2004). In animal models, mice modified to express constitutively active CREB showed increased BDNF expression and facilitated LTP in the hippocampus (Barco et al., 2002). Further, viral-mediated overexpression of CREB in the hippocampus had an antidepressant effect (Chen et al., 2001a), whereas overexpression in the basolateral amygdala increased depression and anxiety related behaviour (Wallace et al., 2004). In a similar manner, viral-mediated expression of a dominant-negative mutant of CREB (mCREB) effectively blocked CREB activity in the NAc and produced an antidepressant effect (Newton et al., 2002; Pliakas et al., 2001), whereas overexpression in the NAc increased depressive behaviour (Pliakas et al., 2001). Furthermore, a growing body of literature indicate a critical role for CREB in the mechanism of action of antidepressants. Chronic administration of SSRI and SNRI antidepressants and ECT in rats increased the transcription of CREB mRNA, as well as CRE-DNA binding activity, in the CA1 and CA3 pyramidal layer and granule layer of the DG after 10 days of treatment (Blom et al., 2002; Nibuya et al., 1996). An increase of phospho-CREB but not CREB was found in the PFC after chronic antidepressant treatment (Laifenfeld et al., 2005). On the other hand, CREB deficient mice treated with desipramine and fluoxetine showed the same antidepressant-like effects as wild type mice, indicating that CREB is not required for the antidepressant actions of SNRIs and SSRIs (Conti et al., 2002). Administration of desipramine in NAc tissue dissected 
from rat brains were reported to decrease pCREB (Chartoff et al., 2009). In addition, in CREB deficient mice, treatment with desipramine neither increased neurogenesis (Gur et al., 2007), nor induced the BDNF upregulation normally seen after desipramine administration (Conti et al., 2002) indicating that CREB may be necessary for the increase in BDNF following antidepressant treatment. Altogether, the current literature indicates that CREB has a central role in depression, but its exact involvement in the aetiology and treatment of depression remains to be further elucidated.

\section{V - Concluding remarks}

Growth factors and associated neuroplasticity signalling play an essential role in the development and maintenance of the central nervous system (Anlar et al., 1999; Ford-Perriss et al., 2001; Greenberg et al., 2009). Accordingly, there is growing evidences that abnormal trophic support in cortico-limbic regions regulating mood and emotions might account in the pathophysiology of depression (Krishnan and Nestler, 2008). In addition, clean-cut evidences also showed that antidepressants require neuroplasticity pathways to rescue the deficits in synapse density, dendritic arborization and neuronal functioning often associated with mood disorders (Pittenger and Duman, 2008). However, several limitations about the neurotrophic hypothesis of depression remain. Current knowledge makes it difficult to conclude whether neuroplasticity and neurogenesis represent a cause or only a consequence of the pathological processes associated with depression. Hence, future research should focus on elucidating the exact involvement of neurotrophic signalling in the onset and aetiology of major depression. Furthermore, mounting evidences seems to indicate that neurogenesis might not be required for the therapeutic action of antidepressants (Bessa et al., 2009). In line with this hypothesis, the usage of N-methyl-D-Aspartate (NMDA) receptor antagonists showed that rapid induction of neurplasticity pathways such as BDNF and mTor signalling pathways was sufficient to produce a robust and prolonged antidepressant effect (Autry et al., 2011; Li et al., 2010). Hence, the rapid enhancement of hippocampal neuroplasticity - involving dendritic growth, spine density and synaptic transmission - represent an original strategy to circumvent the delayed efficacy of current antidepressant drugs. Finally, the use of drugs that specifically target neurotrophic signalling should provide more insights about the involvement of neuroplasticity pathways in the mediation of antidepressant response. Nevertheless, growth factors and neurotrophins have considerable limitations, including a poor blood-brain barrier penetration and a short half-life in plasma, making these small proteins difficult to use in animal models or in the clinic (Nave et al., 1985; Ochs et al., 2000; Poduslo and Curran, 1996). Hence, identification of small non-peptidic neurotrophin mimetics remains a current challenge in neuroscience research, and may represent an interesting target for the development of a new class of therapeutic agents for mood-related disorders. 


\section{VI - References}

Abe, K. and Saito, H. (2000a) The mitogen-activated protein kinase cascade mediates neurotrophic effect of epidermal growth factor in cultured rat hippocampal neurons. Neurosci Lett 282, 89-92.

Abe, K. and Saito, H. (2000b) Neurotrophic effect of basic fibroblast growth factor is mediated by the p42/p44 mitogen-activated protein kinase cascade in cultured rat cortical neurons. Brain research. Developmental brain research 122, 81-85.

Åberg, M. A., Åberg, N. D., Hedbäcker, H., Oscarsson, J. and Eriksson, P. S. (2000) Peripheral infusion of IGF-I selectively induces neurogenesis in the adult rat hippocampus. The Journal of Neuroscience 20, 2896-2903.

Adachi, M., Barrot, M., Autry, A. E., Theobald, D. and Monteggia, L. M. (2008) Selective Loss of Brain-Derived Neurotrophic Factor in the Dentate Gyrus Attenuates Antidepressant Efficacy. Biological Psychiatry 63, 642-649.

Adams, J. P., Roberson, E. D., English, J. D., Selcher, J. C. and Sweatt, J. D. (2000) MAPK regulation of gene expression in the central nervous system. Acta neurobiologiae experimentalis 60, 377-394.

Aggleton, J. P. (1993) The contribution of the amygdala to normal and abnormal emotional states. Trends in neurosciences $16,328-333$.

Alder, J., Thakker-Varia, S., Bangasser, D. A., Kuroiwa, M., Plummer, M. R., Shors, T. J. and Black, I. B. (2003) Brain-derived neurotrophic factor-induced gene expression reveals novel actions of VGF in hippocampal synaptic plasticity. The Journal of neuroscience : the official journal of the Society for Neuroscience 23, 10800-10808.

Altar, C. A., Laeng, P., Jurata, L. W., Brockman, J. A., Lemire, A., Bullard, J., Bukhman, Y. V., Young, T. A., Charles, V. and Palfreyman, M. G. (2004) Electroconvulsive seizures regulate gene expression of distinct neurotrophic signaling pathways. The Journal of neuroscience : the official journal of the Society for Neuroscience 24, 2667-2677.

Altar, C. A., Whitehead, R. E., Chen, R., Wortwein, G. and Madsen, T. M. (2003) Effects of electroconvulsive seizures and antidepressant drugs on brain-derived neurotrophic factor protein in rat brain. Biol Psychiatry 54, 703-709.

Anderson, M. F., Åberg, M. A., Nilsson, M. and Eriksson, P. S. (2002) Insulin-like growth factor-I and neurogenesis in the adult mammalian brain. Developmental brain research 134, 115-122.

Angelucci, F., Aloe, L., Jimenez-Vasquez, P. and Mathe, A. A. (2003a) Electroconvulsive stimuli alter nerve growth factor but not brain-derived neurotrophic factor concentrations in brains of a rat model of depression. Neuropeptides 37, 51-56.

Angelucci, F., Aloe, L., Jimenez-Vasquez, P. and Mathe, A. A. (2003b) Lithium treatment alters brain concentrations of nerve growth factor, brain-derived neurotrophic factor and glial cell line-derived neurotrophic factor in a rat model of depression. The international journal of neuropsychopharmacology / official scientific journal of the Collegium Internationale Neuropsychopharmacologicum (CINP) 6, 225231 .

Angst, F., Stassen, H. H., Clayton, P. J. and Angst, J. (2002) Mortality of patients with mood disorders: follow-up over 34-38 years. Journal of affective disorders 68, 167-181.

Anlar, B., Sullivan, K. A. and Feldman, E. L. (1999) Insulin-like growth factor-I and central nervous system development. Hormone and metabolic research $=$ Hormon- und Stoffwechselforschung $=$ Hormones et metabolisme 31, 120-125. 
Arnold, J. F., Zwiers, M. P., Fitzgerald, D. A., van Eijndhoven, P., Becker, E. S., Rinck, M., Fernandez, G., Speckens, A. E. and Tendolkar, I. (2012) Fronto-limbic microstructure and structural connectivity in remission from major depression. Psychiatry research 204, 40-48.

Arsenijevic, Y. and Weiss, S. (1998) Insulin-like growth factor-I is a differentiation factor for postmitotic CNS stem cell-derived neuronal precursors: distinct actions from those of brain-derived neurotrophic factor. The Journal of neuroscience 18, 2118-2128.

Autry, A. E., Adachi, M., Cheng, P. and Monteggia, L. M. (2009) Gender-Specific Impact of Brain-Derived Neurotrophic Factor Signaling on Stress-Induced Depression-Like Behavior. Biological Psychiatry 66, 8490.

Autry, A. E., Adachi, M., Nosyreva, E., Na, E. S., Los, M. F., Cheng, P. F., Kavalali, E. T. and Monteggia, L. M. (2011) NMDA receptor blockade at rest triggers rapid behavioural antidepressant responses. Nature 475, 91-95.

Aydemir, O., Deveci, A. and Taneli, F. (2005) The effect of chronic antidepressant treatment on serum brainderived neurotrophic factor levels in depressed patients: a preliminary study. Progress in neuropsychopharmacology \& biological psychiatry 29, 261-265.

Balu, D. T., Hoshaw, B. A., Malberg, J. E., Rosenzweig-Lipson, S., Schechter, L. E. and Lucki, I. (2008) Differential regulation of central BDNF protein levels by antidepressant and non-antidepressant drug treatments. Brain research 1211, 37-43.

Banasr, M., Hery, M., Printemps, R. and Daszuta, A. (2004) Serotonin-induced increases in adult cell proliferation and neurogenesis are mediated through different and common 5-HT receptor subtypes in the dentate gyrus and the subventricular zone. Neuropsychopharmacology : official publication of the American College of Neuropsychopharmacology 29, 450-460.

Barco, A., Alarcon, J. M. and Kandel, E. R. (2002) Expression of constitutively active CREB protein facilitates the late phase of long-term potentiation by enhancing synaptic capture. Cell 108, 689-703.

Bath, K. G., Jing, D. Q., Dincheva, I., Neeb, C. C., Pattwell, S. S., Chao, M. V., Lee, F. S. and Ninan, I. (2012) BDNF Val66Met impairs fluoxetine-induced enhancement of adult hippocampus plasticity. Neuropsychopharmacology : official publication of the American College of Neuropsychopharmacology 37, 1297-1304.

Beaulieu, J.-M. (2007) Not only lithium: regulation of glycogen synthase kinase-3 by antipsychotics and serotonergic drugs. The International Journal of Neuropsychopharmacology 10, 3-6.

Beck, K. D., Powell-Braxtont, L., Widmer, H.-R., Valverde, J. and Hefti, F. (1995) Igf1 gene disruption results in reduced brain size, CNS hypomyelination, and loss of hippocampal granule and striatal parvalbumincontaining neurons. Neuron 14, 717-730.

Bellani, M., Baiano, M. and Brambilla, P. (2011) Brain anatomy of major depression II. Focus on amygdala. Epidemiology and Psychiatric Sciences 20, 33-36.

Berton, O., McClung, C. A., Dileone, R. J., Krishnan, V., Renthal, W., Russo, S. J., Graham, D., Tsankova, N. M., Bolanos, C. A., Rios, M., Monteggia, L. M., Self, D. W. and Nestler, E. J. (2006) Essential role of BDNF in the mesolimbic dopamine pathway in social defeat stress. Science (New York, N.Y.) 311, 864-868.

Bessa, J. M., Ferreira, D., Melo, I., Marques, F., Cerqueira, J. J., Palha, J. A., Almeida, O. F. and Sousa, N. (2009) The mood-improving actions of antidepressants do not depend on neurogenesis but are associated with neuronal remodeling. Molecular psychiatry 14, 764-773, 739.

Bewernick, B. H., Hurlemann, R., Matusch, A., Kayser, S., Grubert, C., Hadrysiewicz, B., Axmacher, N., Lemke, M., Cooper-Mahkorn, D., Cohen, M. X., Brockmann, H., Lenartz, D., Sturm, V. and Schlaepfer, T. E. (2010) Nucleus accumbens deep brain stimulation decreases ratings of depression and anxiety in treatmentresistant depression. Biol Psychiatry 67, 110-116. 
Bewernick, B. H., Kayser, S., Sturm, V. and Schlaepfer, T. E. (2012) Long-term effects of nucleus accumbens deep brain stimulation in treatment-resistant depression: evidence for sustained efficacy. Neuropsychopharmacology : official publication of the American College of Neuropsychopharmacology 37, 1975-1985.

Blom, J. M., Tascedda, F., Carra, S., Ferraguti, C., Barden, N. and Brunello, N. (2002) Altered regulation of CREB by chronic antidepressant administration in the brain of transgenic mice with impaired glucocorticoid receptor function. Neuropsychopharmacology : official publication of the American College of Neuropsychopharmacology 26, 605-614.

Boku, S., Nakagawa, S., Takamura, N., Kato, A., Takebayashi, M., Hisaoka-Nakashima, K., Omiya, Y., Inoue, T. and Kusumi, I. (2013) GDNF facilitates differentiation of the adult dentate gyrus-derived neural precursor cells into astrocytes via STAT3. Biochemical and biophysical research communications 434, 779-784.

Boldrini, M., Underwood, M. D., Hen, R., Rosoklija, G. B., Dwork, A. J., John Mann, J. and Arango, V. (2009) Antidepressants increase neural progenitor cells in the human hippocampus. Neuropsychopharmacology : official publication of the American College of Neuropsychopharmacology 34, 2376-2389.

Bonni, A., Brunet, A., West, A. E., Datta, S. R., Takasu, M. A. and Greenberg, M. E. (1999) Cell survival promoted by the Ras-MAPK signaling pathway by transcription-dependent and-independent mechanisms. Science (New York, N.Y.) 286, 1358-1362.

Bowley, M. P., Drevets, W. C., Öngür, D. and Price, J. L. (2002) Low glial numbers in the amygdala in major depressive disorder. Biological Psychiatry 52, 404-412.

Bozdagi, O., Rich, E., Tronel, S., Sadahiro, M., Patterson, K., Shapiro, M. L., Alberini, C. M., Huntley, G. W. and Salton, S. R. (2008) The neurotrophin-inducible gene Vgf regulates hippocampal function and behavior through a brain-derived neurotrophic factor-dependent mechanism. The Journal of neuroscience : the official journal of the Society for Neuroscience 28, 9857-9869.

Bremner, J. D., Narayan, M., Anderson, E. R., Staib, L. H., Miller, H. L. and Charney, D. S. (2000) Hippocampal volume reduction in major depression. American Journal of Psychiatry 157, 115-118.

Bremner, J. D., Vythilingam, M., Vermetten, E., Nazeer, A., Adil, J., Khan, S., Staib, L. H. and Charney, D. S. (2002) Reduced volume of orbitofrontal cortex in major depression. Biological Psychiatry 51, 273-279.

Brezun, J. M. and Daszuta, A. (1999) Depletion in serotonin decreases neurogenesis in the dentate gyrus and the subventricular zone of adult rats. Neuroscience 89, 999-1002.

Bruel-Jungerman, E., Veyrac, A., Dufour, F., Horwood, J., Laroche, S. and Davis, S. (2009) Inhibition of PI3K-Akt signaling blocks exercise-mediated enhancement of adult neurogenesis and synaptic plasticity in the dentate gyrus. PloS one 4, e7901.

Busiguina, S., Fernandez, A. M., Barrios, V., Clark, R., Tolbert, D. L., Berciano, J. and Torres-Aleman, I. (2000) Neurodegeneration is associated to changes in serum insulin-like growth factors. Neurobiology of disease 7, 657-665.

Canli, T., Cooney, R. E., Goldin, P., Shah, M., Sivers, H., Thomason, M. E., Whitfield-Gabrieli, S., Gabrieli, J. D. and Gotlib, I. H. (2005) Amygdala reactivity to emotional faces predicts improvement in major depression. Neuroreport 16, 1267-1270.

Cao, L., Jiao, X., Zuzga, D. S., Liu, Y., Fong, D. M., Young, D. and During, M. J. (2004) VEGF links hippocampal activity with neurogenesis, learning and memory. Nature genetics $\mathbf{3 6}, 827-835$.

Cattaneo, A., Sesta, A., Calabrese, F., Nielsen, G., Riva, M. A. and Gennarelli, M. (2010) The expression of VGF is reduced in leukocytes of depressed patients and it is restored by effective antidepressant treatment. Neuropsychopharmacology : official publication of the American College of Neuropsychopharmacology 35, 1423-1428.

Cattaneo, E. and McKay, R. (1990) Proliferation and differentiation of neuronal stem cells regulated by nerve growth factor. Nature 347, 762-765. 
Cavanaugh, J. E. (2004) Role of extracellular signal regulated kinase 5 in neuronal survival. European journal of biochemistry / FEBS 271, 2056-2059.

Cavanaugh, J. E., Ham, J., Hetman, M., Poser, S., Yan, C. and Xia, Z. (2001) Differential regulation of mitogenactivated protein kinases ERK1/2 and ERK5 by neurotrophins, neuronal activity, and cAMP in neurons. The Journal of neuroscience : the official journal of the Society for Neuroscience 21, 434-443.

Chao, M. V. (2003) Neurotrophins and their receptors: a convergence point for many signalling pathways. Nature Reviews Neuroscience 4, 299-309.

Chartoff, E. H., Papadopoulou, M., MacDonald, M. L., Parsegian, A., Potter, D., Konradi, C. and Carlezon, W. A. (2009) Desipramine reduces stress-activated dynorphin expression and CREB phosphorylation in NAc tissue. Molecular pharmacology 75, 704-712.

Chen, A. C. H., Shirayama, Y., Shin, K.-H., Neve, R. L. and Duman, R. S. (2001a) Expression of the cAMP response element binding protein (CREB) in hippocampus produces an antidepressant effect. Biological Psychiatry 49, 753-762.

Chen, B., Dowlatshahi, D., MacQueen, G. M., Wang, J. F. and Young, L. T. (2001b) Increased hippocampal BDNF immunoreactivity in subjects treated with antidepressant medication. Biol Psychiatry 50, 260-265.

Chen, B. Y., Wang, X., Wang, Z. Y., Wang, Y. Z., Chen, L. W. and Luo, Z. J. (2013) Brain-derived neurotrophic factor stimulates proliferation and differentiation of neural stem cells, possibly by triggering the Wnt/betacatenin signaling pathway. Journal of neuroscience research 91, 30-41.

Chen, M., Nguyen, T., Pike, C. and Russo-Neustadt, A. (2007) Norepinephrine induces BDNF and activates the PI3K and MAPK cascades in embryonic hippocampal neurons. Cellular signalling 19, 114-128.

Chen, Y., Ai, Y., Slevin, J. R., Maley, B. E. and Gash, D. M. (2005) Progenitor proliferation in the adult hippocampus and substantia nigra induced by glial cell line-derived neurotrophic factor. Experimental neurology 196, 87-95.

Chen, Z. Y., Jing, D., Bath, K. G., Ieraci, A., Khan, T., Siao, C. J., Herrera, D. G., Toth, M., Yang, C., McEwen, B. S., Hempstead, B. L. and Lee, F. S. (2006) Genetic variant BDNF (Val66Met) polymorphism alters anxiety-related behavior. Science (New York, N.Y.) 314, 140-143.

Ciani, L., Boyle, K. A., Dickins, E., Sahores, M., Anane, D., Lopes, D. M., Gibb, A. J. and Salinas, P. C. (2011) Wnt7a signaling promotes dendritic spine growth and synaptic strength through $\mathrm{Ca}(2)(+) / \mathrm{Calmodulin}-$ dependent protein kinase II. Proceedings of the National Academy of Sciences of the United States of America 108, 10732-10737.

Clark-Raymond, A. and Halaris, A. (2013) VEGF and depression: A comprehensive assessment of clinical data. $J$ Psychiatr Res.

Cohen, P. and Goedert, M. (2004) GSK3 inhibitors: development and therapeutic potential. Nature reviews Drug discovery 3, 479-487.

Cole, J., Costafreda, S. G., McGuffin, P. and Fu, C. H. (2011) Hippocampal atrophy in first episode depression: a meta-analysis of magnetic resonance imaging studies. Journal of affective disorders 134, 483-487.

Conner, J. M., Franks, K. M., Titterness, A. K., Russell, K., Merrill, D. A., Christie, B. R., Sejnowski, T. J. and Tuszynski, M. H. (2009) NGF is essential for hippocampal plasticity and learning. The Journal of neuroscience : the official journal of the Society for Neuroscience 29, 10883-10889.

Conti, A. C., Cryan, J. F., Dalvi, A., Lucki, I. and Blendy, J. A. (2002) cAMP response element-binding protein is essential for the upregulation of brain-derived neurotrophic factor transcription, but not the behavioral or endocrine responses to antidepressant drugs. The Journal of neuroscience : the official journal of the Society for Neuroscience 22, 3262-3268.

Cook, S. C. and Wellman, C. L. (2004) Chronic stress alters dendritic morphology in rat medial prefrontal cortex. Journal of neurobiology 60, 236-248. 
Cotter, D., Mackay, D., Chana, G., Beasley, C., Landau, S. and Everall, I. P. (2002) Reduced neuronal size and glial cell density in area 9 of the dorsolateral prefrontal cortex in subjects with major depressive disorder. Cerebral cortex (New York, N.Y. : 1991) 12, 386-394.

Creedon, D. J., Johnson, E. M. and Lawrence, J. C. (1996) Mitogen-activated protein kinase-independent pathways mediate the effects of nerve growth factor and cAMP on neuronal survival. Journal of Biological Chemistry 271, 20713-20718.

D'Mello, S. R., Galli, C., Ciotti, T. and Calissano, P. (1993) Induction of apoptosis in cerebellar granule neurons by low potassium: inhibition of death by insulin-like growth factor I and cAMP. Proceedings of the National Academy of Sciences 90, 10989-10993.

David, D. J., Samuels, B. A., Rainer, Q., Wang, J. W., Marsteller, D., Mendez, I., Drew, M., Craig, D. A., Guiard, B. P., Guilloux, J. P., Artymyshyn, R. P., Gardier, A. M., Gerald, C., Antonijevic, I. A., Leonardo, E. D. and Hen, R. (2009) Neurogenesis-dependent and -independent effects of fluoxetine in an animal model of anxiety/depression. Neuron 62, 479-493.

Deltheil, T., Guiard, B. P., Cerdan, J., David, D. J., Tanaka, K. F., Reperant, C., Guilloux, J. P., Coudore, F., Hen, R. and Gardier, A. M. (2008) Behavioral and serotonergic consequences of decreasing or increasing hippocampus brain-derived neurotrophic factor protein levels in mice. Neuropharmacology 55, 1006-1014.

Deltheil, T., Tanaka, K., Reperant, C., Hen, R., David, D. J. and Gardier, A. M. (2009) Synergistic neurochemical and behavioural effects of acute intrahippocampal injection of brain-derived neurotrophic factor and antidepressants in adult mice. The international journal of neuropsychopharmacology / official scientific journal of the Collegium Internationale Neuropsychopharmacologicum (CINP) 12, 905-915.

Dempsey, R. J., Sailor, K. A., Bowen, K. K., Tureyen, K. and Vemuganti, R. (2003) Stroke-induced progenitor cell proliferation in adult spontaneously hypertensive rat brain: effect of exogenous IGF-1 and GDNF. $J$ Neurochem 87, 586-597.

Diniz, B. S., Teixeira, A. L., Machado-Vieira, R., Talib, L. L., Gattaz, W. F. and Forlenza, O. V. (2012a) Reduced Serum Nerve Growth Factor in Patients With Late-Life Depression. The American journal of geriatric psychiatry : official journal of the American Association for Geriatric Psychiatry.

Diniz, B. S., Teixeira, A. L., Miranda, A. S., Talib, L. L., Gattaz, W. F. and Forlenza, O. V. (2012b) Circulating Glial-derived neurotrophic factor is reduced in late-life depression. J Psychiatr Res 46, 135-139.

Diniz, L., dos Santos, T. B., Britto, L. R., Cespedes, I. C., Garcia, M. C., Spadari-Bratfisch, R. C., Medalha, C. C., de Castro, G. M., Montesano, F. T. and Viana, M. B. (2013) Effects of chronic treatment with corticosterone and imipramine on fos immunoreactivity and adult hippocampal neurogenesis. Behavioural brain research $\mathbf{2 3 8 ,}$ 170-177.

Djavadian, R. L. (2004) Serotonin and neurogenesis in the hippocampal dentate gyrus of adult mammals. Acta neurobiologiae experimentalis 64, 189-200.

Doi, M., Miyazaki, I., Nagamachi, T., Shinomiya, K., Matsunaga, H., Sendo, T., Kawasaki, H., Asanuma, M., Gomita, Y. and Kitamura, Y. (2010) Effects of imipramine and lithium on the suppression of cell proliferation in the dentate gyrus of the hippocampus in adrenocorticotropic hormone-treated rats. Acta medica Okayama 64, 219-223.

Dowlatshahi, D., MacQueen, G. M., Wang, J. F. and Young, L. T. (1998) Increased temporal cortex CREB concentrations and antidepressant treatment in major depression. Lancet 352, 1754-1755.

Drevets, W. C. (2000) Functional anatomical abnormalities in limbic and prefrontal cortical structures in major depression. Progress in brain research 126, 413-431.

Drevets, W. C. (2003) Neuroimaging abnormalities in the amygdala in mood disorders. Annals of the New York Academy of Sciences $\mathbf{9 8 5}, 420-444$. 
Drevets, W. C., Videen, T. O., Price, J. L., Preskorn, S. H., Carmichael, S. T. and Raichle, M. E. (1992) A functional anatomical study of unipolar depression. The Journal of neuroscience : the official journal of the Society for Neuroscience 12, 3628-3641.

Duman, C. H., Schlesinger, L., Terwilliger, R., Russell, D. S., Newton, S. S. and Duman, R. S. (2009) Peripheral insulin-like growth factor-I produces antidepressant-like behavior and contributes to the effect of exercise. Behavioural brain research 198, 366-371.

Duman, R. S. and Aghajanian, G. K. (2012) Synaptic dysfunction in depression: potential therapeutic targets. Science (New York, N.Y.) 338, 68-72.

Dunham, J. S., Deakin, J. F. W., Miyajima, F., Payton, A. and Toro, C. T. (2009) Expression of hippocampal brainderived neurotrophic factor and its receptors in Stanley consortium brains. Journal of Psychiatric Research 43, 1175-1184.

During, M. J. and Cao, L. (2006) VEGF, a mediator of the effect of experience on hippocampal neurogenesis. Current Alzheimer research 3, 29-33.

Dwivedi, Y., Rao, J. S., Rizavi, H. S., Kotowski, J., Conley, R. R., Roberts, R. C., Tamminga, C. A. and Pandey, G. N. (2003a) Abnormal expression and functional characteristics of cyclic adenosine monophosphate response element binding protein in postmortem brain of suicide subjects. Archives of general psychiatry 60, 273-282.

Dwivedi, Y., Rizavi, H. S., Conley, R. R., Roberts, R. C., Tamminga, C. A. and Pandey, G. N. (2003b) Altered gene expression of brain-derived neurotrophic factor and receptor tyrosine kinase $\mathrm{B}$ in postmortem brain of suicide subjects. Archives of general psychiatry 60, 804-815.

Eagleson, K. L., Fairfull, L. D., Salton, S. R. and Levitt, P. (2001) Regional differences in neurotrophin availability regulate selective expression of VGF in the developing limbic cortex. The Journal of neuroscience : the official journal of the Society for Neuroscience 21, 9315-9324.

Egan, M. F., Kojima, M., Callicott, J. H., Goldberg, T. E., Kolachana, B. S., Bertolino, A., Zaitsev, E., Gold, B., Goldman, D., Dean, M., Lu, B. and Weinberger, D. R. (2003) The BDNF val66met polymorphism affects activity-dependent secretion of BDNF and human memory and hippocampal function. Cell 112, 257-269.

Eisch, A. J., Bolanos, C. A., de Wit, J., Simonak, R. D., Pudiak, C. M., Barrot, M., Verhaagen, J. and Nestler, E. J. (2003) Brain-derived neurotrophic factor in the ventral midbrain-nucleus accumbens pathway: a role in depression. Biol Psychiatry 54, 994-1005.

Eisch, A. J. and Petrik, D. (2012) Depression and hippocampal neurogenesis: a road to remission? Science (New York, N.Y.) 338, 72-75.

Elfving, B. and Wegener, G. (2012) Electroconvulsive seizures stimulate the vegf pathway via mTORC1. Synapse (New York, N.Y.) 66, 340-345.

Elsayed, M., Banasr, M., Duric, V., Fournier, N. M., Licznerski, P. and Duman, R. S. (2012) Antidepressant effects of fibroblast growth factor-2 in behavioral and cellular models of depression. Biol Psychiatry 72, 258-265.

Encinas, J. M., Vaahtokari, A. and Enikolopov, G. (2006) Fluoxetine targets early progenitor cells in the adult brain. Proceedings of the National Academy of Sciences of the United States of America 103, 8233-8238.

Epstein, J., Pan, H., Kocsis, J. H., Yang, Y., Butler, T., Chusid, J., Hochberg, H., Murrough, J., Strohmayer, E., Stern, E. and Silbersweig, D. A. (2006) Lack of ventral striatal response to positive stimuli in depressed versus normal subjects. The American journal of psychiatry 163, 1784-1790.

Evans, S. J., Choudary, P. V., Neal, C. R., Li, J. Z., Vawter, M. P., Tomita, H., Lopez, J. F., Thompson, R. C., Meng, F., Stead, J. D., Walsh, D. M., Myers, R. M., Bunney, W. E., Watson, S. J., Jones, E. G. and Akil, H. (2004) Dysregulation of the fibroblast growth factor system in major depression. Proceedings of the National Academy of Sciences of the United States of America 101, 15506-15511. 
Falowski, S. M., Sharan, A., Reyes, B. A., Sikkema, C., Szot, P. and Van Bockstaele, E. J. (2011) An evaluation of neuroplasticity and behavior after deep brain stimulation of the nucleus accumbens in an animal model of depression. Neurosurgery 69, 1281-1290.

First, M., Gil-Ad, I., Taler, M., Tarasenko, I., Novak, N. and Weizman, A. (2011) The effects of fluoxetine treatment in a chronic mild stress rat model on depression-related behavior, brain neurotrophins and ERK expression. Journal of molecular neuroscience : MN 45, 246-255.

Ford-Perriss, M., Abud, H. and Murphy, M. (2001) Fibroblast growth factors in the developing central nervous system. Clinical and experimental pharmacology \& physiology 28, 493-503.

Foulstone, E. J., Tavare, J. M. and Gunn-Moore, F. J. (1999) Sustained phosphorylation and activation of protein kinase B correlates with brain-derived neurotrophic factor and insulin stimulated survival of cerebellar granule cells. Neurosci Lett 264, 125-128.

Frielingsdorf, H., Simpson, D. R., Thal, L. J. and Pizzo, D. P. (2007) Nerve growth factor promotes survival of new neurons in the adult hippocampus. Neurobiol Dis 26, 47-55.

Frodl, T., Meisenzahl, E. M., Zetzsche, T., Born, C., Jager, M., Groll, C., Bottlender, R., Leinsinger, G. and Moller, H. J. (2003) Larger amygdala volumes in first depressive episode as compared to recurrent major depression and healthy control subjects. Biol Psychiatry 53, 338-344.

Frodl, T., Schule, C., Schmitt, G., Born, C., Baghai, T., Zill, P., Bottlender, R., Rupprecht, R., Bondy, B., Reiser, M., Moller, H. J. and Meisenzahl, E. M. (2007) Association of the brain-derived neurotrophic factor Val66Met polymorphism with reduced hippocampal volumes in major depression. Archives of general psychiatry 64, 410-416.

Furman, D. J., Hamilton, J. P. and Gotlib, I. H. (2011) Frontostriatal functional connectivity in major depressive disorder. Biology of mood \& anxiety disorders 1, 11.

Gass, P. and Hellweg, R. (2010) Peripheral brain-derived neurotrophic factor (BDNF) as a biomarker for affective disorders? The International Journal of Neuropsychopharmacology 13, 1.

Gaughran, F., Payne, J., Sedgwick, P. M., Cotter, D. and Berry, M. (2006) Hippocampal FGF-2 and FGFR1 mRNA expression in major depression, schizophrenia and bipolar disorder. Brain research bulletin 70, 221-227.

Giacobbe, P., Mayberg, H. S. and Lozano, A. M. (2009) Treatment resistant depression as a failure of brain homeostatic mechanisms: implications for deep brain stimulation. Experimental neurology 219, 44-52.

Gonul, A. S., Akdeniz, F., Taneli, F., Donat, O., Eker, C. and Vahip, S. (2005) Effect of treatment on serum brainderived neurotrophic factor levels in depressed patients. European archives of psychiatry and clinical neuroscience 255, 381-386.

Gould, T. D., Einat, H., Bhat, R. and Manji, H. K. (2004) AR-A 014418, a selective GSK-3 inhibitor, produces antidepressant-like effects in the forced swim test. The International Journal of Neuropsychopharmacology 7, 387-390.

Gould, T. D., O'Donnell, K. C., Picchini, A. M., Dow, E. R., Chen, G. and Manji, H. K. (2008) Generation and behavioral characterization of beta-catenin forebrain-specific conditional knock-out mice. Behavioural brain research 189, 117-125.

Gourley, S. L., Wu, F. J., Kiraly, D. D., Ploski, J. E., Kedves, A. T., Duman, R. S. and Taylor, J. R. (2008) Regionally specific regulation of ERK MAP kinase in a model of antidepressant-sensitive chronic depression. Biological psychiatry 63, 353-359.

Greenberg, M. E., Xu, B., Lu, B. and Hempstead, B. L. (2009) New insights in the biology of BDNF synthesis and release: implications in CNS function. The Journal of neuroscience : the official journal of the Society for Neuroscience 29, 12764-12767.

Greene, J., Banasr, M., Lee, B., Warner-Schmidt, J. and Duman, R. S. (2009) Vascular endothelial growth factor signaling is required for the behavioral actions of antidepressant treatment: pharmacological and cellular 
characterization. Neuropsychopharmacology : official publication of the American College of Neuropsychopharmacology 34, 2459-2468.

Guan, K. L. (1994) The mitogen activated protein kinase signal transduction pathway: From the cell surface to the nucleus. Cellular Signalling 6, 581-589.

Gulacsi, A. A. and Anderson, S. A. (2008) Beta-catenin-mediated Wnt signaling regulates neurogenesis in the ventral telencephalon. Nature neuroscience 11, 1383-1391.

Gur, T. L., Conti, A. C., Holden, J., Bechtholt, A. J., Hill, T. E., Lucki, I., Malberg, J. E. and Blendy, J. A. (2007) cAMP response element-binding protein deficiency allows for increased neurogenesis and a rapid onset of antidepressant response. The Journal of neuroscience : the official journal of the Society for Neuroscience 27, 7860-7868.

Hamidi, M., Drevets, W. C. and Price, J. L. (2004) Glial reduction in amygdala in major depressive disorder is due to oligodendrocytes. Biological Psychiatry 55, 563-569.

Hamilton, J. P. and Gotlib, I. H. (2008) Neural Substrates of Increased Memory Sensitivity for Negative Stimuli in Major Depression. Biological Psychiatry 63, 1155-1162.

Heine, V. M., Zareno, J., Maslam, S., Joels, M. and Lucassen, P. J. (2005) Chronic stress in the adult dentate gyrus reduces cell proliferation near the vasculature and VEGF and Flk-1 protein expression. European Journal of Neuroscience 21, 1304-1314.

Hellweg, R., Ziegenhorn, A., Heuser, I. and Deuschle, M. (2008) Serum concentrations of nerve growth factor and brain-derived neurotrophic factor in depressed patients before and after antidepressant treatment. Pharmacopsychiatry 41, 66-71.

Hetman, M., Hsuan, S. L., Habas, A., Higgins, M. J. and Xia, Z. (2002) ERK1/2 antagonizes glycogen synthase kinase-3beta-induced apoptosis in cortical neurons. The Journal of biological chemistry 277, 49577-49584.

Hetman, M., Kanning, K., Cavanaugh, J. E. and Xia, Z. (1999) Neuroprotection by brain-derived neurotrophic factor is mediated by extracellular signal-regulated kinase and phosphatidylinositol 3-kinase. Journal of Biological Chemistry 274, 22569-22580.

Hisaoka, K., Nishida, A., Koda, T., Miyata, M., Zensho, H., Morinobu, S., Ohta, M. and Yamawaki, S. (2001) Antidepressant drug treatments induce glial cell line-derived neurotrophic factor (GDNF) synthesis and release in rat C6 glioblastoma cells. J Neurochem 79, 25-34.

Hisaoka, K., Takebayashi, M., Tsuchioka, M., Maeda, N., Nakata, Y. and Yamawaki, S. (2007) Antidepressants increase glial cell line-derived neurotrophic factor production through monoamine-independent activation of protein tyrosine kinase and extracellular signal-regulated kinase in glial cells. The Journal of pharmacology and experimental therapeutics 321, 148-157.

Hitoshi, S., Maruta, N., Higashi, M., Kumar, A., Kato, N. and Ikenaka, K. (2007) Antidepressant drugs reverse the loss of adult neural stem cells following chronic stress. Journal of neuroscience research 85, 3574-3585.

Hoshaw, B. A., Hill, T. I., Crowley, J. J., Malberg, J. E., Khawaja, X., Rosenzweig-Lipson, S., Schechter, L. E. and Lucki, I. (2008) Antidepressant-like behavioral effects of IGF-I produced by enhanced serotonin transmission. European Journal of Pharmacology 594, 109-116.

Hoshaw, B. A., Malberg, J. E. and Lucki, I. (2005) Central administration of IGF-I and BDNF leads to long-lasting antidepressant-like effects. Brain research 1037, 204-208.

Hunsberger, J. G., Newton, S. S., Bennett, A. H., Duman, C. H., Russell, D. S., Salton, S. R. and Duman, R. S. (2007) Antidepressant actions of the exercise-regulated gene VGF. Nat Med 13, 1476-1482.

Jacobsen, J. P. R. and Mørk, A. (2004) The effect of escitalopram, desipramine, electroconvulsive seizures and lithium on brain-derived neurotrophic factor mRNA and protein expression in the rat brain and the correlation to 5-HT and 5-HIAA levels. Brain research 1024, 183-192. 
Jessberger, S., Clark, R. E., Broadbent, N. J., Clemenson, G. D., Jr., Consiglio, A., Lie, D. C., Squire, L. R. and Gage, F. H. (2009) Dentate gyrus-specific knockdown of adult neurogenesis impairs spatial and object recognition memory in adult rats. Learning \& memory (Cold Spring Harbor, N.Y.) 16, 147-154.

Jin, K., Sun, Y., Xie, L., Batteur, S., Mao, X. O., Smelick, C., Logvinova, A. and Greenberg, D. A. (2003) Neurogenesis and aging: FGF-2 and HB-EGF restore neurogenesis in hippocampus and subventricular zone of aged mice. Aging cell 2, 175-183.

Jin, K., Zhu, Y., Sun, Y., Mao, X. O., Xie, L. and Greenberg, D. A. (2002) Vascular endothelial growth factor (VEGF) stimulates neurogenesis in vitro and in vivo. Proceedings of the National Academy of Sciences of the United States of America 99, 11946-11950.

Jin, K. L., Mao, X. O. and Greenberg, D. A. (2000) Vascular endothelial growth factor: direct neuroprotective effect in in vitro ischemia. Proceedings of the National Academy of Sciences of the United States of America $\mathbf{9 7 ,}$ 10242-10247.

Kaplan, D. R. and Miller, F. D. (2000) Neurotrophin signal transduction in the nervous system. Current opinion in neurobiology 10, 381-391.

Karege, F., Bondolfi, G., Gervasoni, N., Schwald, M., Aubry, J. M. and Bertschy, G. (2005) Low brain-derived neurotrophic factor (BDNF) levels in serum of depressed patients probably results from lowered platelet BDNF release unrelated to platelet reactivity. Biol Psychiatry 57, 1068-1072.

Karege, F., Perret, G., Bondolfi, G., Schwald, M., Bertschy, G. and Aubry, J.-M. (2002) Decreased serum brainderived neurotrophic factor levels in major depressed patients. Psychiatry research 109, 143-148.

Karege, F., Perroud, N., Burkhardt, S., Fernandez, R., Ballmann, E., La Harpe, R. and Malafosse, A. (2012) Protein levels of beta-catenin and activation state of glycogen synthase kinase-3beta in major depression. A study with postmortem prefrontal cortex. Journal of affective disorders 136, 185-188.

Karege, F., Perroud, N., Burkhardt, S., Schwald, M., Ballmann, E., La Harpe, R. and Malafosse, A. (2007) Alteration in kinase activity but not in protein levels of protein kinase B and glycogen synthase kinase3 beta in ventral prefrontal cortex of depressed suicide victims. Biol Psychiatry 61, 240-245.

Keers, R. and Uher, R. (2012) Gene-environment interaction in major depression and antidepressant treatment response. Current psychiatry reports 14, 129-137.

Kessler, R. C., Berglund, P., Demler, O., Jin, R., Koretz, D., Merikangas, K. R., Rush, A. J., Walters, E. E. and Wang, P. S. (2003) The epidemiology of major depressive disorder. JAMA: the journal of the American Medical Association 289, 3095-3105.

Khaibullina, A. A., Rosenstein, J. M. and Krum, J. M. (2004) Vascular endothelial growth factor promotes neurite maturation in primary CNS neuronal cultures. Brain research. Developmental brain research 148, 59-68.

Kim, W.-Y., Wang, X., Wu, Y., Doble, B. W., Patel, S., Woodgett, J. R. and Snider, W. D. (2009) GSK-3 is a master regulator of neural progenitor homeostasis. Nature neuroscience 12, 1390-1397.

Kim, W.-Y., Zhou, F.-Q., Zhou, J., Yokota, Y., Wang, Y.-M., Yoshimura, T., Kaibuchi, K., Woodgett, James R., Anton, E. S. and Snider, William D. (2006) Essential Roles for GSK-3s and GSK-3-Primed Substrates in Neurotrophin-Induced and Hippocampal Axon Growth. Neuron 52, 981-996.

Kitamura, Y., Doi, M., Kuwatsuka, K., Onoue, Y., Miyazaki, I., Shinomiya, K., Koyama, T., Sendo, T., Kawasaki, H., Asanuma, M. and Gomita, Y. (2011) Chronic treatment with imipramine and lithium increases cell proliferation in the hippocampus in adrenocorticotropic hormone-treated rats. Biological \& pharmaceutical bulletin 34, 77-81.

Klempin, F., Beis, D., Mosienko, V., Kempermann, G., Bader, M. and Alenina, N. (2013) Serotonin is required for exercise-induced adult hippocampal neurogenesis. The Journal of neuroscience : the official journal of the Society for Neuroscience 33, 8270-8275. 
Klesse, L., Meyers, K., Marshall, C. and Parada, L. (1999) Nerve growth factor induces survival and differentiation through two distinct signaling cascades in PC12 cells. Oncogene 18, 2055-2068.

Kobayashi, T., Ahlenius, H., Thored, P., Kobayashi, R., Kokaia, Z. and Lindvall, O. (2006) Intracerebral infusion of glial cell line-derived neurotrophic factor promotes striatal neurogenesis after stroke in adult rats. Stroke; $a$ journal of cerebral circulation 37, 2361-2367.

Krishnan, V. and Nestler, E. J. (2008) The molecular neurobiology of depression. Nature 455, 894-902.

Kromer, L. F. (1987) Nerve growth factor treatment after brain injury prevents neuronal death. Science (New York, N.Y.) 235, 214-216.

Kronenberg, G., Tebartz van Elst, L., Regen, F., Deuschle, M., Heuser, I. and Colla, M. (2009) Reduced amygdala volume in newly admitted psychiatric in-patients with unipolar major depression. Journal of Psychiatric Research 43, 1112-1117.

Laifenfeld, D., Karry, R., Grauer, E., Klein, E. and Ben-Shachar, D. (2005) Antidepressants and prolonged stress in rats modulate CAM-L1, laminin, and pCREB, implicated in neuronal plasticity. Neurobiol Dis 20, 432441 .

Lange, C. and Irle, E. (2004) Enlarged amygdala volume and reduced hippocampal volume in young women with major depression. Psychological medicine 34, 1059-1064.

Lange, C., Mix, E., Frahm, J., Glass, Ä., Müller, J., Schmitt, O., Schmöle, A.-C., Klemm, K., Ortinau, S. and Hübner, R. (2011) Small molecule GSK-3 inhibitors increase neurogenesis of human neural progenitor cells. Neuroscience letters 488, 36-40.

Learish, R. D., Bruss, M. D. and Haak-Frendscho, M. (2000) Inhibition of mitogen-activated protein kinase kinase blocks proliferation of neural progenitor cells. Brain research. Developmental brain research 122, 97-109.

LeDoux, J. E. (2000) Emotion circuits in the brain. Annu Rev Neurosci 23, 155-184.

Li, N., Lee, B., Liu, R. J., Banasr, M., Dwyer, J. M., Iwata, M., Li, X. Y., Aghajanian, G. and Duman, R. S. (2010) mTOR-dependent synapse formation underlies the rapid antidepressant effects of NMDA antagonists. Science (New York, N.Y.) 329, 959-964.

Li, X. and Jope, R. S. (2010) Is glycogen synthase kinase-3 a central modulator in mood regulation? Neuropsychopharmacology : official publication of the American College of Neuropsychopharmacology 35, 2143-2154.

Li, X., Zhu, W., Roh, M. S., Friedman, A. B., Rosborough, K. and Jope, R. S. (2004) In vivo regulation of glycogen synthase kinase-3beta (GSK3beta) by serotonergic activity in mouse brain. Neuropsychopharmacology : official publication of the American College of Neuropsychopharmacology 29, 1426-1431.

Licht, T., Eavri, R., Goshen, I., Shlomai, Y., Mizrahi, A. and Keshet, E. (2010) VEGF is required for dendritogenesis of newly born olfactory bulb interneurons. Development (Cambridge, England) 137, 261271.

Lichtenwalner, R., Forbes, M., Bennett, S., Lynch, C., Sonntag, W. and Riddle, D. (2001) Intracerebroventricular infusion of insulin-like growth factor-I ameliorates the age-related decline in hippocampal neurogenesis. Neuroscience 107, 603-613.

Lie, D.-C., Colamarino, S. A., Song, H.-J., Désiré, L., Mira, H., Consiglio, A., Lein, E. S., Jessberger, S., Lansford, H. and Dearie, A. R. (2005) Wnt signalling regulates adult hippocampal neurogenesis. Nature 437, 13701375 .

Liston, C., Miller, M. M., Goldwater, D. S., Radley, J. J., Rocher, A. B., Hof, P. R., Morrison, J. H. and McEwen, B. S. (2006) Stress-induced alterations in prefrontal cortical dendritic morphology predict selective impairments in perceptual attentional set-shifting. The Journal of Neuroscience 26, 7870-7874. 
Liu, Q., Yu, J., Mao-Ying, Q. L., Mi, W. L., Li, B., Wang, Y. Q., Wang, J. and Wu, G. C. (2008) Repeated clomipramine treatment reversed the inhibition of cell proliferation in adult hippocampus induced by chronic unpredictable stress. Pharmacogenomics $J$ 8, 375-383.

Lonze, B. E., Riccio, A., Cohen, S. and Ginty, D. D. (2002) Apoptosis, axonal growth defects, and degeneration of peripheral neurons in mice lacking CREB. Neuron 34, 371-385.

Lopez, A. D. and Murray, C. (1998) The global burden of disease. Nat Med 4, 1241-1243.

Lorenzetti, V., Allen, N. B., Fornito, A. and Yücel, M. (2009) Structural brain abnormalities in major depressive disorder: A selective review of recent MRI studies. Journal of affective disorders 117, 1-17.

Lu, K.-T., Sun, C.-L., Wo, P. Y., Yen, H.-H., Tang, T.-H., Ng, M.-C., Huang, M.-L. and Yang, Y.-L. (2011) Hippocampal neurogenesis after traumatic brain injury is mediated by vascular endothelial growth factor receptor-2 and the Raf/MEK/ERK cascade. Journal of neurotrauma 28, 441-450.

MacQueen, G. M., Campbell, S., McEwen, B. S., Macdonald, K., Amano, S., Joffe, R. T., Nahmias, C. and Young, L. T. (2003) Course of illness, hippocampal function, and hippocampal volume in major depression. Proceedings of the National Academy of Sciences 100, 1387-1392.

Madsen, T. M., Newton, S. S., Eaton, M. E., Russell, D. S. and Duman, R. S. (2003) Chronic electroconvulsive seizure up-regulates $\beta$-catenin expression in rat hippocampus: role in adult neurogenesis. Biological psychiatry 54, 1006-1014.

Magarinos, A. M., McEwen, B. S., Flugge, G. and Fuchs, E. (1996) Chronic psychosocial stress causes apical dendritic atrophy of hippocampal CA3 pyramidal neurons in subordinate tree shrews. The Journal of neuroscience : the official journal of the Society for Neuroscience 16, 3534-3540.

Mai, L., Jope, R. S. and Li, X. (2002) BDNF-mediated signal transduction is modulated by GSK3beta and mood stabilizing agents. $J$ Neurochem $\mathbf{8 2}, 75-83$.

Malberg, J. E., Eisch, A. J., Nestler, E. J. and Duman, R. S. (2000) Chronic antidepressant treatment increases neurogenesis in adult rat hippocampus. The Journal of neuroscience : the official journal of the Society for Neuroscience 20, 9104-9110.

Malberg, J. E., Platt, B., Rizzo, S. J. S., Ring, R. H., Lucki, I., Schechter, L. E. and Rosenzweig-Lipson, S. (2007) Increasing the levels of insulin-like growth factor-I by an IGF binding protein inhibitor produces anxiolytic and antidepressant-like effects. Neuropsychopharmacology : official publication of the American College of Neuropsychopharmacology 32, 2360-2368.

Malone Jr, D. A., Dougherty, D. D., Rezai, A. R., Carpenter, L. L., Friehs, G. M., Eskandar, E. N., Rauch, S. L., Rasmussen, S. A., Machado, A. G., Kubu, C. S., Tyrka, A. R., Price, L. H., Stypulkowski, P. H., Giftakis, J. E., Rise, M. T., Malloy, P. F., Salloway, S. P. and Greenberg, B. D. (2009) Deep Brain Stimulation of the Ventral Capsule/Ventral Striatum for Treatment-Resistant Depression. Biological Psychiatry 65, 267-275.

Marlatt, M. W., Lucassen, P. J. and van Praag, H. (2010) Comparison of neurogenic effects of fluoxetine, duloxetine and running in mice. Brain research 1341, 93-99.

Martino, M., Rocchi, G., Escelsior, A., Contini, P., Colicchio, S., de Berardis, D., Amore, M., Fornaro, P. and Fornaro, M. (2013) NGF serum levels variations in major depressed patients receiving duloxetine. Psychoneuroendocrinology.

Matrisciano, F., Busceti, C. L., Bucci, D., Orlando, R., Caruso, A., Molinaro, G., Cappuccio, I., Riozzi, B., Gradini, R., Motolese, M., Caraci, F., Copani, A., Scaccianoce, S., Melchiorri, D., Bruno, V., Battaglia, G. and Nicoletti, F. (2011) Induction of the Wnt antagonist Dickkopf-1 is involved in stress-induced hippocampal damage. PloS one 6, e16447.

Matthews, S. C., Strigo, I. A., Simmons, A. N., Yang, T. T. and Paulus, M. P. (2008) Decreased functional coupling of the amygdala and supragenual cingulate is related to increased depression in unmedicated individuals with current major depressive disorder. Journal of affective disorders 111, 13-20. 
Michel, T. M., Frangou, S., Camara, S., Thiemeyer, D., Jecel, J., Tatschner, T., Zoechling, R. and Grunblatt, E. (2008) Altered glial cell line-derived neurotrophic factor (GDNF) concentrations in the brain of patients with depressive disorder: a comparative post-mortem study. European psychiatry : the journal of the Association of European Psychiatrists 23, 413-420.

Miller, J. R., Hocking, A. M., Brown, J. D. and Moon, R. T. (1999) Mechanism and function of signal transduction by the $\mathrm{Wnt} /$ beta-catenin and $\mathrm{Wnt} / \mathrm{Ca} 2+$ pathways. Oncogene 18, 7860-7872.

Mitschelen, M., Yan, H., Farley, J. A., Warrington, J. P., Han, S., Herenu, C. B., Csiszar, A., Ungvari, Z., BaileyDowns, L. C., Bass, C. E. and Sonntag, W. E. (2011) Long-term deficiency of circulating and hippocampal insulin-like growth factor I induces depressive behavior in adult mice: a potential model of geriatric depression. Neuroscience 185, 50-60.

Monteggia, L. M., Barrot, M., Powell, C. M., Berton, O., Galanis, V., Gemelli, T., Meuth, S., Nagy, A., Greene, R. W. and Nestler, E. J. (2004) Essential role of brain-derived neurotrophic factor in adult hippocampal function. Proceedings of the National Academy of Sciences of the United States of America 101, 1082710832.

Monteggia, L. M., Luikart, B., Barrot, M., Theobold, D., Malkovska, I., Nef, S., Parada, L. F. and Nestler, E. J. (2007) Brain-Derived Neurotrophic Factor Conditional Knockouts Show Gender Differences in Depression-Related Behaviors. Biological Psychiatry 61, 187-197.

Morooka, T. and Nishida, E. (1998) Requirement of p38 mitogen-activated protein kinase for neuronal differentiation in PC12 cells. The Journal of biological chemistry 273, 24285-24288.

Mostany, R., Valdizán, E. M. and Pazos, A. (2008) A role for nuclear $\beta$-catenin in SNRI antidepressant-induced hippocampal cell proliferation. Neuropharmacology 55, 18-26.

Mudo, G., Bonomo, A., Di Liberto, V., Frinchi, M., Fuxe, K. and Belluardo, N. (2009) The FGF-2/FGFRs neurotrophic system promotes neurogenesis in the adult brain. Journal of neural transmission (Vienna, Austria : 1996) 116, 995-1005.

Nave, K. A., Probstmeier, R. and Schachner, M. (1985) Epidermal growth factor does not cross the blood-brain barrier. Cell and tissue research 241, 453-457.

Nestler, E. J. and Carlezon Jr, W. A. (2006) The Mesolimbic Dopamine Reward Circuit in Depression. Biological Psychiatry 59, 1151-1159.

Newton, S. S., Collier, E. F., Hunsberger, J., Adams, D., Terwilliger, R., Selvanayagam, E. and Duman, R. S. (2003) Gene profile of electroconvulsive seizures: induction of neurotrophic and angiogenic factors. The Journal of neuroscience : the official journal of the Society for Neuroscience 23, 10841-10851.

Newton, S. S., Thome, J., Wallace, T. L., Shirayama, Y., Schlesinger, L., Sakai, N., Chen, J., Neve, R., Nestler, E. J. and Duman, R. S. (2002) Inhibition of cAMP response element-binding protein or dynorphin in the nucleus accumbens produces an antidepressant-like effect. The Journal of neuroscience : the official journal of the Society for Neuroscience 22, 10883-10890.

Nibuya, M., Morinobu, S. and Duman, R. S. (1995) Regulation of BDNF and trkB mRNA in rat brain by chronic electroconvulsive seizure and antidepressant drug treatments. The Journal of neuroscience : the official journal of the Society for Neuroscience 15, 7539-7547.

Nibuya, M., Nestler, E. J. and Duman, R. S. (1996) Chronic antidepressant administration increases the expression of cAMP response element binding protein (CREB) in rat hippocampus. The Journal of neuroscience : the official journal of the Society for Neuroscience 16, 2365-2372.

Ninan, I., Bath, K. G., Dagar, K., Perez-Castro, R., Plummer, M. R., Lee, F. S. and Chao, M. V. (2010) The BDNF Val66Met polymorphism impairs NMDA receptor-dependent synaptic plasticity in the hippocampus. The Journal of neuroscience : the official journal of the Society for Neuroscience 30, 8866-8870. 
O'Kusky, J. R., Ye, P. and D'Ercole, A. J. (2000) Insulin-like growth factor-I promotes neurogenesis and synaptogenesis in the hippocampal dentate gyrus during postnatal development. The Journal of Neuroscience 20, 8435-8442.

Obrietan, K., Gao, X.-B. and van den Pol, A. N. (2002) Excitatory Actions of GABA Increase BDNF Expression via a MAPK-CREB-Dependent Mechanism-A Positive Feedback Circuit in Developing Neurons. Journal of neurophysiology $\mathbf{8 8}, 1005-1015$.

Ochs, G., Penn, R. D., York, M., Giess, R., Beck, M., Tonn, J., Haigh, J., Malta, E., Traub, M., Sendtner, M. and Toyka, K. V. (2000) A phase I/II trial of recombinant methionyl human brain derived neurotrophic factor administered by intrathecal infusion to patients with amyotrophic lateral sclerosis. Amyotrophic lateral sclerosis and other motor neuron disorders : official publication of the World Federation of Neurology, Research Group on Motor Neuron Diseases 1, 201-206.

Odagaki, Y., Garcia-Sevilla, J. A., Huguelet, P., La Harpe, R., Koyama, T. and Guimon, J. (2001) Cyclic AMPmediated signaling components are upregulated in the prefrontal cortex of depressed suicide victims. Brain research $\mathbf{8 9 8}, 224-231$.

Okamoto, H., Voleti, B., Banasr, M., Sarhan, M., Duric, V., Girgenti, M. J., Dileone, R. J., Newton, S. S. and Duman, R. S. (2010) Wnt2 expression and signaling is increased by different classes of antidepressant treatments. Biol Psychiatry 68, 521-527.

Olson, L. (1967) Outgrowth of sympathetic adrenergic neurons in mice treated with a nerve-growth factor (NGF). Zeitschrift fur Zellforschung und mikroskopische Anatomie (Vienna, Austria : 1948) 81, 155-173.

Öngür, D., Drevets, W. C. and Price, J. L. (1998) Glial reduction in the subgenual prefrontal cortex in mood disorders. Proceedings of the National Academy of Sciences 95, 13290-13295.

Ongur, D. and Price, J. L. (2000) The organization of networks within the orbital and medial prefrontal cortex of rats, monkeys and humans. Cerebral cortex (New York, N.Y. : 1991) 10, 206-219.

Otsuki, K., Uchida, S., Watanuki, T., Wakabayashi, Y., Fujimoto, M., Matsubara, T., Funato, H. and Watanabe, Y. (2008) Altered expression of neurotrophic factors in patients with major depression. Journal of Psychiatric Research 42, 1145-1153.

Overstreet, D. H., Fredericks, K., Knapp, D., Breese, G. and McMichael, J. (2010) Nerve growth factor (NGF) has novel antidepressant-like properties in rats. Pharmacology, biochemistry, and behavior 94, 553-560.

Pallavi, P., Sagar, R., Mehta, M., Sharma, S., Subramanium, A., Shamshi, F., Sengupta, U., Qadri, R., Pandey, R. M. and Mukhopadhyay, A. K. (2013) Serum neurotrophic factors in adolescent depression: Gender difference and correlation with clinical severity. Journal of affective disorders.

Pan, W. and Kastin, A. J. (2000) Interactions of IGF-1 with the blood-brain barrier in vivo and in situ. Neuroendocrinology 72, 171-178.

Pandey, G. N., Ren, X., Rizavi, H. S., Conley, R. R., Roberts, R. C. and Dwivedi, Y. (2008) Brain-derived neurotrophic factor and tyrosine kinase $\mathrm{B}$ receptor signalling in post-mortem brain of teenage suicide victims. The international journal of neuropsychopharmacology / official scientific journal of the Collegium Internationale Neuropsychopharmacologicum (CINP) 11, 1047-1061.

Park, S. E., Dantzer, R., Kelley, K. W. and McCusker, R. H. (2011) Central administration of insulin-like growth factor-I decreases depressive-like behavior and brain cytokine expression in mice. Journal of neuroinflammation $\mathbf{8}, 12$.

Paslakis, G., Blum, W. F. and Deuschle, M. (2012) Intranasal insulin-like growth factor I (IGF-I) as a plausible future treatment of depression. Medical hypotheses 79, 222-225.

Pattwell, S. S., Bath, K. G., Perez-Castro, R., Lee, F. S., Chao, M. V. and Ninan, I. (2012) The BDNF Val66Met polymorphism impairs synaptic transmission and plasticity in the infralimbic medial prefrontal cortex. The Journal of neuroscience : the official journal of the Society for Neuroscience 32, 2410-2421. 
Pechnick, R. N., Zonis, S., Wawrowsky, K., Cosgayon, R., Farrokhi, C., Lacayo, L. and Chesnokova, V. (2011) Antidepressants stimulate hippocampal neurogenesis by inhibiting p21 expression in the subgranular zone of the hipppocampus. PloS one 6, e27290.

Peltier, J., O'Neill, A. and Schaffer, D. V. (2007) PI3K/Akt and CREB regulate adult neural hippocampal progenitor proliferation and differentiation. Developmental neurobiology 67, 1348-1361.

Piccinni, A., Marazziti, D., Catena, M., Domenici, L., Del Debbio, A., Bianchi, C., Mannari, C., Martini, C., Da Pozzo, E., Schiavi, E., Mariotti, A., Roncaglia, I., Palla, A., Consoli, G., Giovannini, L., Massimetti, G. and Dell'Osso, L. (2008) Plasma and serum brain-derived neurotrophic factor (BDNF) in depressed patients during 1 year of antidepressant treatments. Journal of affective disorders 105, 279-283.

Pincus, H. A. and Pettit, A. R. (2001) The societal costs of chronic major depression. The Journal of clinical psychiatry 62 Suppl 6, 5-9.

Pittenger, C. and Duman, R. S. (2008) Stress, depression, and neuroplasticity: a convergence of mechanisms. Neuropsychopharmacology : official publication of the American College of Neuropsychopharmacology 33, 88-109.

Pizzagalli, D. A., Holmes, A. J., Dillon, D. G., Goetz, E. L., Birk, J. L., Bogdan, R., Dougherty, D. D., Iosifescu, D. V., Rauch, S. L. and Fava, M. (2009) Reduced caudate and nucleus accumbens response to rewards in unmedicated individuals with major depressive disorder. The American journal of psychiatry 166, 702-710.

Pliakas, A. M., Carlson, R. R., Neve, R. L., Konradi, C., Nestler, E. J. and Carlezon, W. A., Jr. (2001) Altered responsiveness to cocaine and increased immobility in the forced swim test associated with elevated cAMP response element-binding protein expression in nucleus accumbens. The Journal of neuroscience : the official journal of the Society for Neuroscience 21, 7397-7403.

Poduslo, J. F. and Curran, G. L. (1996) Permeability at the blood-brain and blood-nerve barriers of the neurotrophic factors: NGF, CNTF, NT-3, BDNF. Brain research. Molecular brain research 36, 280-286.

Price, J. L. (1999) Prefrontal cortical networks related to visceral function and mood. Annals of the New York Academy of Sciences 877, 383-396.

Qi, X., Lin, W., Li, J., Pan, Y. and Wang, W. (2006) The depressive-like behaviors are correlated with decreased phosphorylation of mitogen-activated protein kinases in rat brain following chronic forced swim stress. Behavioural brain research 175, 233-240.

Qi, X., Lin, W., Wang, D., Pan, Y., Wang, W. and Sun, M. (2009) A role for the extracellular signal-regulated kinase signal pathway in depressive-like behavior. Behavioural brain research 199, 203-209.

Rai, K. S., Hattiangady, B. and Shetty, A. K. (2007) Enhanced production and dendritic growth of new dentate granule cells in the middle-aged hippocampus following intracerebroventricular FGF-2 infusions. The European journal of neuroscience 26, 1765-1779.

Rajkowska, G., Miguel-Hidalgo, J. J., Wei, J., Dilley, G., Pittman, S. D., Meltzer, H. Y., Overholser, J. C., Roth, B. L. and Stockmeier, C. A. (1999) Morphometric evidence for neuronal and glial prefrontal cell pathology in major depression. Biol Psychiatry 45, 1085-1098.

Redmond, L., Kashani, A. H. and Ghosh, A. (2002) Calcium regulation of dendritic growth via CaM kinase IV and CREB-mediated transcription. Neuron 34, 999-1010.

Rosenstein, J. M., Mani, N., Khaibullina, A. and Krum, J. M. (2003) Neurotrophic effects of vascular endothelial growth factor on organotypic cortical explants and primary cortical neurons. The Journal of neuroscience : the official journal of the Society for Neuroscience 23, 11036-11044.

Sahay, A. and Hen, R. (2007) Adult hippocampal neurogenesis in depression. Nature neuroscience 10, 1110-1115.

Sahores, M., Gibb, A. and Salinas, P. C. (2010) Frizzled-5, a receptor for the synaptic organizer Wnt7a, regulates activity-mediated synaptogenesis. Development (Cambridge, England) 137, 2215-2225. 
Santarelli, L., Saxe, M., Gross, C., Surget, A., Battaglia, F., Dulawa, S., Weisstaub, N., Lee, J., Duman, R., Arancio, O., Belzung, C. and Hen, R. (2003) Requirement of hippocampal neurogenesis for the behavioral effects of antidepressants. Science (New York, N.Y.) 301, 805-809.

Scali, C., Caraci, F., Gianfriddo, M., Diodato, E., Roncarati, R., Pollio, G., Gaviraghi, G., Copani, A., Nicoletti, F., Terstappen, G. C. and Caricasole, A. (2006) Inhibition of Wnt signaling, modulation of Tau phosphorylation and induction of neuronal cell death by DKK1. Neurobiol Dis 24, 254-265.

Schaeffer, H. J. and Weber, M. J. (1999) Mitogen-activated protein kinases: specific messages from ubiquitous messengers. Mol Cell Biol 19, 2435-2444.

Schiavon, A. P., Milani, H., Romanini, C. V., Foresti, M. L., Castro, O. W., Garcia-Cairasco, N. and de Oliveira, R. M. (2010) Imipramine enhances cell proliferation and decreases neurodegeneration in the hippocampus after transient global cerebral ischemia in rats. Neurosci Lett 470, 43-48.

Schlaepfer, T. E., Cohen, M. X., Frick, C., Kosel, M., Brodesser, D., Axmacher, N., Joe, A. Y., Kreft, M., Lenartz, D. and Sturm, V. (2008) Deep brain stimulation to reward circuitry alleviates anhedonia in refractory major depression. Neuropsychopharmacology : official publication of the American College of Neuropsychopharmacology 33, 368-377.

Schmuckermair, C., Gaburro, S., Sah, A., Landgraf, R., Sartori, S. B. and Singewald, N. (2013) Behavioral and Neurobiological Effects of Deep Brain Stimulation in a Mouse Model of High Anxiety- and DepressionLike Behavior. Neuropsychopharmacology : official publication of the American College of Neuropsychopharmacology.

Segi-Nishida, E., Warner-Schmidt, J. L. and Duman, R. S. (2008) Electroconvulsive seizure and VEGF increase the proliferation of neural stem-like cells in rat hippocampus. Proceedings of the National Academy of Sciences of the United States of America 105, 11352-11357.

Sen, S., Duman, R. and Sanacora, G. (2008) Serum Brain-Derived Neurotrophic Factor, Depression, and Antidepressant Medications: Meta-Analyses and Implications. Biological Psychiatry 64, 527-532.

Sheline, Y. I., Barch, D. M., Donnelly, J. M., Ollinger, J. M., Snyder, A. Z. and Mintun, M. A. (2001) Increased amygdala response to masked emotional faces in depressed subjects resolves with antidepressant treatment: an fMRI study. Biological Psychiatry 50, 651-658.

Sheline, Y. I., Wang, P. W., Gado, M. H., Csernansky, J. G. and Vannier, M. W. (1996) Hippocampal atrophy in recurrent major depression. Proceedings of the National Academy of Sciences of the United States of America 93, 3908-3913.

Shigeno, T., Mima, T., Takakura, K., Graham, D. I., Kato, G., Hashimoto, Y. and Furukawa, S. (1991) Amelioration of delayed neuronal death in the hippocampus by nerve growth factor. The Journal of neuroscience 11, 2914-2919.

Shimizu, E., Hashimoto, K., Okamura, N., Koike, K., Komatsu, N., Kumakiri, C., Nakazato, M., Watanabe, H., Shinoda, N., Okada, S.-i. and Iyo, M. (2003) Alterations of serum levels of brain-derived neurotrophic factor (BDNF) in depressed patients with or without antidepressants. Biological Psychiatry 54, 70-75.

Shirayama, Y., Chen, A. C., Nakagawa, S., Russell, D. S. and Duman, R. S. (2002) Brain-derived neurotrophic factor produces antidepressant effects in behavioral models of depression. The Journal of neuroscience : the official journal of the Society for Neuroscience 22, 3251-3261.

Silverman, W. F., Krum, J. M., Mani, N. and Rosenstein, J. M. (1999) Vascular, glial and neuronal effects of vascular endothelial growth factor in mesencephalic explant cultures. Neuroscience 90, 1529-1541.

Sirerol-Piquer, M., Gomez-Ramos, P., Hernandez, F., Perez, M., Moran, M. A., Fuster-Matanzo, A., Lucas, J. J., Avila, J. and Garcia-Verdugo, J. M. (2011) GSK3beta overexpression induces neuronal death and a depletion of the neurogenic niches in the dentate gyrus. Hippocampus 21, 910-922.

Sirianni, R. W., Olausson, P., Chiu, A. S., Taylor, J. R. and Saltzman, W. M. (2010) The behavioral and biochemical effects of BDNF containing polymers implanted in the hippocampus of rats. Brain research 1321, 40-50. 
Siuciak, J. A., Lewis, D. R., Wiegand, S. J. and Lindsay, R. M. (1997) Antidepressant-Like Effect of Brain-derived Neurotrophic Factor (BDNF). Pharmacology Biochemistry and Behavior 56, 131-137.

Smoski, M. J., Felder, J., Bizzell, J., Green, S. R., Ernst, M., Lynch, T. R. and Dichter, G. S. (2009) fMRI of alterations in reward selection, anticipation, and feedback in major depressive disorder. Journal of affective disorders 118, 69-78.

Sofroniew, M. V., Howe, C. L. and Mobley, W. C. (2001) Nerve growth factor signaling, neuroprotection, and neural repair. Annual review of neuroscience 24, 1217-1281.

Sondell, M., Lundborg, G. and Kanje, M. (1999) Vascular endothelial growth factor has neurotrophic activity and stimulates axonal outgrowth, enhancing cell survival and Schwann cell proliferation in the peripheral nervous system. The Journal of neuroscience : the official journal of the Society for Neuroscience 19, 5731-5740.

Sousa, K. M., Villaescusa, J. C., Cajanek, L., Ondr, J. K., Castelo-Branco, G., Hofstra, W., Bryja, V., Palmberg, C., Bergman, T., Wainwright, B., Lang, R. A. and Arenas, E. (2010) Wnt2 regulates progenitor proliferation in the developing ventral midbrain. The Journal of biological chemistry 285, 7246-7253.

Stewart, C. A. and Reid, I. C. (2000) Repeated ECS and fluoxetine administration have equivalent effects on hippocampal synaptic plasticity. Psychopharmacology 148, 217-223.

Stockmeier, C. A., Mahajan, G. J., Konick, L. C., Overholser, J. C., Jurjus, G. J., Meltzer, H. Y., Uylings, H. B., Friedman, L. and Rajkowska, G. (2004) Cellular changes in the postmortem hippocampus in major depression. Biol Psychiatry 56, 640-650.

Sun, R., Li, N. and Li, T. (2012) VEGF regulates antidepressant effects of lamotrigine. European neuropsychopharmacology : the journal of the European College of Neuropsychopharmacology 22, 424430.

Sun, Y., Jin, K., Childs, J. T., Xie, L., Mao, X. O. and Greenberg, D. A. (2006) Vascular endothelial growth factorB (VEGFB) stimulates neurogenesis: evidence from knockout mice and growth factor administration. Developmental biology 289, 329-335.

Sun, Y., Jin, K., Xie, L., Childs, J., Mao, X. O., Logvinova, A. and Greenberg, D. A. (2003) VEGF-induced neuroprotection, neurogenesis, and angiogenesis after focal cerebral ischemia. The Journal of clinical investigation 111, 1843-1851.

Surget, A., Tanti, A., Leonardo, E. D., Laugeray, A., Rainer, Q., Touma, C., Palme, R., Griebel, G., IbarguenVargas, Y., Hen, R. and Belzung, C. (2011) Antidepressants recruit new neurons to improve stress response regulation. Molecular psychiatry 16, 1177-1188.

Taliaz, D., Stall, N., Dar, D. E. and Zangen, A. (2010) Knockdown of brain-derived neurotrophic factor in specific brain sites precipitates behaviors associated with depression and reduces neurogenesis. Molecular psychiatry 15, 80-92.

Tang, M., Miyamoto, Y. and Huang, E. J. (2009) Multiple roles of beta-catenin in controlling the neurogenic niche for midbrain dopamine neurons. Development (Cambridge, England) 136, 2027-2038.

Tardito, D., Perez, J., Tiraboschi, E., Musazzi, L., Racagni, G. and Popoli, M. (2006) Signaling pathways regulating gene expression, neuroplasticity, and neurotrophic mechanisms in the action of antidepressants: a critical overview. Pharmacological reviews 58, 115-134.

Thakker-Varia, S. and Alder, J. (2009) Neuropeptides in depression: role of VGF. Behavioural brain research 197, 262-278.

Thakker-Varia, S., Krol, J. J., Nettleton, J., Bilimoria, P. M., Bangasser, D. A., Shors, T. J., Black, I. B. and Alder, J. (2007) The neuropeptide VGF produces antidepressant-like behavioral effects and enhances proliferation in the hippocampus. The Journal of neuroscience : the official journal of the Society for Neuroscience 27, 12156-12167. 
Tsai, T. H., Chen, S. L., Chiang, Y. H., Lin, S. Z., Ma, H. I., Kuo, S. W. and Tsao, Y. P. (2000) Recombinant adenoassociated virus vector expressing glial cell line-derived neurotrophic factor reduces ischemia-induced damage. Experimental neurology 166, 266-275.

Turner, C. A., Calvo, N., Frost, D. O., Akil, H. and Watson, S. J. (2008a) The fibroblast growth factor system is downregulated following social defeat. Neurosci Lett 430, 147-150.

Turner, C. A., Gula, E. L., Taylor, L. P., Watson, S. J. and Akil, H. (2008b) Antidepressant-like effects of intracerebroventricular FGF2 in rats. Brain research 1224, 63-68.

Valvezan, A. J. and Klein, P. S. (2012) GSK-3 and Wnt signaling in neurogenesis and bipolar disorder. Frontiers in molecular neuroscience $\mathbf{5}$.

Van Bokhoven, P., Oomen, C. A., Hoogendijk, W. J., Smit, A. B., Lucassen, P. J. and Spijker, S. (2011) Reduction in hippocampal neurogenesis after social defeat is long-lasting and responsive to late antidepressant treatment. The European journal of neuroscience 33, 1833-1840.

Varela-Nallar, L., Alfaro, I. E., Serrano, F. G., Parodi, J. and Inestrosa, N. C. (2010) Wingless-type family member 5A (Wnt-5a) stimulates synaptic differentiation and function of glutamatergic synapses. Proceedings of the National Academy of Sciences of the United States of America 107, 21164-21169.

Varela-Nallar, L., Parodi, J., Farias, G. G. and Inestrosa, N. C. (2012) Wnt-5a is a synaptogenic factor with neuroprotective properties against Abeta toxicity. Neuro-degenerative diseases 10, 23-26.

Vassilopoulou, K., Papathanasiou, M., Michopoulos, I., Boufidou, F., Oulis, P., Kelekis, N., Rizos, E., Nikolaou, C., Pantelis, C., Velakoulis, D. and Lykouras, L. (2013) A magnetic resonance imaging study of hippocampal, amygdala and subgenual prefrontal cortex volumes in major depression subtypes: Melancholic versus psychotic depression. Journal of affective disorders 146, 197-204.

Voleti, B., Tanis, K. Q., Newton, S. S. and Duman, R. S. (2012) Analysis of target genes regulated by chronic electroconvulsive therapy reveals role for Fzd6 in depression. Biol Psychiatry 71, 51-58.

Vyas, A., Jadhav, S. and Chattarji, S. (2006) Prolonged behavioral stress enhances synaptic connectivity in the basolateral amygdala. Neuroscience 143, 387-393.

Vyas, A., Mitra, R., Shankaranarayana Rao, B. S. and Chattarji, S. (2002) Chronic stress induces contrasting patterns of dendritic remodeling in hippocampal and amygdaloid neurons. The Journal of neuroscience : the official journal of the Society for Neuroscience 22, 6810-6818.

Wallace, T. L., Stellitano, K. E., Neve, R. L. and Duman, R. S. (2004) Effects of cyclic adenosine monophosphate response element binding protein overexpression in the basolateral amygdala on behavioral models of depression and anxiety. Biol Psychiatry 56, 151-160.

Walton, M., Woodgate, A. M., Muravlev, A., Xu, R., During, M. J. and Dragunow, M. (1999) CREB phosphorylation promotes nerve cell survival. J Neurochem 73, 1836-1842.

Wang, Y., Liu, L. and Xia, Z. (2007) Brain-derived neurotrophic factor stimulates the transcriptional and neuroprotective activity of myocyte-enhancer factor 2C through an ERK1/2-RSK2 signaling cascade. $J$ Neurochem 102, 957-966.

Warner-Schmidt, J. L. and Duman, R. S. (2007) VEGF is an essential mediator of the neurogenic and behavioral actions of antidepressants. Proceedings of the National Academy of Sciences of the United States of America 104, 4647-4652.

Warner-Schmidt, J. L. and Duman, R. S. (2008) VEGF as a potential target for therapeutic intervention in depression. Current opinion in pharmacology 8, 14-19.

Watanabe, Y., Gould, E. and McEwen, B. S. (1992) Stress induces atrophy of apical dendrites of hippocampal CA3 pyramidal neurons. Brain research 588, 341-345. 
Wayman, G. A., Impey, S., Marks, D., Saneyoshi, T., Grant, W. F., Derkach, V. and Soderling, T. R. (2006) Activity-dependent dendritic arborization mediated by CaM-kinase I activation and enhanced CREBdependent transcription of Wnt-2. Neuron 50, 897-909.

Wellman, C. L. (2001) Dendritic reorganization in pyramidal neurons in medial prefrontal cortex after chronic corticosterone administration. Journal of neurobiology 49, 245-253.

Werner, S., Unsicker, K. and von Bohlen und Halbach, O. (2011) Fibroblast growth factor-2 deficiency causes defects in adult hippocampal neurogenesis, which are not rescued by exogenous fibroblast growth factor- 2 . Journal of neuroscience research 89, 1605-1617.

Wexler, E., Geschwind, D. and Palmer, T. (2007) Lithium regulates adult hippocampal progenitor development through canonical Wnt pathway activation. Molecular psychiatry 13, 285-292.

Woolley, C. S., Gould, E. and McEwen, B. S. (1990) Exposure to excess glucocorticoids alters dendritic morphology of adult hippocampal pyramidal neurons. Brain research 531, 225-231.

Xia, Z., Dickens, M., Raingeaud, J., Davis, R. J. and Greenberg, M. E. (1995) Opposing effects of ERK and JNKp38 MAP kinases on apoptosis. Science (New York, N.Y.) 270, 1326-1331.

Xu, H., Chen, Z., He, J., Haimanot, S., Li, X., Dyck, L. and Li, X. M. (2006) Synergetic effects of quetiapine and venlafaxine in preventing the chronic restraint stress-induced decrease in cell proliferation and BDNF expression in rat hippocampus. Hippocampus 16, 551-559.

Yadid, G. and Friedman, A. (2008) Dynamics of the dopaminergic system as a key component to the understanding of depression. In: Progress in brain research. pp. 265-286. Eds. V. D. M. Giuseppe Di Giovann, E. Ennio. Elsevier.

Yamada, M., Iwabuchi, T., Takahashi, K., Kurahashi, C., Ohata, H., Honda, K., Higuchi, T. and Yamada, M. (2005) Identification and expression of frizzled-3 protein in rat frontal cortex after antidepressant and electroconvulsive treatment. Journal of pharmacological sciences 99, 239-246.

Yamada, S., Yamamoto, M., Ozawa, H., Riederer, P. and Saito, T. (2003) Reduced phosphorylation of cyclic AMPresponsive element binding protein in the postmortem orbitofrontal cortex of patients with major depressive disorder. Journal of neural transmission (Vienna, Austria : 1996) 110, 671-680.

Yao, R. and Cooper, G. M. (1995) Requirement for phosphatidylinositol-3 kinase in the prevention of apoptosis by nerve growth factor. Science (New York, N.Y.) 267, 2003-2006.

Young, L. T., Bezchlibnyk, Y. B., Chen, B., Wang, J.-F. and MacQueen, G. M. (2004) Amygdala cyclic adenosine monophosphate response element binding protein phosphorylation in patients with mood disorders: effects of diagnosis, suicide, and drug treatment. Biological Psychiatry 55, 570-577.

Yu, X. and Malenka, R. C. (2003) Beta-catenin is critical for dendritic morphogenesis. Nature neuroscience 6, 1169-1177.

Yuan, P., Zhou, R., Wang, Y., Li, X., Li, J., Chen, G., Guitart, X. and Manji, H. K. (2010) Altered levels of extracellular signal-regulated kinase signaling proteins in postmortem frontal cortex of individuals with mood disorders and schizophrenia. Journal of affective disorders 124, 164-169.

Zhang, X., Zhang, Z., Sha, W., Xie, C., Xi, G., Zhou, H. and Zhang, Y. (2009) Electroconvulsive therapy increases glial cell-line derived neurotrophic factor (GDNF) serum levels in patients with drug-resistant depression. Psychiatry research 170, 273-275.

Zhang, X., Zhang, Z., Xie, C., Xi, G., Zhou, H., Zhang, Y. and Sha, W. (2008) Effect of treatment on serum glial cell line-derived neurotrophic factor in depressed patients. Progress in neuro-psychopharmacology \& biological psychiatry 32, 886-890.

Zhao, H. M., Liu, X. F., Mao, X. W. and Chen, C. F. (2004) Intranasal delivery of nerve growth factor to protect the central nervous system against acute cerebral infarction. Chinese medical sciences journal $=$ Chung-kuo $i$ hsueh k'o hsueh tsa chih / Chinese Academy of Medical Sciences 19, 257-261. 
Zhao, M., Li, D., Shimazu, K., Zhou, Y. X., Lu, B. and Deng, C. X. (2007) Fibroblast growth factor receptor-1 is required for long-term potentiation, memory consolidation, and neurogenesis. Biol Psychiatry 62, 381-390.

Zhou, F. Q., Zhou, J., Dedhar, S., Wu, Y. H. and Snider, W. D. (2004) NGF-induced axon growth is mediated by localized inactivation of GSK-3beta and functions of the microtubule plus end binding protein APC. Neuron 42, 897-912.

Zhu, W., Cheng, S., Xu, G., Ma, M., Zhou, Z., Liu, D. and Liu, X. (2011) Intranasal nerve growth factor enhances striatal neurogenesis in adult rats with focal cerebral ischemia. Drug delivery 18, 338-343.

Zhu, Y., Jin, K., Mao, X. O. and Greenberg, D. A. (2003) Vascular endothelial growth factor promotes proliferation of cortical neuron precursors by regulating E2F expression. FASEB journal : official publication of the Federation of American Societies for Experimental Biology 17, 186-193. 
Chapter III 


\title{
CHAPTER IV
}

\section{TrkB inhibition as a therapeutic target for CNS-related disorders}

\author{
FABIEN BOULLE ${ }^{1,2}$, GUNTER KENIS ${ }^{1}$, MAXIME CAZORLA ${ }^{3}$, Michel HAMON ${ }^{2}$, HARry W STEINBUSCH$^{1}$, \\ LAURENCE LANFUMEY ${ }^{2}$, DANIEL L.A VAN DEN HOVE ${ }^{1,4}$
}

${ }^{1}$ Department of Psychiatry and Neuropsychology, Maastricht University, European Graduate School for Neuroscience (EURON), Maastricht, The Netherlands

\footnotetext{
${ }^{2}$ Center for Psychiatry and Neuroscience, INSERM U894, Univ. Pierre \& Marie Curie, Paris, France

${ }^{3}$ Department of Pharmacology and Psychiatry, Columbia University, New York, USA

${ }^{4}$ Department of Psychiatry, Psychosomatics and Psychotherapy, University of Wurzburg, Wurzburg, Germany
}

Progress in Neurobiology, 2012 Aug; 98 (2): 197-206 


\begin{abstract}
The interaction of brain-derived neurotrophic factor (BDNF) with its tropomyosin-related kinase receptor B (TrkB) is involved in fundamental cellular processes including neuronal proliferation, differentiation and survival as well as neurotransmitter release and synaptic plasticity. TrkB signaling has been widely associated with beneficial, trophic effects and many commonly used psychotropic drugs aim to increase BDNF levels in the brain. However, it is likely that a prolonged increased TrkB activation is observed in many pathological conditions, which may underlie the development and course of clinical symptoms. Interestingly, genetic and pharmacological studies aiming at decreasing TrkB activation in rodent models mimicking human pathology have demonstrated a promising therapeutic landscape for TrkB inhibitors in the treatment of various diseases, e.g. central nervous system (CNS) disorders and several types of cancer. Up to date, only a few selective and potent TrkB inhibitors have been developed. As such, the use of crystallography and in silico approaches to model BDNF-TrkB interaction and to generate relevant pharmacophores represents powerful tools to develop novel compounds targeting the TrkB receptor.
\end{abstract}

Key words: BDNF, Cancer, CNS disorders, TrkB inhibitors, Treatments 


\section{I - Introduction}

Neurotrophins are a family of small-secreted proteins that play a key role in the development and maintenance of the vertebrate nervous system (Chao, 2003; Lewin and Barde, 1996). To mediate their effects, neurotrophins can bind to two distinct classes of receptors, displaying opposite effects. The high affinity interaction with the "tropomyosin-related kinase" receptor family (Trks) is usually associated with cell survival, differentiation and synaptic plasticity, whereas the low affinity interaction with the p75 (p75NTR) promotes proteolysis and apoptosis (Lu et al., 2005). The neurotrophin tyrosine kinase receptor 2 (NTRK2), also known as TrkB, has been shown to be specifically activated by several neurotrophins including brain-derived neurotrophic factor (BDNF), neurotrophin 3 (NT 3) and neurotrophic 4/5 (NT 4/5), thereby exerting its trophic effects (Klein et al., 1991; Klein et al., 1992; Soppet et al., 1991). In addition to the classical activation of TrkB, other mechanisms have been described to activate this receptor independently to the binding of neurotrophins (Lee et al., 2002; Nagappan et al., 2008). These transactivations occur at cell membrane and are able to induce TrkB phosphorylation within a few hours. However, the physiological relevance of such mechanisms is not yet elucidated. Among all the neurotrophins, the interaction of BDNF with TrkB has been characterized most thoroughly. The expression of TrkB, as well as of BDNF, is very abundant in the brain and both are also present at lower levels in different peripheral tissues (Maisonpierre et al., 1990; Pruunsild et al., 2007; Yamamoto et al., 1996). TrkB signaling has been reported as critical in various physiological processes such as learning, memory and reward. Abnormal BDNF-mediated activation of TrkB has been reported in various neurological and psychiatric disorders (Andero et al., 2011; Baydyuk et al., 2011; Beckinschtein et al., 2008; Mao et al., 2010; Pezet and Malcangio, 2004). Although the trophic effect of TrkB activation is mainly associated with a positive outcome, increasing evidence suggests that an upregulation of TrkB signaling in specific brain areas can underlie the molecular and cellular changes responsible for the induction and persistence of pathophysiological processes. For instance, an increase in TrkB receptor expression has been observed in different types of cancer, neuropathic pain, drug abuse and epilepsy (Douma et al., 2005; Heinrich et al., 2011; Lu et al., 2010; Wang et al., 2009). As such, TrkB inhibitors can represent promising drugs for the treatment of a wide range of diseases in which over-activation of TrkB has been reported. Up to date, only few compounds that act as specific TrkB inhibitors have been described. The development of small agents displaying high affinity and specificity for TrkB can represent a useful tool to better understand TrkB signaling and its possible implication in pathophysiology providing new therapeutic avenues.

After reviewing the different mechanisms leading to the activation of $\operatorname{TrkB}$, we will focus on pathological conditions where an upregulation of TrkB signaling has been reported. Further, we will consider some important pharmacological issues regarding emerging compounds that act as TrkB inhibitors. 


\section{II - Mechanisms of TrkB activation}

Trk receptors are cell-surface receptors belonging to the tyrosine kinase receptor (RTK) family (Klein et al., 1989). In addition to the classical activation by endogenous ligands, increasing evidence supports the notion that RTKs can be activated by other mechanisms involving various intracellular pathways (Fergusson et al., 2003; Flajolet et al., 2008).

Activation bv neurotrophins: The activation of TrkB by neurotrophins, namely BDNF, NT 4/5 and NT 3, generally follows the common pattern associated with RTK activation (Friedman and Greene, 1999). Neurotrophins exist preferentially as homodimer complexes, and bind to the extracellular interface of a TrkB monomer resulting in receptor dimerisation (Jing et al., 1992). The dimerisation increases the catalytic activity of the intracellular domain of the receptor enabling the phosphorylation of tyrosine residues inside the activation loop (tyrosine Y701, Y705 and Y706) and subsequently the autophosphorylation of tyrosine situated outside of the activation loop (tyrosine Y515 and Y816) (Cunningham and Greene, 1998). Then, activation and recruitment of partner proteins and adaptators to the different tyrosine sites will lead to activation of three main intracellular signaling pathways that are strongly interconnected (Huang and Reichardt, 2003). Briefly, phosphorylation of tyrosine Y515 activates 1) the Ras-mitogen-activated protein kinase (MAPK) signaling cascade, which promotes neuronal differentiation and growth, and 2) the activation of phosphatidylinositol 3-kinase (PI3-K) signaling cascade, which promotes neuronal survival and growth. Phosphorylation of tyrosine Y816 activates 3) the phospholipase $\mathrm{C} \gamma$ (PLC $\gamma$ ) pathway generally associated with synaptic plasticity and neurotransmission (Minichiello, 2009). The neurotrophin/Trk complex is internalized by endocytosis and the intracellular domain of receptor, present on the outside of the endosome, is still phosphorylated and susceptible to bind to signaling molecules (Grimes et al., 1996; Howe et al., 2001). However, the exact mechanism underlying TrkB internalization and recycling is still poorly understood. In addition, different alternative TrkB mRNA splice variants can lead to the translation of different TrkB isoforms including two truncated forms (Middlemas et al., 1991). It has been described that the two truncated forms of TrkB (TrkB-T1 and TrkB-T2) lacking the intrinsic tyrosine kinase activity, was able to inhibit full-length TrkB (TrkB-FL) signaling via the binding of a truncated form with a full form (Biffo et al., 1995; Dorsey et al., 2006; Eide et al., 1996).

Activation in absence of neurotrophins: There are several ways to activate TrkB signaling independent from the binding of neurotrophins. Although this phenomenon is not clearly described, TrkB receptor may show a basal activity induced by a local increase in receptor density within intracellular vesicles and lipid rafts of the plasma membrane, sufficient to enhance biological responses usually associated with neurotrophin signaling (Cazorla et al., 2010, Swift et al., 2010). In addition to this basal TrkB activity, another mechanism known as transactivation has been extensively documented. Chao and colleagues 
have shown that the pharmacological activation of the adenosine 2a receptor (A2aR) was able to promote TrkB phosphorylation and activation of PLC $\gamma$ and PI3K pathways in hippocampal neuronal cultures (Lee and Chao, 2001). Furthermore, several studies have indicated that a wide range of $G$ protein-coupled receptors (GPCRs) including the dopamine receptor 1 (D1R), the pituitary adenylate cyclase-activated polypeptide receptor (PACAPR) and the cannabinoid receptor 1 (CB1R) were also able to transactivate the TrkB receptor upon respective stimulation (Berghuis et al., 2005; Iwakura et al., 2008; Lee et al., 2002; Wiese et al., 2007). This alternative mode of TrkB activation in the absence of neurotrophin binding is mediated by intracellular proteins belonging to the Src kinase family (Huang and McNamara, 2010; Lee and Chao, 2001; Rajagopal and Chao, 2006). This process seems to occur at the cell membrane and may persist in intracellular vesicles inside neuronal cells (Rajagopal et al., 2004). Interestingly, the response is similar to the effects of neurotrophins on the TrkB receptor, but the temporal pattern of activation is longer (Nagappan et al., 2008). In contrast with this long delayed activation of TrkB by GPCRs, a newly identified mechanism of TrkB transactivation involving zinc has been described. Intense neuronal activity results in the release of large amounts of zinc along with glutamate at nerve terminals (Vogt et al., 2000). These zinc ions are able to penetrate postsynaptic neurons via voltage-dependant calcium channels (VDCCs) and the N-methyl-D-aspartate (NMDA) glutamate receptor and indirectly activate Src kinases by inhibiting C-Src tyrosine kinase (CSK) (Huang et al., 2008; Hwang et al., 2005). Such process leads to phosphorylation of TrkB as well as the activation of the three associated pathways within only a few minutes, playing an important role in mossy fiber related long-term potentiation within the hippocampus (Nagappan et al., 2008). More recently, also glucocorticoids have been shown to be able to transactivate TrkB receptors (Jeanneteau et al., 2009). Acute dexamethasone administration promotes TrkB phosphorylation and activates the corresponding signaling pathways within both the rat brain and in primary neuronal cell cultures resulting in a neuroprotective effect (Jeanneteau et al., 2009). However, the exact mechanism by which glucocorticoids transactivate TrkB remains to be elucidated. Finally, various types of antidepressant including Fluoxetine, citalopram, roboxetine and imipramine were shown to induce TrkB phosphorylation, independently of BDNF and monoamine transporter blockade in the rat brain (Rantamaki et al., 2011). 


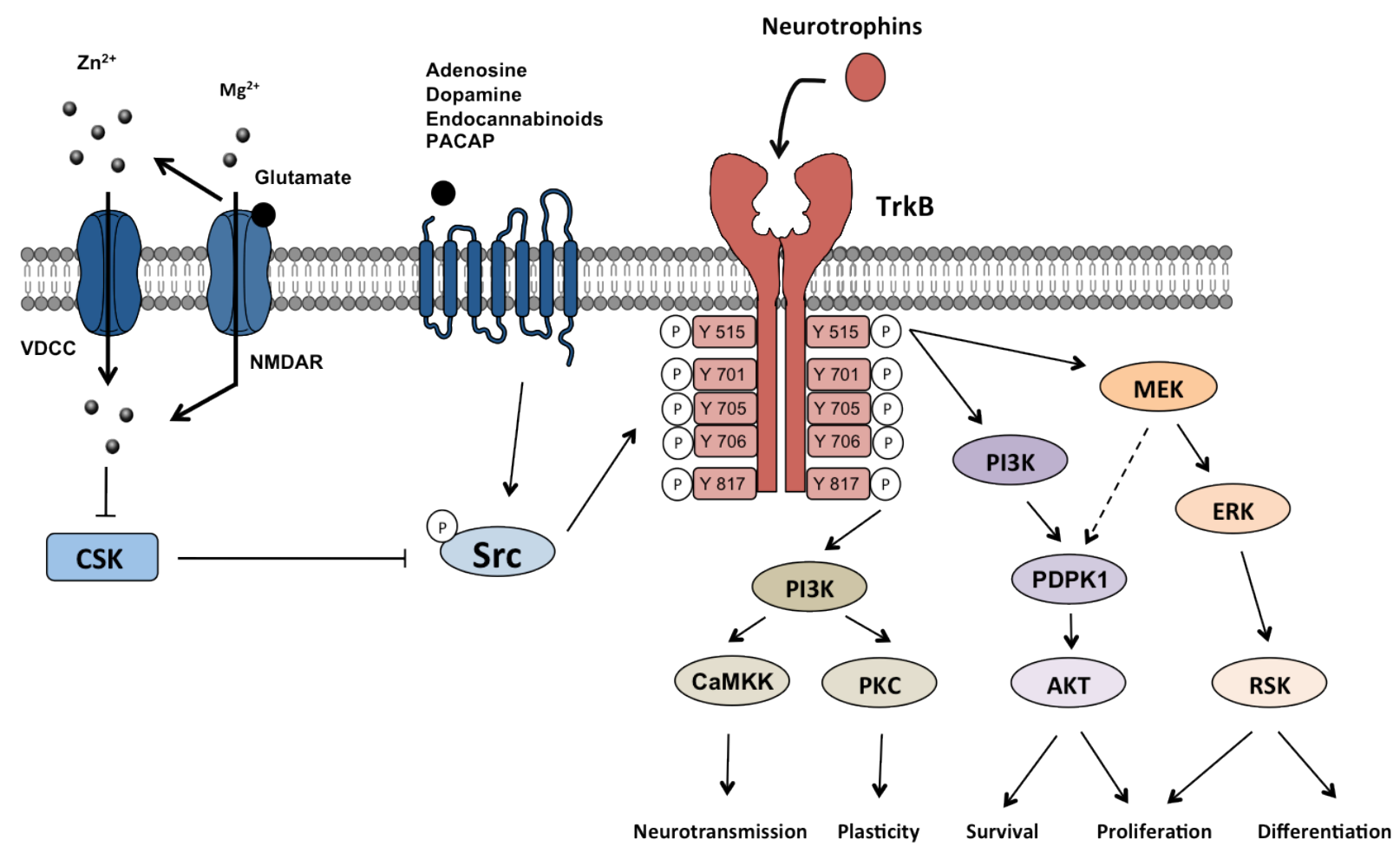

Fig. 1. Neurotrophin -dependent and -independent activation of TrkB receptor and associated signaling pathways.

The binding of neurotrophins to TrkB induces the phosphorylation of the different tyrosines in the intracellular domain leading to three main signaling pathways (i.e. MapK. PI3K and PLC $\gamma$ ). The activation of NMDA receptor (NMDAR) by glutamate allows zinc to penetrate in the cells via voltage-dependent calcium channels (VDCC), which inhibits C-terminal Src Kinase (CSK) usually implicated in the inhibition of Src kinases proteins. This indirect activation of Src kinases can lead to the phosphorylation of tyrosine residues of TrkB intracellular domain within a few minutes. In contrast, a longer mechanism of TrkB activation can be observed upon stimulation of many GPCRs including A2aR, D1R, PACAPR or CB1R. The activation of such receptors can promote the phosphorylation of Src kinases and lead to the subsequent phosphorylation of tyrosine residues of TrkB intracellular domain within few hours. Diverse classes of antidepressants, as well as glucocorticoids, have been shown to transactivate TrkB. However, the exact mechanisms remain unclear. This illustration was realized with "Servier medical art" (http://www.servier.fr/servier-medical-art). 


\section{III - Upregulation of TrkB signaling in CNS-related disorders}

\section{1 - Neurological and psychiatric diseases}

The proper regulation of TrkB levels and their activation is critically important in cell functioning. Downregulation of TrkB signaling is often observed in various brain regions in relation to neurodegenerative diseases, as well as in some psychiatric disorders (Bernard et al., 2011; Pezet and Malcangio, 2004; Weickert et al., 2005). On the other hand, upregulation of TrkB signaling seems to have important implications in the pathogenesis of a broad range of illnesses including CNS-related diseases, metabolic diseases and cancer.

TrkB signaling in epilepsy: Many experimental models and post-mortem brain analyses of epileptic patients have revealed that BDNF mRNA and proteins levels were increased after epileptic seizures (Gall, 1993; Humpel et al., 1993; Isackson et al., 1991; Jankowsky and Petterson, 2001; Schmidt-kastner et al., 1996; Takahashi et al., 1999;). TrkB mRNA is also increased in the striatum and cortical regions after seizures in rodents (Merlio et al., 1993; Salin et al., 1995; Wyneken et al., 2001). Hence, TrkB signaling has been suspected to participate in the molecular mechanism underlying epileptogenesis, e.g the process by which a normal brain becomes epileptic. Early reports showed that phosphorylation of TrkB within the mossy fiber pathway and CA3 region of the mouse hippocampus is associated with seizure induction in the kindling model (He et al., 2002). The selective inhibition of TrkB using intraventricular administration of TrkB antibodies showed a decrease in kindling development (Binder et al., 1999). Then, using genetic disruption in the kindling model, a modest impairment in epileptogenesis was detected in conditional BDNF -/- mice, whereas conditional TrkB -/- mice showed reduced electrographic seizure duration and no behavioral evidence of limbic epileptogenesis (He et al., 2004). More specifically, mice carrying the Y186F mutation that disrupts the PLC $\gamma$ mediated pathway, showed impaired long-term potentiation in the mossy fiber pathway and decreased kindling development indicating a key role for TrkB-dependent activation of PLC $\gamma$ signaling in epileptogenesis (He et al., 2010). In ex vivo rat hippocampal cultures, the excessive activation of L-type Ca2+ channels was shown to lead to the extracellular release of BDNF, thus stimulating TrkB receptors in the mossy fibers to induce axonal branching (Koyama et al., 2004). This phenomenon induces hyperexcitable reentrant circuits in the dentate gyrus, and might play a role in the cellular basis at the origin of recurrent epileptic seizures (koyama et al., 2004). Increasing BDNF levels in the brain using transgenic mice models or acute intrahippocampal infusion revealed that this trophic factor could increase seizure severity (Croll et al., 1999; Scharfman et al., 2002). The convulsant drug cyclothiazide can induce robust epileptiform activity in rat hippocampal neurons both in vitro and in vivo (Qi et al., 2006). Inhibition of TrkB before administration of cyclothiazide in rat hippocampal neurons or cerebral ventricles suppressed the epileptiform activity of this convulsant drug (Wang et al., 2009). In Bassoon mutant mice, a genetic 
model for epilepsy, higher levels of TrkB and altered distribution of BDNF were found in the striatum in response to seizures, which were normalized after chronic treatment with the anticonvulsant drug valproic acid (Ghiglieri et al., 2010). Transgenic mice overexpressing the truncated form of TrkB, associated with decreased of TrkB signaling, show reduced hippocampal epileptogenesis after induction of status epilepticus by kainate acid (Heinrich et al., 2011; Lahteinen et al., 2002). All in all, genetic and pharmacological inhibition of TrkB signaling clearly showed that TrkB activation is implicated in the induction of seizures in rodent models of epilepsy. The PLC $\gamma$ pathway seems to be specifically responsible in this pro-epileptic effect. However, the exact mechanism underlying TrkB activation and the spatiotemporal pattern of BDNF release in the physiopathology of epilepsy still needs to be further clarified.

TrkB signaling in addiction: Changes in BDNF mRNA and protein have been observed in many brain regions, especially in relation to the mesolimbic dopaminergic system, following administration or withdrawal of different classes of addictive compounds in rodents (Russo et al., 2009). In addition, NT-4 mRNA and proteins levels was also shown to be increased in distinct brain areas such as the brain stem, cerebellum and cerebral hemisphere in rats after chronic treatment with ecstasy (Hatami et al., 2010). BDNF is particularly implicated in the regulation of dendrite structure and neuronal plasticity (including dopamine receptor expression) indicating a key role in the molecular and cellular adaptations leading to addictive behavior (Guillin et al., 2001; Russo et al., 2010). Moreover, the stimulation of dopamine receptors in striatal neurons in the adult rat brain leads to increased BDNF production (Hasbi et al., 2009). Acute opiate administration in rodents increases BDNF mRNA levels in many regions such as the nucleus accumbens (NAc), medial prefrontal cortex (mPFC), ventral tegmental area (VTA), and orbitofrontal cortex (Chu et al., 2007; Russo et al., 2009). Withdrawal after chronic exposure to opiates led to a rapid and prolonged increase in BDNF mRNA and TrkB mRNA in the locus coeruleus (Numan et al., 1998), while infusion of BDNF into the VTA induces an opiate-dependant-like reward state in naïve rats (Vargas-Perez et al., 2009). Regarding psychostimulants (e.g., cocaine, amphetamine and alcohol), many studies have been performed that suggest an increase in BDNF protein and/or mRNA in many areas following acute or chronic administration (Russo et al., 2009). More specifically, both acute and chronic cocaine administration have been shown to increase BDNF mRNA and protein levels in the rodent striatum (Graham et al., 2007; Liu et al., 2006; Zhang et al., 2002). Long-term cocaine withdrawal is also correlated with increased BDNF protein levels in the NAc, VTA and amygdala (Grimm et al., 2003; Pu and Poo, 2006). Infusion of BDNF directly in the NAc caused enduring increases in cocaine selfadministration and facilitated relapse in rats, which was neutralized by infusions of BDNF antibodies (Graham et al., 2007). In a similar manner, TrkB protein levels are increased in the rodent NAc after chronic cocaine administration (Graham et al., 2009; Sadri-Vakili et al., 2010; Toda et al., 2002). A recent study suggests that cocaine induced BDNF activation of TrkB in the NAc is essential for the onset of addictive states (Graham et al., 2009). Moreover, a single injection of cocaine is sufficient to increase the 
phosphorylation of TrkB in the NAc of rats after 9 hours (Crooks et al., 2010). The reduction of TrkB signaling in the NAc, using non-specific Trk inhibitors or conditional TrkB deletion, was able to prevent behavioral sensitization, conditioned place preference and ultrasonic vocalization induced by cocaine administration in rats (Crooks et al., 2010, Williams et al., 2010). Altogether, these data support the notion that BDNF-dependent activation of TrkB plays a key role in cellular and molecular adaptations leading to the development and persistence of addictive behavior in rodents. However, compelling evidence from human studies to support findings observed in animal models is lacking.

TrkB signaling in neuropathic pain: Immunocytochemistry and in situ hybridization studies have revealed that BDNF and its receptor TrkB are abundantly distributed within nociceptive pathways of adult animals (Merighi et al., 2008). As such, BDNF-dependent activation of TrkB signaling has been suspected to play a pivotal role in the mediation of pain processes, at least in part, through a possible modulation of glutamatergic excitatory and GABAergic inhibitory systems in the spinal cord (Kerr et al., 1999; Pezet et al., 2002). Additionally, both TrkB and BDNF are increased during inflammation (known as a mediator of neuropathic pain) preferentially in the dorsal root ganglions (Apfel et al., 1996; Cho et al., 1997). One of the first arguments for the implication of BDNF in neuropathic pain came with the observation that L5 spinal nerve ligation in rats, a neuropathic pain model, increased both BDNF immunoreactivity and BDNF mRNA in the ipsilateral L4 dorsal root ganglia neurons (Fukuoka et al., 2001). Additionally, intrathecal injections of BDNF can produce enduring thermal hyperalgesia and tactile allodynia in normal mice, suggesting a direct link for this trophic factor in the induction of neuropathic pain (Yajima et al., 2005). Furthermore, pharmacological studies aiming at reducing BDNF levels showed a direct role of TrkB signaling in the development of neuropathic pain. Intrathecal injection of BDNF antibodies at third day after surgery could attenuate thermal hyperalgesia induced by L5 spinal nerve ligation in rats (Fukuoka et al., 2001). Similarly, sequestration of endogenous BDNF levels using TrkB-Fc chimera injections suppressed the thermal hyperalgesia and tactile allodynia induced by sciatic nerve ligation in mice (Yajima et al., 2005). The use of the non-specific tyrosine kinase inhibitor K252a was shown to block early pain behavior induced by sciatic nerve ligation in rats (Miletic and Miletic, 2008), and likewise, to reduce the hyperalgesia and allodynia induced by intrathecal injection of BDNF in normal mice (Yajima et al., 2005). The blockade of TrkB phosphorylation within the spinal cord of adult mice using 1NM-PP1 was able to prevent the development of nerve injury-induced persistent pain (Wang et al., 2009). At the cellular level, BDNF, which is a crucial signaling molecule between microglia and neurons, is suspected to participate in neuronal sensitization to neuropathic pain transmission. Functional inhibition of BDNF-TrkB signaling using TrkB-Fc reverses the allodynia and the depolarizing shift in $\mathrm{E}_{\text {anion }}$ that follows both nerve injury and administration of ATP-stimulated microglia in the lumbar dorsal horn of peripheral-injured rats (Coull et al., 2005). Regarding genetic manipulations, antisense treatments directed against TrkB attenuates inflammation-induced hyperalgesia in rats (Groth and Aanonsen, 2002). Moreover, in BDNF +/- mice, a significant decrease in hyperalgesia and allodynia after nerve ligation was 
observed as compared to wild-type mice (Yajima et al., 2005). Taken together, these data support the notion that BDNF, probably released from microglia, is crucial for neuronal TrkB activation underlying neuropathic pain. Blocking microglial-induced TrkB signaling in neurons may represent a promising strategy for the treatment of neuropathic pain in this respect.

TrkB signaling in depression: BDNF-mediated TrkB signaling has been extensively studied in relation to mood disorders in both human and animal models (Boulle et al., 2011; Duman and Monteggia, 2006; Martinowich et al., 2007). TrkB and BDNF expression in the hippocampus, as well as circulating BDNF in peripheral blood, are decreased in depressed patients, suggesting that BDNF can represent a valuable biomarker in major depression (Dwivedi et al., 2003; Hashimoto, 2010). Additionally, in animal models of stress and/or depressive-like behavior, BDNF-TrkB signaling is downregulated in many brain regions including the hippocampus and prefrontal cortex (PFC), and antidepressant action is mediated at least in part through an elevation of BDNF levels in the hippocampus (Duman and Monteggia, 2006; Shirayama et al., 2002; Taliaz et al., 2010; Tsankova et al., 2006). While TrkB signaling in these regions plays a critical role in depression, only limited research has been carried out regarding its activity in other brain structures related to depression such as the striatum. BDNF and TrkB are abundantly expressed in the nucleus accumbens (NAc) and ventral tegmental area (VTA), two critical structures of the mesolimbic dopamine pathway involved in reward, pleasure and aversion (Baydyuk et al., 2011; Freeman et al., 2003; Hung and Lee, 1996; Yu and Chen, 2011). As such, anhedonia, reduced motivation and lethargia have been suspected to be modulated by BDNF-mediated TrkB signaling in the striatum. A first line of evidence came with the observation that infusions of BDNF into the VTA exerted a depressive-like effect in the forced-swim test in mice (Eisch et al., 2003). In this same study, a viral-mediated overexpression of a truncated form of TrkB (TrkB-T1) produced an antidepressant-like effect in the forced-swim test (Eisch et al., 2003). In the social defeated stress model, a mouse model of depression displaying several features of anhedonia, an upregulation of BDNF-TrkB signaling in the striatum has been reported. Viral-mediated specific knockdown of BDNF in the VTA showed that BDNF was critically important for the development of long-lasting aversion to social contact in mice (Berton et al., 2006). Moreover, increased BDNF levels in the NAc seem to mediate the susceptibility towards social defeat in mice (Krishnan et al., 2007). However, no changes were observed in TrkB and Phospho-TrkB levels in the NAc of susceptible versus control mice (Krishnan et al., 2007). In this same study, the authors showed that BDNF levels in the NAc are significantly higher in depressed patients as compared to controls (Krishnan et al., 2007). Clearly, BDNF-TrkB signaling in depression is complicated and brain region dependent. This questions whether therapeutic interventions targeting TrkB may be a useful approach. Interestingly, a newly developed TrkB antagonist, Ana 12, showed preferential distribution in the striatum as well as antidepressant-like properties in the forced-swim test and tail-suspension test in mice (Cazorla et al., 2011; see section 4.2. for more details). It would be of interest to test the ability of such compounds to reverse aversive behavior and anhedonia in rodent models of depression. Additionally, further studies 
measuring BDNF levels as well as TrkB expression/activation in post-mortem brain analysis of depressed patients should be carried on.

\section{2 - Other diseases}

TrkB signaling in cancer: BDNF-dependent and -independent activation of TrkB represent a critical transduction pathway in tumor cell survival and proliferation. Overexpression of TrkB, a hallmark of many tumors, results in activation of autocrine and paracrine survival pathways, promoting survival of cancerous cells, but also resistance to anticancer drugs and facilitation of angiogenesis (Thiele et al., 2009). More specifically, TrkB-expressing neuroblastoma tumors treated with BDNF are less sensitive to cytotoxic drugs, and patients with tumors expressing high levels of $\operatorname{TrkB}$ and BDNF have a poor prognosis (Asgharzadeh et al., 2006; Nakagawara et al., 1994; Scala et al., 1996). Many types of human cancer (melanoma, lung adenocarcinoma and colorectal tumors) have been founded with TrkB mutations, although a real gain-of-function has not been elucidated yet (Geiger et al., 2011). Similarly, BDNF and NT-4 was shown to be increased in many types of cancers (Lam et al., 2011; Vanhecke et al., 2011). Moreover, a first line of evidence suggested that TrkB mediated PI3-K activation is responsible of the anoikis (process by which the loss of cell-matrix interaction leads to apoptosis) resistance and induction of metastasis in rat intestinal epithelial cells (Douma et al., 2004). Further studies have confirmed the implication of TrkB signaling in anoikis resistance and induction of metastasis in many other types of cancerous cells (Sclabas et al., 2005; Yu et al., 2008; Zhang et al., 2008). More recently, a couple of pharmacological studies assessing the potential therapeutic effects of Trk inhibitors have been carried out. The inhibition of TrkB with either a soluble TrkB ectodomain or the Trk receptor inhibitor K252a was shown to restrain proliferation and to enhance apoptosis in cultured choriocarcinoma cells (Kawamura et al., 2010). Similarly, K252a was able to increase anoikis sensitization in nasopharyngeal carcinoma cells (Ng et al., 2010). The Trk inhibitor AZ623 can inhibit BDNF-induced TrkB phosphorylation and subsequent proliferation of neuroblastoma cells and potentiates the effects of topotecan (a topoisomeraseI inhibitor, commonly used in the treatment of various cancers) on the regrowth of human neuroblastoma xenographs (Zage et al., 2011). A phase I clinical trial also suggest that high doses of lestaurtinib, a potent Trk inhibitor, can reduce phospho-TrkB levels in the plasma of patient with refractory neuroblastoma (Minturn et al., 2011). Lestaurtinib was well tolerated in those patients suggesting that further investigation should be pursued especially regarding the clinical relevance of reduced phospho-TrkB levels in the remission of the patients. Altogether, preclinical and clinical studies showed a major role for TrkB signaling in angiogenesis and metastatic processes, pointing out the necessity to develop new potent TrkB antagonists for the treatment of a broad range of cancers. 


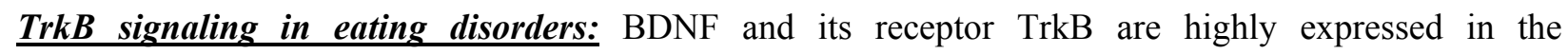
hypothalamus, a key region controlling neuroendocrine regulated functions such as food intake and energy balance homeostasis (Berg von ver Emde et al., 1995; Marmigere et al., 1998; Yan et al., 1997). BDNF +/- heterozygous mice, in which BDNF levels are reduced, display abnormalities in eating behavior and locomotor activity resulting in weight gain (Kernie et al., 2000). Moreover, a selective deletion of BDNF in the ventromedial and dorsomedial hypothalamus in adult mice was associated with a stimulation of appetite leading to hyperphagic behavior and obesity (Unger el al., 2007). Similarly, a de novo mutation in the gene encoding TrkB, reducing receptor autophosphorylation and downstream MAPK signaling, was associated with hyperphagic obesity in an 8-year-old patient (Yeo et al., 2004). In mice, a single intrahypothalamic application of agonist TrkB antibody was able to reduce food intake and body weight (Tsao et al., 2008). In non-human primates, administration of BDNF or NT4 had anorexigenic effects when applied centrally, and on the contrary, orexigenic effects when applied peripherally (Lin et al., 2008). All together, these studies bring evidence that BDNF has an important implication in the control of appetite in the central nervous system. As reduced BDNF/TrkB signaling in hypothalamic areas stimulates appetitive behaviors, developing drugs that specifically activate TrkB can represent promising therapy for the treatment of obesity. Additionally, the use of TrkB inhibitors to modulate the energy balance towards an orexigenic effect might also be an interesting approach for the treatment of eating disorders such as anorexia and bulimia.

\section{IV - Development of TrkB inhibitors}

Currently, only few TrkB inhibitors are available. The use of different strategies to better understand BDNF-TrkB interaction, the identification of new pharmacophores and the development of selective and potent TrkB inhibitors are promising pharmacological challenges.

Modeling BDNF - TrkB interaction: Crystallography studies modeling BDNF-NT3 and BDNF-NT4 heterodimers have enabled researchers to better characterize the molecular conformation of the BDNF protein (i.e. folding of the protein and mapping of the surface residues) and identify key-role regions implicated in the binding to TrkB (Robinson et al., 1995, 1999). The use of BDNF/NGF chimeric molecules encompassing site-directed mutagenesis revealed that structural elements determining the biological activity of BDNF were similar to those found in NGF (Ibanez et al., 1991, 1993). Further, it was shown that some residues in loop II, loop IV and $\beta$-strands of BDNF were critical in the binding to TrkB (Fletcher et al., 2008; O’Leary et al., 1998; Pattarawarapan and Burgess, 2003). Loop IV of BDNF seems to be also important in p75 binding (Fletcher et al., 2008; Ryden et al., 1995). More recently, using the crystal structure of the BDNF-NT3 heterodimer, the structure of BDNF loop II was further unraveled to generate a pharmacophore, and subsequent in silico screening was performed to identify multiple small 
non-peptidic TrkB ligands (Massa et al., 2010). Regarding TrkB structure, it was revealed that the Immunoglobulin- like domain 5, connecting the extracellular portion of the receptor to the transmembrane domain, was sufficient for binding of BDNF (Urfer et al., 1995). Further, the crystal structure of TrkB-D5 in complex with NT-4/5 showed a major role for N-terminal regions of neurotrophins in Trk receptor specificity and binding (Banfield et al., 2001; Ultsch et al., 1999). A virtual screening using the TrkB-D5-BDNF x-ray structure and focusing on the specific BDNF N-terminal region interaction with TrkB-D5 domain has recently led to the development of small non-peptidic TrkB antagonists (Cazorla et al., 2011). As such, computational modeling involving structure-based in silico screening represents a promising tool in drug discovery and may open new therapeutic strategies to develop potent and selective TrkB ligands.

$\underline{\text { TrkB antagonists: }}$ The staurosporine analogue K252a is a potent protein kinase inhibitor (Kase et al., 1987). This alkanoid is able to penetrate the cell and acts as a potent and selective Trk receptor inhibitor at low concentrations making it an interesting tool to explore TrkB signaling (Tapley et al., 1992). Nevertheless, the lack of specificity for TrkB, as compared to TrkA and TrkC, constitutes a major limitation for the use of K252a. More recently, using distinct approaches, two specific and potent TrkB antagonists with different biochemical properties and structures have been developed. The first one, cyclotraxin-B, is an 11 amino acid peptide mimicking the reverse turn structure of BDNF region III (Cazorla et al., 2010). This compound was shown to specifically bind to TrkB with high affinity as compared to TrkA and TrkC (Cazorla et al., 2010). The interaction with p75 is still to be determined. Interestingly, cyclotraxin-B is able to inhibit both BDNF-dependent and -independent activation of TrkB in cell line models (Cazorla et al., 2010). After a fusion with the "tat" transduction domain of the human immunodeficiency virus (HIV), the formed tat-cyclotraxin-B complex is able to cross the blood-brain barrier when administrated intravenously and induces anxiolytic effects in the open field paradigm in mice (Cazorla et al., 2010). Additionally, using a structure-based in silico screening that models the interaction of low-molecular weight compounds with the N-terminal region of TrkB-D5 domain, a new TrkB inhibitor, namely Ana-12, has been developed (Cazorla et al., 2011). In vitro studies showed that this compound is a selective and potent TrkB antagonist, as compared to TrkA and TrkC (Cazorla et al., 2011). When administrated peripherally, Ana-12 is able to cross the blood-brain barrier and preferentially diffuses into the striatum resulting in an antidepressant and anxiolytic effect in mice (Cazorla et al., 2011). Together, cyclotraxin-B and Ana-12 represent powerful agents to better explore TrkB signaling and investigate the possible therapeutic value of TrkB inhibitors in a broad range of diseases. 


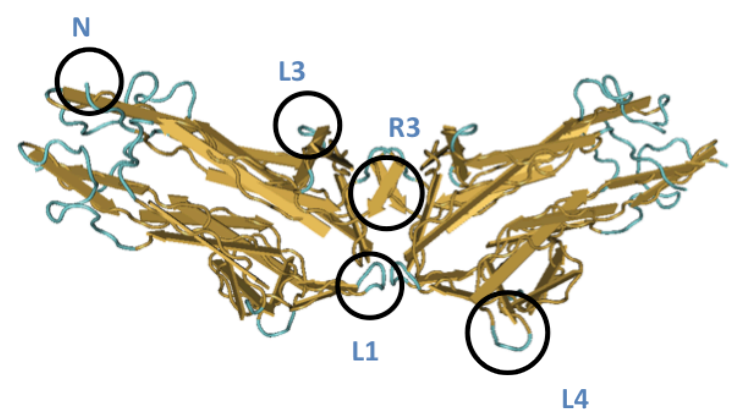

Structure of BDNF homodimer

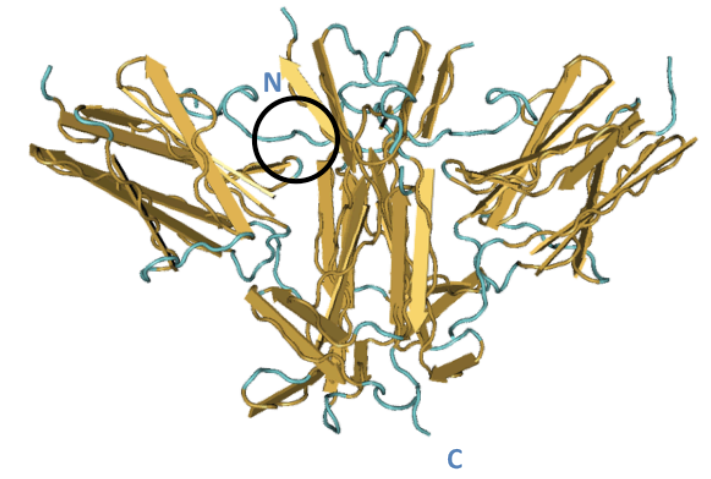

Structure of TrkB-d5:NT 4/5 dimer

\begin{tabular}{|c|c|c|c|}
\hline Authors & Compound & Approach & Characteristic \\
\hline Cazorla et al., 2010 & Cyclotraxin-B & Peptidic mimicking of BDNF region III & TrkB antagonist \\
\hline Cazorla et al., 2011 & Ana-12 & In silico screening of $\mathrm{N}$-term TrkB-d5 & TrkB antagonist \\
\hline Fletcher et al., 2008 & Pentapeptide 2 & Peptidic mimicking of BDNF loop IV & p75 agonist \\
\hline Fobian et al., 2009 & Betrofin 3 & Peptidic mimicking of BDNF loop III & TrkB/p75 agonist \\
\hline Fobian et al., 2009 & Betrophin 4 & Peptidic mimicking of BDNF loop IV & TrkB/p75 agonist \\
\hline Jang et al., 2010 & $7,8 \mathrm{DHF}$ & Random screening strategy & TrkB agonist \\
\hline Massa et al., 2010 & LM 22A-4 & In silico screening of BDNF loop I & TrkB agonist \\
\hline O'Leary et al., 2003 & Dimeric peptides & Peptidic mimicking of BDNF loop II & TrkB agonist \\
\hline
\end{tabular}

Fig. 2. Pharmacological agents developed using different strategies targeting BDNF and TrkB epitopes.

The crystal structures of BDNF homodimer and TrkB-D5 in complex with NT 4/5 are represented. The N-terminus (N) and C-terminus (C) as well as the different loop (L1, L2 and L4) and the region III of BDNF protein are indicated. The table summarizes the different compounds that have been developed with peptidic mimicking or in silico screening of either BDNF or TrkB epitopes. 


\section{V-Concluding remarks}

The activation of TrkB, through e.g. the binding of neurotrophins or other transactivating mechanisms, plays an essential role in cell proliferation, differentiation and survival as well as in neurotransmitter release and synaptic plasticity. TrkB activation has been widely reported in the mediation of various pathophysiological processes, making this receptor an interesting target for many treatment strategies. Preclinical studies have demonstrated that the inhibition of TrkB has significant beneficial effects in animal models of depression, neuropathic pain, addictive behavior, epilepsy, and cancer. However, given the widespread distribution of TrkB throughout the central and peripheral nervous system as well as its pivotal role in brain plasticity, the use of TrkB inhibitors may have potential undesirable effects. Interestingly, in this respect, it was recently shown that the systemic administration of the TrkB antagonist Ana12 at low doses could efficiently alter behavior without affecting the survival of neurons in naïve mice (Cazorla et al., 2011). Thus, the development of therapeutic agents that can specifically block neurotrophin-dependent overactivation of TrkB preferably restricted to certain brain regions, without altering normal physiological function remains a current challenge.

Developing novel, potent and selective TrkB inhibitors represents a promising approach in drug discovery. Peptide-derived ligands are of limited efficacy because of their proteolytical instability and their poor blood-brain-barrier penetration. As such, in silico screening of small non-peptidic molecules has emerged as a promising method to develop TrkB ligands. Computational techniques directed at modeling BDNF-TrkB interaction derived from crystal structures can lead to the identification of novel pharmacophores displaying high specificity for TrkB as compared to p75 and other Trk receptors. It is also important to use an appropriate in vitro screening assay as a follow-up validation to address the functional properties of newly developed compounds. In that respect, the KIRA-ELISA assay was described as a rapid, sensitive and quantitative technique to measure TrkB activation in various cell types (Cazorla et al., 2010; Sadick et al., 1997).

In conclusion, increasing evidences suggest that TrkB activation and signaling is implicated in the course and development in a broad range of diseases. As such, the use of functional TrkB inhibitors in preclinical and clinical studies can considerably advance neurological, psychiatric and cancer research.

\section{VI - References}

Alvaro, J. D., Tatro, J. B., Quillan, J. M., Fogliano, M., Eisenhard, M., Lerner, M. R., Nestler, E. J., Duman, R. S., 1996. Morphine down-regulates melanocortin-4 receptor expression in brain regions that mediate opiate addiction. Mol. Pharmacol. 50, 583-591. 
Andero, R., Heldt, S. A., Ye, K., Liu, X., Armario, A., Ressler, K. J., 2011. Effect of 7,8-dihydroxyflavone, a smallmolecule TrkB agonist, on emotional learning. Am. J. Psychiatry. 168, 163-172.

Apfel, S. C., Kessler, J. A., 1996. Neurotrophic factors in the treatment of peripheral neuropathy. Ciba. Found. Symp. 196, 98-108; discussion 108-112.

Asgharzadeh, S., Pique-Regi, R., Sposto, R., Wang, H., Yang, Y., Shimada, H., Matthay, K., Buckley, J., Ortega, A., Seeger, R. C., 2006. Prognostic significance of gene expression profiles of metastatic neuroblastomas lacking MYCN gene amplification. J. Natl. Cancer Inst. 98, 1193-1203.

Banfield, M. J., Naylor, R. L., Robertson, A. G., Allen, S. J., Dawbarn, D., Brady, R. L., 2001. Specificity in Trk receptor:neurotrophin interactions: the crystal structure of TrkB-d5 in complex with neurotrophin-4/5. Structure. 9 , 1191-1199.

Baydyuk, M., Nguyen, M. T., Xu, B., 2011. Chronic deprivation of TrkB signaling leads to selective late-onset nigrostriatal dopaminergic degeneration. Exp. Neurol. 228, 118-125.

Baydyuk, M., Russell, T., Liao, G. Y., Zang, K., An, J. J., Reichardt, L. F., Xu, B., 2011. TrkB receptor controls striatal formation by regulating the number of newborn striatal neurons. Proc. Natl. Acad. Sci. U S A. 108, 16691674.

Berg-von der Emde, K., Dees, W. L., Hiney, J. K., Hill, D. F., Dissen, G. A., Costa, M. E., Moholt-Siebert, M., Ojeda, S. R., 1995. Neurotrophins and the neuroendocrine brain: different neurotrophins sustain anatomically and functionally segregated subsets of hypothalamic dopaminergic neurons. J. Neurosci. 15, 4223-4237.

Berghuis, P., Dobszay, M. B., Wang, X., Spano, S., Ledda, F., Sousa, K. M., Schulte, G., Ernfors, P., Mackie, K., Paratcha, G., Hurd, Y. L., Harkany, T., 2005. Endocannabinoids regulate interneuron migration and morphogenesis by transactivating the TrkB receptor. Proc. Natl. Acad. Sci. U S A. 102, 19115-19120.

Bernard, R., Kerman, I. A., Thompson, R. C., Jones, E. G., Bunney, W. E., Barchas, J. D., Schatzberg, A. F., Myers, R. M., Akil, H., Watson, S. J., 2011. Altered expression of glutamate signaling, growth factor, and glia genes in the locus coeruleus of patients with major depression. Mol. Psychiatry. 16, 634-646.

Berton, O., McClung, C. A., Dileone, R. J., Krishnan, V., Renthal, W., Russo, S. J., Graham, D., Tsankova, N. M., Bolanos, C. A., Rios, M., Monteggia, L. M., Self, D. W., Nestler, E. J., 2006. Essential role of BDNF in the mesolimbic dopamine pathway in social defeat stress. Science. 311, 864-868.

Biffo, S., Offenhauser, N., Carter, B. D., Barde, Y. A., 1995. Selective binding and internalisation by truncated receptors restrict the availability of BDNF during development. Development. 121, 2461-2470.

Binder, D. K., Croll, S. D., Gall, C. M., Scharfman, H. E., 2001. BDNF and epilepsy: too much of a good thing? Trends Neurosci. 24, 47-53.

Binder, D. K., Routbort, M. J., Ryan, T. E., Yancopoulos, G. D., McNamara, J. O., 1999. Selective inhibition of kindling development by intraventricular administration of TrkB receptor body. J. Neurosci. 19, 1424-1436.

Boulle, F., van den Hove, D. L., Jakob, S. B., Rutten, B. P., Hamon, M., van Os, J., Lesch, K. P., Lanfumey, L., Steinbusch, H. W., Kenis, G., 2011. Epigenetic regulation of the BDNF gene: implications for psychiatric disorders. Mol. Psychiatry. DOI:10.1038

Cazorla, M., Jouvenceau, A., Rose, C., Guilloux, J. P., Pilon, C., Dranovsky, A., Premont, J., 2010. Cyclotraxin-B, the first highly potent and selective TrkB inhibitor, has anxiolytic properties in mice. PLoS One. 5, e9777.

Cazorla, M., Premont, J., Mann, A., Girard, N., Kellendonk, C., Rognan, D., 2011. Identification of a low-molecular weight TrkB antagonist with anxiolytic and antidepressant activity in mice. J. Clin. Invest. 121, 1846-1857.

Chao, M. V., 2003. Neurotrophins and their receptors: a convergence point for many signalling pathways. Nat. Rev. Neurosci. 4, 299-309.

Cho, H. J., Kim, S. Y., Park, M. J., Kim, D. S., Kim, J. K., Chu, M. Y., 1997. Expression of mRNA for brainderived neurotrophic factor in the dorsal root ganglion following peripheral inflammation. Brain Res. 749, 358-362. 
Chu, N. N., Zuo, Y. F., Meng, L., Lee, D. Y., Han, J. S., Cui, C. L., 2007. Peripheral electrical stimulation reversed the cell size reduction and increased BDNF level in the ventral tegmental area in chronic morphine-treated rats. Brain Res. 1182, 90-98.

Coull, J. A., Beggs, S., Boudreau, D., Boivin, D., Tsuda, M., Inoue, K., Gravel, C., Salter, M. W., De Koninck, Y., 2005. BDNF from microglia causes the shift in neuronal anion gradient underlying neuropathic pain. Nature. 438, 1017-1021.

Croll, S. D., Suri, C., Compton, D. L., Simmons, M. V., Yancopoulos, G. D., Lindsay, R. M., Wiegand, S. J., Rudge, J. S., Scharfman, H. E., 1999. Brain-derived neurotrophic factor transgenic mice exhibit passive avoidance deficits, increased seizure severity and in vitro hyperexcitability in the hippocampus and entorhinal cortex. Neuroscience. 93, 1491-1506.

Crooks, K. R., Kleven, D. T., Rodriguiz, R. M., Wetsel, W. C., McNamara, J. O., 2010. TrkB signaling is required for behavioral sensitization and conditioned place preference induced by a single injection of cocaine. Neuropharmacology. 58, 1067-1077.

Cunningham, M. E., Greene, L. A., 1998. A function-structure model for NGF-activated TRK. EMBO J. 17, 72827293.

Dorsey, S. G., Renn, C. L., Carim-Todd, L., Barrick, C. A., Bambrick, L., Krueger, B. K., Ward, C. W., Tessarollo, L., 2006. In vivo restoration of physiological levels of truncated TrkB.T1 receptor rescues neuronal cell death in a trisomic mouse model. Neuron. 51, 21-28.

Douma, S., Van Laar, T., Zevenhoven, J., Meuwissen, R., Van Garderen, E., Peeper, D. S., 2004. Suppression of anoikis and induction of metastasis by the neurotrophic receptor TrkB. Nature. 430, 1034-1039.

Duman, R. S., Heninger, G. R., Nestler, E. J., 1997. A molecular and cellular theory of depression. Arch. Gen. Psychiatry. 54, 597-606.

Duman, R. S., Monteggia, L. M., 2006. A neurotrophic model for stress-related mood disorders. Biol. Psychiatry. 59, 1116-1127.

Dwivedi, Y., Rizavi, H. S., Conley, R. R., Roberts, R. C., Tamminga, C. A., Pandey, G. N., 2003. Altered gene expression of brain-derived neurotrophic factor and receptor tyrosine kinase B in postmortem brain of suicide subjects. Arch. Gen. Psychiatry. 60, 804-815.

Eide, F. F., Vining, E. R., Eide, B. L., Zang, K., Wang, X. Y., Reichardt, L. F., 1996. Naturally occurring truncated trkB receptors have dominant inhibitory effects on brain-derived neurotrophic factor signaling. J. Neurosci. 16, 3123-3129.

Eisch, A. J., Bolanos, C. A., de Wit, J., Simonak, R. D., Pudiak, C. M., Barrot, M., Verhaagen, J., Nestler, E. J., 2003. Brain-derived neurotrophic factor in the ventral midbrain-nucleus accumbens pathway: a role in depression. Biol. Psychiatry. 54, 994-1005.

Ferguson, S. S., 2003. Receptor tyrosine kinase transactivation: fine-tuning synaptic transmission. Trends Neurosci. 26, 119-122.

Flajolet, M., Wang, Z., Futter, M., Shen, W., Nuangchamnong, N., Bendor, J., Wallach, I., Nairn, A. C., Surmeier, D. J., Greengard, P., 2008. FGF acts as a co-transmitter through adenosine A(2A) receptor to regulate synaptic plasticity. Nat. Neurosci. 11, 1402-1409.

Fletcher, J. M., Morton, C. J., Zwar, R. A., Murray, S. S., O'Leary, P. D., Hughes, R. A., 2008. Design of a conformationally defined and proteolytically stable circular mimetic of brain-derived neurotrophic factor. J. Biol. Chem. 283, 33375-33383.

Fobian, K., Owczarek, S., Budtz, C., Bock, E., Berezin, V., Pedersen, M. V., 2009. Peptides derived from the solvent-exposed loops 3 and 4 of BDNF bind TrkB and p75(NTR) receptors and stimulate neurite outgrowth and survival. J. Neurosci. Res. 88, 1170-1181. 
Freeman, A. Y., Soghomonian, J. J., Pierce, R. C., 2003. Tyrosine kinase B and C receptors in the neostriatum and nucleus accumbens are co-localized in enkephalin-positive and enkephalin-negative neuronal profiles and their expression is influenced by cocaine. Neuroscience. 117, 147-156.

Friedman, W. J., Greene, L. A., 1999. Neurotrophin signaling via Trks and p75. Exp. Cell. Res. 253, 131-142.

Fukuoka, T., Kondo, E., Dai, Y., Hashimoto, N., Noguchi, K., 2001. Brain-derived neurotrophic factor increases in the uninjured dorsal root ganglion neurons in selective spinal nerve ligation model. J. Neurosci. 21, 4891-4900.

Gall, C. M., 1993. Seizure-induced changes in neurotrophin expression: implications for epilepsy. Exp. Neurol. 124, 150-166.

Geiger, T. R., Song, J. Y., Rosado, A., Peeper, D. S., 2011. Functional characterization of human cancer-derived TRKB mutations. PLoS One. 6, e16871.

Ghiglieri, V., Sgobio, C., Patassini, S., Bagetta, V., Fejtova, A., Giampa, C., Marinucci, S., Heyden, A., Gundelfinger, E. D., Fusco, F. R., Calabresi, P., Picconi, B., 2010. TrkB/BDNF-dependent striatal plasticity and behavior in a genetic model of epilepsy: modulation by valproic acid. Neuropsychopharmacology. 35, 1531-1540.

Graham, D. L., Edwards, S., Bachtell, R. K., DiLeone, R. J., Rios, M. and Self, D. W., 2007. Dynamic BDNF activity in nucleus accumbens with cocaine use increases self-administration and relapse. Nat. Neurosci. 10, 10291037.

Graham, D. L., Krishnan, V., Larson, E. B., Graham, A., Edwards, S., Bachtell, R. K., Simmons, D., Gent, L. M., Berton, O., Bolanos, C. A., DiLeone, R. J., Parada, L. F., Nestler, E. J., Self, D. W., 2009. Tropomyosin-related kinase B in the mesolimbic dopamine system: region-specific effects on cocaine reward. Biol. Psychiatry. 65, 696701.

Grimes, M. L., Zhou, J., Beattie, E. C., Yuen, E. C., Hall, D. E., Valletta, J. S., Topp, K. S., LaVail, J. H., Bunnett, N. W. and Mobley, W. C., 1996. Endocytosis of activated TrkA: evidence that nerve growth factor induces formation of signaling endosomes. J. Neurosci. 16, 7950-7964.

Grimm, J. W., Lu, L., Hayashi, T., Hope, B. T., Su, T. P., Shaham, Y., 2003. Time-dependent increases in brainderived neurotrophic factor protein levels within the mesolimbic dopamine system after withdrawal from cocaine: implications for incubation of cocaine craving. J. Neurosci. 23, 742-747.

Groth, R., Aanonsen, L., 2002. Spinal brain-derived neurotrophic factor (BDNF) produces hyperalgesia in normal mice while antisense directed against either BDNF or trkB, prevent inflammation-induced hyperalgesia. Pain. 100, $171-181$.

Guillin, O., Diaz, J., Carroll, P., Griffon, N., Schwartz, J. C., Sokoloff, P., 2001. BDNF controls dopamine D3 receptor expression and triggers behavioural sensitization. Nature. 411, 86-89.

Hall, F. S., Drgonova, J., Goeb, M., Uhl, G. R., 2003. Reduced behavioral effects of cocaine in heterozygous brainderived neurotrophic factor (BDNF) knockout mice. Neuropsychopharmacology. 28, 1485-1490.

Hasbi, A., Fan, T., Alijaniaram, M., Nguyen, T., Perreault, M. L., O'Dowd, B. F., George, S. R., 2009. Calcium signaling cascade links dopamine D1-D2 receptor heteromer to striatal BDNF production and neuronal growth. Proc. Natl. Acad. Sci. U S A. 106, 21377-21382.

Hashimoto, K., 2010. Brain-derived neurotrophic factor as a biomarker for mood disorders: an historical overview and future directions. Psychiatry Clin. Neurosci. 64, 341-357.

Hatami, H., Hossainpour-Faizi, M. A., Azarfarin, M., Azarfam, P., 2010. Chronic ecstasy use increases neurotrophin-4 gene expression and protein levels in the rat brain. Pharmacol Rep. 62, 998-1004.

He, X. P., Kotloski, R., Nef, S., Luikart, B. W., Parada, L. F., McNamara, J. O., 2004. Conditional deletion of TrkB but not BDNF prevents epileptogenesis in the kindling model. Neuron. 43, 31-42.

He, X. P., Minichiello, L., Klein, R., McNamara, J. O., 2002. Immunohistochemical evidence of seizure-induced activation of trkB receptors in the mossy fiber pathway of adult mouse hippocampus. J. Neurosci. 22, 7502-7508. 
He, X. P., Pan, E., Sciarretta, C., Minichiello, L., McNamara, J. O., 2010. Disruption of TrkB-mediated phospholipase Cgamma signaling inhibits limbic epileptogenesis. J. Neurosci. 30, 6188-6196.

Heinrich, C., Lahteinen, S., Suzuki, F., Anne-Marie, L., Huber, S., Haussler, U., Haas, C., Larmet, Y., Castren, E., Depaulis, A., 2011. Increase in BDNF-mediated TrkB signaling promotes epileptogenesis in a mouse model of mesial temporal lobe epilepsy. Neurobiol. Dis. 42, 35-47.

Howe, C. L., Valletta, J. S., Rusnak, A. S., Mobley, W. C., 2001. NGF signaling from clathrin-coated vesicles: evidence that signaling endosomes serve as a platform for the Ras-MAPK pathway. Neuron. 32, 801-814.

Huang, E. J., Reichardt, L. F., 2003. Trk receptors: roles in neuronal signal transduction. Annu. Rev. Biochem. 72 , 609-642.

Huang, Y. Z., McNamara, J. O., 2010. Mutual regulation of Src family kinases and the neurotrophin receptor TrkB. J. Biol. Chem. 285, 8207-8217.

Huang, Y. Z., Pan, E., Xiong, Z. Q., McNamara, J. O., 2008. Zinc-mediated transactivation of TrkB potentiates the hippocampal mossy fiber-CA3 pyramid synapse. Neuron. 57, 546-558.

Humpel, C., Wetmore, C., Olson, L., 1993. Regulation of brain-derived neurotrophic factor messenger RNA and protein at the cellular level in pentylenetetrazol-induced epileptic seizures. Neuroscience. 53, 909-918.

Hung, H. C., Lee, E. H., 1996. The mesolimbic dopaminergic pathway is more resistant than the nigrostriatal dopaminergic pathway to MPTP and MPP+ toxicity: role of BDNF gene expression. Brain Res. Mol. Brain Res. 41, 14-26.

Hwang, J. J., Park, M. H., Choi, S. Y., Koh, J. Y., 2005. Activation of the Trk signaling pathway by extracellular zinc. Role of metalloproteinases. J. Biol. Chem. 280, 11995-12001.

Ibanez, C. F., Ebendal, T., Persson, H., 1991. Chimeric molecules with multiple neurotrophic activities reveal structural elements determining the specificities of NGF and BDNF. EMBO J. 10, 2105-2110.

Ibanez, C. F., Ilag, L. L., Murray-Rust, J., Persson, H., 1993. An extended surface of binding to Trk tyrosine kinase receptors in NGF and BDNF allows the engineering of a multifunctional pan-neurotrophin. EMBO J. 12, 22812293.

Isackson, P. J., Huntsman, M. M., Murray, K. D., Gall, C. M., 1991. BDNF mRNA expression is increased in adult rat forebrain after limbic seizures: temporal patterns of induction distinct from NGF. Neuron. 6, 937-948.

Iwakura, Y., Nawa, H., Sora, I., Chao, M. V., 2008. Dopamine D1 receptor-induced signaling through TrkB receptors in striatal neurons. J. Biol. Chem. 283, 15799-15806.

Jang, S. W., Liu, X., Yepes, M., Shepherd, K. R., Miller, G. W., Liu, Y., Wilson, W. D., Xiao, G., Blanchi, B., Sun, Y. E., Ye, K., 2010. A selective TrkB agonist with potent neurotrophic activities by 7,8-dihydroxyflavone. Proc. Natl. Acad. Sci. U S A. 107, 2687-2692.

Jankowsky, J. L., Patterson, P. H., 2001. The role of cytokines and growth factors in seizures and their sequelae. Prog. Neurobiol. 63, 125-149.

Jeanneteau, F., Garabedian, M. J., Chao, M. V., 2008. Activation of Trk neurotrophin receptors by glucocorticoids provides a neuroprotective effect. Proc. Natl. Acad. Sci. U S A. 105, 4862-4867.

Jing, S., Tapley, P., Barbacid, M., 1992. Nerve growth factor mediates signal transduction through trk homodimer receptors. Neuron. 9, 1067-1079.

Kase, H., Iwahashi, K., Nakanishi, S., Matsuda, Y., Yamada, K., Takahashi, M., Murakata, C., Sato, A., Kaneko, M., 1987. K-252 compounds, novel and potent inhibitors of protein kinase C and cyclic nucleotide-dependent protein kinases. Biochem. Biophys. Res. Commun. 142, 436-440.

Kawamura, N., Kawamura, K., Manabe, M., Tanaka, T., 2010. Inhibition of brain-derived neurotrophic factor/tyrosine kinase B signaling suppresses choriocarcinoma cell growth. Endocrinology. 151, 3006-3014. 
Kernie, S. G., Liebl, D. J., Parada, L. F., 2000. BDNF regulates eating behavior and locomotor activity in mice. EMBO J. 19, 1290-1300.

Kerr, B. J., Bradbury, E. J., Bennett, D. L., Trivedi, P. M., Dassan, P., French, J., Shelton, D. B., McMahon, S. B., Thompson, S. W., 1999. Brain-derived neurotrophic factor modulates nociceptive sensory inputs and NMDAevoked responses in the rat spinal cord. J. Neurosci. 19, 5138-5148.

Klein, R., Lamballe, F., Bryant, S., Barbacid, M., 1992. The trkB tyrosine protein kinase is a receptor for neurotrophin-4. Neuron. 8, 947-956.

Klein, R., Nanduri, V., Jing, S. A., Lamballe, F., Tapley, P., Bryant, S., Cordon-Cardo, C., Jones, K. R., Reichardt, L. F., Barbacid, M., 1991. The trkB tyrosine protein kinase is a receptor for brain-derived neurotrophic factor and neurotrophin-3. Cell. 66, 395-403.

Klein, R., Parada, L. F., Coulier, F., Barbacid, M., 1989. TrkB, a novel tyrosine protein kinase receptor expressed during mouse neural development. EMBO J. 8, 3701-3709.

Koyama, R., Yamada, M. K., Fujisawa, S., Katoh-Semba, R., Matsuki, N., Ikegaya, Y., 2004. Brain-derived neurotrophic factor induces hyperexcitable reentrant circuits in the dentate gyrus. J. Neurosci. 24, 7215-7224.

Krishnan, V., Han, M. H., Graham, D. L., Berton, O., Renthal, W., Russo, S. J., Laplant, Q., Graham, A., Lutter, M., Lagace, D. C., Ghose, S., Reister, R., Tannous, P., Green, T. A., Neve, R. L., Chakravarty, S., Kumar, A., Eisch, A. J., Self, D. W., Lee, F. S., Tamminga, C. A., Cooper, D. C., Gershenfeld, H. K., Nestler, E. J., 2007. Molecular adaptations underlying susceptibility and resistance to social defeat in brain reward regions. Cell. 131, 391-404.

Lahteinen, S., Pitkanen, A., Saarelainen, T., Nissinen, J., Koponen, E. and Castren, E. (2002) Decreased BDNF signalling in transgenic mice reduces epileptogenesis. Eur J Neurosci 15, 721-734.

Lam, C. T., Yang, Z. F., Lau, C. K., Tam, K. H., Fan, S. T., Poon, R. T., 2011. Brain-derived neurotrophic factor promotes tumorigenesis via induction of neovascularization: implication in hepatocellular carcinoma. Clin Cancer Res. 17, 3123-3133.

Le Foll, B., Diaz, J., Sokoloff, P., 2005. A single cocaine exposure increases BDNF and D3 receptor expression: implications for drug-conditioning. Neuroreport. 16, 175-178.

Lee, F. S., Chao, M. V., 2001. Activation of Trk neurotrophin receptors in the absence of neurotrophins. Proc. Natl. Acad. Sci. U S A. 98, 3555-3560.

Lee, F. S., Rajagopal, R., Chao, M. V., 2002. Distinctive features of Trk neurotrophin receptor transactivation by G protein-coupled receptors. Cytokine Growth Factor Rev. 13, 11-17.

Lee, F. S., Rajagopal, R., Kim, A. H., Chang, P. C., Chao, M. V., 2002. Activation of Trk neurotrophin receptor signaling by pituitary adenylate cyclase-activating polypeptides. J. Biol. Chem. 277, 9096-9102.

Lewin, G. R., Barde, Y. A., 1996. Physiology of the neurotrophins. Annu. Rev. Neurosci. 19, 289-317.

Lin, J. C., Tsao, D., Barras, P., Bastarrachea, R. A., Boyd, B., Chou, J., Rosete, R., Long, H., Forgie, A., Abdiche, Y., Dilley, J., Stratton, J., Garcia, C., Sloane, D. L., Comuzzie, A. G., Rosenthal, A., 2008. Appetite enhancement and weight gain by peripheral administration of TrkB agonists in non-human primates. PLoS One. 3, e1900.

Liu, Q. R., Lu, L., Zhu, X. G., Gong, J. P., Shaham, Y., Uhl, G. R., 2006. Rodent BDNF genes, novel promoters, novel splice variants, and regulation by cocaine. Brain Res. 1067, 1-12.

Lu, B., Pang, P. T., Woo, N. H., 2005. The yin and yang of neurotrophin action. Nat. Rev. Neurosci. 6, 603-614.

Lu, H., Cheng, P. L., Lim, B. K., Khoshnevisrad, N., Poo, M. M., 2010. Elevated BDNF after cocaine withdrawal facilitates LTP in medial prefrontal cortex by suppressing GABA inhibition. Neuron. 67, 821-833.

Maisonpierre, P. C., Belluscio, L., Friedman, B., Alderson, R. F., Wiegand, S. J., Furth, M. E., Lindsay, R. M., Yancopoulos, G. D., 1990. NT-3, BDNF, and NGF in the developing rat nervous system: parallel as well as reciprocal patterns of expression. Neuron. 5, 501-509. 
Mao, L. M., Fibuch, E. E., Wang, J. Q., 2010. Decoding BDNF-LTP coupling in cocaine addiction. Neuron. 67, 679-681.

Marmigere, F., Rage, F., Tapia-Arancibia, L., Arancibia, S., 1998. Expression of mRNAs encoding BDNF and its receptor in adult rat hypothalamus. Neuroreport. 9, 1159-1163.

Martinowich, K., Manji, H., Lu, B., 2007. New insights into BDNF function in depression and anxiety. Nat. Neurosci. 10, 1089-1093.

Massa, S. M., Yang, T., Xie, Y., Shi, J., Bilgen, M., Joyce, J. N., Nehama, D., Rajadas, J., Longo, F. M., 2010. Small molecule BDNF mimetics activate TrkB signaling and prevent neuronal degeneration in rodents. J. Clin. Invest. 120, 1774-1785.

Merighi, A., Salio, C., Ghirri, A., Lossi, L., Ferrini, F., Betelli, C., Bardoni, R., 2008. BDNF as a pain modulator. Prog. Neurobiol. 85, 297-317.

Merlio, J. P., Ernfors, P., Kokaia, Z., Middlemas, D. S., Bengzon, J., Kokaia, M., Smith, M. L., Siesjo, B. K., Hunter, T., Lindvall, O., 1993. Increased production of the TrkB protein tyrosine kinase receptor after brain insults. Neuron. 10, 151-164.

Middlemas, D. S., Lindberg, R. A., Hunter, T., 1991. TrkB, a neural receptor protein-tyrosine kinase: evidence for a full-length and two truncated receptors. Mol. Cell. Biol. 11, 143-153.

Miletic, G., Miletic, V., 2008. Loose ligation of the sciatic nerve is associated with TrkB receptor-dependent decreases in KCC2 protein levels in the ipsilateral spinal dorsal horn. Pain. 137, 532-539.

Minichiello, L., 2009. TrkB signalling pathways in LTP and learning. Nat. Rev. Neurosci. 10, 850-860.

Minturn, J. E., Evans, A. E., Villablanca, J. G., Yanik, G. A., Park, J. R., Shusterman, S., Groshen, S., Hellriegel, E. T., Bensen-Kennedy, D., Matthay, K. K., Brodeur, G. M., Maris, J. M., 2011. Phase I trial of lestaurtinib for children with refractory neuroblastoma: a new approaches to neuroblastoma therapy consortium study. Cancer Chemother. Pharmacol. 68, 1057-1065.

Nagappan, G., Woo, N. H., Lu, B., 2008. Ama "zinc" link between TrkB transactivation and synaptic plasticity. Neuron. 57, 477-479.

Nakagawara, A., Arima-Nakagawara, M., Azar, C. G., Scavarda, N. J., Brodeur, G. M., 1994. Clinical significance of expression of neurotrophic factors and their receptors in neuroblastoma. Prog. Clin. Biol. Res. 385, 155-161.

Ng, Y. K., Wong, E. Y., Lau, C. P., Chan, J. P., Wong, S. C., Chan, A. S., Kwan, M. P., Tsao, S. W., Tsang, C. M., Lai, P. B., Chan, A. T., Lui, V. W., 2010. K252a induces anoikis-sensitization with suppression of cellular migration in Epstein-Barr Virus (EBV)-associated nasopharyngeal carcinoma cells. Invest. New. Drugs. DOI 10.1007/s10637010-9513-4

Numakawa, T., Kumamaru, E., Adachi, N., Yagasaki, Y., Izumi, A. and Kunugi, H., 2009. Glucocorticoid receptor interaction with TrkB promotes BDNF-triggered PLC-gamma signaling for glutamate release via a glutamate transporter. Proc. Natl. Acad. Sci. U S A. 106, 647-652.

Numan, S., Lane-Ladd, S. B., Zhang, L., Lundgren, K. H., Russell, D. S., Seroogy, K. B. and Nestler, E. J., 1998. Differential regulation of neurotrophin and trk receptor mRNAs in catecholaminergic nuclei during chronic opiate treatment and withdrawal. J. Neurosci. 18, 10700-10708.

O'Leary, P. D., Hughes, R. A., 1998. Structure-activity relationships of conformationally constrained peptide analogues of loop 2 of brain-derived neurotrophic factor. J. Neurochem. 70, 1712-1721.

O'Leary, P. D., Hughes, R. A., 2003. Design of potent peptide mimetics of brain-derived neurotrophic factor. J. Biol. Chem. 278, 25738-25744.

Pattarawarapan, M., Burgess, K., 2003. Molecular basis of neurotrophin-receptor interactions. J. Med. Chem. 46, 5277-5291. 
Pezet, S., Cunningham, J., Patel, J., Grist, J., Gavazzi, I., Lever, I. J., Malcangio, M., 2002. BDNF modulates sensory neuron synaptic activity by a facilitation of GABA transmission in the dorsal horn. Mol. Cell. Neurosci. 21, $51-62$.

Pezet, S., Malcangio, M., 2004. Brain-derived neurotrophic factor as a drug target for CNS disorders. Expert Opin. Ther. Targets. 8, 391-399.

Pezet, S., Malcangio, M., McMahon, S. B., 2002. BDNF: a neuromodulator in nociceptive pathways? Brain Res. Brain Res. Rev. 40, 240-249.

Pruunsild, P., Kazantseva, A., Aid, T., Palm, K., Timmusk, T., 2007. Dissecting the human BDNF locus: bidirectional transcription, complex splicing, and multiple promoters. Genomics. 90, 397-406.

Pu, L., Liu, Q. S., Poo, M. M., 2006. BDNF-dependent synaptic sensitization in midbrain dopamine neurons after cocaine withdrawal. Nat. Neurosci. 9, 605-607.

Qi, J., Wang, Y., Jiang, M., Warren, P., Chen, G., 2006. Cyclothiazide induces robust epileptiform activity in rat hippocampal neurons both in vitro and in vivo. J. Physiol. 571, 605-618.

Rajagopal, R., Chao, M. V., 2006. A role for Fyn in Trk receptor transactivation by G-protein-coupled receptor signaling. Mol. Cell. Neurosci. 33, 36-46.

Rajagopal, R., Chen, Z. Y., Lee, F. S., Chao, M. V., 2004. Transactivation of Trk neurotrophin receptors by Gprotein-coupled receptor ligands occurs on intracellular membranes. J. Neurosci. 24, 6650-6658.

Rantamaki, T., Vesa, L., Antila, H., Di Lieto, A., Tammela, P., Schmitt, A., Lesch, K. P., Rios, M., Castren, E., 2011. Antidepressant drugs transactivate TrkB neurotrophin receptors in the adult rodent brain independently of BDNF and monoamine transporter blockade. PLoS One. 6, e20567.

Robinson, R. C., Radziejewski, C., Spraggon, G., Greenwald, J., Kostura, M. R., Burtnick, L. D., Stuart, D. I., Choe, S., Jones, E. Y., 1999. The structures of the neurotrophin 4 homodimer and the brain-derived neurotrophic factor/neurotrophin 4 heterodimer reveal a common Trk-binding site. Protein. Sci. 8, 2589-2597.

Robinson, R. C., Radziejewski, C., Stuart, D. I., Jones, E. Y., 1995. Structure of the brain-derived neurotrophic factor/neurotrophin 3 heterodimer. Biochemistry. 34, 4139-4146.

Russo, S. J., Dietz, D. M., Dumitriu, D., Morrison, J. H., Malenka, R. C., Nestler, E. J., 2010. The addicted synapse: mechanisms of synaptic and structural plasticity in nucleus accumbens. Trends Neurosci. 33, 267-276.

Russo, S. J., Mazei-Robison, M. S., Ables, J. L., Nestler, E. J., 2009. Neurotrophic factors and structural plasticity in addiction. Neuropharmacology. 56 Suppl 1, 73-82.

Ryden, M., Murray-Rust, J., Glass, D., Ilag, L. L., Trupp, M., Yancopoulos, G. D., McDonald, N. Q., Ibanez, C. F., 1995. Functional analysis of mutant neurotrophins deficient in low-affinity binding reveals a role for p75LNGFR in NT-4 signalling. EMBO J. 14, 1979-1990.

Sadick, M. D., Galloway, A., Shelton, D., Hale, V., Weck, S., Anicetti, V., Wong, W. L., 1997. Analysis of neurotrophin/receptor interactions with a gD-flag-modified quantitative kinase receptor activation (gD.KIRA) enzyme-linked immunosorbent assay. Exp. Cell. Res. 234, 354-361.

Sadri-Vakili, G., Kumaresan, V., Schmidt, H. D., Famous, K. R., Chawla, P., Vassoler, F. M., Overland, R. P., Xia, E., Bass, C. E., Terwilliger, E. F., Pierce, R. C., Cha, J. H., 2010. Cocaine-induced chromatin remodeling increases brain-derived neurotrophic factor transcription in the rat medial prefrontal cortex, which alters the reinforcing efficacy of cocaine. J. Neurosci. 30, 11735-11744.

Salin, T., Mudo, G., Jiang, X. H., Timmusk, T., Metsis, M., Belluardo, N., 1995. Up-regulation of trkB mRNA expression in the rat striatum after seizures. Neurosci. Lett. 194, 181-184.

Scala, S., Wosikowski, K., Giannakakou, P., Valle, P., Biedler, J. L., Spengler, B. A., Lucarelli, E., Bates, S. E., Thiele, C. J., 1996. Brain-derived neurotrophic factor protects neuroblastoma cells from vinblastine toxicity. Cancer. Res. 56, 3737-3742. 
Scharfman, H. E., Goodman, J. H., Sollas, A. L., Croll, S. D., 2002. Spontaneous limbic seizures after intrahippocampal infusion of brain-derived neurotrophic factor. Exp. Neurol. 174, 201-214.

Schmidt-Kastner, R., Humpel, C., Wetmore, C., Olson, L., 1996. Cellular hybridization for BDNF, trkB, and NGF mRNAs and BDNF-immunoreactivity in rat forebrain after pilocarpine-induced status epilepticus. Exp. Brain Res. 107, 331-347.

Sclabas, G. M., Fujioka, S., Schmidt, C., Li, Z., Frederick, W. A., Yang, W., Yokoi, K., Evans, D. B., Abbruzzese, J. L., Hess, K. R., Zhang, W., Fidler, I. J., Chiao, P. J., 2005. Overexpression of tropomysin-related kinase B in metastatic human pancreatic cancer cells. Clin. Cancer Res. 11, 440-449.

Shirayama, Y., Chen, A. C., Nakagawa, S., Russell, D. S., Duman, R. S., 2002. Brain-derived neurotrophic factor produces antidepressant effects in behavioral models of depression. J. Neurosci. 22, 3251-3261.

Soppet, D., Escandon, E., Maragos, J., Middlemas, D. S., Reid, S. W., Blair, J., Burton, L. E., Stanton, B. R., Kaplan, D. R., Hunter, T., Nikolics, K., Parada, L. F., 1991. The neurotrophic factors brain-derived neurotrophic factor and neurotrophin-3 are ligands for the trkB tyrosine kinase receptor. Cell. 65, 895-903.

Swift, J. L., Godin, A. G., Dore, K., Freland, L., Bouchard, N., Nimmo, C., Sergeev, M., De Koninck, Y., Wiseman, P. W., Beaulieu, J. M., 2011. Quantification of receptor tyrosine kinase transactivation through direct dimerization and surface density measurements in single cells. Proc. Natl. Acad. Sci. U S A. 108, 7016-7021.

Takahashi, M., Hayashi, S., Kakita, A., Wakabayashi, K., Fukuda, M., Kameyama, S., Tanaka, R., Takahashi, H., Nawa, H., 1999. Patients with temporal lobe epilepsy show an increase in brain-derived neurotrophic factor protein and its correlation with neuropeptide Y. Brain Res. 818, 579-582.

Taliaz, D., Stall, N., Dar, D. E., Zangen, A., 2010. Knockdown of brain-derived neurotrophic factor in specific brain sites precipitates behaviors associated with depression and reduces neurogenesis. Mol. Psychiatry. 15, 80-92.

Tapley, P., Lamballe, F., Barbacid, M., 1992. K252a is a selective inhibitor of the tyrosine protein kinase activity of the trk family of oncogenes and neurotrophin receptors. Oncogene. 7, 371-381.

Thiele, C. J., Li, Z., McKee, A. E., 2009. On Trk--the TrkB signal transduction pathway is an increasingly important target in cancer biology. Clin. Cancer Res. 15, 5962-5967.

Toda, S., McGinty, J. F., Kalivas, P. W., 2002. Repeated cocaine administration alters the expression of genes in corticolimbic circuitry after a 3-week withdrawal: a DNA macroarray study. J. Neurochem. 82, 1290-1299.

Tsankova, N. M., Berton, O., Renthal, W., Kumar, A., Neve, R. L., Nestler, E. J., 2006. Sustained hippocampal chromatin regulation in a mouse model of depression and antidepressant action. Nat. Neurosci. 9, 519-525.

Tsao, D., Thomsen, H. K., Chou, J., Stratton, J., Hagen, M., Loo, C., Garcia, C., Sloane, D. L., Rosenthal, A., Lin, J. C., 2008. TrkB agonists ameliorate obesity and associated metabolic conditions in mice. Endocrinology. 149, 10381048 .

Ultsch, M. H., Wiesmann, C., Simmons, L. C., Henrich, J., Yang, M., Reilly, D., Bass, S. H., de Vos, A. M., 1999. Crystal structures of the neurotrophin-binding domain of TrkA, TrkB and TrkC. J. Mol. Biol. 290, 149-159.

Unger, T. J., Calderon, G. A., Bradley, L. C., Sena-Esteves, M., Rios, M., 2007. Selective deletion of Bdnf in the ventromedial and dorsomedial hypothalamus of adult mice results in hyperphagic behavior and obesity. J. Neurosci. $27,14265-14274$.

Urfer, R., Tsoulfas, P., O'Connell, L., Shelton, D. L., Parada, L. F., Presta, L. G., 1995. An immunoglobulin-like domain determines the specificity of neurotrophin receptors. EMBO J. 14, 2795-2805.

Vanhecke, E., Adriaenssens, E., Verbeke, S., Meignan, S., Germain, E., Berteaux, N., Nurcombe, V., Le Bourhis, X. Hondermarck, H., 2011. Brain-derived neurotrophic factor and neurotrophin-4/5 are expressed in breast cancer and can be targeted to inhibit tumor cell survival. Clin Cancer Res. 17, 1741-1752.

Vargas-Perez, H., Ting, A. K. R., Walton, C. H., Hansen, D. M., Razavi, R., Clarke, L., Bufalino, M. R., Allison, D. W., Steffensen, S. C., van der Kooy, D., 2009. Ventral tegmental area BDNF induces an opiate-dependent-like reward state in naive rats. Science. $324,1732-1734$. 
Vogt, K., Mellor, J., Tong, G., Nicoll, R., 2000. The actions of synaptically released zinc at hippocampal mossy fiber synapses. Neuron. 26, 187-196.

Wang, X., Ratnam, J., Zou, B., England, P. M., Basbaum, A. I., 2009. TrkB signaling is required for both the induction and maintenance of tissue and nerve injury-induced persistent pain. J. Neurosci. 29, 5508-5515.

Wang, Y., Qi, J. S., Kong, S., Sun, Y., Fan, J., Jiang, M., Chen, G., 2009. BDNF-TrkB signaling pathway mediates the induction of epileptiform activity induced by a convulsant drug cyclothiazide. Neuropharmacology. 57, 49-59.

Weickert, C. S., Ligons, D. L., Romanczyk, T., Ungaro, G., Hyde, T. M., Herman, M. M., Weinberger, D. R., Kleinman, J. E., 2005. Reductions in neurotrophin receptor mRNAs in the prefrontal cortex of patients with schizophrenia. Mol. Psychiatry. 10, 637-650.

Wiese, S., Jablonka, S., Holtmann, B., Orel, N., Rajagopal, R., Chao, M. V., Sendtner, M., 2007. Adenosine receptor A2A-R contributes to motoneuron survival by transactivating the tyrosine kinase receptor TrkB. Proc. Natl. Acad. Sci. U S A. 104, 17210-17215.

Williams, S. N., Undieh, A. S., 2010. Brain-derived neurotrophic factor signaling modulates cocaine induction of reward-associated ultrasonic vocalization in rats. J. Pharmacol. Exp. Ther. 332, 463-468.

Wyneken, U., Smalla, K. H., Marengo, J. J., Soto, D., de la Cerda, A., Tischmeyer, W., Grimm, R., Boeckers, T. M., Wolf, G., Orrego, F., Gundelfinger, E. D., 2001. Kainate-induced seizures alter protein composition and N-methylD-aspartate receptor function of rat forebrain postsynaptic densities. Neuroscience. 102, 65-74.

Yajima, Y., Narita, M., Usui, A., Kaneko, C., Miyatake, M., Yamaguchi, T., Tamaki, H., Wachi, H., Seyama, Y., Suzuki, T., 2005. Direct evidence for the involvement of brain-derived neurotrophic factor in the development of a neuropathic pain-like state in mice. J. Neurochem. 93, 584-594.

Yamamoto, M., Sobue, G., Yamamoto, K., Terao, S., Mitsuma, T., 1996. Expression of mRNAs for neurotrophic factors (NGF, BDNF, NT-3, and GDNF) and their receptors (p75NGFR, trkA, trkB, and trkC) in the adult human peripheral nervous system and nonneural tissues. Neurochem. Res. 21, 929-938.

Yan, Q., Rosenfeld, R. D., Matheson, C. R., Hawkins, N., Lopez, O. T., Bennett, L., Welcher, A. A., 1997. Expression of brain-derived neurotrophic factor protein in the adult rat central nervous system. Neuroscience. 78, 431-448.

Yeo, G. S., Connie Hung, C. C., Rochford, J., Keogh, J., Gray, J., Sivaramakrishnan, S., O'Rahilly, S., Farooqi, I. S., 2004. A de novo mutation affecting human TrkB associated with severe obesity and developmental delay. Nat. Neurosci. 7, 1187-1189.

Yu, H., Chen, Z. Y., 2011. The role of BDNF in depression on the basis of its location in the neural circuitry. Acta Pharmacol. Sin. 32, 3-11.

Yu, X., Liu, L., Cai, B., He, Y., Wan, X., 2008. Suppression of anoikis by the neurotrophic receptor TrkB in human ovarian cancer. Cancer Sci. 99, 543-552.

Zage, P. E., Graham, T. C., Zeng, L., Fang, W., Pien, C., Thress, K., Omer, C., Brown, J. L., Zweidler-McKay, P. A., 2011. The selective Trk inhibitor AZ623 inhibits brain-derived neurotrophic factor-mediated neuroblastoma cell proliferation and signaling and is synergistic with topotecan. Cancer. 117, 1321-1391.

Zhang, D., Zhang, L., Lou, D. W., Nakabeppu, Y., Zhang, J., Xu, M., 2002. The dopamine D1 receptor is a critical mediator for cocaine-induced gene expression. J. Neurochem. 82, 1453-1464.

Zhang, J. H., Li, A. M., Chen, S., Tong, H. X., Zhang, K. R., 2008. [Blocking TrkB-BDNF signal pathway decreases the livability of neuroblastoma cells]. Zhongguo. Dang. Dai. Er. Ke. Za. Zhi. 10, 47-50. 


\section{CHAPTER V}

\section{Blockade of the BDNF receptor TrkB by cyclotraxin-B downregulates plasticity genes concomitant with epigenetic changes in differentiated human neuroblastoma cells}

\footnotetext{
FABIEn BOUlLE ${ }^{1,2}$, DANiel L.A VAN DEN HOVE ${ }^{1,3}$, ANDromache GOETHALS ${ }^{1}$, Justina CHINWANG ${ }^{1,4}$, PiERre PANNAYE ${ }^{1}$, BARBIE MACHIELS ${ }^{1}$, ANDREA ROMANO $^{5}$, MiCHEL HAMON $^{2}$, HARRY W STEINBUSCH $^{1}$, LAURENCE LANFUMEY², GUNTER KENIS ${ }^{1}$
}

${ }^{I}$ Department of Psychiatry and Neuropsychology, European Graduate School for Neuroscience (EURON), School for Mental Health and Neuroscience, Maastricht University, Maastricht, The Netherlands

${ }^{2}$ Centre de Psychiatrie et Neuroscience (INSERM U894), Universite Pierre et Marie Curie, Paris, France

${ }^{3}$ Department of Psychiatry, Psychosomatics and Psychotherapy, University of Wuerzburg, Wuerzburg, Germany

${ }^{4}$ Chemistry Department, York College of the City University of New York

${ }^{5}$ Department of Obstetrics and Gynecology, GROW - School for Oncology and Developmental Biology, Maastricht University Medical Center, Maastricht, The Netherlands

Submitted, European Neuropsychopharmacology 


\section{Abstract}

Brain-derived neurotrophic factor (BDNF) is a key-role player in structural and functional plasticity, especially within the midbrain dopamine neurons that project to the ventral striatum. Recent evidence showed that drug abuse and social defeat in rodents could produce lasting epigenetic remodeling as well as BDNF upregulation, associated with major reorganizations within the neuronal network of the mesolimbic dopaminergic system. In the present study, we wanted to explore to which extent the inhibition of the BDNF tropomyosin-related kinase receptor B (TrkB) with the novel antagonist cyclotraxin-B could induce epigenetic remodeling at downstream TrkB target genes involved in neuroplasticity. As such, we used SH-SY5Y human neuroblastoma cells, known for their ability to differentiate into mature dopaminergic cells expressing high levels of activated TrkB. Our data indicate that cyclotraxin-B produced enduring downregulation of AKT1 and BCL2 expression, two major players in dendritic arborization and neuronal survival. Moreover, we showed that cyclotraxin-B-induced persistent changes in gene expression were associated with post-translational modifications at histone tails and changes in the machinery controlling DNA methylation. Hence, our findings provide further insight into the neuroplastic and epigenetic effects of cyclotraxin-B, and point out that the ability of TrkB antagonists to reverse abnormal BDNF-mediated epigenetic remodeling in the dopaminergic system could have therapeutic potentialities.

Key words: TrkB inhibitor, gene expression, chromatin, methylation, acetylation, epigenetics, neuronal plasticity 


\section{I - Introduction}

The interaction of brain-derived neurotrophic factor (BDNF) with its tropomyosin-related kinase receptor B (TrkB) plays an essential role in the establishment and maintenance of neuronal and synaptic plasticity (Chao, 2003). It is well established that chronic stress can lead to reduced BDNF expression resulting into neuronal atrophy and cell loss in the hippocampus, which might play an important role in the pathophysiology of stress-related diseases including post-traumatic stress disorders (PTSD), anxiety disorders and depression (Autry and Monteggia, 2012). In contrast, repeated administration of psychostimulants has been associated with increased levels of BDNF in the mesolimbic dopaminergic system, a process that is required for both sensitization and dependence to drugs (Graham et al., 2007; Russo et al., 2009). In addition, the increased plasticity induced by elevation of BDNF was also shown to be important in epileptogenesis, as well as in the induction and maintenance of neuropathic pain (Isackson et al., 1991; Wang et al., 2009). Mounting evidence suggests that the variations observed in BDNF expression and downstream signaling may rely on epigenetic regulation, conferring a stable imprint on gene transcription and susceptibility for disease (Boulle et al., 2012). BDNF has a complex gene structure that has been reported to be highly sensitive to environmental variations and concomitant epigenetic modifications (Boulle et al., 2012) underlying changes in gene expression. For instance, the methyl-CpG binding protein 2 (MeCP2) binds selectively to methylated DNA at BDNF promoter IV to repress its transcription (Chen et al., 2003). In addition, stable post-translational modifications at histone tails (i.e. H3K9 acetylation and H3K27 methylation) have been reported at the BDNF gene in ventral tegmental area (VTA) dopaminergic neurons projecting into the nucleus accumbens (NAc) in response to drug administration or withdrawal (Kumar et al., 2005; Sadri-Vakili et al., 2010; Schmidt et al., 2011).

Hence, the identification and further characterization of drugs that directly target TrkB and its downstream neuroplastic effectors represent a promising avenue in neuroscience research. To date, only few drugs with TrkB inhibitory properties have been described (Boulle et al., 2012). In our experiments, we used a recently developed and innovative TrkB inhibitor, known as cyclotraxin-B. This small peptidic compound acts as a selective and potent TrkB antagonist that can block both BDNF-dependent and BDNF-independent activation of TrkB (Cazorla et al., 2010). In addition, cyclotraxin-B was shown to cross the blood-brain-barrier (BBB), reduce neuropathic pain in rats (Constandil et al., 2011), and produce anxiolytic effects in mice (Cazorla et al., 2010). In the present study, we wanted to explore to which extent the blockade of TrkB with cyclotraxin-B could involve lasting epigenetic changes at downstream plasticity-related genes in an in vitro model of differentiated dopaminergic cells. 


\section{II - Experimental procedures}

Cell culture and treatment: SH-SY5Y cells were obtained from the European Collection of Cell Cultures (ECACC, Salisbury, UK) and had undergone between 20 and 30 passages before use in our experiments. The cells were cultured in a 1:1 mixture of F-12K Kaighn's modification nutrient medium and Dulbecco's Modified Eagle Medium (ATCC, Molsheim, France) supplemented with $10 \%$ fetal calf serum, $10 \mathrm{U} / \mathrm{ml}$ penicillin $\mathrm{G}, 10 \mathrm{mg} / \mathrm{ml}$ streptomycin and $2 \mathrm{nM}$ of L-Glutamine. To induce differentiation, the cells were treated with $10 \mu \mathrm{M}$ of retinoic acid (RA) in culture medium for 5 days, and the medium was refreshed every 2 days. Pharmacological treatment was performed on 5-days-RA-differentiated SHSY5Y cells using the TrkB antagonist cyclotraxin-B (Cazorla et al., 2010). Based on previous reports, a dose of $1 \mu \mathrm{M}$ cyclotraxin-B was used (Cazorla et al., 2010). Cyclotraxin-B was added to the culture medium for 6 or 24 hours, while chronic $96 \mathrm{~h}$ treatments consisted of 4 successive cyclotraxin-B exposures of $24 \mathrm{~h}$ each.

Cell survival and differentiation: Cell viability (mitochondrial activity) was measured using a 3-(4,5dimethylthiazol-2-yl)-2,5-diphenyltetrazolium bromide (MTT) reduction assay. SH-SY5Y cells were incubated for $2 \mathrm{~h}$ at $37^{\circ} \mathrm{C}$ in the presence of MTT $(0.5 \mathrm{mg} / \mathrm{mL})$ diluted in culture medium. Incubation with isopropanol was performed for one additional hour. The absorbance was then measured at $540 \mathrm{~nm}$ (Victor X3, Perkin Elmer). Cells treated with 10\% DMSO $1 \mathrm{~h}$ prior to the MTT addition were used as blank and the corresponding value was subtracted as background for each sample. For neurite outgrowth measurements, images of the cells were taken using an Olympus IX81 phase-contrast microscope (Olympus, Hamburg, Germany), and the neurite extensions were traced and quantified using the Neuron J plug-in of the Image J software (Image J 1.42, NIH, USA).

Western blot: SH-SY5Y cells were lysed in ice-cold lysis buffer (1\% Nonidet P-40, $150 \mathrm{mM} \mathrm{NaCl}, 1$ mM EDTA, $10 \mathrm{mM}$ Tris, $\mathrm{pH}$ 8.0, $10 \mathrm{mM} \mathrm{NaF}, 1 \mathrm{mM}$ sodium orthovanadate and protease inhibitors cocktail) and protein content was loaded on a SDS-PAGE gel for electrophoretic migration and then transferred to a nitrocellulose membrane for $1 \mathrm{~h}$ at $4^{\circ} \mathrm{C}$. Non-specific binding was blocked by incubating the membranes in an Odyssey blocking buffer (LI-COR Biosciences, NE, USA) for $1 \mathrm{~h}$ at room temperature. Rabbit anti-TrkB (Merck Millipore, MA, USA) and rabbit anti-phospho-TrkB Y817 (Epitomics Inc, CA, USA) were used as primary antibodies for the detection of endogenous TrkB and its activated form. The membranes were incubated with the primary antibodies overnight at $4^{\circ} \mathrm{C}$ in the Odyssey blocking buffer. Then, after extensive washing, the membranes were incubated with the appropriate fluorescent secondary antibodies (Alexa Fluor 488 goat anti-rabbit; Molecular Probes, OR, USA) for $1 \mathrm{~h}$ at room temperature. Finally, the membranes were washed, dried and scanned using the Odyssey ${ }^{\circledR}$ infrared imaging system (Westburg, Leusden, The Netherlands). 
Reverse transcription and real-time quantitative PCR (RT-qPCR): Total mRNA extraction was performed using Trizol ${ }^{\circledR}$ (Invitrogen, CA, USA), after which, cDNA synthesis was performed using a First Strand cDNA synthesis kit (Fermantas International Inc. Canada) according to the manufacturer's protocol. Amplification was made with SYBR green I Master Mix (Roche Diagnostic, IN, USA). Primer sequences are indicated in Table S1. Gene expression was normalized using HPRT and RS27A as reference genes. Gene expression analysis was performed with the LightCycler 480 Real-Time PCR System (Roche Applied Science, IN, USA) and the conditions for the reaction involved 35 cycles in a fixed sequence of $95^{\circ} \mathrm{C}$ for $30 \mathrm{~s}, 62^{\circ} \mathrm{C}$ for $15 \mathrm{~s}$, and $72^{\circ} \mathrm{C}$ for $15 \mathrm{~s}$.

Chromatin immunoprecipitation (ChIP): Briefly, cells were fixed in a 1\% formaldehyde solution, after which they were lysed in ice-cold SDS lysis buffer containing protease inhibitors (Roche, Meylan, France). The chromatin was sheared in order to obtain DNA fragments that were approximately between 400 and 800 base pairs. The solution of chromatin was pre-cleared with a mixture of protein A-agarose (Pierce, Thermo-Fischer, Illkirch, France) and salmon sperm (Agilent technologies, CA, USA), and then immunoprecipitated overnight at $4^{\circ} \mathrm{C}$ with $2 \mu \mathrm{g}$ of rabbit anti-H3K9ac, mouse anti-H3K27me3 (Millipore, Molsheim, France) or rabbit anti-MeCP2 (Sigma Aldrich, MO, USA) antibodies. After intensive washes, the immunoprecipitate was eluted from the beads using a $1 \%$ SDS elution buffer and the protein-DNA cross-links were reversed by incubating the samples overnight at $65^{\circ} \mathrm{C}$ in the presence of $5 \mathrm{M} \mathrm{NaCl}$. DNA fragments were then treated with proteinase $\mathrm{K}$ in order to digest the proteins, and DNA was isolated using phenol/chloroform/isoamyl alcohol and then precipitated with $100 \%$ ethanol and $20 \mu \mathrm{g}$ of glycogen. Fragments of promoter regions of target genes were quantified by quantitative PCR (see Table S2 for primer sequences and design). Ct values of immunoprecipitated samples were normalized to $\mathrm{Ct}$ values obtained from Input DNA. The specificity of the antibodies used in the experiments was determined by immunoprecipitation of the sample with non-specific HA-probe (Y-11) antibody (Santa Cruz Biotechnology Inc, CA, USA).

Statistical analysis: Data are presented as mean + SEM. Statistical significance was determined using a two-tailed Student's t test for comparison between two groups and, when necessary, a Welsh's correction was used (Prism 5.0, GraphPad software, USA). The level of significance was set as $P<0.05$.

\section{III - Results}

Effects of $R A$ treatment on cell differentiation and BDNF/TrkB signaling: To induce differentiation, we treated SH-SY5Y cells with $10 \mu \mathrm{M}$ of RA for 5 days. Tracing and quantification of neurite length indicated that RA treatment increased neurite outgrowth as compared to non-treated cells ( $p=0,0019$, after 5 days of treatment; Figure 1A). In a similar manner, RA-treated SH-SY5Y cells showed increased 
viability as compared to non-treated cells ( $\mathrm{p}=0.0007$; Figure $1 \mathrm{~A})$. Then, we wanted to investigate the potential implication of BDNF/TrkB signaling in RA-induced SH-SY5Y cell differentiation. We thus performed different kinetics of stimulation with $10 \mu \mathrm{M}$ of RA in order to visualize the time-dependent implication of BDNF/TrkB signaling during SH-SY5Y cell differentiation. As shown by western blot analysis, the expression of full-length $\operatorname{TrkB}(\cong 145 \mathrm{kDa})$ increased gradually over the 5 days of RA treatment (Figure 1B). In a similar manner, the phosphorylation of TrkB at tyrosine residue 817 progressively increased with RA treatment, indicating an overall increase of TrkB activation during RAinduced SH-SY5Y cell differentiation (Figure 1B). Parallel RT-PCR quantifications showed that TrkB mRNA levels were increased by more than 200 times after a 5-day RA treatment ( $\mathrm{p}=0.0087$; Figure 1B), while those of BDNF mRNA did not significantly change (Figure 1B). As such, we also measured the expression of diverse genes implicated at different levels of neuronal and synaptic plasticity, and known to be involved in BDNF/TrkB downstream signaling. Accordingly, the transcripts of AKT1, BCL2, cFOS, HOMER1 and VGF were significantly upregulated $(\mathrm{p}=0.033, \mathrm{p}=0.0008, \mathrm{p}<0.0001, \mathrm{p}=0.004$ and $p=0.03$ respectively; Figure 2), while those of CREB, ERK1 and JNK genes did not change significantly after a 5-day RA treatment ( $>00.05$; Figure 2).

Effects of cyclotraxin-B on gene expression and epigenetic regulation: Because differentiated SHSY5Y cells were found to express high levels of TrkB and phospho-TrkB, experiments were performed in order to assess whether they could represent a model of choice to explore the cellular and molecular changes evoked by TrkB blockade. Differentiated SH-SY5Y cells were exposed for various times to the TrkB antagonist cyclotraxin-B $(1 \mu \mathrm{M})$, and the resulting effects on the expression of downstream target genes were evaluated by real-time RT-qPCR. Quantitative determination of gene expression profiles at various times (see Figure 3) revealed that the AKT1, BCL2, TRKB and VGF genes were significantly downregulated after a $6 \mathrm{~h}$ exposure to cyclotraxin-B ( $\mathrm{p}=0.011, \mathrm{p}=0.0003, \mathrm{p}=0.0062$ and $\mathrm{p}=0.042$ respectively), whereas mRNA expression of the BDNF and cFOS genes remained unchanged. After a 24 $\mathrm{h}$ treatment with cyclotraxin-B, only the AKT1 and BCL2 gene expression was still downregulated $(p=0.0002$ and $p=0.0021$ respectively; Figure 3). Finally, a tendency for a downregulation of AKT1 expression and a significant decreased expression of BCL2 were observed after the $96 \mathrm{~h}$ exposure to cyclotraxin- $\mathrm{B}(\mathrm{p}=0.10$ and $\mathrm{p}=0.014$ respectively; Figure 3 ). Thus, the gene expression profiles pointed towards a lasting downregulation of BCL2 and AKT1 during exposure to cyclotraxin-B.

We then examined whether these changes observed at the gene expression level could be attributed to epigenetic modifications. As such, we performed chromatin immunoprecipitation after 4 successive stimulations of 24 hours each with $1 \mu \mathrm{M}$ of cyclotraxin-B and measured H3K9ac, H3K27me3 and MeCP2 binding at the AKT1, BCL2, TRKB and VGF genes. A t-test comparison between control and cyclotraxin-B groups showed a specific enrichment of H3K27me3 (generally known as a repressive 
mark) at the AKT1 gene promoter ( $\mathrm{p}=0.036$; Figure 4). Similarly, MeCP2, known as a repressor of gene transcription, was significantly increased at the TRKB and VGF gene promoters $(p=0.0057$ and $p=0.030$ respectively; Figure 4). In contrast, a tendency ( $\mathrm{p}=0.083$; Figure 4) for decreased H3K9ac, known as a permissive mark, was observed at the BCL2 gene promoter. Of note, a general tendency towards a decreased $\mathrm{H} 3 \mathrm{~K} 9 \mathrm{ac}$ and increased $\mathrm{H} 3 \mathrm{~K} 27 \mathrm{me} 3$ at TrkB target genes was observed. Hence, cyclotraxin-B appears to mediate its effects on gene expression via modification at histone tails and MeCP2 binding.

\section{IV - Discussion}

In the present study, we explored to which extent the inhibition of BDNF/TrkB signaling by cyclotraxin-B underlies epigenetic remodeling at downstream target genes. Our results showed that cyclotraxin-B induced a lasting downregulation of the expression of a subset of genes involved in neuroplasticity pathways, concomitant with post-translational modifications at histone tails as well as altered MeCP2 binding at those genes.

A recent study demonstrated that RA treatment of SH-SY5Y cells induced their differentiation into a predominantly mature dopaminergic-like neuronal phenotype, characterized by increased dopamine synthesis and reuptake, together with a substantial suppression of other neurotransmitter phenotypes (Korecka et al., 2013). In the present study, we showed that RA treatment induced the expression and activation of TrkB receptor as previously reported (Encinas et al., 2000). Hence, the RA-treated SHSY5Y cells constitute a unique in vitro approach to explore BDNF/TrkB signaling in human dopaminergic neuron-like cells, and the high levels of TrkB phosphorylation represent a valuable model to study the action of TrkB inhibitors. An increase of TrkB signaling in the mesolimbic dopaminergic system has been reported following repetitive administration of psychostimulants, as well as after social defeat stress in rodents (Krishnan et al., 2007; Russo et al., 2009). In SH-SY5Y cells, we showed that BDNF levels were not significantly modulated by RA treatment indicating that the increased TrkB activation observed in differentiated SH-SY5Y cells might be triggered by BDNF-independent mechanisms. Such kind of phenomenon, known as transactivation, has been described for the TrkB receptor, and might be responsible for the maintenance of an excessive TrkB activation and a disturbed cellular homeostasis (Boulle et al., 2012). Interestingly, cyclotraxin-B was previously shown to inhibit both BDNF-dependent and -independent activation of TrkB (Cazorla et al., 2010). The administration of cyclotraxin-B on RA-treated cells resulted in the lasting downregulation of the AKT1 and the BCL2 genes. Activation of the PI3K/Akt pathway through TrkB stimulation, involving AKT1 gene, is known to lead to structural changes in neuronal plasticity such as dendritic arborization and cellular morphology (Kumar et al., 2005), whereas BCL2 has been described as an important regulator of cell survival (Davies, 1995). Some studies found that the activation of Akt signaling in the striatal dopaminergic 


\section{Chapter V}

system mediated excessive alcohol drinking behavior in rats, as well as nicotine and cocaine-induced plasticity (Neasta et al., 2011; Collo et al., 2012, 2013). Similarly, repetitive administration of cocaine was shown to induce BCL2 activation in the rat dorsal striatum (Ahn et al., 2010).

On the other hand, an expanding body of evidence indicates that the maintenance of neuronal plasticity and integrity is controlled by epigenetic regulation involving DNA methylation and histones modifications (Maze et al., 2012; Sultan and Day, 2011). In particular, BDNF appears to be a primary target for epigenetic regulation, and persistent epigenetic modification of BDNF in the striatum has been observed after cocaine administration or prolonged stressors of high intensity (Boulle et al., 2012). Hence, the lasting upregulation of BDNF might subsequently impact on TrkB signaling and the epigenetic control of downstream gene expression. In the present study, we provide evidence that cyclotraxin-B, via the downregulation of TrkB signaling, could involve persistent changes in gene expression, mediated by epigenetic regulations. We found that cyclotraxin-B impacts on post-translational modifications at histone residues as observed by the changes in H3K9 acetylation and H3K27 tri-methylation. Similarly, cyclotraxin-B increased MeCP2 binding at some specific TrkB target genes, suggesting higher levels of methylation at the corresponding promoters. These latter observations might explain, at least in part, the persistent downregulation of TrkB target gene expression and indicate that epigenetic remodeling is part of the pharmacological action of cyclotraxin-B.

Altogether, our data support the notion that $\operatorname{TrkB}$ signaling can underlie epigenetic remodeling at plasticity-related genes, and that its selective blockade by cyclotraxin-B is able to induce epigenetic remodeling in order to significantly impact on neuroplasticity. The usage of such compounds might be relevant to investigate the therapeutic value of TrkB inhibitors in models of drug addiction, where epigenetic alterations at BDNF/TrkB signaling seem to be critically implicated in underlying pathophysiological mechanisms.

\section{V-Acknowledgements}

This research was supported by grants from INSERM, University Pierre \& Marie Curie and ANR (Contract “TrkBDNFarmod” R 12006KK-2011).

We are grateful to Dr. Olga Riveiro and Prof. Klaus-Peter Lesch for kindly providing the SH-SY5Y cells. 


\section{VI - References}

Ahn, S.M., Jang, D.H., Choe, E.S., 2010. Repeated cocaine administration increases B-cell leukemia/lymphoma 2 phosphorylation in the rat dorsal striatum. Neurosci. Lett. 468, 125-129.

Autry, A.E., Monteggia, L.M., 2012. Brain-derived neurotrophic factor and neuropsychiatric disorders. Pharmacol. Rev. 64, 238-258.

Boulle, F., Kenis, G., Cazorla, M., Hamon, M., Steinbusch, H. W., Lanfumey, L. van den Hove, D.L., 2012. TrkB inhibition as a therapeutic target for CNS-related disorders. Prog. Neurobiol. 98, 197-206.

Boulle, F., van den Hove, D.L., Jakob, S.B., Rutten, B.P., Hamon, M., van Os, J., Lesch, K.P., Lanfumey, L., Steinbusch, H.W., Kenis, G., 2012. Epigenetic regulation of the BDNF gene: implications for psychiatric disorders. Mol. Psychiatry 17, 584-596.

Cazorla, M., Jouvenceau, A., Rose, C., Guilloux, J. P., Pilon, C., Dranovsky, A., Premont, J., 2010. Cyclotraxin-B, the first highly potent and selective TrkB inhibitor, has anxiolytic properties in mice. PLoS One 5, e9777.

Chao, M.V., 2003. Neurotrophins and their receptors: a convergence point for many signalling pathways. Nat. Rev. Neurosci. 4, 299-309.

Chen, W.G., Chang, Q., Lin, Y., Meissner, A., West, A.E., Griffith, E.C., Jaenisch, R., Greenberg, M.E., 2003. Derepression of BDNF transcription involves calcium-dependent phosphorylation of MeCP2. Science 302, 885-889.

Collo, G., Bono, F., Cavalleri, L., Plebani, L., Merlo Pich, E., Millan, M.J., Spano, P.F., Missale, C., 2012. Presynaptic dopamine $\mathrm{D}(3)$ receptor mediates cocaine-induced structural plasticity in mesencephalic dopaminergic neurons via ERK and Akt pathways. J. Neurochem. 120, 765-778.

Collo, G., Bono, F., Cavalleri, L., Plebani, L., Mitola, S., Merlo Pich, E., Millan, M.J., Zoli, M., Maskos, U., Spano, P., Missale, C., 2013. Nicotine-induced structural plasticity in mesencephalic dopaminergic neurons is mediated by dopamine D3 receptors and Akt-mTORC1 signaling. Mol. Pharmacol. 83, 1176-1189.

Constandil, L., Goich, M., Hernandez, A., Bourgeais, L., Cazorla, M., Hamon, M., Villanueva, L., Pelissier, T., 2011. Cyclotraxin-B, a new TrkB antagonist, and glial blockade by propentofylline, equally prevent and reverse cold allodynia induced by BDNF or partial infraorbital nerve constriction in mice. J. Pain 13, 579-589.

Davies, A.M.. 1995. The Bcl-2 family of proteins, and the regulation of neuronal survival. Trends Neurosci. 18, 355-358.

Encinas, M., Iglesias, M., Liu, Y., Wang, H., Muhaisen, A., Cena, V., Gallego, C., Comella, J.X., 2000. Sequential treatment of SH-SY5Y cells with retinoic acid and brain-derived neurotrophic factor gives rise to fully differentiated, neurotrophic factor-dependent, human neuron-like cells. J. Neurochem. 75, 991-1003.

Graham, D.L., Edwards, S., Bachtell, R.K., DiLeone, R.J., Rios, M., Self, D.W., 2007. Dynamic BDNF activity in nucleus accumbens with cocaine use increases self-administration and relapse. Nat. Neurosci. 10, 1029-1037.

Isackson, P.J., Huntsman, M.M., Murray, K.D., Gall, C.M., 1991. BDNF mRNA expression is increased in adult rat forebrain after limbic seizures: temporal patterns of induction distinct from NGF. Neuron 6, 937-948.

Korecka, J.A., van Kesteren, R.E., Blaas, E., Spitzer, S.O., Kamstra, J.H., Smit, A.B., Swaab, D.F., Verhaagen, J., Bossers, K., 2013. Phenotypic characterization of retinoic acid differentiated SH-SY5Y cells by transcriptional profiling. PLoS One 8, e63862.

Krishnan, V., Han, M.H., Graham, D.L., Berton, O., Renthal, W., Russo, S.J., Laplant, Q., Graham, A., Lutter, M., Lagace, D.C., Ghose, S., Reister, R., Tannous, P., Green, T.A., Neve, R.L., Chakravarty, S., Kumar, A., Eisch, A.J., Self, D.W., Lee, F.S., Tamminga, C.A., Cooper, D.C., Gershenfeld, H.K., Nestler, E.J., 2007. Molecular adaptations underlying susceptibility and resistance to social defeat in brain reward regions. Cell 131, 391-404.

Kumar, A., Choi, K.H., Renthal, W., Tsankova, N.M., Theobald, D.E., Truong, H.T., Russo, S.J., Laplant, Q., Sasaki, T.S., Whistler, K.N., Neve, R.L., Self, D.W., Nestler, E.J., 2005. Chromatin remodeling is a key mechanism underlying cocaine-induced plasticity in striatum. Neuron 48, 303-314. 
Kumar, V., Zhang, M.X., Swank, M.W., Kunz, J., Wu, G.Y., 2005. Regulation of dendritic morphogenesis by RasPI3K-Akt-mTOR and Ras-MAPK signaling pathways. J. Neurosci. 25, 11288-11299.

Maze, I., Noh, K.M., Allis, C.D., 2012. Histone regulation in the CNS: basic principles of epigenetic plasticity. Neuropsychopharmacology 38, 3-22.

Neasta, J., Ben Hamida, S., Yowell, Q.V., Carnicella, S., Ron, D., 2011. AKT signaling pathway in the nucleus accumbens mediates excessive alcohol drinking behaviors. Biol. Psychiatry 70, 575-582.

Russo, S.J., Mazei-Robison, M.S., Ables, J.L., Nestler, E. J., 2009. Neurotrophic factors and structural plasticity in addiction. Neuropharmacology 56 Suppl 1, 73-82.

Sadri-Vakili, G., Kumaresan, V., Schmidt, H.D., Famous, K.R., Chawla, P., Vassoler, F.M., Overland, R.P., Xia, E., Bass, C.E., Terwilliger, E.F., Pierce, R.C., Cha, J.H., 2010. Cocaine-induced chromatin remodeling increases brainderived neurotrophic factor transcription in the rat medial prefrontal cortex, which alters the reinforcing efficacy of cocaine. J. Neurosci. 30, 11735-11744.

Schmidt, H.D., Sangrey, G.R., Darnell, S.B., Schassburger, R.L., Cha, J.H., Pierce, R.C., Sadri-Vakili, G., 2011. Increased brain-derived neurotrophic factor (BDNF) expression in the ventral tegmental area during cocaine abstinence is associated with increased histone acetylation at BDNF exon I-containing promoters. J. Neurochem. 120, 202-209.

Sultan, F.A., Day, J.J., 2011. Epigenetic mechanisms in memory and synaptic function. Epigenomics 3, $157-181$.

Wang, X., Ratnam, J., Zou, B., England, P.M., Basbaum, A.I., 2009. TrkB signaling is required for both the induction and maintenance of tissue and nerve injury-induced persistent pain. J. Neurosci. 29, 5508-5515. 


\section{Figures and legends.}

A

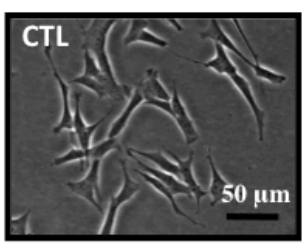

Differentiation

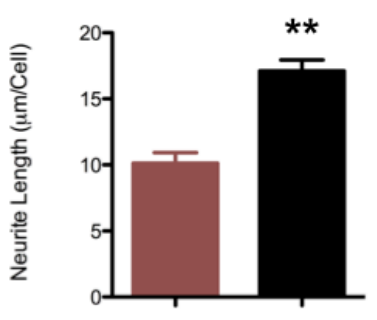

CTL

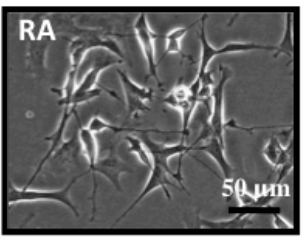

Survival

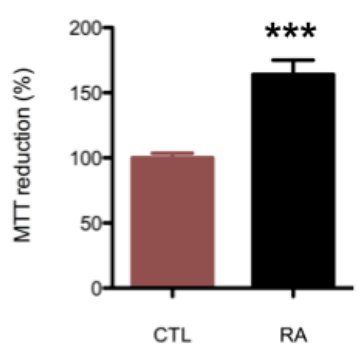

B

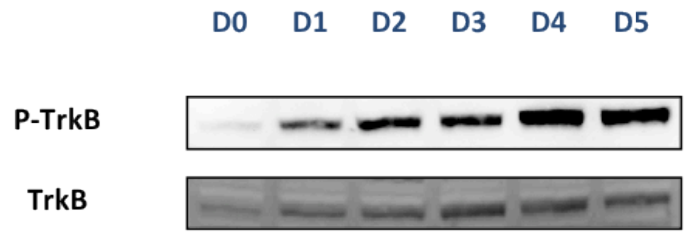

TRKB

BDNF

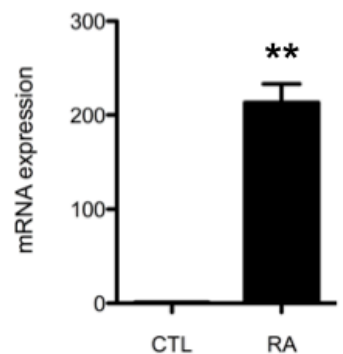

Figure 1. TrkB receptor is essential for SH-SY5Y cells differentiation and survival.

(A) SH-SY5Y cells were treated with RA $(10 \mu \mathrm{M})$ or kept in normal culture medium for 5 days. Representative micrographs of 3 independent experiments are shown in the top panel (scale bar $=50 \mu \mathrm{m})$. Neurite extensions, measured using the Neuron J plug-in of Image J software, are expressed as mean length $(\mu \mathrm{m})$ per cell (bottom panel left). SH-SY5Y cell viability after 5 days of RA was determined by a MTT assay (bottom panel right). (B) Western Blot analysis of SH-SY5Y cells treated for 1, 2, 3, 4 or 5 days (D1, D2, D3, D4 and D5) with $10 \mu \mathrm{M}$ of RA. A representative picture from 3 independent experiments is shown. TRKB and BDNF mRNA expressions after 5 days of RA treatment are depicted in the bottom panel. Data are expressed as mean + SEM of triplicate determinations in 3 independent experiments. $* * \mathrm{p}<0.01, * * * \mathrm{p}<0.001$ vs. CTL; Student's t test. 

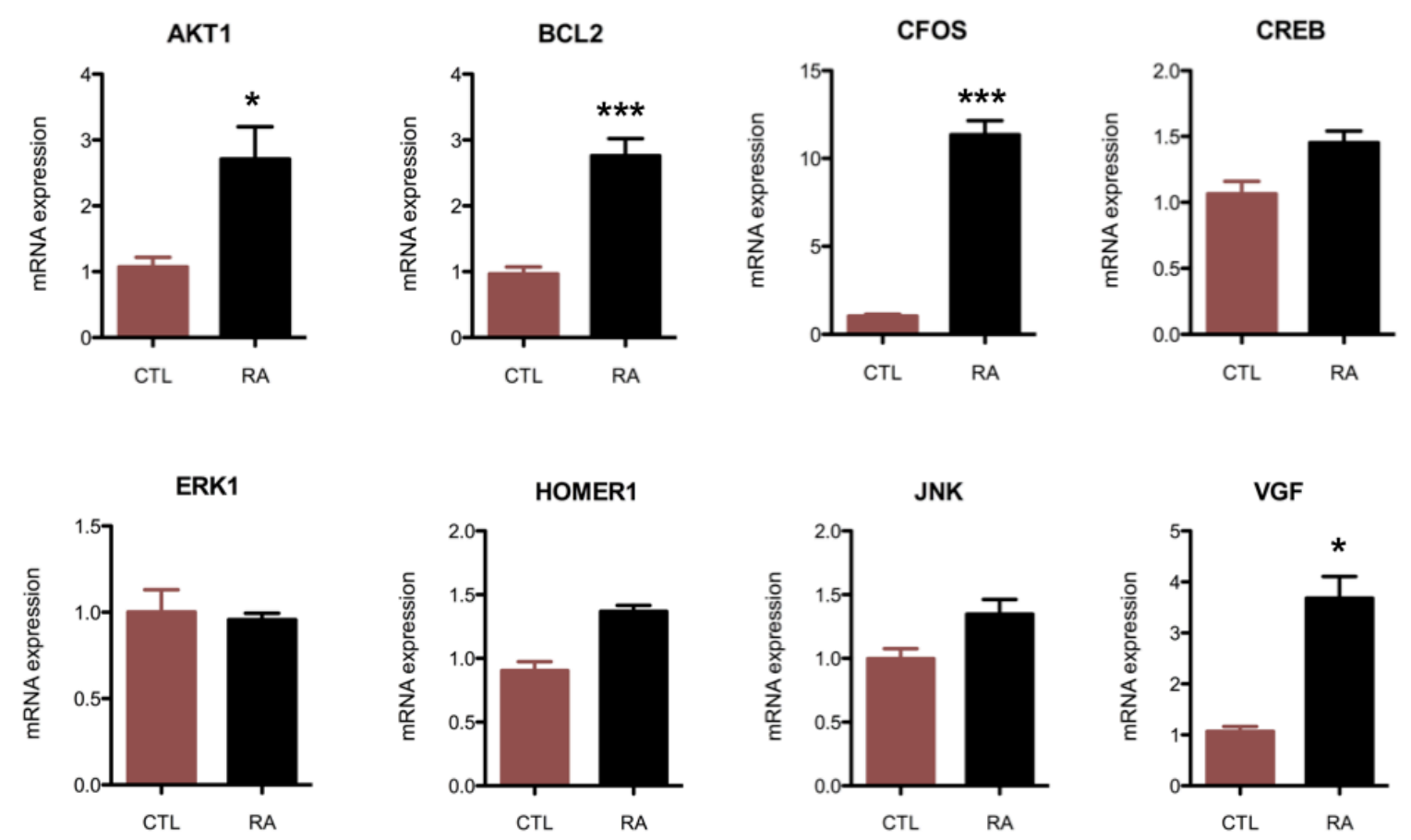

Figure 2. Effects of RA treatment on the expression of genes involved in TrkB-mediated neuroplasticity.

SH-SY5Y cells were treated with RA $(10 \mu \mathrm{M})$ or maintained under normal control conditions for 5 days before RTqPCR determinations of mRNAs. The fold changes evoked by RA are expressed with respect to non-treated cells (CTL). Each bar is the mean + SEM of two representative experiments performed in triplicate. ${ }^{*} \mathrm{p}<0.05, * * p<$ $0.01, * * * \mathrm{p}<0.001$ vs. CTL; Student's t test. 

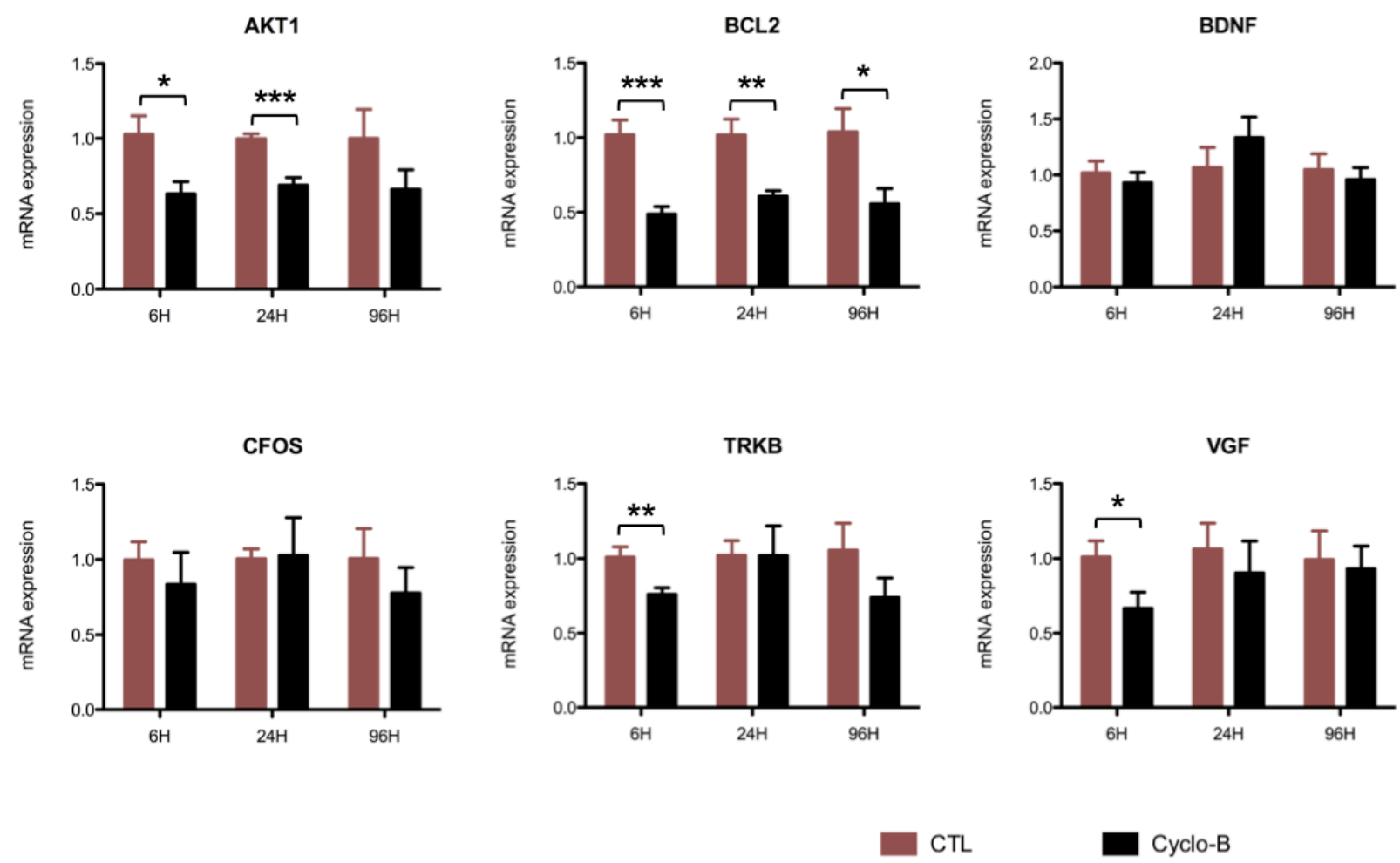

Figure 3. Gene expression profiles after TrkB inhibition in differentiated cells.

Differentiated SH-SY5Y cells were exposed to $1 \mu \mathrm{M}$ of cyclotraxin-B (Cyclo-B) for 6, 24 or 96 hours. Exposure for 96 hours corresponded to 4 successive administrations, every 24 hours. Cyclotraxin-B-induced effects on mRNA expression are expressed as fold changes in respective mRNA levels compared to the non-treated conditions (CTL). Each bar is the mean + SEM of two representative experiments performed in triplicate. ${ }^{*} \mathrm{p}<0.05,{ }^{* *} \mathrm{p}<0.01,{ }^{* * *} \mathrm{p}$ $<0.001$ vs. CTL; Student's t test. 

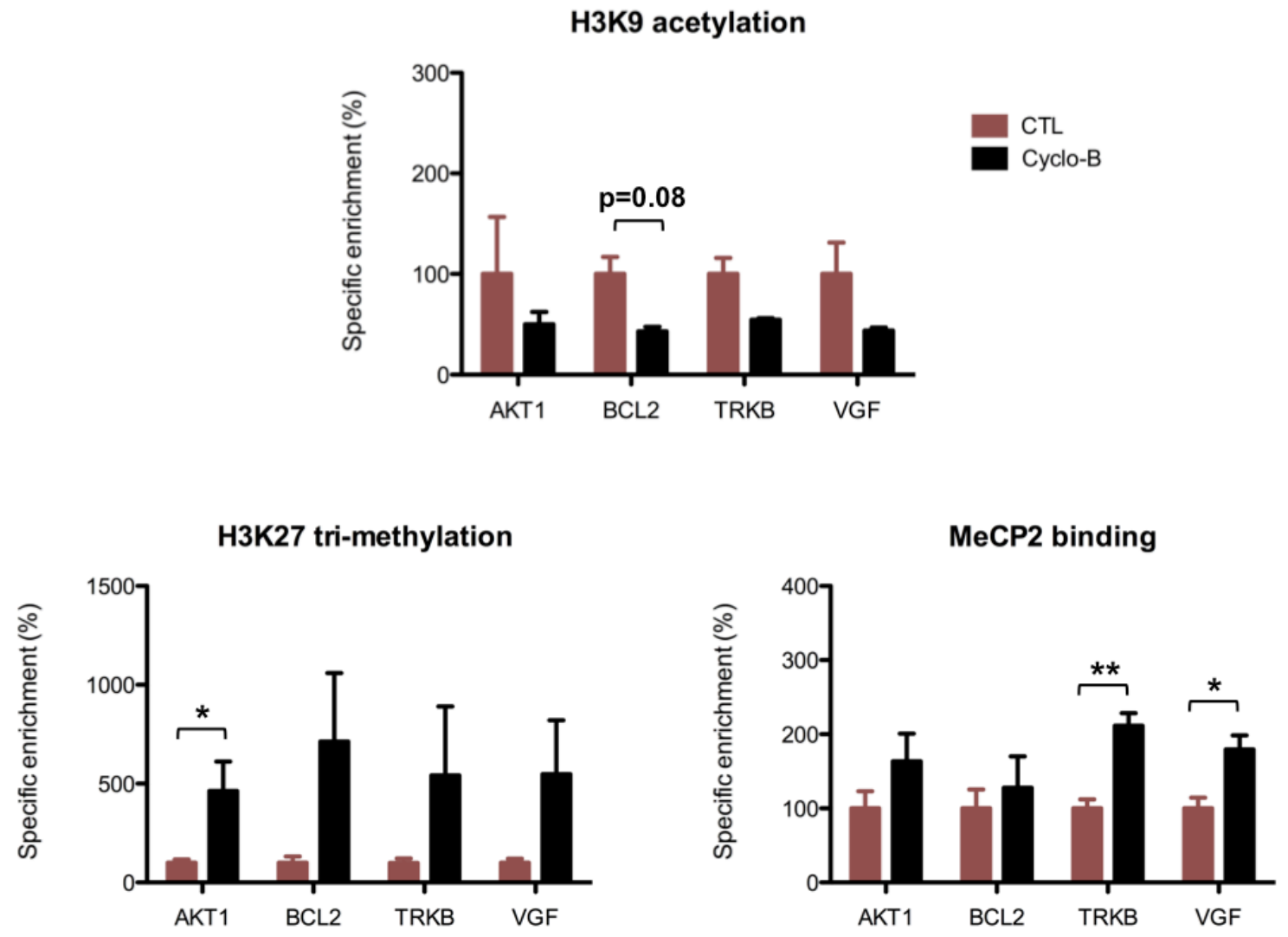

Figure 4. Epigenetic expression profiles after TrkB inhibition in differentiated cells.

Differentiated SH-SY5Y cells were exposed to $1 \mu \mathrm{M}$ of cyclotraxin-B (Cyclo-B) for 96 hours, corresponding to 4 successive administrations for 24 hours each. The specific enrichment of H3K9ac, H3K27me3 and MeCP2 at corresponding genes is expressed as percentage of non-treated conditions (CTL). Each bar is the mean + SEM of 3 independent determinations. ${ }^{*} \mathrm{p}<0.05,{ }^{* *} \mathrm{p}<0.01$ vs. CTL; Student's t test. 


\section{Supplementary Material.}

Gene Abbreviation

AKT1
BCL2
BDNF
CREB1
CFOS
HOMER1
HPRT
MAPK3
RS27A
TRKB

Forward primer

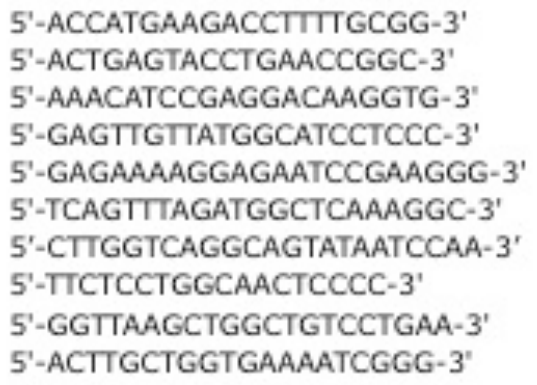

Reverse primer

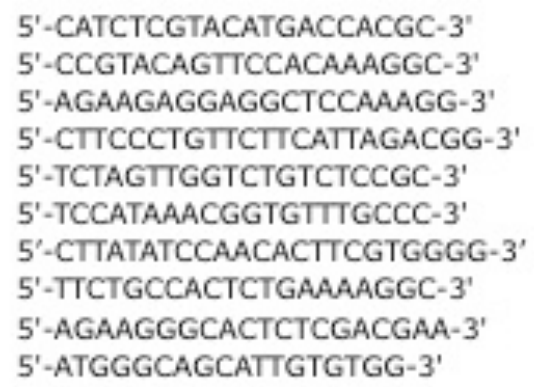

Table S1. Sequences of primers used for real time quantitative RT-PCR.

\section{Gene Abbreviation}

AKT1
BCL2
TRKB
VGF

Forward primer

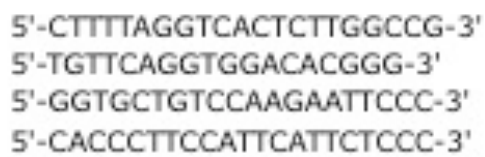

Reverse primer

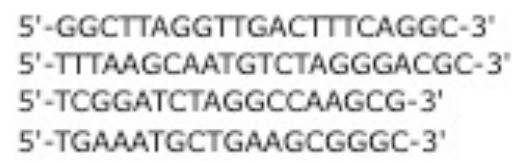


Chapter V

122 


\title{
CHAPTER VI
}

\section{Long-term behavioral and neurobiological consequences of developmental exposure to fluoxetine in a rodent model of maternal adversity}

\author{
FABIEN BOULLE ${ }^{1,2}$, JOdY L PAWLUSKI $^{1,3^{*}}$, BARBIE MACHIELS ${ }^{1}$, NEHA KUMAR $^{5}$, HARRY W STEINBUSCH $^{1}$, \\ LAURENCE LANFUMEY ${ }^{2}$, GUNTER KENIS ${ }^{1}$, DANIEL L.A VAN DEN HOVE ${ }^{1,4}$
}

*These authors contributed equally to this work

${ }^{I}$ School for Mental Health and Neuroscience (MHeNS), Maastricht University, European Graduate School of Neuroscience (EURON), Universiteitssingel 50, P.O. box 616, 6200 MD, Maastricht, The Netherlands

${ }^{2}$ Center for Psychiatry and Neuroscience, INSERM U894, University Pierre and Marie Curie, Paris, France

${ }^{3}$ University of Liege, GIGA-Neurosciences, 1 avenue de l'Hôpital (Bat. B36), B-4000 Liège, Belgium

${ }^{4}$ Molecular Psychiatry, Department of Psychiatry, Psychosomatics and Psychotherapy, University of Wuerzburg, Fuechsleinstrasse 15, 97080 Wuerzburg, Germany

In preparation 


\begin{abstract}
There is a growing use of selective serotonin reuptake inhibitor (SSRIs) medications for treatment of depression during pregnancy and the postpartum period. However, very little research has investigated the long-term effects of perinatal SSRI exposure on offspring development. The aim of the present study was to determine the role of developmental fluoxetine exposure on affect-related behaviors and associated molecular mechanisms in adult male and female offspring using a rodent model of maternal adversity. For this purpose, gestationally stressed and non-stressed Sprague-Dawley rat dams were treated with either fluoxetine $(5 \mathrm{mg} / \mathrm{kg} /$ day) or its vehicle from postnatal day 1 (P1) to postnatal day 21 (P21). At adulthood, male and female offspring were assessed for anxiety- and depressive-like behaviors, and after sacrifice, epigenetic regulation of hippocampal brain-derived neurotrophic factor (BDNF) signaling was investigated. Results show that among male offspring, maternal fluoxetine exposure increased anxiety in naïve animals, while it decreased anxiety in prenatally stressed offspring. Moreover, among male offspring, exposure to prenatal stress increased depressive-like behavior, whereas among females, fluoxetine exposure, independent of maternal adversity, profoundly increased depressive-like behavior in adulthood. In addition, developmental exposure to fluoxetine decreased BDNF exon IV mRNA levels, which was associated with increased levels of the repressive histone 3 lysine 27 tri-methylated (H3K27me3) mark at the corresponding promoter in female offspring. Altogether, these data provide important evidence on the long-term programming effects of early-life exposure to SSRIs on the regulation of adult mood-related behaviors and their underlying molecular mechanisms.
\end{abstract}

Keywords: Antidepressant, Prenatal stress, Mood, Serotonin, Epigenetics, BDNF 


\section{I - Introduction}

Selective serotonin reuptake inhibitor (SSRIs) medications are commonly used for the treatment of maternal mood disorders with up to $10 \%$ of pregnant women being prescribed these medications (Cooper et al., 2007; Oberlander et al., 2006; Ververs et al., 2006). SSRIs cross the placental barrier and are present in breast milk and, therefore, can affect development (Homberg et al., 2010; Kristensen et al., 1999; Rampono et al., 2004). Recent clinical studies reported that neonates exposed to SSRI medications during gestation have an increased risk for complications at birth such as low birth weight, younger gestational age, and reduced heart rate variability (Moses-Kolko et al., 2005; Nulman et al., 2002; Oberlander et al., 2009). In addition, clinical reports in infants also showed that prenatal exposure to SSRI-medications may alter neurodevelopment as evidenced by alterations in S100B levels (Pawluski et al., 2009), alter serotonergic system functioning (Laine et al., 2003), and the actions of the hypothalamicpituitary-adrenal (HPA) system (Oberlander et al., 2009; Oberlander et al., 2008; Pawluski et al., 2011; Pawluski et al., 2012b). Although there is limited clinical evidence on the long-term outcomes of developmental exposure to SSRI medications on mood-related outcomes in children, preclinical research is showing that perinatal exposure to SSRIs can impact upon measures of mood and HPA physiology in juvenile and adult offspring (Noorlander et al., 2008; Pawluski et al., 2012b; Rayen et al., 2011). Studies in rodent models have shown that there is a well-documented increase in anxiety-like behavior in adult male rodents perinatally exposed to fluoxetine (Ansorge et al., 2004; Noorlander et al., 2008; Karpova et al., 2009; Smit-Rigter et al., 2012; Lee et al., 2009). Interestingly, the reverse is true in female offspring, with a recent report showing that perinatal exposure to fluoxetine decreases anxiety- and depressive-like behaviors in adult female offspring (McAllister et al., 2012). Nevertheless, the molecular pathways underlying neurodevelopmental changes and long-term behavioral effects of early-life SSRIs exposure are still poorly understood. Serotonin plays an important role in the development of the brain modulating neuronal differentiation, axon guidance or dendritic pruning (Gaspar et al., 2003; Homberg et al., 2010). Conversely, administration of SSRIs, possibly by increasing the levels of serotonin at the synapse, is known to enhance brain-derived neurotrophic factor (BDNF) levels and promote neuroplasticity (Castren et al., 2008).

Brain-derived neurotrophic factor (BDNF) is a small-secreted protein known to be critically involved in the regulation of neuronal plasticity, and alterations of BDNF signaling have been extensively implicated in the pathophysiology and treatment of mood disorders (Castren et al., 2010). Accordingly, a recent study showed that early postnatal administration of fluoxetine could induce long-lasting behavioral impairment, accompanied with changes in hippocampal BDNF mRNA levels in adult mice (Karpova et al., 2009). Similarly, epigenetic changes at the BDNF gene in adulthood have been associated with mood disorders (Boulle et al., 2012). Furthermore, serotonin transporter (5-HTT) knockout rats displayed decreased BDNF levels in the hippocampus and frontal cortex, concomitant with epigenetic dysregulation at the BDNF gene - i.e. increased DNA methylation at BDNF promoters IV and VI (Molteni et al., 2010). 
Interestingly, mounting evidence suggest that early-life experience, including environmental adversity, reduced maternal care and exposure to toxins, can induce epigenetic reprogramming and increase the susceptibility for the development of mood disorders in adulthood (Onishchenko et al., 2008; Roth et al., 2009; Weaver et al., 2004).

The aim of the present study was to investigate the long-term molecular and behavioral consequences of developmental administration of fluoxetine, a popular SSRI regularly used during pregnancy and the post-partum period. Since perinatal maternal stress and depression itself can have marked, sex-dependent effects on the development of mood disorders and stress regulation (Morley-Fletcher et al., 2003; Maccari et al., 2007; Van den Hove et al., 2013), it is also important to investigate the effects of SSRIs using a model of maternal adversity (Ishiwata et al., 2005; Van den Hove et al., 2008; Pawluski., 2011). Hence, we explored the effects of maternal fluoxetine using a model of prenatal stress in rat, and focused particularly on measures related to affective behavior, HPA axis responsivity as well as epigenetic regulation of hippocampal BDNF signaling in adult male and female offspring.

\section{II - Material and methods}

Animals and procedures: All experiments were approved by the Animal Ethics Board of Maastricht University in accordance with Dutch governmental regulations (DEC 2008-157 and 2008-158). All efforts were made to minimize the pain and stress levels experienced by the animals. Thirty-eight adult female Sprague-Dawley rats (250-300 g; Charles River Laboratories, France) were used in the present study. Females were initially housed in pairs in opaque polyurethane bins $(48 \mathrm{~cm} \times 27 \mathrm{~cm} \times 20 \mathrm{~cm})$ with ad libitum access to rat chow (Sniff, The Netherlands) and tap water. Rats were kept under standard laboratory conditions in a $12 \mathrm{~h}: 12 \mathrm{~h}$ light/dark schedule (lights on at 07:00 h). Pregnancy was determined by observation of vaginal plugs (embryonic day 0 - E0). Restraint stress was performed daily during the last week of pregnancy (E14-E21). Pregnant female rats $(n=18)$ were individually restrained 3 times a day (at approximately 9.00, 13.00, and $17.00 \mathrm{~h}$ ) for 45 minutes in transparent plastic cylinders, whilst being exposed to bright light (Van den Hove et al., 2005; Ward and Weisz, 1984). Control pregnant females $(n=20)$ were left undisturbed in their home cages. Only litters of 10 or more pups were included in this study. Litters were culled to 10 pups if necessary ( 5 males and 5 females). Dams were randomly assigned to one of two treatment groups: fluoxetine $(5 \mathrm{mg} / \mathrm{kg} / \mathrm{day})$ or vehicle, for a total of four groups of dams: (1) No stress + Vehicle (NS VEH), (2) No stress + Fluoxetine (NS FLX), (3) Prenatal Stress + Vehicle (PNS VEH), (4) Prenatal Stress + Fluoxetine (PNS FLX). A maximum of 2 male and female pups per litter were examined to prevent litter effects (Chapman and Stern, 1978). At postnatal day 21 (P21), pups were weaned and group-housed for further examination ( 2 male or 2 female rats/cage; $n=12-16$ rats per experimental condition per sex). Rats were kept at a reversed day-night cycle from this point onwards 
(lights on from $17.00-5.00 \mathrm{~h}$ ). Anxiety- and depression-related behavior of the rats was analyzed from P140 onwards (in the order as discussed below). At P196, the animals were killed by quick decapitation.

Fluoxetine treatments: Fluoxetine and its active metabolite, norfluoxetine, can pass to offspring through lactation (Gentile et al., 2007), therefore fluoxetine treatment was administered via osmotic minipumps (Alzet Osmotic pumps, 2ML4) to the dams as previously described (Rayen et al., 2011). Implants were filled with either fluoxetine- $\mathrm{HCl}$ (Fagron, Belgium) dissolved in vehicle (50\% propylenediol in saline; $5 \mathrm{mg} / \mathrm{kg} /$ day), or with vehicle as previously described (Pawluski et al., 2012a). Minipumps were implanted subcutaneously in the dorsal region of the dams while the dams were under mild isofluorene anaesthesia on post-partum day 1 (P1). Implants took a maximum of $20 \mathrm{~min}$ and therefore dams were separated from their litters for a maximum of $20 \mathrm{~min}$. Fluoxetine exposure to offspring occurred during a stage of neural development in rodents analogous to that of the third trimester in humans (Romijn et al., 1991).

\section{Behavioral testing:}

\section{Open field test (OFT)}

The open field test (OFT) was conducted in a square Plexiglas base $(100 \times 100 \mathrm{~cm})$ with a black floor and transparent plexiglas walls (40 cm high; Van den Hove et al., 2013). The arena was subdivided into a $60 \mathrm{x}$ $60 \mathrm{~cm}$ central zone, $20 \times 20 \mathrm{~cm}$ corners and $60 \times 20 \mathrm{~cm}$ walls. Immediately after the rat had been placed in the centre of the open field, the movements of the animal were scored automatically under low light conditions using a camera connected to a computerized system (Ethovision Pro, Noldus, The Netherlands). Both the time spent in the different zones and total distance moved were scored. After five minutes, the rat was removed from the apparatus and the maze was cleaned with ethanol (70\%) and water and dried thoroughly to prevent transmission of olfactory cues.

\section{Forced swim test (FST)}

In the forced swimming test (FST), originally designed by Porsolt and colleagues (2006), four cylindrical glass tanks $\left(50 \mathrm{~cm}\right.$ tall, $20 \mathrm{~cm}$ in diameter) were filled to a height of $30 \mathrm{~cm}$ with $25^{\circ} \mathrm{C}$ water. The movements of the rat were scored automatically with a computerized system (Ethovision Pro, Noldus, The Netherlands) during a 10 min session under low light conditions. Scored were 'immobility', which reflects no movement at all and/or minor movements necessary to keep the nose above the water, and 'strong mobility', reflecting 'escape behavior' (e.g. climbing against the walls and diving). Settings within Ethovision were adjusted based on manually recorded sessions and were attuned for each sex separately (immobility/mobility threshold: 12 and 20; mobility/strong mobility threshold: 16.5 and 23.9 for males and females, respectively (Strackx et al., 2009; Van den Hove et al., 2013). 
The elevated zero maze (EZM) introduced by Shepherd and colleagues (1994) consisted of a circular alley (diameter of $100 \mathrm{~cm}$; path width $10 \mathrm{~cm}$ ) made from black plastic material that was transparent for infrared light and elevated $20 \mathrm{~cm}$ above the floor. The maze was divided into four parts, i.e., two opposite open parts and two opposite closed parts with sidewalls $30 \mathrm{~cm}$ in height. The open parts (open arms; OA) had borders with a height of $5 \mathrm{~mm}$ to prevent the rat from stepping down from the apparatus. For the test, the rat was placed into one of the open parts facing a closed part (closed arms; CA) of the apparatus. After five minutes the rat was removed from the apparatus and the maze was cleaned with ethanol $(70 \%)$ and water and dried thoroughly. The movements of the rat were scored automatically under dark conditions with a computerized system using an infrared video camera (Ethovision Pro, Noldus, The Netherlands). Percentage of time spent in the open part of the maze and total distance traveled were determined as described previously (Van den Hove et al. 2013).

Corticosterone response and radioimmuno assay: To test the HPA axis responsivity, rats were individually placed in a type II (mouse) cage filled with $500 \mathrm{ml} 25^{\circ} \mathrm{C}$ water. Experiments were performed in an isolated room between 09.00 and $13.00 \mathrm{~h}$. Immediately after taking the rat from its home cage, a first blood sample was collected via a saphenous vein puncture representing the basal corticosterone level. Immediately after this first sample was taken, the rat was put in the cage filled with water for 20 min after which a second blood sample was taken. Afterwards, the animal was returned to its home cage and left undisturbed for $40 \mathrm{~min}$ after which a final blood sample was taken. Blood samples were kept on ice and centrifuged at $5000 \mathrm{rpm}$ for $10 \mathrm{~min}$ at $4{ }^{\circ} \mathrm{C}$, after which the plasma was frozen down to $-75{ }^{\circ} \mathrm{C}$ for subsequent determination of corticosterone levels. Samples were run in duplicate using a commercially available radioimmunoassay (RIA) kit for rat corticosterone from MP Biomedicals (Corticosterone I-125 for rats and mice, MP Biomedicals), as explained previously (Van den Hove et al., 2013). The average intra- and inter-assay coefficients of variation for all assays were below $10 \%$. The assay had a sensitivity of $7.7 \mathrm{ng} / \mathrm{mL}$.

Quantitative reverse transcriptase PCR (qRT-PCR): Total mRNA extraction was performed using RNeasy lipid tissue mini kit (Qiagen, Venlo, The Netherlands), after which, cDNA synthesis was performed using a First Strand cDNA synthesis kit (Fermantas International Inc. Canada) according to the manufacturer's protocol. Amplification was performed using SYBR green I Master Mix (Roche Diagnostic, IN, USA). Primer sequences are indicated in Table S1. Gene expression analysis was performed with the LightCycler 480 Real-Time PCR System (Roche Applied Science, IN, USA) and the conditions for the reaction involved 35 cycles in a fixed sequence of $95^{\circ} \mathrm{C}$ for $30 \mathrm{~s}, 62^{\circ} \mathrm{C}$ for $15 \mathrm{~s}$, and $72^{\circ} \mathrm{C}$ for $15 \mathrm{~s}$. Gene expression was normalized using HPRT and RS27A as reference genes. 
Chromatin immunoprecipitation (ChIP): Since developmental exposure to fluoxetine markedly affected behavior and BDNF IV mRNA expression in females as compared to males, we decided to investigate the epigenetic regulation at BDNF promoters only in the female gender. Hippocampal tissues were fixed in a $1 \%$ formaldehyde solution, after which they were lysed in ice-cold SDS lysis buffer containing protease inhibitors (Roche, Meylan, France). The chromatin was sheared in order to obtain DNA fragments that were approximately between 400 and 800 base pairs. The solution of chromatin was pre-cleared with a mixture of protein A-agarose (Pierce, Thermo-Fischer, Illkirch, France) and salmon sperm (Agilent technologies, CA, USA), and then immunoprecipitated overnight at $4^{\circ} \mathrm{C}$ with $2 \mu \mathrm{g}$ of rabbit anti-H3K9ac, mouse anti-H3K27me3 (Millipore, Molsheim, France) or rabbit anti-MeCP2 (Sigma Aldrich, MO, USA) antibodies. After intensive washing, the immunoprecipitate was eluted from the beads using a $1 \%$ SDS elution buffer and the protein-DNA cross-links were removed by incubating the samples overnight at $65^{\circ} \mathrm{C}$ in the presence of $5 \mathrm{M} \mathrm{NaCl}$. DNA fragments were then treated with proteinase $\mathrm{K}$ in order to digest the proteins, after which DNA was isolated using phenol/chloroform/isoamyl alcohol and subsequently precipitated with $100 \%$ ethanol and $20 \mu \mathrm{g}$ of glycogen. Fragments of promoter regions of target genes were quantified by quantitative PCR (see Table S2 for primer sequences and design). Ct values of immunoprecipitated samples were normalized to $\mathrm{Ct}$ values obtained from Input DNA. The specificity of the antibodies used in the experiments was determined by immunoprecipitation of the sample with nonspecific HA-probe (Y-11) antibody (Santa Cruz Biotechnology Inc, CA, USA).

Statistical analysis: Because of profound expected sex and experimental condition interactions (e.g. Van den Hove et al., 2013; Zuena et al., 2008), parameters studied in the offspring were analyzed for each sex separately using a two-way analysis of variance (ANOVA; condition $\mathrm{x}$ treatment). Plasma corticosterone levels were analyzed by a repeated measures ANOVA (experimental condition $\mathrm{x}$ time) and also independently at the different time points using ANOVA. Statistical significance was assumed to exist at $\mathrm{p} \leq 0.05$. All statistics were carried out using SPSS software version 17 (SPSS Inc, USA).

\section{III - Results}

\section{Effect of prenatal stress and maternal fluoxetine on affective behaviors:}

\section{Elevated Zero Maze (EZM)}

The time spent in the open arms and the distance covered in the EZM are depicted in Figure 1. In addition, the frequency to visit the open and closed arms is shown in Table S3. No differences were found in terms of the time spent in the open arms or the frequency of open arm visits in the EZM. 
Among males, a significant condition $\mathrm{x}$ treatment interaction was observed regarding the distance traveled within the EZM $[\mathrm{F}(3,51)=4.038 ; \mathrm{p}=0.05]$, indicating that FLX exposure decreased the distance traveled in naïve animals, while it increased the distance moved in animals previously exposed to PNS. Among females, there was significant condition $\mathrm{x}$ treatment interaction effect regarding the distance traveled within the EZM $[\mathrm{F}(1,52)=3.99, \mathrm{p}=0.05]$.

\section{Open Field Test (OFT)}

Time spent in the various zones of the open field as well as the number of visits to the center and the total distance covered in the OFT are shown in Figure 2 and Figure S4.

Among males, a significant condition $\mathrm{x}$ treatment interaction was observed on the number of visits to the center of the open field $[\mathrm{F}(1,51)=5.04 ; \mathrm{p}=0.029]$, with $\mathrm{FLX}$ decreasing the number of visits to the center in naïve animals and increasing the frequency of visits to the center in prenatally stressed offspring (NS FLX $<$ PNS FLX; $p=0.024)$. Similarly, regarding the distance traveled within the open field, a tendency towards a condition $x$ treatment interaction was observed in adult males $[F(1,51)=3.48 ; p=0.067]$, indicating that FLX exposure differentially affected distance traveled in NS versus PNS adult male offspring.

Among females, PNS exposure tended to increase time spent along the walls $[\mathrm{F}(1,52)=3.78 ; \mathrm{p}=0.057]$ of the open field. There were no other significant effects observed in any of the other parameters.

\section{Forced Swim Test (FST)}

Results from the FST are shown in Figure 3. Among males, a significant effect of PNS on strong mobility in the FST was found $[F(3,51)=4.09 ; \mathrm{p}=0.048]$, indicating that PNS increased escape-like behavior i.e. struggling in this behavioral test.

Among females, a significant treatment effect was observed $[F(1,52)=11.48 ; p=0.001]$, indicating increased immobility after FLX exposure, independent of prenatal stress experience (NS VEH < NS FLX; $\mathrm{p}=0.016$ and PNS VEH $<$ PNS FLX; $\mathrm{p}=0.025)$.

\section{Effects of prenatal stress and maternal fluoxetine on biological parameters:}

\section{Weight and corticosterone response}

Plasma corticosterone levels prior to restraint, immediately after $20 \mathrm{~min}$ of restraint stress, and $40 \mathrm{~min}$ after being placed back into the home cage are depicted in Figure S2. As expected, there was a significant main effect of time in both males $(F(2,36)=71.215, p<0.001)$ and females $(F(2,38)=72.284, p<0.001)$ showing that $20 \mathrm{~min}$ after restraint stress plasma corticosterone levels were elevated. There were no other significant differences with treatment in males or females in corticosterone levels $(0.2<p<0.9)$. 
In addition, the weight of the animals was modified neither by developmental fluoxetine exposure nor than maternal adversity in male and female offspring (Figure S3).

\section{Gene expression in the hippocampus}

Hippocampal gene expression profiles are shown in Figure 4 and Table S4. Among males, a significant effect of FLX treatment on BDNF IV and tropomyosin-related kinase receptor B (TrkB) mRNA levels was observed $[F(1,51)=5.57 ; p=0.022$ and $F(1,51)=7.21 ; p=0.0098$ respectively], indicating that FLX decreased both BDNF IV and TrkB mRNA levels. In addition, BDNF IV mRNA levels were decreased in animals exposed to PNS (PNS VEH $<$ NS VEH; $p=0.041$ ). Finally, there was a tendency towards a stress $\mathrm{x}$ treatment interaction for BDNF IX mRNA levels $[\mathrm{F}(1,51)=4.30 ; \mathrm{p}=0.043]$.

Among females, there was a significant effect of PNS exposure on BDNF IV mRNA levels $[F(1,47)=8.34 ; p=0.0058]$. Accordingly, BDNF IV mRNA expression was increased in the hippocampus of female rats exposed to PNS (NS VEH $<$ PNS VEH; $p=0.018$ ). Finally, there was a significant effect of FLX exposure on BDNF IV mRNA levels $[\mathrm{F}(1,47)=5.01 ; \mathrm{p}=0.030]$, pointing towards a global decrease of BDNF IV mRNA levels independent of prenatal stress experience.

\section{Epigenetic regulation of the BDNF gene}

The specific enrichments of methyl CpG binding protein 2 (MeCP2), histone 3 lysine 27 tri-methylated (H3K27me3) and histone 3 lysine 9 acetylated (H3K9ac) at the BDNF promoter IV and the BDNF promoter IX in female offspring are represented in Figure 5. There was a significant stress $\mathrm{x}$ treatment interaction for $\mathrm{H} 3 \mathrm{~K} 27 \mathrm{me} 3$ enrichment at the BDNF promoter IV $[\mathrm{F}(1,32)=6.35 ; \mathrm{p}=0.017]$. In addition, FLX treatment significantly increased the specific enrichment of H3K27me3 at the BDNF promoter IV (PNS VEH < PNS FLX; $\mathrm{p}=0.016$ ). Of note, a trend for PNS exposure to decrease the specific enrichment of H3K27me3 at the BDNF promoter IV (PNS VEH < PNS FLX; $\mathrm{p}=0.056$ ) was observed. Furthermore, a tendency for a treatment effect on MeCP2 specific enrichment at the BDNF promoter IV was observed $[F(1,30)=3.00 ; p=0.093]$, indicating that FLX tended to increase MeCP2 occupancy in this promoter region. It is interesting to note that $\mathrm{MeCP} 2$ binding at the BDNF promoter IV correlated with immobility score in the FST (Figure S7). Finally, a tendency for a stress $x$ treatment effect on H3K9ac specific enrichment was also reported $[F(1,30)=3.00 ; p=0.073]$, indicating that $F L X$ tended to increase H3K9ac at the BDNF promoter IX, while decreasing $\mathrm{H} 3 \mathrm{~K} 9 \mathrm{ac}$ at this same promoter.

\section{IV - Discussion}

Fluoxetine, an antidepressant belonging to the class of SSRIs, is widely used in the clinic for the treatment of mood disorders during pregnancy and the post-partum period (Cooper et al., 2007; Oberlander et al., 2006; Ververs et al., 2006). However, the long-term effects of early-life treatment with this medication are still poorly understood. In this context, the aim of the present study was to investigate 
the long-term effects of developmental fluoxetine exposure using a model of maternal adversity, at the level of anxiety and depression-related behavior, HPA axis responsivity and epigenetic regulation of $\mathrm{BDNF} / \mathrm{TrkB}$ signaling in adult male and female offspring.

Effect of prenatal stress and maternal fluoxetine on affective behavior and HPA response: Our data showed that maternal adversity tended to increase depressive-like behavior in male offspring, whereas, among females, no effects of prenatal stress on depressive-like or anxiety-like behaviors were observed. Those results are in accordance with previous studies that reported similar observation in male and females offspring prenatally exposed to maternal stress, and further support a sex-dependent effect of perinatal maternal stress on mood-related behaviors (Van den Hove et al., 2013).

Further, among male offspring, maternal fluoxetine exposure increased anxiety in naïve animals, while it decreased anxiety in prenatally stressed offspring. Increase in anxiety behavior following perinatal exposure to fluoxetine has been well documented in male rodents (Ansorge et al., 2004; Ansorge et al., 2008; Noorlander et al., 2008; Karpova et al., 2009; Smit-Rigter et al., 2012; Lee et al., 2009). However, the present study was one of the first to investigate the long-term effects of fluoxetine using a model of maternal adversity. Accordingly, this work shows that the effects of developmental exposure to SSRI medications may profoundly differ when using healthy dams and offspring in comparison to using a model of maternal adversity. This notion may have important implications when examining e.g. the longterm behavioral effects (and its neurobiological underpinnings) of early life SSRI exposure.

On the other hand, among females, fluoxetine exposure profoundly increased depressive-like behavior in adulthood, independent of maternal adversity. This finding is of particular interest because it demonstrates that the effects of developmental SSRI exposure are strongly sex- and age-dependent, as we have previously shown, using the exact "fluoxetine-maternal adversity model" that developmental fluoxetine exposure was able to reverse the effects of prenatal maternal stress on depressive-like behavior in adolescent male and female offspring (Rayen et al., 2011), i.e. pointing towards overall beneficial effects of perinatal SSRI exposure. Here, we provide clean-cut evidence that early-life exposure to SSRIs negatively impacts upon mood-related behaviors in adult female offspring.

Nevertheless, previous findings using the exact prenatal stress procedures found an alteration in HPA axis responsivity, showing that male offspring prenatally exposed to maternal restrain stress displayed a significant alteration in basal and stress-induced corticosterone secretion (Van den Hove et al., 2013). The discordance between this study and previous reports may be attributed to the implantation minipump. Such type of surgery might represent additional stress for the mothers and result in differential outcome in the neuroendocrine measures.

Effect of prenatal stress and maternal fluoxetine on BDNF/TrkB signaling: To further understand the molecular pathways underlying behavioral dysfunction in male and female offspring prenatally exposed to fluoxetine, we examined the hippocampal expression of BDNF/TrkB downstream target genes. BDNF 
IV mRNA levels were decreased in males prenatally exposed to stress, whereas the opposite was observed in females. The literature on prenatal stress and BDNF expression is not very consistent, and the timing, duration and intensity of stress as well as the species or strain of animals used seems to meticulously interfere with this biological parameter (Roceri et al., 2002; Karpova et al., 2009; Neeley et al., 2011). The present findings indicate that distinct mechanisms are implicated in the adaptation and response to stress in male versus female offspring, leading to differential BDNF expression. Moreover, maternal fluoxetine decreased BDNF IV mRNA levels only in naïve male offspring. Similarly, the mRNA levels of TrkB, the high-affinity receptor for BDNF, were decreased in naïve male offspring exposed to maternal fluoxetine. These findings, together with the observation that maternal fluoxetine increased anxiety-like behavior in naïve male offspring, support the notion that BDNF/TrkB signaling plays an important role in anxiety regulation (Chen et al 2006; Martinowich et al., 2007).

Moreover, maternal fluoxetine decreased BDNF IV mRNA levels independently of exposure to prenatal stress in female offspring, an observation that correlated with the increased despair-like behavior found in the FST. A decrease of BDNF in the hippocampus has been reported in post-mortem brain analysis of suicide victims (Dwivedi et al., 2003; Pandey et al., 2008), and rodent models of stress and depression also showed similar decrease of BDNF expression, including reduced levels of BDNF exon IV and exon IX (Tsankova et al., 2006; Onishchenko et al., 2008; Fuchikami et al., 2009). BDNF expression is tightly regulated at the level of transcription with differential exon usage, suggesting a crucial role for the various transcripts in different functions and related processes (Pruunsild et al., 2007; Baj et al., 2011). More specifically, the BDNF IV transcript was shown to be involved in the regulation of the stress response, and in the mechanism of action of antidepressants (Boulle et al., 2012). Interestingly, fluoxetine treatment in adulthood has been shown to increase BDNF levels (including BDNF IV mRNA levels) in corticolimbic structures to induce antidepressant and anxiolytic effects in rodents (Martinowich et al., 2007). Data from the current study suggest that the molecular mechanisms involve in early-life versus adulthood intervention with fluoxetine are distinct. This can partly be explained by the fact that during postnatal development, certain populations of neurons express a transient serotonergic phenotype that no longer exists at adulthood, and the modulation of this partial serotonin system might interfere with the finetuning process of neuronal networks (Cases et al., 1998; Gaspar et al., 2003). Moreover, fluoxetine was shown to interact with several targets including serotonin receptors $(2 \mathrm{~A}, 2 \mathrm{C}$ and $2 \mathrm{~B})$ and ion channels (Mostert et al., 2008), next to the serotonin transporter. Hence, the differential patterns of expression of these systems in early-life might be determinant in the long-term biological action of fluoxetine.

Epigenetic regulation of BDNF/TrkB siganling in female offspring: Since maternal fluoxetine mostly affected long-lasting behavioral and molecular measures in female offspring, we conducted additional investigations in this sex to test whether the observed alterations could be attributed to epigenetic programming. Developmental experiences have been shown to modulate post-translational histone 
modifications and DNA methylation, thereby altering the epigenetic program and leading to long-lasting neurochemical changes causally related to adult psychopathology (Onishchenko et al., 2008; Weaver et al., 2004). In addition, increasing evidences suggest that epigenetic regulations are involved in the molecular mechanisms of action of antidepressant drugs, including SSRIs (Vialou et al., 2013). In the present study, maternal fluoxetine tended to increase MeCP2 binding at BDNF promoter IV in female offspring, independent of prenatal stress exposure. $\mathrm{MeCP} 2$ has been shown to selectively bind to BDNF promoter IV to repress its transcription in post-mitotic neurons (Chen et al., 2003; Martinowich et al., 2003). In addition, this epigenetic regulator is essential in neurodevelopment (Gonzales et al., 2010), and increased $\mathrm{MeCP} 2$ binding and upregulation in the brain promoted anxiety in mice (Samaco et al., 2012). Furthermore, developmental fluoxetine increased H3K27me3 at the BDNF promoter IV in female offspring prenatally exposed to maternal adversity. $\mathrm{H} 3 \mathrm{~K} 27 \mathrm{me} 3$ is a repressive histone mark. Hence, this observation is in accordance with the decreased expression of BDNF IV mRNA in the hippocampus of female offspring. This finding is of particular interest because it indicates that the long-term neurochemical effects of developmental fluoxetine might reside in long-lasting epigenetic repression of gene transcription. Of note, this effect was observed only in female offspring prenatally exposed to stress, indicating that maternal adversity increased the vulnerability for fluoxetine-induced epigenetic reprogramming in the hippocampus.

Conclusion and perspectives: The number of children exposed to SSRI medications during development in constantly increasing (Oberlander et al., 2006; Cooper et al., 2007), and the long-term effects of such exposure are still to be determined. In this context, we showed that the developmental exposure to fluoxetine, a popular SSRI for post-partum depression, had negative impact on mood-related behaviors, which appeared to be strongly age- and sex- dependent. In addition, the effect on developmental fluoxetine may profoundly differ when using healthy dams and offspring in comparison to using a model of maternal adversity in rodents. Further, the present study brings novel insights into the long-term molecular regulations underlying developmental exposure to fluoxetine. To our knowledge, this study is the first one to demonstrate that maternal fluoxetine exposure could be associated with persistent epigenetic remodeling at BDNF/TrkB signaling in adulthood. Hence, our data support the idea that exposure to SSRI medications during development might have negative consequences on neurodevelopment and mood-related behavior in adulthood, which may be attributed, at least in part, to enduring epigenetic reprogramming in signaling pathways implicated in neuronal plasticity. 


\section{V - References}

Ansorge, M. S., Morelli, E. and Gingrich, J. A. (2008) Inhibition of serotonin but not norepinephrine transport during development produces delayed, persistent perturbations of emotional behaviors in mice. J Neurosci 28, 199207.

Ansorge, M. S., Zhou, M., Lira, A., Hen, R. and Gingrich, J. A. (2004) Early-life blockade of the 5-HT transporter alters emotional behavior in adult mice. Science 306, 879-881.

Baj, G., Leone, E., Chao, M. V. and Tongiorgi, E. (2011) Spatial segregation of BDNF transcripts enables BDNF to differentially shape distinct dendritic compartments. Proc Natl Acad Sci U S A 108, 16813-16818.

Boulle, F., van den Hove, D. L., Jakob, S. B., Rutten, B. P., Hamon, M., van Os, J., Lesch, K. P., Lanfumey, L., Steinbusch, H. W. and Kenis, G. (2012) Epigenetic regulation of the BDNF gene: implications for psychiatric disorders. Mol Psychiatry 17, 584-596.

Cases, O., Lebrand, C., Giros, B., Vitalis, T., De Maeyer, E., Caron, M. G., Price, D. J., Gaspar, P. and Seif, I. (1998) Plasma membrane transporters of serotonin, dopamine, and norepinephrine mediate serotonin accumulation in atypical locations in the developing brain of monoamine oxidase A knock-outs. J Neurosci 18, 6914-6927.

Castren, E. and Rantamaki, T. (2010) The role of BDNF and its receptors in depression and antidepressant drug action: Reactivation of developmental plasticity. Dev Neurobiol 70, 289-297.

Chapman, R. H. and Stern, J. M. (1978) Maternal stress and pituitary-adrenal manipulations during pregnancy in rats: effects on morphology and sexual behavior of male offspring. J Comp Physiol Psychol 92, 1074-1083.

Chen, W. G., Chang, Q., Lin, Y., Meissner, A., West, A. E., Griffith, E. C., Jaenisch, R. and Greenberg, M. E. (2003) Derepression of BDNF transcription involves calcium-dependent phosphorylation of MeCP2. Science 302, $885-889$.

Chen, Z. Y., Jing, D., Bath, K. G., Ieraci, A., Khan, T., Siao, C. J., Herrera, D. G., Toth, M., Yang, C., McEwen, B. S., Hempstead, B. L. and Lee, F. S. (2006) Genetic variant BDNF (Val66Met) polymorphism alters anxiety-related behavior. Science 314, 140-143.

Cooper, W. O., Willy, M. E., Pont, S. J. and Ray, W. A. (2007) Increasing use of antidepressants in pregnancy. Am J Obstet Gynecol 196, 544 e541-545.

Covington, H. E., 3rd, Maze, I., LaPlant, Q. C., Vialou, V. F., Ohnishi, Y. N., Berton, O., Fass, D. M., Renthal, W., Rush, A. J., 3rd, Wu, E. Y., Ghose, S., Krishnan, V., Russo, S. J., Tamminga, C., Haggarty, S. J. and Nestler, E. J. (2009) Antidepressant actions of histone deacetylase inhibitors. J Neurosci 29, 11451-11460.

Dwivedi, Y., Rizavi, H. S., Conley, R. R., Roberts, R. C., Tamminga, C. A. and Pandey, G. N. (2003) Altered gene expression of brain-derived neurotrophic factor and receptor tyrosine kinase B in postmortem brain of suicide subjects. Arch Gen Psychiatry 60, 804-815.

Dwivedi, Y., Rizavi, H. S., Zhang, H., Mondal, A. C., Roberts, R. C., Conley, R. R. and Pandey, G. N. (2009) Neurotrophin receptor activation and expression in human postmortem brain: effect of suicide. Biol Psychiatry 65, 319-328.

Fuchikami, M., Morinobu, S., Kurata, A., Yamamoto, S. and Yamawaki, S. (2009) Single immobilization stress differentially alters the expression profile of transcripts of the brain-derived neurotrophic factor (BDNF) gene and histone acetylation at its promoters in the rat hippocampus. Int J Neuropsychopharmacol 12, 73-82.

Gaspar, P., Cases, O. and Maroteaux, L. (2003) The developmental role of serotonin: news from mouse molecular genetics. Nat Rev Neurosci 4, 1002-1012.

Gentile, S., Rossi, A. and Bellantuono, C. (2007) SSRIs during breastfeeding: spotlight on milk-to-plasma ratio. Arch Womens Ment Health 10, 39-51.

Gonzales, M. L. and LaSalle, J. M. (2010) The role of MeCP2 in brain development and neurodevelopmental disorders. Curr Psychiatry Rep 12, 127-134. 
Homberg, J. R., Schubert, D. and Gaspar, P. (2010) New perspectives on the neurodevelopmental effects of SSRIs. Trends Pharmacol Sci 31, 60-65.

Ishiwata, H., Shiga, T. and Okado, N. (2005) Selective serotonin reuptake inhibitor treatment of early postnatal mice reverses their prenatal stress-induced brain dysfunction. Neuroscience 133, 893-901.

Karpova, N. N., Lindholm, J., Pruunsild, P., Timmusk, T. and Castren, E. (2009) Long-lasting behavioural and molecular alterations induced by early postnatal fluoxetine exposure are restored by chronic fluoxetine treatment in adult mice. Eur Neuropsychopharmacol 19, 97-108.

Kristensen, J. H., Ilett, K. F., Hackett, L. P., Yapp, P., Paech, M. and Begg, E. J. (1999) Distribution and excretion of fluoxetine and norfluoxetine in human milk. Br J Clin Pharmacol 48, 521-527.

Laine, K., Heikkinen, T., Ekblad, U. and Kero, P. (2003) Effects of exposure to selective serotonin reuptake inhibitors during pregnancy on serotonergic symptoms in newborns and cord blood monoamine and prolactin concentrations. Arch Gen Psychiatry 60, 720-726.

Lee, L. J. (2009) Neonatal fluoxetine exposure affects the neuronal structure in the somatosensory cortex and somatosensory-related behaviors in adolescent rats. Neurotox Res 15, 212-223.

Maccari, S. and Morley-Fletcher, S. (2007) Effects of prenatal restraint stress on the hypothalamus-pituitary-adrenal axis and related behavioural and neurobiological alterations. Psychoneuroendocrinology 32 Suppl 1, S10-15.

Martinowich, K., Hattori, D., Wu, H., Fouse, S., He, F., Hu, Y., Fan, G. and Sun, Y. E. (2003) DNA methylationrelated chromatin remodeling in activity-dependent BDNF gene regulation. Science 302, 890-893.

Martinowich, K., Manji, H. and Lu, B. (2007) New insights into BDNF function in depression and anxiety. Nat Neurosci 10, 1089-1093.

McAllister, B. B., Kiryanova, V. and Dyck, R. H. (2012) Behavioural outcomes of perinatal maternal fluoxetine treatment. Neuroscience 226, 356-366.

Molteni, R., Cattaneo, A., Calabrese, F., Macchi, F., Olivier, J. D., Racagni, G., Ellenbroek, B. A., Gennarelli, M. and Riva, M. A. (2010) Reduced function of the serotonin transporter is associated with decreased expression of BDNF in rodents as well as in humans. Neurobiol Dis $37,747-755$.

Morley-Fletcher, S., Rea, M., Maccari, S. and Laviola, G. (2003) Environmental enrichment during adolescence reverses the effects of prenatal stress on play behaviour and HPA axis reactivity in rats. Eur J Neurosci 18, 33673374 .

Moses-Kolko, E. L., Bogen, D., Perel, J., Bregar, A., Uhl, K., Levin, B. and Wisner, K. L. (2005) Neonatal signs after late in utero exposure to serotonin reuptake inhibitors: literature review and implications for clinical applications. JAMA 293, 2372-2383.

Mostert, J. P., Koch, M. W., Heerings, M., Heersema, D. J. and De Keyser, J. (2008) Therapeutic potential of fluoxetine in neurological disorders. CNS Neurosci Ther 14, 153-164.

Neeley, E. W., Berger, R., Koenig, J. I. and Leonard, S. (2011) Prenatal stress differentially alters brain-derived neurotrophic factor expression and signaling across rat strains. Neuroscience 187, 24-35.

Noorlander, C. W., Ververs, F. F., Nikkels, P. G., van Echteld, C. J., Visser, G. H. and Smidt, M. P. (2008) Modulation of serotonin transporter function during fetal development causes dilated heart cardiomyopathy and lifelong behavioral abnormalities. PLoS One 3, e2782.

Nulman, I., Rovet, J., Stewart, D. E., Wolpin, J., Pace-Asciak, P., Shuhaiber, S. and Koren, G. (2002) Child development following exposure to tricyclic antidepressants or fluoxetine throughout fetal life: a prospective, controlled study. Am J Psychiatry 159, 1889-1895.

Oberlander, T. F., Gingrich, J. A. and Ansorge, M. S. (2009) Sustained neurobehavioral effects of exposure to SSRI antidepressants during development: molecular to clinical evidence. Clin Pharmacol Ther 86, 672-677. 
Oberlander, T. F., Grunau, R., Mayes, L., Riggs, W., Rurak, D., Papsdorf, M., Misri, S. and Weinberg, J. (2008) Hypothalamic-pituitary-adrenal (HPA) axis function in 3-month old infants with prenatal selective serotonin reuptake inhibitor (SSRI) antidepressant exposure. Early Hum Dev 84, 689-697.

Oberlander, T. F., Warburton, W., Misri, S., Aghajanian, J. and Hertzman, C. (2006) Neonatal outcomes after prenatal exposure to selective serotonin reuptake inhibitor antidepressants and maternal depression using population-based linked health data. Arch Gen Psychiatry 63, 898-906.

Onishchenko, N., Karpova, N., Sabri, F., Castren, E. and Ceccatelli, S. (2008) Long-lasting depression-like behavior and epigenetic changes of BDNF gene expression induced by perinatal exposure to methylmercury. J Neurochem $106,1378-1387$.

Pandey, G. N., Ren, X., Rizavi, H. S., Conley, R. R., Roberts, R. C. and Dwivedi, Y. (2008) Brain-derived neurotrophic factor and tyrosine kinase $\mathrm{B}$ receptor signalling in post-mortem brain of teenage suicide victims. Int $\mathrm{J}$ Neuropsychopharmacol 11, 1047-1061.

Pawluski, J. L., Brain, U. M., Underhill, C. M., Hammond, G. L. and Oberlander, T. F. (2011) Prenatal SSRI exposure alters neonatal corticosteroid binding globulin, infant cortisol levels, and emerging HPA function. Psychoneuroendocrinology 37, 1019-1028.

Pawluski, J. L., Charlier, T. D., Fillet, M., Houbart, V., Crispin, H. T., Steinbusch, H. W. and van den Hove, D. L. (2011) Chronic fluoxetine treatment and maternal adversity differentially alter neurobehavioral outcomes in the rat dam. Behav Brain Res 228, 159-168.

Pawluski, J. L., Galea, L. A., Brain, U., Papsdorf, M. and Oberlander, T. F. (2009) Neonatal S100B protein levels after prenatal exposure to selective serotonin reuptake inhibitors. Pediatrics 124, e662-670.

Pawluski, J. L., Rayen, I., Niessen, N. A., Kristensen, S., van Donkelaar, E. L., Balthazart, J., Steinbusch, H. W. and Charlier, T. D. (2012) Developmental fluoxetine exposure differentially alters central and peripheral measures of the HPA system in adolescent male and female offspring. Neuroscience 220, 131-141.

Pruunsild, P., Kazantseva, A., Aid, T., Palm, K. and Timmusk, T. (2007) Dissecting the human BDNF locus: bidirectional transcription, complex splicing, and multiple promoters. Genomics 90, 397-406.

Rampono, J., Proud, S., Hackett, L. P., Kristensen, J. H. and Ilett, K. F. (2004) A pilot study of newer antidepressant concentrations in cord and maternal serum and possible effects in the neonate. Int J Neuropsychopharmacol 7, 329334.

Rayen, I., van den Hove, D. L., Prickaerts, J., Steinbusch, H. W. and Pawluski, J. L. (2011) Fluoxetine during development reverses the effects of prenatal stress on depressive-like behavior and hippocampal neurogenesis in adolescence. PLoS One 6, e24003.

Roceri, M., Hendriks, W., Racagni, G., Ellenbroek, B. A. and Riva, M. A. (2002) Early maternal deprivation reduces the expression of BDNF and NMDA receptor subunits in rat hippocampus. Mol Psychiatry 7, 609-616.

Romijn, H. J., Hofman, M. A. and Gramsbergen, A. (1991) At what age is the developing cerebral cortex of the rat comparable to that of the full-term newborn human baby? Early Hum Dev 26, 61-67.

Roth, T. L., Lubin, F. D., Funk, A. J. and Sweatt, J. D. (2009) Lasting epigenetic influence of early-life adversity on the BDNF gene. Biol Psychiatry 65, 760-769.

Samaco, R. C., Mandel-Brehm, C., McGraw, C. M., Shaw, C. A., McGill, B. E. and Zoghbi, H. Y. (2012) Crh and Oprm1 mediate anxiety-related behavior and social approach in a mouse model of MECP2 duplication syndrome. Nat Genet 44, 206-211.

Smit-Rigter, L. A., Noorlander, C. W., von Oerthel, L., Chameau, P., Smidt, M. P. and van Hooft, J. A. (2012) Prenatal fluoxetine exposure induces life-long serotonin 5-HT(3) receptor-dependent cortical abnormalities and anxiety-like behaviour. Neuropharmacology 62, 865-870.

Strackx, E., Van den Hove, D. L., Prickaerts, J., Zimmermann, L., Steinbusch, H. W., Blanco, C. E., Gavilanes, A. W. and Vles, J. S. (2009) Fetal asphyctic preconditioning protects against perinatal asphyxia-induced behavioral consequences in adulthood. Behav Brain Res 208, 343-351. 
Tsankova, N. M., Berton, O., Renthal, W., Kumar, A., Neve, R. L. and Nestler, E. J. (2006) Sustained hippocampal chromatin regulation in a mouse model of depression and antidepressant action. Nat Neurosci 9, 519-525.

Van den Hove, D. L., Blanco, C. E., Aendekerk, B., Desbonnet, L., Bruschettini, M., Steinbusch, H. P., Prickaerts, J. and Steinbusch, H. W. (2005) Prenatal restraint stress and long-term affective consequences. Dev Neurosci 27, 313320 .

Van den Hove, D. L., Kenis, G., Brass, A., Opstelten, R., Rutten, B. P., Bruschettini, M., Blanco, C. E., Lesch, K. P., Steinbusch, H. W. and Prickaerts, J. (2013) Vulnerability versus resilience to prenatal stress in male and female rats; Implications from gene expression profiles in the hippocampus and frontal cortex. Eur Neuropsychopharmacol.

Ververs, T., Kaasenbrood, H., Visser, G., Schobben, F., de Jong-van den Berg, L. and Egberts, T. (2006) Prevalence and patterns of antidepressant drug use during pregnancy. Eur J Clin Pharmacol 62, 863-870.

Vialou, V., Feng, J., Robison, A. J. and Nestler, E. J. (2013) Epigenetic mechanisms of depression and antidepressant action. Annu Rev Pharmacol Toxicol 53, 59-87.

Ward, I. L. and Weisz, J. (1984) Differential effects of maternal stress on circulating levels of corticosterone, progesterone, and testosterone in male and female rat fetuses and their mothers. Endocrinology 114, 1635-1644.

Weaver, I. C., Cervoni, N., Champagne, F. A., D'Alessio, A. C., Sharma, S., Seckl, J. R., Dymov, S., Szyf, M. and Meaney, M. J. (2004) Epigenetic programming by maternal behavior. Nat Neurosci 7, 847-854.

Zuena, A. R., Mairesse, J., Casolini, P., Cinque, C., Alema, G. S., Morley-Fletcher, S., Chiodi, V., Spagnoli, L. G., Gradini, R., Catalani, A., Nicoletti, F. and Maccari, S. (2008) Prenatal restraint stress generates two distinct behavioral and neurochemical profiles in male and female rats. PLoS One 3, e2170. 


\section{Figures and legends.}

\section{A Males}
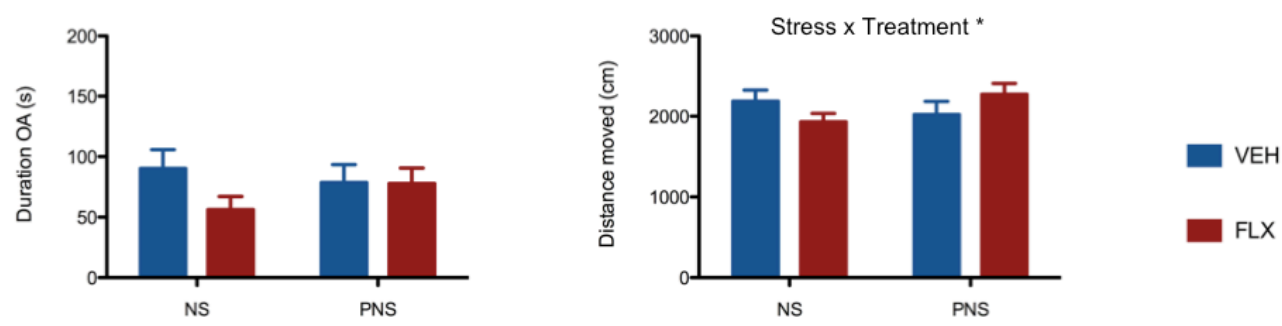

\section{B Females}
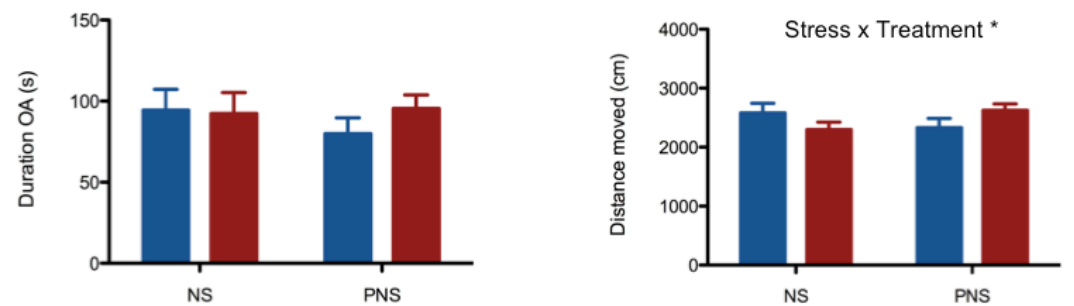

Figure 1. Effect of prenatal stress and maternal fluoxetine in the elevated zero maze (EZM)

Males (A) and females (B) offspring were exposed to an EZM, and the time spent in open arms (OA) and the total distance travelled are represented. In both male and female offspring, there was a significant stress $\mathrm{x}$ treatment interaction in the distance moved in the EZM, suggesting a differential effect of fluoxetine in naïve versus prenatally stressed animals. Data are expressed as mean + SEM of $n=12-16$ rats per group. ${ }^{*} \mathrm{p}<0.05$; Two-way ANOVA. NS $=$ no stress, PNS $=$ prenatal stress, VEH $=$ vehicle, FLX = fluoxetine. 


\section{A Males}

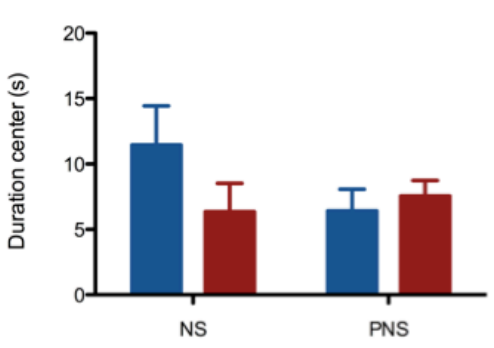

\section{B Females}

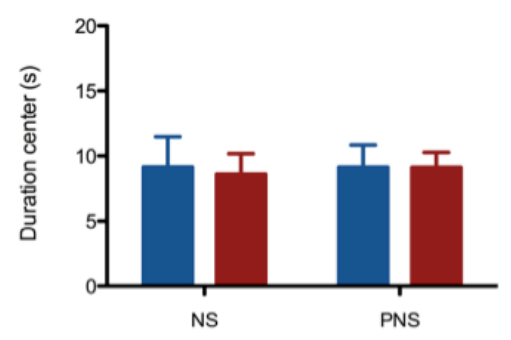

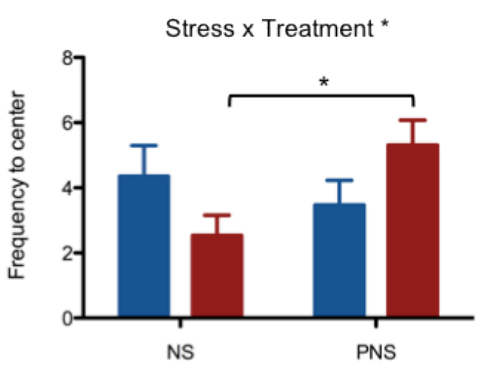
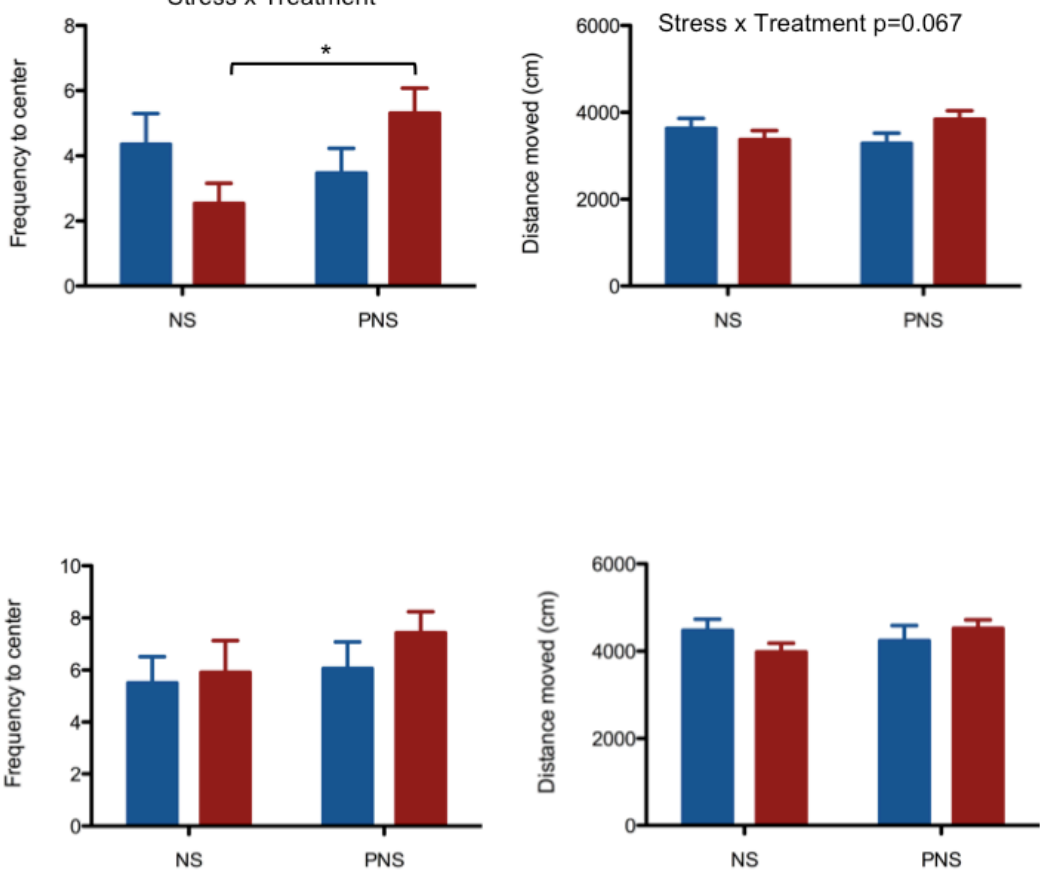

VEH

Figure 2. Effect of prenatal stress and maternal fluoxetine in the open field test (OFT)

Males (A) and females (B) offspring were exposed to an OFT, and the time spent in the center, the frequency to the center and the total distance travelled are represented. Maternal fluoxetine treatment (FLX) had opposite effects on the frequency to the center in naïve animals (NS) as compared to prenatally stressed animals (PNS) in male offspring. Of note, a trend towards a similar effect was observed in the distance moved in males. No differences in any parameter were observed in females. Data are expressed as mean $+\mathrm{SEM}$ of $\mathrm{n}=12-16$ rats per group. ${ }^{*} \mathrm{p}<0.05$; Two-way ANOVA, Fisher LSD post hoc test. NS $=$ no stress, PNS $=$ prenatal stress, $\mathrm{VEH}=$ vehicle, $\mathrm{FLX}=$ fluoxetine. 


\section{A Males}
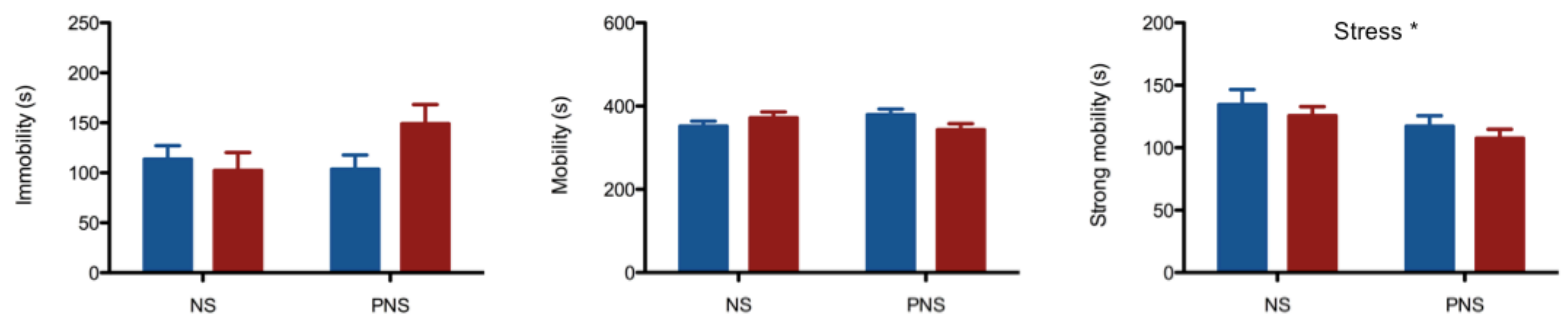

\section{B Females}
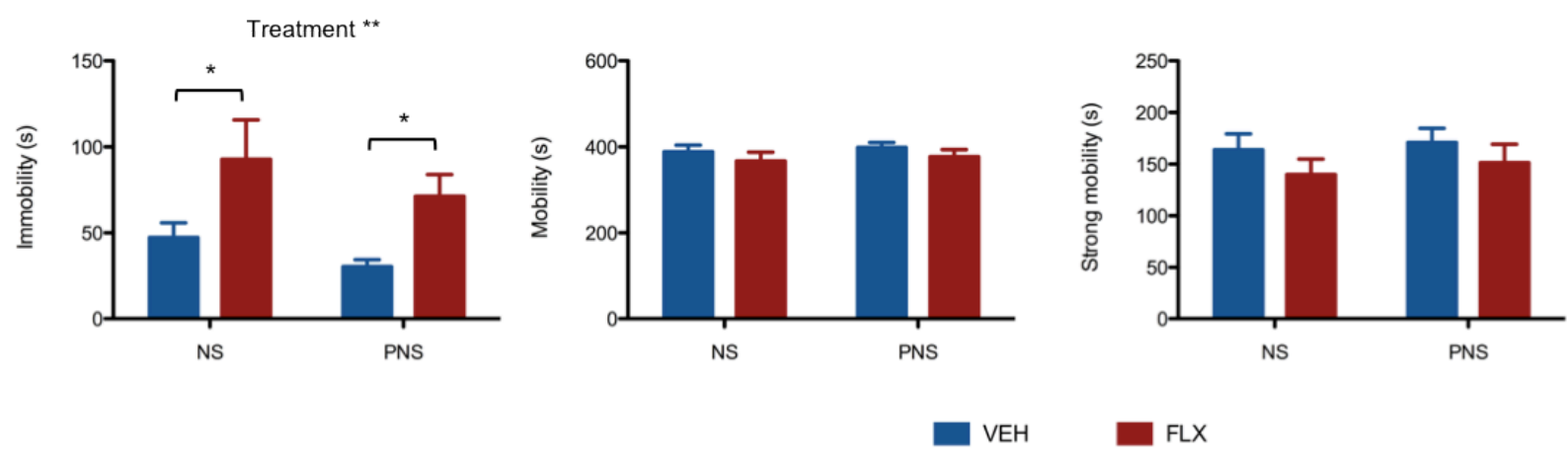

Figure 3. Effect of prenatal stress and maternal fluoxetine in the forced swim test (FST)

Males (A) and females (B) offspring were exposed to a FST, and the time spent in immobility, mobility and strong mobility is represented. There was a significant stress $x$ treatment interaction in the mobility time in males. A trend toward a similar effect in the immobility time was also observed. In addition, male rats exposed to prenatal stress (PNS) showed a decrease time of strong mobility as compared to non-stress animals (NS). In females, maternal fluoxetine treatment (FLX) significantly increased the time spent in immobility in naïve (NS) and prenatally stressed (PNS) animals. No differences were observed in the mobility and strong mobility time in female offspring. Data are expressed as mean + SEM of $n=12-16$ rats per group. ${ }^{*} p<0.05 ; * * p 0.01$; Two-way ANOVA, Fisher LSD post hoc test. NS = no stress, PNS = prenatal stress, VEH = vehicle, FLX = fluoxetine. 
A Males
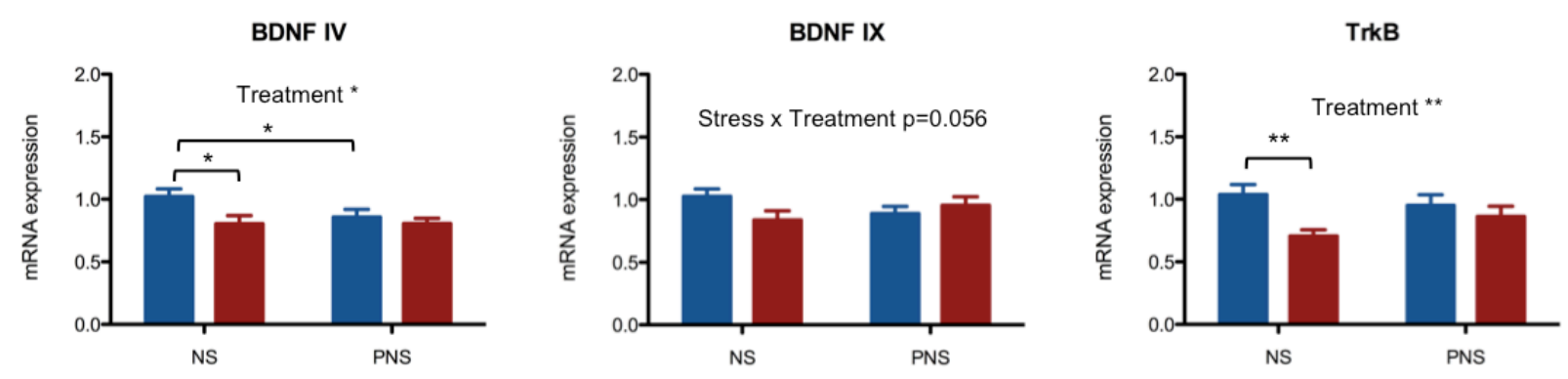

\section{B Females}
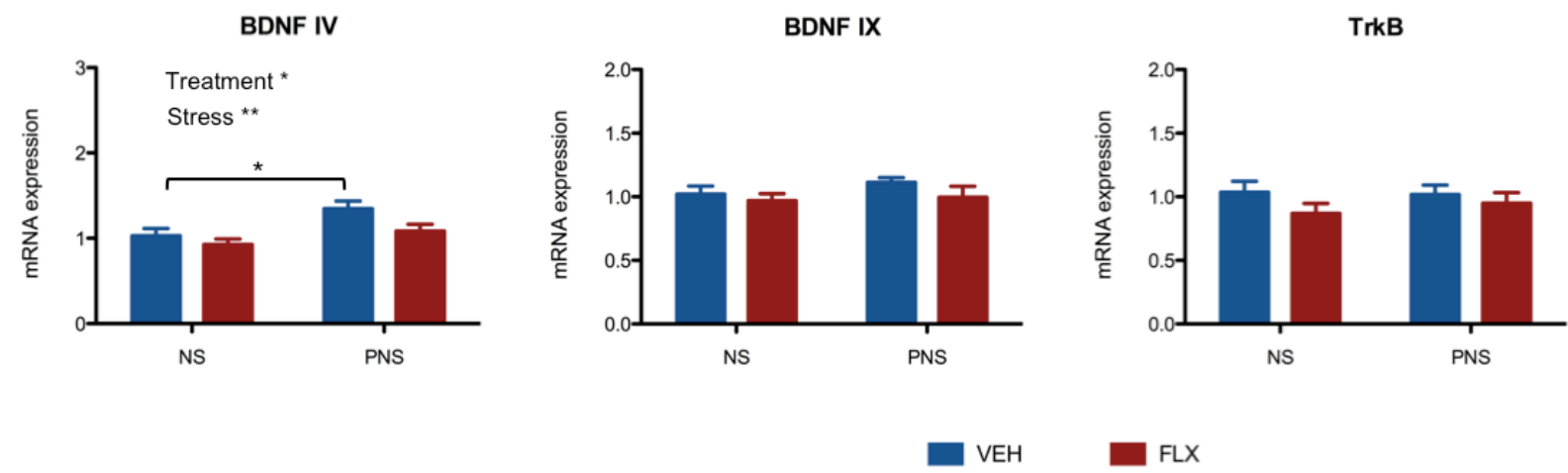

Figure 4. Effect of prenatal stress and maternal fluoxetine on BDNF/TrkB signaling in the hippocampus

mRNA levels of BDNF and TrkB in the hippocampus of males (A) and females (B) offspring were measured by quantitative real-time RT-PCR, and are expressed as fold changes as compared to naïve animals (NS SAL). There was a significant effect of maternal fluoxetine treatment (FLX) on BDNF IV and TrkB mRNA levels in males. In addition, male rats exposed to prenatal stress (PNS) showed decreased BDNF IV mRNA expression as compared to non-stressed animals. In females, there was a significant effect of maternal fluoxetine on BDNF IV mRNA levels. In contrast to what observed in males, prenatal stress increased BDNF IV mRNA levels in female offspring. No differences were observed in BDNF IX and TrkB mRNA levels in females. Data are expressed as mean + SEM of $n=12-16$ rats per group. ${ }^{*} p<0.05 ; * p<0.01$; Two-way ANOVA, Fisher LSD post hoc test. NS = no stress, PNS = prenatal stress, VEH $=$ vehicle, FLX = fluoxetine. 


\section{A BDNF IV}
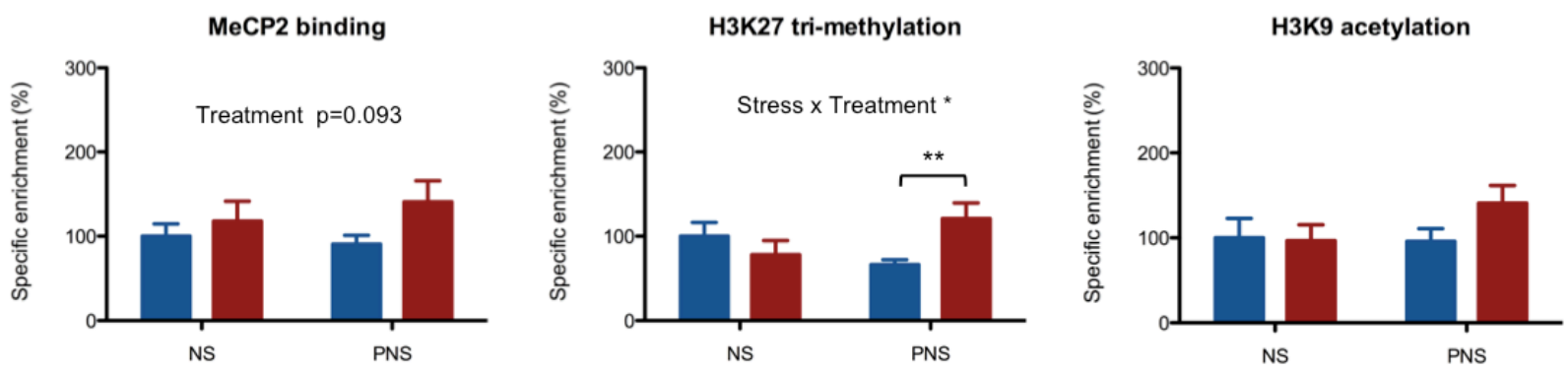

\section{B BDNF IX}
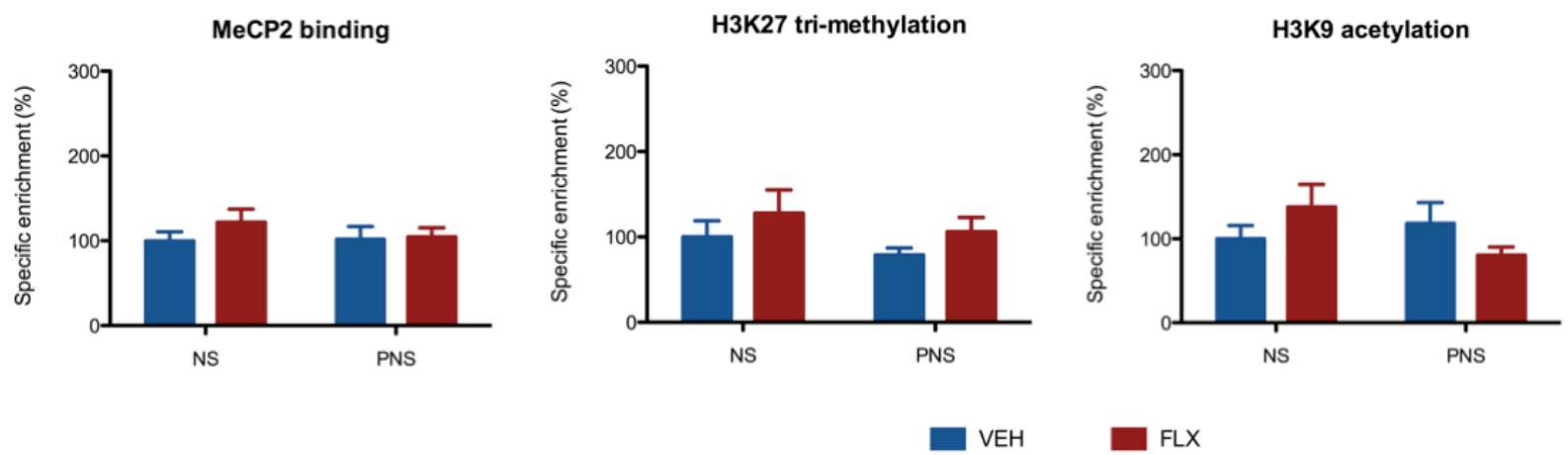

Figure 5. Effect of prenatal stress and maternal fluoxetine on epigenetic regulation of BDNF gene in female offspring

The specific enrichment of MeCP2, H3K27me3 and H3K9ac at the BDNF promoter IV (A) and the BDNF promoter IX (B) was measured by chromatin immunoprecipitation (ChIP) followed by quantitative real-time PCR, and is expressed as percentage of control animals (NS SAL). A trend towards an increase of MeCP2 binding at the BDNF promoter IV was observed after maternal fluoxetine treatment (FLX). In addition, maternal fluoxetine treatment significantly increased the enrichment of $\mathrm{H} 3 \mathrm{~K} 27 \mathrm{me} 3$ at the BDNF promoter IV in female rats exposed to prenatal stress (PNS). Further, a tendency for a stress $\mathrm{x}$ treatment interaction for H3K9ac enrichment at the BDNF promoter IX was observed, but did not reach statistical significance. Data are expressed as mean + SEM of $n=7-9$ rats per group. ${ }^{* *} \mathrm{p}<0.01$; Two-way ANOVA, Fisher LSD post hoc test. NS $=$ no stress, PNS $=$ prenatal stress, $\mathrm{VEH}=$ vehicle, FLX $=$ fluoxetine. 


\section{$\underline{\text { Supplementary data. }}$}

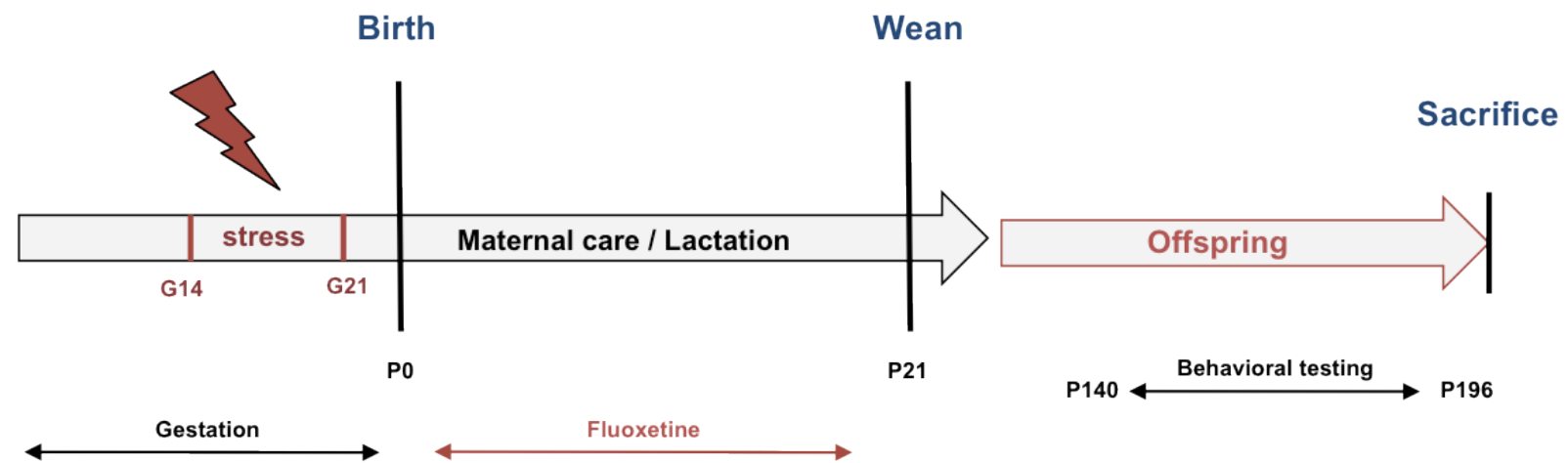

Figure S1. Schematic representation of experimental timeline

Restraint stress was performed daily during the last week of gestation (G14-G21). Fluoxetine or with vehicle was administered via osmotic minipumps (Alzet Osmotic pumps, 2ML4) to the dams during the postpartum period (P1-P21). At postnatal day 21 (P21), pups were weaned and group-housed for further examination ( 2 male or 2 female rats/cage; $\mathrm{n}=12-16$ rats per experimental condition per sex). Anxiety- and depression-related behavior of the rats was analyzed from P140 onwards (in the order as discussed below). At P196, the animals were killed by quick decapitation. 


\begin{tabular}{|c|c|c|c|c|c|c|}
\hline Behaviroral measure & NS VEH & NS FLX & PNS VEH & PNS FLX & ANOVA & LSD post hoc \\
\hline \multicolumn{7}{|l|}{ A-Eleveated zero maze (EZM) } \\
\hline Duration open arms (s) & $90.2 \pm 15.5$ & $56.2 \pm 10.8$ & $78.5 \pm 14.9$ & $77.75 \pm 12.9$ & - & - \\
\hline Frequency open arms & $20.3 \pm 8.3$ & $9.7 \pm 2.0$ & $12.2 \pm 2.0$ & $15.21 \pm 2.6$ & - & - \\
\hline Frequency closed arms & $20.5 \pm 8.3$ & $9.6 \pm 2.1$ & $12.4 \pm 2.0$ & $15.71 \pm 2.5$ & - & - \\
\hline Distance moved $(\mathrm{cm})$ & $2165 \pm 130$ & $1932 \pm 104$ & $1956 \pm 157$ & $2274 \pm 135$ & Stress $\times$ Treatment * & - \\
\hline \multicolumn{7}{|l|}{ B-Open field test (OFI) } \\
\hline Duration center (s) & $11.4 \pm 2.9$ & $6.3 \pm 2.2$ & $6.4 \pm 1.6$ & $7.5 \pm 1.1$ & - & - \\
\hline Duration walls (s) & $119.8 \pm 4.9$ & $107.4 \pm 8.2$ & $122.7 \pm 5.2$ & $119.3 \pm 5.4$ & - & - \\
\hline Duration corners (s) & $165.3 \pm 5.8$ & $183.1 \pm 8.4$ & $167.9 \pm 5.8$ & $169.8 \pm 6.1$ & - & - \\
\hline Frequency center & $4.3 \pm 0.9$ & $2.5 \pm 0.6$ & $3.4 \pm 0.7$ & $5.1 \pm 0.7$ & Stress $\times$ Treatment * & NS FLX $<$ PNS FLX * \\
\hline Distance moved $(\mathrm{cm})$ & $3632 \pm 228$ & $3372 \pm 210$ & $3289 \pm 235$ & $3845 \pm 190$ & - & - \\
\hline \multicolumn{7}{|l|}{ C-Forced swim test (EST) } \\
\hline Immobility (s) & $113.7 \pm 13.2$ & $102.5 \pm 17.9$ & $103.7 \pm 14.1$ & $149.0 \pm 19.3$ & - & - \\
\hline Mobility (s) & $351.8 \pm 12.5$ & $371.9 \pm 13.9$ & $379.1 \pm 13.4$ & $343.4 \pm 14.2$ & - & - \\
\hline Strong mobility (s) & $134.6 \pm 12.1$ & $125.6 \pm 7.3$ & $117.2 \pm 8.3$ & $107.6 \pm 7.2$ & Stress * & - \\
\hline
\end{tabular}

\section{Table S1. Summary table of behavioral analysis in male offspring}

Data are represent mean \pm SEM of $n=12-16$ rats per group. ${ }^{*} \mathrm{p}<0.05$; Two-way ANOVA, Fisher LSD post hoc test. NS $=$ no stress, $\mathrm{PNS}=$ prenatal stress, $\mathrm{VEH}=$ vehicle, $\mathrm{FLX}=$ fluoxetine. 
Duration open arms (s)

Frequency open arms

Frequency closed arms

Distance moved $(\mathrm{cm})$

\section{B- doen field test (OEI)}

Duration center (s)

Duration walls (s)

Duration corners (s)

Frequency center

Distance moved $(\mathrm{cm})$

C-Forced swim test (EST)

\section{$94.4 \pm 12.8$}

$25.5 \pm 10.4$

$25.9 \pm 10.4$

$2581 \pm 162$

$9.1 \pm 2.3$

$100.5 \pm 5.6$

$187.1 \pm 7.3$

$5.5 \pm 1.0$

$4475 \pm 255$

$8.6 \pm 1.56$

$97.7 \pm 5.8$

$190.6 \pm 6.8$

$5.9 \pm 1.2$

$3980 \pm 203$

182

$9.1 \pm 1.7$

$105.9 \pm 7.3$

$182.1 \pm 7.8$

$6.0 \pm 1.0$

$4244 \pm 342$

$9.1 \pm 1.1$

$116.6 \pm 4.3$

$170.8 \pm 5.0$

$8.0 \pm 0.8$

$4522 \pm 193$

Immobility (s)

Mobility (s)

Strong mobility (s)
$47.3 \pm 8.5$

$388.9 \pm 15.2$

$163.8 \pm 15.4$
$92.7 \pm 22.9$

$367 \pm 20.3$

$139.8 \pm 15.0$
$30.4 \pm 4.0$

$398.6 \pm 11.7$

$170.9 \pm 13.7$
$71.3 \pm 12.6$

Treatment **

$377.3 \pm 16.31$

$151.3 \pm 18.0$
Stress $\times$ Treatment *

\section{Table S2. Summary table of behavioral analysis in female offspring}

Data are represent mean \pm SEM of $\mathrm{n}=12-16$ rats per group. ${ }^{*} \mathrm{p}<0.05 ;{ }^{*} \mathrm{p}<0.01$; Two-way ANOVA, Fisher LSD post hoc test. $\mathrm{NS}=$ no stress, $\mathrm{PNS}=$ prenatal stress, $\mathrm{VEH}=$ vehicle, $\mathrm{FLX}=$ fluoxetine. 


\section{Males}

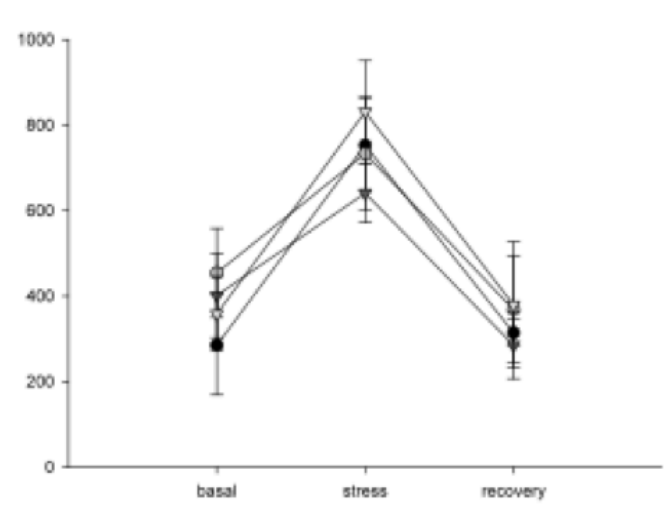

Females

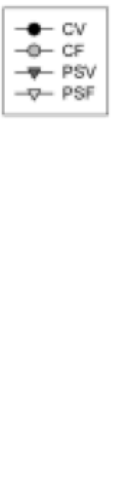

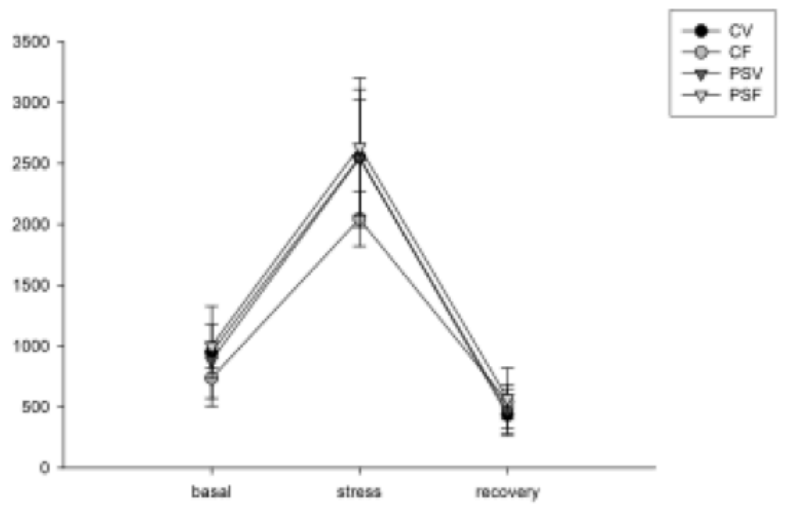

Figure S2. Effect of prenatal stress and maternal fluoxetine on corticosterone response

The plasma corticosterone levels were measured by radioimmuno assay in basal condition, stress condition and after recovery from stress. Corticosterone levels were increased after $20 \mathrm{~min}$ of stress exposure in both males and females, and returned to baseline after $40 \mathrm{~min}$ after the stress exposure. Maternal fluoxetine treatment and prenatal stress did not affect corticosterone response in basal, stress or recovery condition. Data are expressed as mean $\pm \mathrm{SEM}$ of $\mathrm{n}=12-16$ rats per group. $\mathrm{CV}=\mathrm{control}$ vehicle, $\mathrm{CF}=$ control fluoxetine, $\mathrm{PSV}=$ prenatal stress vehicle, $\mathrm{PSF}=$ prenatal stress fluoxetine 
Males

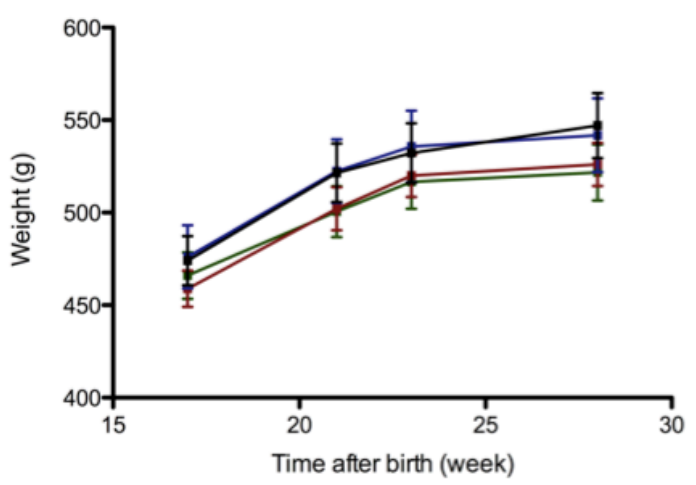

$\rightarrow$ PNS FLX

$\rightarrow$ PNS VEH

\section{Females}

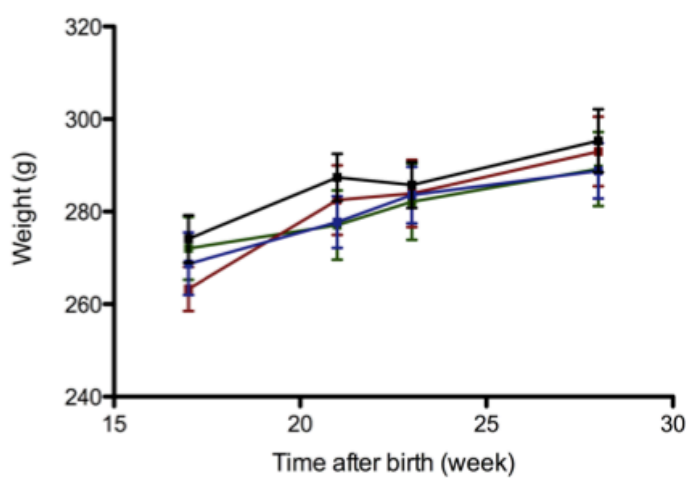

$\rightarrow-$ NS VEH

$\rightarrow$ NS FLX

Figure S3. Effect of prenatal stress and maternal fluoxetine on body weight

The weight of rats was measure on week 17, week 21, week 23 and week 28 after birth. No differences between groups were found at any time point. Data are expressed as mean \pm SEM of $n=12-16$ rats per group. Two-way ANOVA. NS $=$ no stress, PNS $=$ prenatal stress, $\mathrm{SAL}=$ saline, $\mathrm{FLX}=$ fluoxetine. 
Developmental fluoxetine and epigenetic reprogramming

$\begin{array}{ll}\text { Gene } & \text { Definition } \\ \text { Akt1 } & \text { RAC-alpha serine/threonine-protein kinase } \\ \text { Bcl2 } & \text { B cell leukemia/lymphoma 2 } \\ \text { Bdnf4 } & \text { Brain-derived neurotrophic factor exon } 4 \\ \text { Bdnf9 } & \text { Brain-derived neurotrophic factor exon } 9 \\ \text { Cdh13 } & \text { Cadherin 13 } \\ \text { cFos } & \text { FBJ osteosarcoma oncogene } \\ \text { Egr1 } & \text { Early growth response 1 } \\ \text { Mapk3 } & \text { Mitogen-activated protein kinase 3 } \\ \text { NeuroD1 } & \text { Neurogenic differentiation 1 } \\ \text { Rpl13a } & \text { Ribosomal protein L13A } \\ \text { Slc2a3 } & \text { Solute carrier family 2 } \\ \text { TrkB } & \text { Neurotrophic tyrosine kinase, receptor, type 2 }\end{array}$

Forward

GAAGGAGAAGGCCACAGGTC CTTCTCTCGTCGCTACCGTC

AGCAGCTGCCTTGATGTTTAC

TCACAGCGGCAGATAAAAAG GGAAATCCTGGGCAGAGCTT TACTACCATTCCCCAGCCGA AACAACCCTACGAGCACCTG GGCATCCGAGACATCCTCAG CCCTACTCCTACCAGTCCCC CCCTCCACCCTATGACAAG TGGAAGAGCGGTTGGAAGAC GCTGACGAGTTTGTCCAGGA

\section{Reverse}

TTCTGCAGGACACGGTTCTC CAATCCTCCCCCAGTTCACC ACCATAGTAAGGAAAAGGATGGTC TGGGATTACACTTGGTCTCG CCAAGACCGTGATGTGGACA GCTGTCACCGTGGGGATAAA AAAGGGGTTCAGGCCACAAA TATGTACTTGAGGCCCCGGA GTGCAATCAGTTAGGGGGCT AGGTAAGCAAACTTTCTGGTAG CCCAAGGATGGCAATCAGGT TGCTGCTCTCATTGAGGCAA

Table S3. Primer sequences used in q RT-PCR experiments 


\section{Chapter VI}

$\begin{array}{llll}\text { Gene } & \text { Promoter } & \text { Forward } & \text { Reverse } \\ \text { Bdnf } & \text { IV } & \text { TCTATTCGAGGCAGAGGAGGTATC } & \text { AATGGGAAAGTGGGTGGGAG } \\ \text { Bdnf } & \text { IX } & \text { GGCTTTACGGTCCCACTTCA } & \text { CTCAGAACTGCTTGGACGGT }\end{array}$

Table S4. Primer sequences used in ChIP experiments

The primers for the BDNF IV promoter were obtained from previous studies (Gomez-Pinilla et al., 2011). The promoter region of BDNF IX and its transcription start sites (TSS) were predicted using the "TRED Promoter Database". Genomic regions of 2000 bases upstream of the first TSS of each candidate gene were used to design the different primer pairs. Further, CpG islands in the promoter regions were determined with Methprimer software and used as a putative indicator of MeCP2 binding sites. 


\begin{tabular}{|c|c|c|c|c|c|c|}
\hline Genes & NS VEH & NS FLX & PNS VEH & PNS FLX & ANOVA & LSD post hoc \\
\hline Akt1 & $1.00 \pm 0.14$ & $0.75 \pm 0.10$ & $0.94 \pm 0.11$ & $0.83 \pm 0.09$ & - & - \\
\hline $\mathrm{BCl} 2$ & $1.00 \pm 0.07$ & $0.92 \pm 0.10$ & $1.07 \pm 0.08$ & $1.01 \pm 0.09$ & - & - \\
\hline Bdnf IV & $1.00 \pm 0.05$ & $0.80 \pm 0.06$ & $0.85 \pm 0.06$ & $0.80 \pm 0.04$ & Treatment * & $\begin{array}{l}\text { NS VEH }>\text { NS FLX } * \\
\text { NS VEH }>\text { PNS VEH * }\end{array}$ \\
\hline Bdnf IX & $1.00 \pm 0.06$ & $0.83 \pm 0.07$ & $0.88 \pm 0.05$ & $0.95 \pm 0.06$ & - & - \\
\hline Cdh13 & $1.00 \pm 0.08$ & $1.20 \pm 0.35$ & $1.10 \pm 0.16$ & $0.96 \pm 0.10$ & - & - \\
\hline cFos & $1.00 \pm 0.08$ & $0.86 \pm 0.10$ & $1.02 \pm 0.21$ & $0.95 \pm 0.08$ & - & - \\
\hline Egr1 & $1.00 \pm 0.08$ & $0.71 \pm 0.09$ & $0.98 \pm 0.14$ & $0.86 \pm 0.06$ & - & - \\
\hline Mapk3 & $1.00 \pm 0.12$ & $0.79 \pm 0.08$ & $0.96 \pm 0.09$ & $0.83 \pm 0.07$ & - & - \\
\hline NeuroD1 & $1.00 \pm 0.06$ & $0.83 \pm 0.07$ & $0.86 \pm 0.07$ & $0.94 \pm 0.09$ & - & - \\
\hline SIc2a3 & $1.00 \pm 0.10$ & $0.76 \pm 0.10$ & $1.11 \pm 0.19$ & $0.98 \pm 0.12$ & - & - \\
\hline TrkB & $1.00 \pm 0.07$ & $0.68 \pm 0.04$ & $0.91 \pm 0.08$ & $0.83 \pm 0.07$ & Treatment * & NS VEH > NS FLX * \\
\hline
\end{tabular}

\section{Table S5. Effect of prenatal stress and maternal fluoxetine on hippocampal gene expression in male offspring}

mRNA levels of BDNF/TrkB downstream target genes were measured in the hippocampus of males offspring by quantitative real-time RT-PCR, and are expressed as fold changes as compared to naïve animals (NS SAL). Data are represent mean $\pm \mathrm{SEM}$ of $\mathrm{n}=12-16$ rats per group. ${ }^{*} \mathrm{p}<0.05$; Two-way ANOVA, Fisher LSD post hoc test. NS $=$ no stress, PNS $=$ prenatal stress, VEH $=$ vehicle, FLX $=$ fluoxetine. 


$\begin{array}{lllllll}\text { Genes } & \text { NS VEH } & \text { NS FLX } & \text { PNS VEH } & \text { PNS FLX } & \text { ANOVA } & \text { LSD post hoc } \\ \text { Akt1 } & 1.00 \pm 0.14 & 1.02 \pm 0.13 & 0.80 \pm 0.10 & 0.61 \pm 0.08 & \text { Stress * } & \text { NS FLX > PNS FLX * } \\ \text { Bcl2 } & 1.00 \pm 0.05 & 0.99 \pm 0.13 & 1.27 \pm 0.08 & 0.91 \pm 0.08 & \text { Treatment * } & \text { PNS VEH > PNS FLX * } \\ \text { Bdnf IV } & 1.00 \pm 0.08 & 0.92 \pm 0.06 & 1.34 \pm 0.08 & 1.08 \pm 0.07 & \begin{array}{l}\text { Treatment * } \\ \text { Stress ** }\end{array} & \\ \text { Bdnf IX } & 1.02 \pm 0.06 & 0.96 \pm 0.05 & 1.11 \pm 0.03 & 0.99 \pm 0.08 & - & - \\ \text { Cdh13 } & 1.00 \pm 0.09 & 0.95 \pm 0.13 & 1.10 \pm 0.09 & 0.89 \pm 0.11 & - & \text { - } \\ \text { cFos } & 1.00 \pm 0.14 & 1.04 \pm 0.12 & 1.08 \pm 0.11 & 0.86 \pm 0.06 & - & \text { NS VEH > PNS VEH * } \\ \text { Egr1 } & 1.00 \pm 0.16 & 0.80 \pm 0.15 & 0.51 \pm 0.12 & 0.41 \pm 0.06 & \text { Stress ** } \\ \text { Mapk3 } & 1.00 \pm 0.10 & 1.01 \pm 0.13 & 1.02 \pm 0.13 & 0.59 \pm 0.07 & - \\ \text { NeuroD1 } & 1.00 \pm 0.20 & 0.90 \pm 0.15 & 1.19 \pm 0.12 & 0.93 \pm 0.11 & - \\ \text { Slc2a3 } & 1.00 \pm 0.20 & 0.77 \pm 0.13 & 0.86 \pm 0.12 & 0.67 \pm 0.13 & - \\ \text { TrkB } & 1.00 \pm 0.08 & 0.86 \pm 0.07 & 1.01 \pm 0.07 & 0.94 \pm 0.08 & -\end{array}$

\section{Table S6. Effect of prenatal stress and maternal fluoxetine on hippocampal gene expression in female offspring}

mRNA levels of BDNF/TrkB downstream target genes were measured in the hippocampus of females offspring by quantitative real-time RT-PCR, and are expressed as fold changes as compared to naïve animals (NS SAL). Data are represent mean $\pm \mathrm{SEM}$ of $\mathrm{n}=12-16$ rats per group. ${ }^{*} \mathrm{p}<0.05$; Two-way ANOVA, Fisher LSD post hoc test. NS $=$ no stress, PNS $=$ prenatal stress, VEH $=$ vehicle, $\mathrm{FLX}=$ fluoxetine. 


\section{CHAPTER VII}

\section{Behavioral and neurochemical characterization of TrkB-dependent mechanisms of agomelatine in glucocorticoid receptor-impaired mice}

\footnotetext{
Fabien BOUlle ${ }^{1,2}$, Hester Velthuis ${ }^{1}$, NeHA KUMAR ${ }^{2}$, Koen KOEDAM $^{2}$, Harry W STEINBUSCH${ }^{2}$, Gunter KENIS ${ }^{2}$, DANiel L.A VAN DEN HOVE ${ }^{2,3}$, Cecilia GABriEL ${ }^{4}$, Elisabeth MOCAER ${ }^{4}$, Michel HAMON $^{1}$, LAURENCE LANFUMEY ${ }^{1}$
}

${ }^{I}$ Centre de Psychiatrie et Neuroscience (INSERM U894), Universite Pierre et Marie Curie, Paris, France

${ }^{2}$ Department of Psychiatry and Neuropsychology, European Graduate School for Neuroscience (EURON), Maastricht University, Maastricht, The Netherlands

${ }^{3}$ Department of Psychiatry, Psychosomatics and Psychotherapy, University of Wuerzburg, Wuerzburg, Germany

${ }^{4}$ Institut de Recherche International Servier, Suresnes, France

In preparation 


\begin{abstract}
Growing evidences indicate that impairment of the hypothalamo-pituitary-adrenal (HPA) axis, a key regulator of the stress response, might be responsible for the hippocampal atrophy and dysfunction often observed in mood disorders. Antidepressants, possibly through the activation of BDNF signaling, may be able to enhance neuroplasticity and restore a normal hippocampal function. In this context, glucocorticoid receptor-impaired (GRi) mice - a transgenic mouse model for mood disorders - were used to investigate the role of BDNF/TrkB signaling in the behavioral and neurochemical effects of the new generation antidepressant agomelatine. GRi mice and their wild-type littermates were treated for 21 days with either agomelatine $(50 \mathrm{mg} / \mathrm{kg} /$ day; i.p) or the TrkB inhibitor Ana12 $(0.5 \mathrm{mg} / \mathrm{kg} /$ day, i.p) alone, or in combination. GRi mice exhibited a marked alteration in depressive and anxiety-like behaviors as well as fear response, together with a decreased cell proliferation and altered neuroplastic and epigenetic regulation in the hippocampus. Chronic treatment with agomelatine resulted in antidepressant and anxiolytic effects in GRi mice, and reversed the deficit in hippocampal cell proliferation and alteration of plasticity-related gene expression. The dual administration with Ana12 could block the anxiolytic effect of agomelatine as well as its ability to restore a normal expression of $B c l 2$ and $c F o s$ mRNA. Altogether, our findings indicate that agomelatine represents an efficient alternative to reverse the neuroplastic and behavioral alterations caused by HPA axis impairment. In addition, our findings provide further insights into the role of BDNF/TrkB signaling in the molecular and behavioral actions of antidepressants, as well as in the pathophysiology of mood disorders.
\end{abstract}

Key words: Plasticity, hippocampus, antidepressants, BDNF, glucocorticoid, epigenetic 


\section{I - Introduction}

The impairment of the hypothalamo-pituitary-adrenal (HPA) axis, a major component of the neuroendocrine system regulating the stress response, has been implicated in the pathophysiology of mood disorders (Pariante et al., 2008; Vreeburg et al., 2009). Among several growth factors, brainderived neurotrophic factor (BDNF) has been postulated as a key mediator of stress-induced synaptic dysfunction and neuronal atrophy often observed in the prefrontal cortex and hippocampus of mood disorder patients (Duman et al., 2012; Berton et al., 2006). The decrease of BDNF and its tropomyosinrelated kinase receptor (TrkB) were both observed in the hippocampus of suicide completers and depressed patients (Autry et al., 2012; Dwivedi et al., 2003), and the functional val66met polymorphism in the gene encoding BDNF has been associated with a wide variety of psychiatric phenotypes (Hong et al., 2009). In addition, animal studies showed that prolonged exposure to stress could be associated with decreased BDNF signaling, as well as impaired neurogenesis in the hippocampus (Mirescu et al., 2006; Taliaz et al., 2011; Tsankova et al., 2006). Accordingly, various classes of antidepressants were shown to activate BDNF-mediated signaling and reverse neuronal atrophy and cell loss induced by chronic stress in rodents (Castren et al., 2010; Schmidt et al., 2007), and infusion of BDNF directly into the hippocampus resulted in antidepressant effect in naïve mice (Shirayama et al., 2002; Ye et al., 2011). BDNF heterozygous knockout mice $\left(\mathrm{BDNF}^{+} /\right.$), displaying a reduction by half of BDNF levels, failed to show any depressive-like behavior in basal condition (Korte et al., 1995; MacQueen et al., 2001), whereas knockdown of BDNF in specific brain sites could impair neurogenesis and precipitate depressive-like behavior (Taliaz et al., 2010). In addition, genetic mice models lacking BDNF showed an increased vulnerability to stress as compared to their wild-type littermates (Yu et al., 2012), as well as an inability to respond to antidepressant treatment (Adachi et al., 2008; Yu et al., 2012), indicating a critical role for BDNF in the behavioral and neurochemical mediation of antidepressant response. Increasing evidences also suggest that the elevation of BDNF levels observed after antidepressant treatment might be attributed to epigenetic regulation (Boulle et al., 2012). Interestingly, diverse classes of antidepressants were evidenced to target the epigenetic machinery, which appeared to be necessary in mediating their therapeutic effects (Vialou et al., 2013). For instance, chronic treatment with imipramine was sufficient to increase histone acetylation specifically at the BDNF gene, which causally correlate with the reversal of behavioral impairments induced by social defeat stress in mice (Tsankova et al., 2006). Additionally, in this same model, the downregulation of histone deacetylase 5 (HDAC5) was necessary to correct for histone H3K9 hypoacetylation in the hippocampus and mediate the antidepressant action of imipramine (Tsankova et al., 2006). Moreover, DNA methyltransferase (DNMT) inhibitors and HDAC inhibitors produced antidepressant-like effects when administered in naïve mice (Sales et al., 2011; Covington et al., 2011), and the local administration of HDAC inhibitors in the nucleus accumbens exhibited similar gene expression profiles than the selective serotonin recapture inhibitor (SSRI) antidepressant fluoxetine 
(Covington et al., 2009). Among antidepressants, agomelatine has emerged as an innovative and atypical treatment, mediating its effects via the activation of melatonin receptor 1 (MT1) and 2 (MT2), and the inhibition of the serotonin $2 \mathrm{C}$ receptor $\left(5-\mathrm{HT}_{2 \mathrm{C}}\right)$. Agomelatine was shown to normalize altered BDNF regulation and impaired neurogenesis in rodent models of depression (Paizanis et al., 2010). Hence in the present study, we wanted to determine whether TrkB signaling was required for the neurobiological and behavioral actions of agomelatine. We used a recently developed TrkB inhibitor, Ana-12, which has been described as a potent and selective TrkB inhibitor that could lead to a decreased TrkB activity in mouse brain after peripheral administration (Cazorla et al., 2011). In our experiments, we performed dual administration of agomelatine, together with Ana-12, in a transgenic mouse model of affective disorders known as the glucocorticoid-receptor impaired (GR-i) mice. We previously showed that GR-i mice displayed a deficit in the hypothalamo-pituitary-adrenal (HPA) axis feedback under stressful conditions as well as neuroplastic impairment and despair-like behavior (Froger et al., 2004; Paizanis et al., 2010). Hence, in this transgenic mouse model we wanted to test the ability of agomelatine to rescue the behavioral and neurochemical alterations, and explore the involvement of TrkB in the mechanism of action of this new generation antidepressant.

\section{II - Material and methods}

Animals: Transgenic mice (strain B6C3F1; line 1.3) bearing a transgene for the glucocorticoid receptor (GR-i) and their paired wild-type (WT) were used in the experiments. Mice issued from the same gestation were housed in the same cage, under standard conditions $(22 \pm 21 \mathrm{C}, 60 \%$ humidity, 12-h lightdark cycle with lights on at $7.00 \mathrm{am}$, food and water ad libitum). The mice were bred at INSERM UMR894 / UPMC animal facility. Experiments were performed using 12-week-old mice (25-30 gm body weight). Procedures involving animals and their care were conducted in conformity with the institutional guidelines that are in compliance with national and international laws and policies (Council directive 87848, October 19, 1987, Ministere de l'Agriculture et de la Foret, Service Veterinaire de la Sante et de la Protection Animale; permissions 75-116 to M.H. and 006269 to L.L.).

Drug treatments: Administration of drugs was performed everyday at $6.00 \mathrm{pm}$ (i.e. 1 hour before the onset of dark period), for a total period of 21 days. The doses used in the experiments have been chosen on the basis of previous studies performed in validated mice models of depression and anxiety (Cazorla et al., 2011; Paizanis et al., 2010). First, Ana-12 (0.5 mg/kg, Maybridge, Illkirch, France) or its vehicle ( $\mathrm{NaCl} 0,9 \%$, tween $801 \%$ and dimethylsuphoxyde 1\%) was administered via intraperitoneal injections. After a 30-minute delay, agomelatine $(50 \mathrm{mg} / \mathrm{kg}$, Servier, Suresnes, France) or its vehicle hydroxyethylcellulose (HEC 1\%, Servier, Suresnes, France) were administered via the same injection mode. The animals were sacrificed 18 hours after the last injection. 


\section{Behavioral testing:}

\section{Tail suspension test (TST)}

The apparatus consists of three suspension units divided by walls (ID-Tech-Bioseb, Chaville, France). The mice were suspended by the tail with an adhesive tape, and the duration of immobility was measured automatically by the software over a 6-minute period.

\section{Splash test}

The splash test, previously described by Surget et al., 2008, consists into spraying a 10\% sucrose solution on the back of mice in their home cage. Because of its viscosity, the sucrose solution dirties the coat and induces grooming behavior. The total time of grooming over a 5-minute period was recorded in our experiments.

\section{Open field test}

The apparatus consisted of four open boxes of $40 \times 40 \mathrm{~cm}$ separated by white wood walls and equipped with an infrared floor for the measurement of motor activity. The arena was subdivided into a central and a peripheral zone. Mice were placed in the open field boxes for 20 min under normal light conditions, and the motor activity of the animals were automatically scored with a camera connected to a computerized system (Viewpoint, Lyon, France). The time spent in the different zones and the distance moved were scored.

\section{Forced swim test (FST)}

In the FST, originally designed by Porsolt and colleagues (1977), mice were placed into plastic buckets (19 cm diameter, $23 \mathrm{~cm}$ deep, filled with $23^{\circ} \mathrm{C}-25^{\circ} \mathrm{C}$ water) under low light conditions and videotaped for 6 min (Viewpoint, Lyon, France). The different outcome measures were "immobility" reflecting no movement at all and/or minor movements necessary to keep the nose above the water; "mobility" reflecting medium activity such as swimming; and "bursts" reflecting strong mobility and struggling behaviors.

\section{Fear conditioning}

The fear conditioning paradigm consisted into 3 days of behavioral testing, and was conducted in an operant chamber $(26 \mathrm{~cm}$ long $\times 18 \mathrm{~cm}$ wide $\times 22 \mathrm{~cm}$ high $)$ possessing aluminum sidewalls and Plexiglas rear and front walls, and a stainless steel grid floor. On the first day, all mice were allowed to acclimate to the training chamber for $3 \mathrm{~min}$, and then a tone (CS; conditioned stimulus) of $2500 \mathrm{~Hz}$ frequency and 85 $\mathrm{dB}$ intensity was presented for $30 \mathrm{~s}$ and terminated in the last $2 \mathrm{~s}$ with a mild foot shock $(0.75 \mathrm{~mA})$ (US; unconditioned stimulus). After a period of two minutes (ITI; inter-trial interval), another CS-US pairing was presented. For the contextual fear conditioning test, rats were returned to the same chamber used for 
the conditioning trial $24 \mathrm{~h}$ after conditioning and allowed to explore for $20 \mathrm{~min}$ without presentation of the auditory CS or foot shock. Twenty-four hours after the contextual fear conditioning test, the mice were tested for cued fear memory by returning them to the same chamber, which was modified by adding various hatch designs to the walls as well as a vanilla scent. Stimulus presentation and data acquisition were controlled by a computerized system interface. Freezing behavior, defined as complete absence of voluntary movements except for respiratory movements, was measured every $1 \mathrm{~s}$.

\section{Social interaction}

Mice were placed in an open boxes of $40 \times 40 \mathrm{~cm} 2$ separated by white wood walls for 20 minutes the day preceding the experiment in order to habituate the animal to the novel arena, and to maximize the duration of social interactions. The following day, mice of same genotype and unfamiliar to each other were placed in the same arena for 10 minutes, and videotaped using a fixed camera. Total time spent in active social interactions (including sniffing, chasing and grooming) was scored by an observer unaware of groups.

Quantitative reverse transcriptase PCR (qRT-PCR): Total mRNA extraction was performed using NucleoSpin RNA II kit (Macherey-Nagel, Hoerdt, France), after which, the cDNA synthesis was performed using a High Capacity cDNA Reverse Transcription kit (Applied Biosystems, Courtaboeuf, France) according to the manufacturer's protocol. The amplification was made with Absolute SYBR Green ROX Mix (Thermo Scientific, Illkirch, France) using the 7300 Real Time PCR System (Applied Biosystems, Courtaboeuf, France) and the sequences of primers used are indicated in Supplementary Table 1. Gene expressions were normalized using Hprt as a reference gene and the conditions for the reaction included 35 cycles in a fixed sequence of $95^{\circ} \mathrm{C}$ for $20 \mathrm{~s}, 62^{\circ} \mathrm{C}$ for $30 \mathrm{~s}$, and $72^{\circ} \mathrm{C}$ for $30 \mathrm{~s}$. The $2^{\Delta \Delta \mathrm{CT}}$ (Delta-Delta Comparative Threshold) method was used to normalize the fold change in gene expressions.

Immunohistochemistry: Coronal sections of $25 \mu \mathrm{m}$ between bregma levels -1.340 and -2.300 were collected at the cryostat (Leica CM 3050, Leica Microsystems, Wetzlar, Germany), after which sections were directly mounted on double dipped gelatin coated glass slides and stored at $-80^{\circ} \mathrm{C}$ until use. The sections were then fixed with $4 \%$ paraformaldehyde at $4^{\circ} \mathrm{C}$ for $10 \mathrm{~min}$. After permeabilizing the membranes with TBS-triton $0.05 \%$, the sections were incubated overnight at $4^{\circ} \mathrm{C}$ with the $\mathrm{Ki}-67$ antibody (1:1000, Vector Laboratories, Burlingame, Calif., USA). The sections were then incubated for 2 hour at room temperature in presence of appropriated biotinylated secondary antibodies, and the reaction was amplified using the $\mathrm{ABC}$ staining system (Vector Laboratories, Burlingame, Calif., USA) for one additional hour. Finally, the sections were treated with 3,3'-diaminobenzidine for 4 minutes. After dehydrating the sections and mounting with cover slip, the positive cells were counted under the microscope (Nikon Eclipse E400, Nikon Instruments Inc., Shanghai, China). 
Statistical analysis: Data are represented as mean \pm SEM and were analyzed using Student's $t$ test for comparison between two groups (Prism 5.0, GraphPad software, USA). When more than two groups of data, a one-way analysis of variance (ANOVA) was used followed by Fisher's LSD post hoc test in order to compare all the groups between them. In addition, a two-way ANOVA (agomelatine treatment $\mathrm{x}$ Ana12 treatment) was sometimes used to investigate the effect of the drug treatments in the GRi phenotype. The level of significance was set as $P<0.05$.

\section{III - Results}

Effects of impaired GR function on behavior: The battery of test routinely used to characterize depressive-like, anxiety-like and fear-related behaviors in rodents showed that GRi mice exhibited robust alterations in mood and emotions as compared to their wild-type littermates. As shown by figure S1, GRi mice showed an increased immobility in the TST $(+27 \%$, Figure S1) and decreased grooming behavior in the splash test (- $28 \%$, Figure S1). As previously reported by Barden and colleagues, GRi mice showed increased escape-like behavior in the FST (Barden et al., 2005). GRi mice had an increase of swimming behavior (+ $59 \%$, Figure S1), and a decrease immobility time (- $20 \%$, Figure S1) as compared to wild type mice. GRi mice also showed increased anxiety behavior and exaggerated fear responses. GRi mice had a decreased motor activity ( $-23 \%$ in small movement duration) and exploration ( $-31 \%$ in distance moved) in the open field test (Figure S2). In addition, these transgenic mice displayed a high score of inactivity in the open field arena $(+15 \%$, Figure S2), which might involve freezing behaviors (Figure S2). Accordingly, GRi mice displayed an increased freezing behavior when subjected to the fear conditioning paradigm (Figure S3). GRi mice showed higher rates of freezing in the fear acquisition test, the contextual fear conditioning test and the cued fear memory test. In addition, GRi mice showed elevated freezing behavior at baseline in the cued fear memory test, possibly indicating a generalization of fear (data not shown). Hence, the phenotype characterization of GRi mice pointed towards a marked dysregulation in mood and emotion responses, making this transgenic mouse a suitable model to explore different aspects of antidepressant action.

Effects of impaired GR function on hippocampal cell proliferation and gene expression: To further elucidate the cellular and molecular mechanisms underlying the reduced glucocorticoid receptor function, the expression of Ki67 (a marker of cell proliferation), as well as the expression of various genes implicated in neuronal plasticity and in transcription and epigenetic regulations, were measured. Immunohistochemical analysis revealed that cell proliferation in the subventricular zone (SVZ) of the dentate gyrus was decreased in GRi mice (- $34 \%$, Figure 4). Similar results using BrdU and DCX stainings in this region were reported in GRi mice (Paizanis et al., 2011). qRT-PCR analysis revealed a complex regulation of genes involved in neuronal plasticity. There was a decreased expression of the 
Bdnf4 transcript (- $24 \%$, Figure 5). Similarly, GRi mice exhibited a decreased expression of the B-cell lymphoma 2 (Bcl2) gene (- $26 \%$, Figure 5), a critical mediator of cell survival, as well as decreased expression of the FBJ osteosarcoma oncogene ( $C F O S)$ gene (- $50 \%$, Figure 6), known as a marker of neuronal activity. In contrast, the expression of glial cell line-derived neurotrophic factor $(G d n f)$ and nerve growth factor inducible $(V g f)$, two genes involved in neurotrophic signaling, were increased in GRi mice (+58\% and $+37 \%$ respectively, Figure 5). The expression of the corticotropin releasing factor $(\mathrm{Crf})$ gene was also increased in GRi mice. The GR usually exert a negative feedback on Crf expression, so it is not surprising to observe such variation. Similarly, the gene expression of various transcription factors, including the cAMP responsive element binding protein ( $\mathrm{Creb}$ ) gene and the early growth response 1 (Egrl) gene was increased $(+31 \%$ and $+22 \%$ respectively, Figure 5 and 6). Finally, expression of the epigenetic regulators was investigated. The expression of the DNA methyltransferase 1 (Dnmtl) gene and the DNA methyltransferase 3a (Dnmt3a) gene, both involved in active DNA methylation, was decreased in GRi mice (- $43 \%$ and $-46 \%$ respectively, Figure 6). In addition, the expression of the histone-lysine N-methyltransferase HRX 3 (Mll3) gene and the histone-lysine Nmethyltransferase HRX 4 (Mll4) gene, involved in histone methylation activity and transcription coactivation, was decreased in GRi mice (- $35 \%$ and $-28 \%$ respectively, Figure 6), but did not reach statistical significance.

Effects of agomelatine and TrkB antagonist on grooming and despair-like behavior: In a second step of the work, the ability of agomelatine to reverse the behavioral alterations was investigated. We combined the administration of agomelatine with a newly developed TrkB antagonist, Ana12, in order to investigate the involvement of TrkB in the mechanism of action of agomelatine. Agomelatine could significantly increase the time spent in grooming behavior in GRi mice (Figure 1). However, this effect could not be blocked when co-administered with Ana12 (Figure 1). In the TST, chronic administration of agomelatine to GRi mice could restore the immobility time to the level observed in wild type (GRi HEC SAL vs. GRi AGO SAL: $-42 \%$, Figure 1). Chronic treatment with the TrkB inhibitor Ana12 could reverse the increased immobility observed in GRi mice receiving only the vehicle (GRi HEC SAL v.s. GRi HEC ANA: $-44 \%$, Figure 1). This effect has already been described after acute exposure of $4 \mathrm{~h}$ with Ana12 in naïve mice (Cazorla et al., 2011). However, the co-administration of agomelatine and Ana12 did not show such kind of antidepressant effects. In the FST, GRi mice treated for 3 weeks with the vehicle of agomelatine and Ana12 (GRi HEC SAL) showed increased immobility as compared to WT mice treated with the 2 vehicles (WT HEC SAL), which appeared to be in opposition to what have been reported in basal conditions. This contrasting observation might be attributed to the effects of manipulation and stress of chronic injections on innate flight response and reactivity. However, chronic treatment with agomelatine significantly decreased the immobility time in the FST in the GRi phenotype (Two-way ANOVA, Figure 1), an effect usually observed after acute treatment with selective serotonin reuptake inhibitor (SSRI) antidepressants in this behavioral test. Similarly, agomelatine could increase the mobility 
of GRi mice, as shown by higher swimming and burst duration (Figure 1). Of note, the antidepressant-like effect of agomelatine could not be abolished by Ana12 treatment (Figure 1).

Effects of agomelatine and TrkB antagonist on fear and anxiety: Chronic treatment with agomelatine significantly reversed the anxious phenotype of GRi mice in the open field test (Figure 2). Accordingly, agomelatine increased the distance covered and the small movement activity, and decreased the inactivity duration. In contrast, Ana12 had an anxiogenic effect in the open field test by decreasing the distance covered and duration in small movement activity, and increasing the inactivity duration. Interestingly, the effect of agomelatine on the distance covered and activity duration could be blocked when this antidepressant was administered together with Ana12. No effect was observed for the inactivity duration. Further, the effects of agomelatine and Ana12 on fear response were investigated. GRi mice displayed robust freezing behavior in response to fearful stimuli, as well as impairment to erase fear memories (Figure S3 and Figure 3). However, neither agomelatine nor Ana12 could prevent the exaggerated fear response in the fear conditioning test.

Effects of agomelatine and TrkB antagonist on hippocampal gene expression and cell proliferation: As previously reported, GRi mice have an impaired hippocampal neurogenesis including a decrease proliferation in the SGZ of the dentate gyrus (Paizanis et al., 2011). In this same study, it was evidenced by BrdU labeling that chronic treatment of 21 days with agomelatine $(50 \mathrm{mg} / \mathrm{kg} /$ day $)$ could significantly restore a normal cell proliferation in the SGZ. Here, a similar effect of agomelatine on cell proliferation in the SGZ was evidenced by Ki67 immunolabelling (Figure 4). Agomelatine increase the number of proliferative cells by approximately $74 \%$ in GRi mice. In addition, clear-cut evidences demonstrate that this effect could be abolished when agomelatine was administered together with the TrkB antagonist Ana12 (- $44 \%$ between GRi AGO SAL and GRi AGO ANA, Figure 4). Further, the levels of Bcl2, Bdnf4 and cFos mRNAs, which was decreased in GRi mice, could be significantly upregulated after chronic treatment with agomelatine $(+66 \%,+50 \%$ and $+61 \%$ respectively, Figure 5 and 6$)$. In contrast, chronic administration of agomelatine significantly decreased the levels of $V g f$ mRNAs (- $37 \%$, Figure 5). Furthermore, chronic treatment with Ana12 significantly decreased the expression of $G d n f$ and $c F o s$ in GRi mice (two-way ANOVA, Figure 5 and 6), whereas an upregulation of Bdnf4, Crf and Egrl mRNA levels was observed (GRi HEC SAL vs. GRi HEC ANA: $+116 \%,+31 \%$ and $+30 \%$ respectively, Figure 5 and 6). However, no modulations of Creb, Dnmt1, Dnmt3a, Mll3 and Mll4 mRNA levels were observed after either agomeltine or Ana12 treatments. Finally, there was a significant difference between GRi mice treated with agomelatine alone (GRi AGO SAL) and GRi mice treated with agomelatine + Ana12 (GRi AGO ANA) regarding the expression of Bcl2 and $c F$ os genes (GRi AGO SAL vs. GRi AGO ANA: - $39 \%$ and - $49 \%$ respectively, Figure 5 and 6), suggesting that Ana12 could block the ability of agomelatine to restore a normal expression at those specific genes. 


\section{IV - Discussion}

Mounting evidences suggest that HPA axis impairment may play an important part in the pathophysiology of major depression, and that the neuronal loss and synaptic dysfunction induced by prolonged stress exposure might involve alterations in neurotrophic signaling (Pariante et al., 2008; Vreeburg et al., 2009). Furthermore, many studies have reported a critical involvement of BDNF/TrkB signaling in the mechanism of action of conventional antidepressants (Castren et al., 2010). In this context, the aim of the present study was to investigate the implication of TrkB signaling in the behavioral and neuroplastic effect of the new generation antidepressant agomelatine in the GRi transgenic mouse, a rodent model of glucocorticoid-induced mood disorders.

Effect of impaired GR function on neuroplasticity and behavior: As previously reported, GRi mice displayed a reduced expression of GR mRNA in the brain and a disrupted HPA axis (Pepin et al., 1992; Froger et al., 2004). In addition, the present study showed an elevation of $C r f$ mRNA in the hippocampus of GRi mice. Under normal conditions, the HPA axis exerts a negative feedback on $C r f$ expression via GRs. Hence, it is not surprising that a reduced function of GR resulted in increasing Crf mRNA levels in the brain. Further, an impairment of hippocampal cell proliferation and decreased Bdnf mRNA levels were observed in previous investigations (Paizanis et al., 2011). Here, we confirmed the deficit in hippocampal cell proliferation, and bring more insight into the exon-specific regulation of the $B d n f$ gene and in GRi mice. The expression of Bdnf4 transcript was decreased in the hippocampus of GRi mice. BDNF expression is tightly regulated at the level of transcription with differential exon usage, suggesting a crucial role for the various transcripts in different functions and related processes (Pruunsild et al., 2007; Baj et al., 2011). The Bdnf4 transcript has been particularly reported in rodent models of stress, and in the mechanism of action of antidepressants (Tsankova et al., 2006; Dwivedi et al., 2006; Boulle et al., 2012). Next to that, the mRNA levels of Bcl2 and $c F o s$ were decreased in GRi mice. Bcl2 plays a critical role in cell survival, and cFos is a marker of neuronal activation (Bullitt et al., 1990; Davies et al., 1995; Zhang et al., 2002). Hence, the decrease of these two factors, together with Bdnf4, is in accordance with the impaired hippocampal neurogenesis in GRi mice. In contrast, the mRNA levels of Gdnf, Vgf, Creb and Egrl were increased in the hippocampus of GRi mice. These genes are also implicated, at different levels, in the mediation of neuronal plasticity (Benito et al., 2010; Bozdagi et al., 2008; Li et al., 2005; Sariola et al., 2003). Accordingly, it is possible that compensatory mechanisms involving other types of neuroplastic adaptations might be activated in response to the deficit in neurogenesis. Finally, the investigation of epigenetic markers revealed a strong alteration in the machinery controlling histone posttranslational modifications and DNA methylation. Such kind of epigenetic regulations in the central nervous system has been described as a key-role mechanism in the maintenance of neuronal plasticity (Maze et al., 2012; Sultan and Day, 2011). In particular, stress and environmental adversity has been 
shown to impact on chromatin and histone regulations to generate an epigenetic reprogramming, possibly increasing the susceptibility for mood disorders (Tsankova et al., 2007; Boulle et al., 2012).

At the behavioral level, we found that GRi mice exhibited an anxious phenotype as well as a marked impairment in fear-related behaviors. GRi mice also showed a decrease in grooming behavior, an indicator of a self-neglecting and motivational deficit that has been linked to altered ACTH function (Argiolas et al., 2000). As reported by previous findings, GRi mice displayed an increase immobility time in the TST and increased activity in the FST in basal conditions (Barden et al., 2005; Paizanis et al., 2011). These results could be confirmed in the present study. However, the observed phenotype in the FST tended to disappear after 21 days of chronic drug injections. This effect can be attributed to the manipulation of the animals that might interfere with the innate mechanisms involved in the stress response. Altogether, the behavioral analysis indicated a marked alteration in mood-related behaviors in the transgenic GRi mice. Accordingly, the impairment of neurogenesis, together with the alterations in gene expression and epigenetic regulations, might be causally related to the alterations observed at the behavioral level.

TrkB signaling in the mechanism of action of agomelatine: Chronic treatment with agomelatine could produce an antidepressant-like effect in GRi mice, as observed by the decrease of despair-like behavior in the TST and FST, and increase of self-grooming behavior in the splash test. Interestingly, the effect of agomelatine in the splash test and the FST was not dependent on TrkB signaling. On the other hand, the effects of agomelatine in the TST were blocked by Ana12, suggesting a critical role of TrkB signaling in the neurochemical pathways underlying this behavioral performance. Similarly, the inhibition of TrkB could abolish the anxiolytic effect of agomelatine in the open field test. This observation is especially interesting since other studies, using genetic BDNF knockdown approaches in mice, also showed an inability for diverse classes of antidepressants to exert their effects in the above-mentioned behavioral tasks (Adachi et al., 2008; Yu et al., 2012). In addition, post-mortem studies showed that the expression of BDNF was significantly higher in patients treated with antidepressants (Chen et al., 2001), and some subpopulation of individuals carrying the functional val66met polymorphism in the gene encoding for BDNF showed an impaired antidepressant response (Niitsu et al., 2013). Further, agomelatine could restore the deficit in hippocampal cell proliferation observed in GRi mice. This effect was entirely dependent on TrkB, since the co-administration of agomelatine with Ana12 completely abolished the increased hippocampal cell proliferation observed with agomelatine treatment alone. This finding is of particular relevance because BDNF/TrkB signaling has been frequently associated with neurogenesis, and alteration of such physiological mechanisms might be causally linked to mood disorders (Snyder et al., 2011). Accordingly, the decrease of Bcl2, Bdnf4 and $c F o s$ in GRi mice could be restored by chronic agomelatine treatment, which appeared to be dependent on TrkB signaling. This latter finding confirmed the importance of BDNF/TrkB signaling and downstream neuroplastic changes in the mediation of 
antidepressant actions. Interestingly, agomelatine could normalize the expression of other genes such as Egrl and $\mathrm{Vgf}$ further supporting that this antidepressant is efficient to restore a normal balance in gene expression profiles in pathological models. However, chronic treatment with agomelatine could not restore normal epigenetic patterns in the hippocampus of GRi mice. These latter findings do not support the notion that the reversal of epigenetic alterations by antidepressant drugs is required for their therapeutic response.

Effect of TrkB antagonist on mood-related behaviors: Moreover, the present findings also bring some novel insights into the behavioral and neuroplastic properties of TrkB inhibitors. As already shown by Cazorla and colleagues in a recent study, the newly developed TrkB inhibitor Ana12 displayed antidepressant properties in the TST when injected acutely (Cazorla et al., 2011). Using this same dose of $0.5 \mathrm{mg} / \mathrm{kg}$, we found a comparable effect after chronic injections of 21 days. These findings are rather provocative because a growing body of literature indicated similar results after administration of BDNF directly in the hippocampus, or peripheral administration of TrkB agonists (Liu et al., 2010; Shirayama et al., 2002). However, clean-cut evidences in both rodents and human studies demonstrated that stress and/or major depression could be associated with increased BDNF levels in the nucleus accumbens (Krishnan et al., 2007). Hence, the pathophysiology of depression appears to be complex, and might involve a region-specific regulation of BDNF/TrkB signaling. Further, chronic administration of Ana12 resulted in an anxiogenic effects in GRi mice, and might causally correlate with the reduced expression of $c F o s$ and Gdnf observed in the hippocampus. In line with the present results, previous studies showed the val66met polymorphism in the gene encoding BDNF has been linked to anxiety disorders (Chen et al 2006), and reduced levels of BDNF in the hippocampus have been associated with an increased anxiety in rodents (Martinowich et al., 2007).

Conclusion and perspectives: In conclusion, our data provide a deeper understanding about the involvement of TrkB signaling in the mechanism of action of agomelatine, and in the treatment of mood disorders. In accordance with other studies that proposed a critical role for BDNF in the therapeutic action of classical antidepressants (Castren et al., 2010), our findings provide further evidences that novel antidepressant displaying an atypical mechanism of action could also target BDNF/TrkB signaling to exert its behavioral and neuroplastic effects in a transgenic mouse model of mood disorders. Our data support the idea that therapeutic actions of antidepressants involve various neurocircuits, and that some of these neurochemical pathways may require $\mathrm{BDNF} / \mathrm{TrkB}$ and downstream neuroplastic signaling to regulate mood. 


\section{V - References}

Adachi, M., Barrot, M., Autry, A. E., Theobald, D. and Monteggia, L. M. (2008) Selective loss of brain-derived neurotrophic factor in the dentate gyrus attenuates antidepressant efficacy. Biol Psychiatry 63, 642-649.

Argiolas, A., Melis, M. R., Murgia, S. and Schioth, H. B. (2000) ACTH- and alpha-MSH-induced grooming, stretching, yawning and penile erection in male rats: site of action in the brain and role of melanocortin receptors. Brain Res Bull 51, 425-431.

Autry, A. E. and Monteggia, L. M. (2012) Brain-derived neurotrophic factor and neuropsychiatric disorders. Pharmacol Rev 64, 238-258.

Baj, G., Leone, E., Chao, M. V. and Tongiorgi, E. (2011) Spatial segregation of BDNF transcripts enables BDNF to differentially shape distinct dendritic compartments. Proc Natl Acad Sci U S A 108, 16813-16818.

Barden, N., Shink, E., Labbe, M., Vacher, R., Rochford, J. and Mocaer, E. (2005) Antidepressant action of agomelatine (S 20098) in a transgenic mouse model. Prog Neuropsychopharmacol Biol Psychiatry 29, 908-916.

Benito, E. and Barco, A. (2010) CREB's control of intrinsic and synaptic plasticity: implications for CREBdependent memory models. Trends Neurosci 33, 230-240.

Berton, O. and Nestler, E. J. (2006) New approaches to antidepressant drug discovery: beyond monoamines. Nat Rev Neurosci 7, 137-151.

Boulle, F., van den Hove, D. L., Jakob, S. B., Rutten, B. P., Hamon, M., van Os, J., Lesch, K. P., Lanfumey, L., Steinbusch, H. W. and Kenis, G. (2012) Epigenetic regulation of the BDNF gene: implications for psychiatric disorders. Mol Psychiatry 17, 584-596.

Bozdagi, O., Rich, E., Tronel, S., Sadahiro, M., Patterson, K., Shapiro, M. L., Alberini, C. M., Huntley, G. W. and Salton, S. R. (2008) The neurotrophin-inducible gene Vgf regulates hippocampal function and behavior through a brain-derived neurotrophic factor-dependent mechanism. J Neurosci 28, 9857-9869.

Bullitt, E. (1990) Expression of c-fos-like protein as a marker for neuronal activity following noxious stimulation in the rat. J Comp Neurol 296, 517-530.

Castren, E. and Rantamaki, T. (2010) The role of BDNF and its receptors in depression and antidepressant drug action: Reactivation of developmental plasticity. Dev Neurobiol 70, 289-297.

Cazorla, M., Premont, J., Mann, A., Girard, N., Kellendonk, C. and Rognan, D. (2011) Identification of a lowmolecular weight TrkB antagonist with anxiolytic and antidepressant activity in mice. J Clin Invest 121, $1846-1857$.

Chen, B., Dowlatshahi, D., MacQueen, G. M., Wang, J. F. and Young, L. T. (2001) Increased hippocampal BDNF immunoreactivity in subjects treated with antidepressant medication. Biol Psychiatry 50, 260-265.

Chen, Z. Y., Jing, D., Bath, K. G., Ieraci, A., Khan, T., Siao, C. J., Herrera, D. G., Toth, M., Yang, C., McEwen, B. S., Hempstead, B. L. and Lee, F. S. (2006) Genetic variant BDNF (Val66Met) polymorphism alters anxiety-related behavior. Science 314, 140-143.

Covington, H. E., 3rd, Maze, I., LaPlant, Q. C., Vialou, V. F., Ohnishi, Y. N., Berton, O., Fass, D. M., Renthal, W., Rush, A. J., 3rd, Wu, E. Y., Ghose, S., Krishnan, V., Russo, S. J., Tamminga, C., Haggarty, S. J. and Nestler, E. J. (2009) Antidepressant actions of histone deacetylase inhibitors. J Neurosci 29, 11451-11460.

Covington, H. E., 3rd, Vialou, V. F., LaPlant, Q., Ohnishi, Y. N. and Nestler, E. J. (2011) Hippocampal-dependent antidepressant-like activity of histone deacetylase inhibition. Neurosci Lett 493, 122-126.

Davies, A. M. (1995) The Bcl-2 family of proteins, and the regulation of neuronal survival. Trends Neurosci 18, 355-358.

Duman, R. S. and Aghajanian, G. K. (2012) Synaptic dysfunction in depression: potential therapeutic targets. Science 338, 68-72. 
Dwivedi, Y., Rizavi, H. S., Conley, R. R., Roberts, R. C., Tamminga, C. A. and Pandey, G. N. (2003) Altered gene expression of brain-derived neurotrophic factor and receptor tyrosine kinase $\mathrm{B}$ in postmortem brain of suicide subjects. Arch Gen Psychiatry 60, 804-815.

Dwivedi, Y., Rizavi, H. S. and Pandey, G. N. (2006) Antidepressants reverse corticosterone-mediated decrease in brain-derived neurotrophic factor expression: differential regulation of specific exons by antidepressants and corticosterone. Neuroscience 139, 1017-1029.

Froger, N., Palazzo, E., Boni, C., Hanoun, N., Saurini, F., Joubert, C., Dutriez-Casteloot, I., Enache, M., Maccari, S., Barden, N., Cohen-Salmon, C., Hamon, M. and Lanfumey, L. (2004) Neurochemical and behavioral alterations in glucocorticoid receptor-impaired transgenic mice after chronic mild stress. J Neurosci 24, 2787-2796.

Hong, C. J., Liou, Y. J. and Tsai, S. J. (2009) Effects of BDNF polymorphisms on brain function and behavior in health and disease. Brain Res Bull 86, 287-297.

Korte, M., Carroll, P., Wolf, E., Brem, G., Thoenen, H. and Bonhoeffer, T. (1995) Hippocampal long-term potentiation is impaired in mice lacking brain-derived neurotrophic factor. Proc Natl Acad Sci U S A 92, 8856-8860.

Krishnan, V., Han, M. H., Graham, D. L., Berton, O., Renthal, W., Russo, S. J., Laplant, Q., Graham, A., Lutter, M., Lagace, D. C., Ghose, S., Reister, R., Tannous, P., Green, T. A., Neve, R. L., Chakravarty, S., Kumar, A., Eisch, A. J., Self, D. W., Lee, F. S., Tamminga, C. A., Cooper, D. C., Gershenfeld, H. K. and Nestler, E. J. (2007) Molecular adaptations underlying susceptibility and resistance to social defeat in brain reward regions. Cell 131, 391-404.

Li, L., Carter, J., Gao, X., Whitehead, J. and Tourtellotte, W. G. (2005) The neuroplasticity-associated arc gene is a direct transcriptional target of early growth response (Egr) transcription factors. Mol Cell Biol 25, 10286-10300.

Liu, X., Chan, C. B., Jang, S. W., Pradoldej, S., Huang, J., He, K., Phun, L. H., France, S., Xiao, G., Jia, Y., Luo, H. R. and Ye, K. (2010) A Synthetic 7,8-Dihydroxyflavone Derivative Promotes Neurogenesis and Exhibits Potent Antidepressant Effect. J Med Chem.

Lu, B. and Martinowich, K. (2008) Cell biology of BDNF and its relevance to schizophrenia. Novartis Found Symp 289, 119-129; discussion 129-135, 193-115.

MacQueen, G. M., Ramakrishnan, K., Croll, S. D., Siuciak, J. A., Yu, G., Young, L. T. and Fahnestock, M. (2001) Performance of heterozygous brain-derived neurotrophic factor knockout mice on behavioral analogues of anxiety, nociception, and depression. Behav Neurosci 115, 1145-1153.

Martinowich, K., Manji, H. and Lu, B. (2007) New insights into BDNF function in depression and anxiety. Nat Neurosci 10, 1089-1093.

Maze, I., Noh, K. M. and Allis, C. D. (2012) Histone regulation in the CNS: basic principles of epigenetic plasticity. Neuropsychopharmacology 38, 3-22.

Mirescu, C. and Gould, E. (2006) Stress and adult neurogenesis. Hippocampus 16, 233-238.

Niitsu, T., Fabbri, C., Bentini, F. and Serretti, A. (2013) Pharmacogenetics in major depression: a comprehensive meta-analysis. Prog Neuropsychopharmacol Biol Psychiatry 45, 183-194.

Paizanis, E., Renoir, T., Lelievre, V., Saurini, F., Melfort, M., Gabriel, C., Barden, N., Mocaer, E., Hamon, M. and Lanfumey, L. (2010) Behavioural and neuroplastic effects of the new-generation antidepressant agomelatine compared to fluoxetine in glucocorticoid receptor-impaired mice. Int J Neuropsychopharmacol 13, 759-774.

Pariante, C. M. and Lightman, S. L. (2008) The HPA axis in major depression: classical theories and new developments. Trends Neurosci 31, 464-468.

Pepin, M. C., Pothier, F. and Barden, N. (1992) Impaired type II glucocorticoid-receptor function in mice bearing antisense RNA transgene. Nature 355, 725-728.

Porsolt, R. D., Le Pichon, M. and Jalfre, M. (1977) Depression: a new animal model sensitive to antidepressant treatments. Nature 266, 730-732. 
Pruunsild, P., Kazantseva, A., Aid, T., Palm, K. and Timmusk, T. (2007) Dissecting the human BDNF locus: bidirectional transcription, complex splicing, and multiple promoters. Genomics 90, 397-406.

Sales, A. J., Biojone, C., Terceti, M. S., Guimaraes, F. S., Gomes, M. V. and Joca, S. R. (2011) Antidepressant-like effect induced by systemic and intra-hippocampal administration of DNA methylation inhibitors. Br J Pharmacol 164, 1711-1721.

Sariola, H. and Saarma, M. (2003) Novel functions and signalling pathways for GDNF. J Cell Sci 116, 3855-3862.

Schmidt, H. D. and Duman, R. S. (2007) The role of neurotrophic factors in adult hippocampal neurogenesis, antidepressant treatments and animal models of depressive-like behavior. Behav Pharmacol 18, 391-418.

Shirayama, Y., Chen, A. C., Nakagawa, S., Russell, D. S. and Duman, R. S. (2002) Brain-derived neurotrophic factor produces antidepressant effects in behavioral models of depression. J Neurosci 22, 3251-3261.

Shirayama, Y., Chen, A. C., Nakagawa, S., Russell, D. S. and Duman, R. S. (2002) Brain-derived neurotrophic factor produces antidepressant effects in behavioral models of depression. J Neurosci 22, 3251-3261.

Snyder, J. S., Soumier, A., Brewer, M., Pickel, J. and Cameron, H. A. (2011) Adult hippocampal neurogenesis buffers stress responses and depressive behaviour. Nature 476, 458-461.

Sultan, F. A. and Day, J. J. (2011) Epigenetic mechanisms in memory and synaptic function. Epigenomics 3, 157181.

Surget, A., Saxe, M., Leman, S., Ibarguen-Vargas, Y., Chalon, S., Griebel, G., Hen, R. and Belzung, C. (2008) Drug-dependent requirement of hippocampal neurogenesis in a model of depression and of antidepressant reversal. Biol Psychiatry 64, 293-301.

Taliaz, D., Loya, A., Gersner, R., Haramati, S., Chen, A. and Zangen, A. (2011) Resilience to chronic stress is mediated by hippocampal brain-derived neurotrophic factor. J Neurosci 31, 4475-4483.

Taliaz, D., Stall, N., Dar, D. E. and Zangen, A. (2010) Knockdown of brain-derived neurotrophic factor in specific brain sites precipitates behaviors associated with depression and reduces neurogenesis. Mol Psychiatry 15, 80-92.

Tsankova, N., Renthal, W., Kumar, A. and Nestler, E. J. (2007) Epigenetic regulation in psychiatric disorders. Nat Rev Neurosci 8, 355-367.

Tsankova, N. M., Berton, O., Renthal, W., Kumar, A., Neve, R. L. and Nestler, E. J. (2006) Sustained hippocampal chromatin regulation in a mouse model of depression and antidepressant action. Nat Neurosci 9, 519-525.

Vialou, V., Feng, J., Robison, A. J. and Nestler, E. J. (2013) Epigenetic mechanisms of depression and antidepressant action. Annu Rev Pharmacol Toxicol 53, 59-87.

Vreeburg, S. A., Hoogendijk, W. J., van Pelt, J., Derijk, R. H., Verhagen, J. C., van Dyck, R., Smit, J. H., Zitman, F. G. and Penninx, B. W. (2009) Major depressive disorder and hypothalamic-pituitary-adrenal axis activity: results from a large cohort study. Arch Gen Psychiatry 66, 617-626.

Ye, Y., Wang, G., Wang, H. and Wang, X. (2011) Brain-derived neurotrophic factor (BDNF) infusion restored astrocytic plasticity in the hippocampus of a rat model of depression. Neurosci Lett 503, 15-19.

Yu, H., Wang, D. D., Wang, Y., Liu, T., Lee, F. S. and Chen, Z. Y. (2012) Variant brain-derived neurotrophic factor Val66Met polymorphism alters vulnerability to stress and response to antidepressants. J Neurosci 32, 4092-4101.

Zhang, J., Zhang, D., McQuade, J. S., Behbehani, M., Tsien, J. Z. and Xu, M. (2002) c-fos regulates neuronal excitability and survival. Nat Genet 30, 416-420. 


\section{Figures and legends.}

A

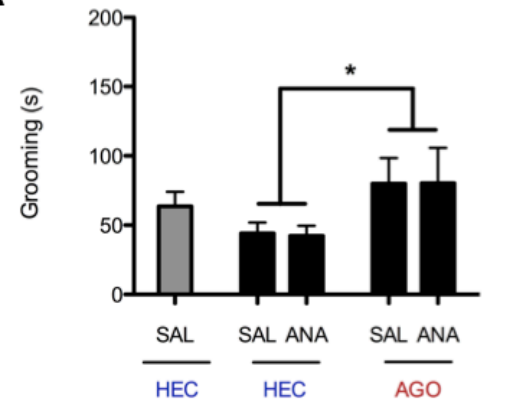

B

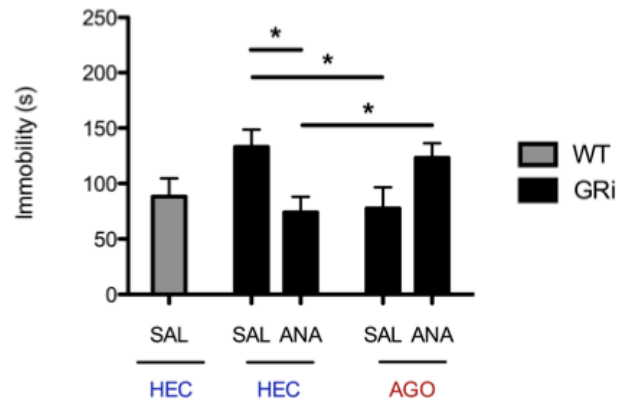

C

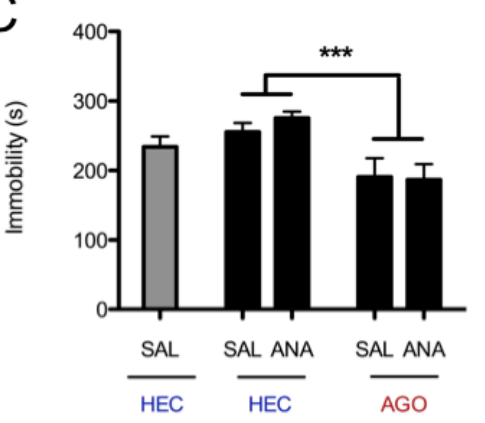

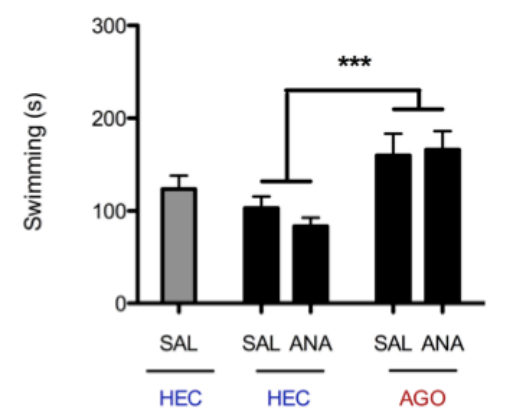

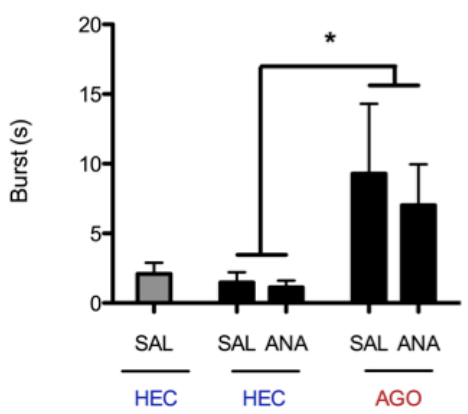

Figure 1. Effects of chronic agomelatine treatment in combination with a TrkB inhibitor on depressive-like behavior

(A) The time spent in grooming behavior over a total period of 5 minutes was measured in mice. The two-way ANOVA between agomelatine and Ana12 factors in the GRi genotype indicated a significant effect of agomelatine $[F(1,21)=5.71 ; p<0.01]$, but no effect of $\operatorname{Ana} 12[F(1,21)=0.002 ; p>0.05]$ on the time spent in grooming behavior. (B) The immobility time in the tail suspension test paradigm was measured after chronic mild stress. The one-way ANOVA indicated a significant interaction $\mathrm{F}(4,28)=3.17 ; \mathrm{p}<0.05]$. A LSD post hoc test was used to determine the significant difference between groups $(* \mathrm{p}<0.05)$. (C) Mice were subjected to a forced swim test, and the time spent in immobility, swimming and high mobility (burst), over a 6-minute period, is represented. The two-way ANOVA between agomelatine and Ana12 factors in the GRi genotype indicated a significant effect of agomelatine on immobility $[F(1,22)=17.65 ; \mathrm{p}<0.001]$, swimming $[\mathrm{F}(1,22)=17.94 ; \mathrm{p}<0.001]$ and high mobility $[\mathrm{F}(1,22)=6.39$; $\mathrm{p}<0.05]$. No significant effects were observed in the LSD post hoc test. Data are expressed as mean + S.E.M of $\mathrm{n}=5-$ 8 mice per group. $* \mathrm{p}<0.05 ; * * * \mathrm{p}<0.001$. 

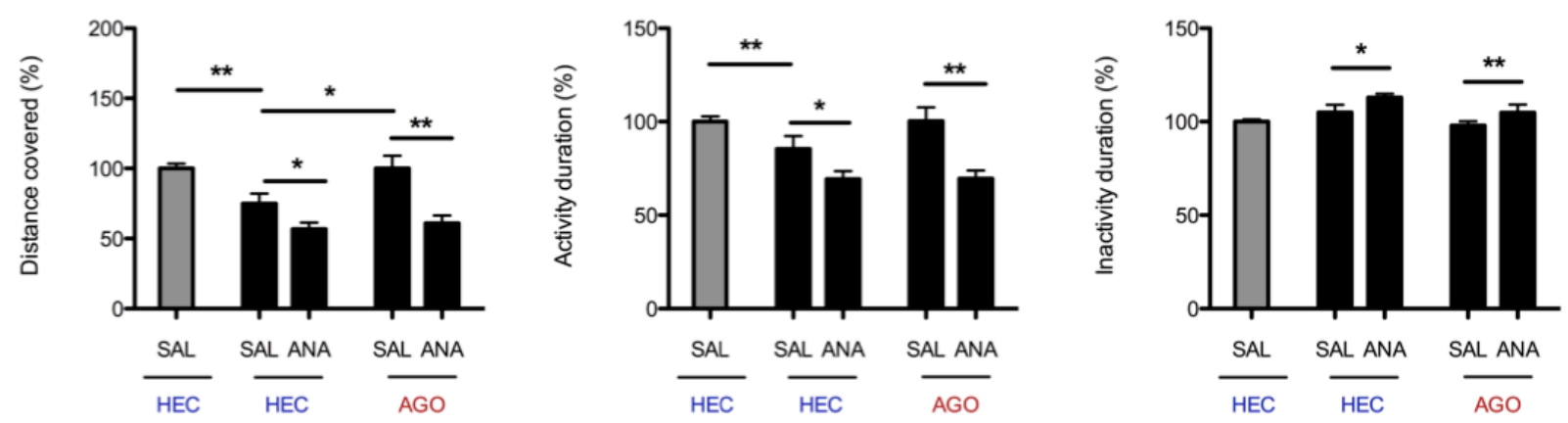

$\square$ WT $\square$ GRi

\section{Figure 2. Effects of chronic agomelatine treatment in combination with a TrkB inhibitor on anxiety behavior}

Mice were subjected to an open field test, and the distance covered, the time spent in small movement activity and the time spent in inactivity were measured over 20 minutes. A one-way ANOVA indicated a significant interaction in the distance covered $[\mathrm{F}(4,32)=10.72 ; \mathrm{p}<0.001]$, the time spent in small movement activity $[\mathrm{F}(4,32)=9.20$; $\mathrm{p}<0.001]$ and the time spent in inactivity $[\mathrm{F}(4,32)=6.91 ; \mathrm{p}<0.01]$. A LSD post hoc test was used to determine the significant difference between groups $\left({ }^{*} \mathrm{p}<0.05 ; *{ }^{*} \mathrm{p}<0.01\right)$. Data are expressed as mean + S.E.M of $\mathrm{n}=5-8 \mathrm{mice}$ per group. 
A Day 1:
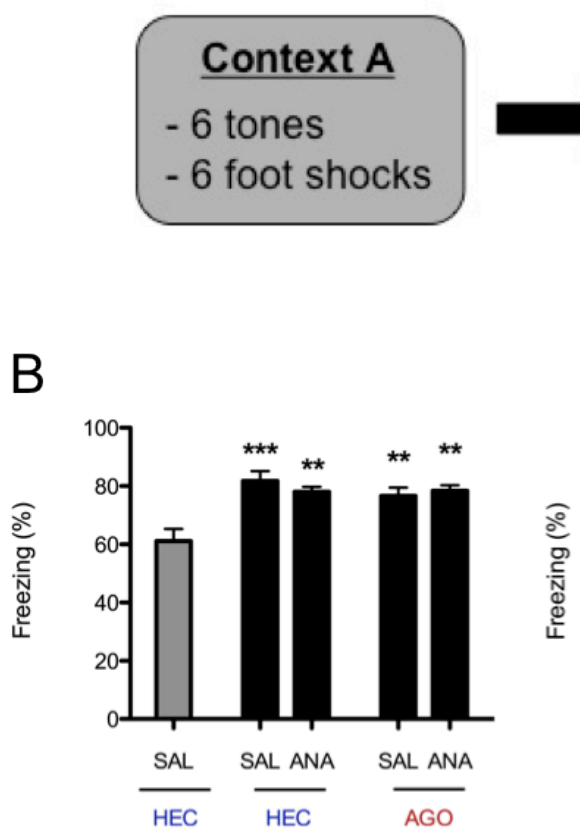

Day 2:

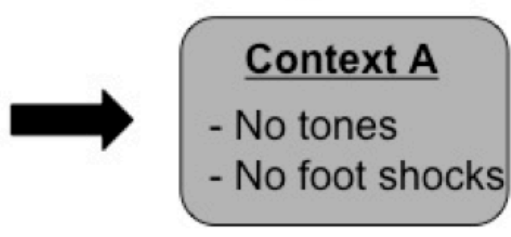

Day 3:

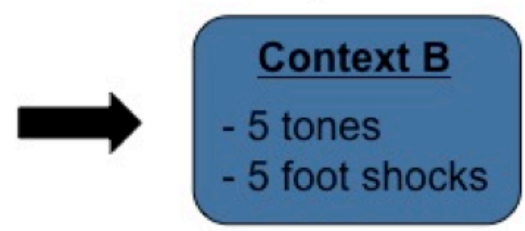

Figure 3. Effects of chronic agomelatine treatment in combination with a TrkB inhibitor on fear behavior

(A) A schematic representation of the fear conditioning procedure is represented. For more details see the material and methods section. (B) The freezing behavior during the fear acquisition (Day 1; left panel), the contextual fear conditioning (Day 2; center panel) and the cued fear memory (Day 3; right panel) test was measured during the tone periods, and the average freezing is represented. A one-way ANOVA indicated a significant interaction in the fear acquisition test $[\mathrm{F}(4,32)=6.76 ; \mathrm{p}<0.001]$, the contextual fear conditioning test $[\mathrm{F}(4,32)=9.23 ; \mathrm{p}<0.001]$ and the cued fear memory test $[\mathrm{F}(4,32)=13.75 ; \mathrm{p}<0.001]$. The LSD post hoc test revealed a significant difference in freezing between WT mice treated with vehicles (WT HEC SAL) and GRi mice treated with all the different combinations of treatments (GRi HEC SAL, GRi HEC ANA, GRi AGO SAL and GRi AGO ANA). Data are expressed as mean + S.E.M of $\mathrm{n}=5-9$ mice per group. ${ }^{*} \mathrm{p}<0.05 ; * * \mathrm{p}<0.01 ; * * * \mathrm{p}<0.001$. 
A

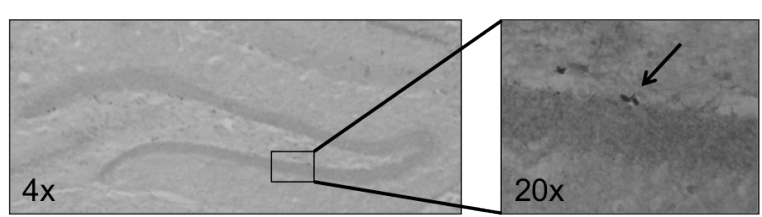

B

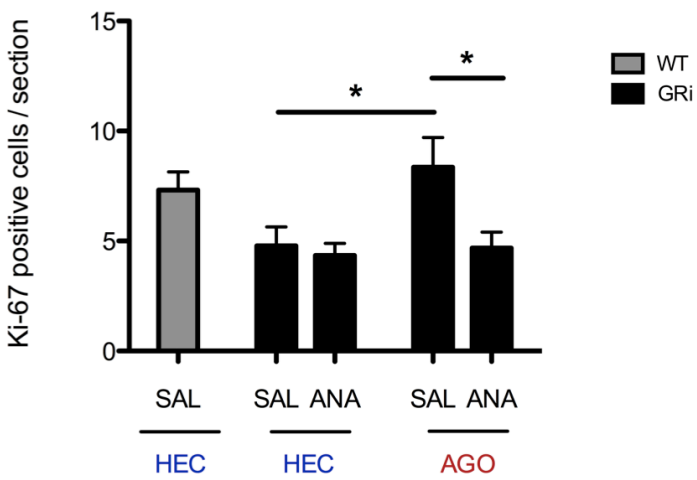

Figure 4. Effects of chronic agomelatine treatment on hippocampal cell proliferation

(A) An example of proliferative Ki67 immunoreactive cells in the dentate gyrus (DG) of the hippocampus is illustrated. (B) Mice were treated with agomelatine with or without TrkB inhibitor, and the number of proliferative Ki67 immunoreactive cells per section in the SGZ of the DG was investigated. A one-way ANOVA indicated a significant interaction $[F(4,29)=3.07 ; p<0.05]$, and the significant differences between groups were determined with a LSD post hoc test $\left({ }^{*} \mathrm{p}<0.05 ;{ }^{* *} \mathrm{p}<0.01 ; * * * \mathrm{p}<0.001\right)$. Data are expressed as mean + S.E.M of $\mathrm{n}=5-9$ mice per group. 

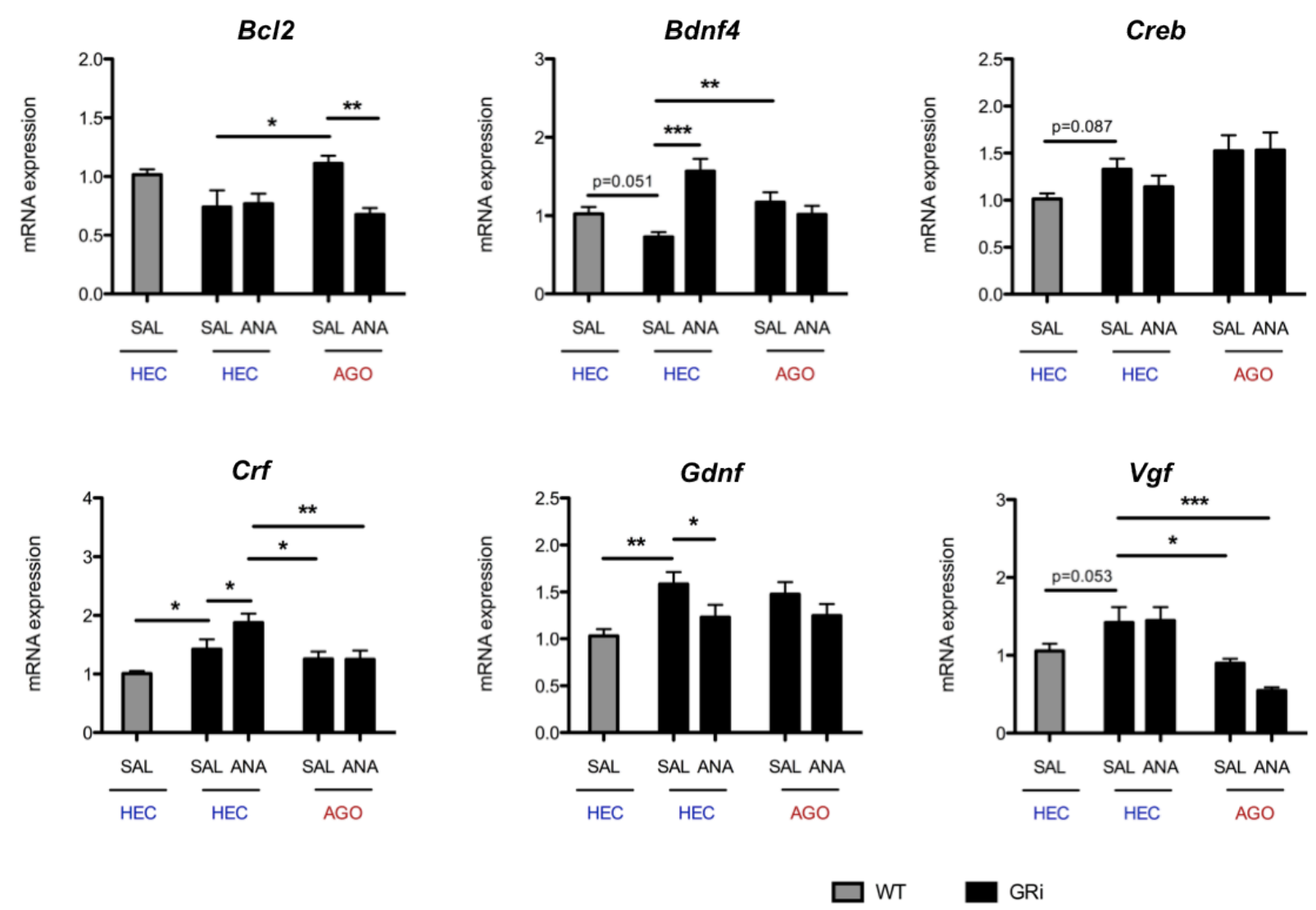

Figure 5. Effects of chronic agomelatine treatment in combination with a TrkB inhibitor on plasticity-related gene expression in the hippocampus

mRNA levels of plasticity-related genes in the hippocampus of mice were measured by quantitative real-time RTPCR, and are expressed as fold changes as compared to the WT mice treated with the two vehicles (WT HEC SAL). A one-way ANOVA indicated a significant interaction for $B c l 2[\mathrm{~F}(4,65)=4.16 ; \mathrm{p}<0.01], B \operatorname{lnf} 4[\mathrm{~F}(1,29)=7.12$; $\mathrm{p}<0.01]$, Creb $[\mathrm{F}(4,34)=3.86 ; \mathrm{p}<0.05], \operatorname{Crf}[\mathrm{F}(4,34)=7.61 ; \mathrm{p}<0.001], \operatorname{Gdnf}[\mathrm{F}(4,66)=7.44 ; \mathrm{p}<0.001]$ and $\operatorname{Vgf}$ $[\mathrm{F}(4,66)=7.56 ; \mathrm{p}<0.001]$. In addition, the significant differences between each groups revealed by the LSD post hoc test are represented $\left({ }^{*} \mathrm{p}<0.05 ;{ }^{* *} \mathrm{p}<0.01 ; * * * \mathrm{p}<0.001\right)$. Of note, the two-way ANOVA between Agomelatine and Ana12 factors in the GRi genotype indicated a significant effect of Ana12 on $\operatorname{Gdnf}[\mathrm{F}(1,45)=12.64 ; \mathrm{p}<0.001]$. Data are expressed as mean + S.E.M of $\mathrm{n}=5-9$ mice per group. 

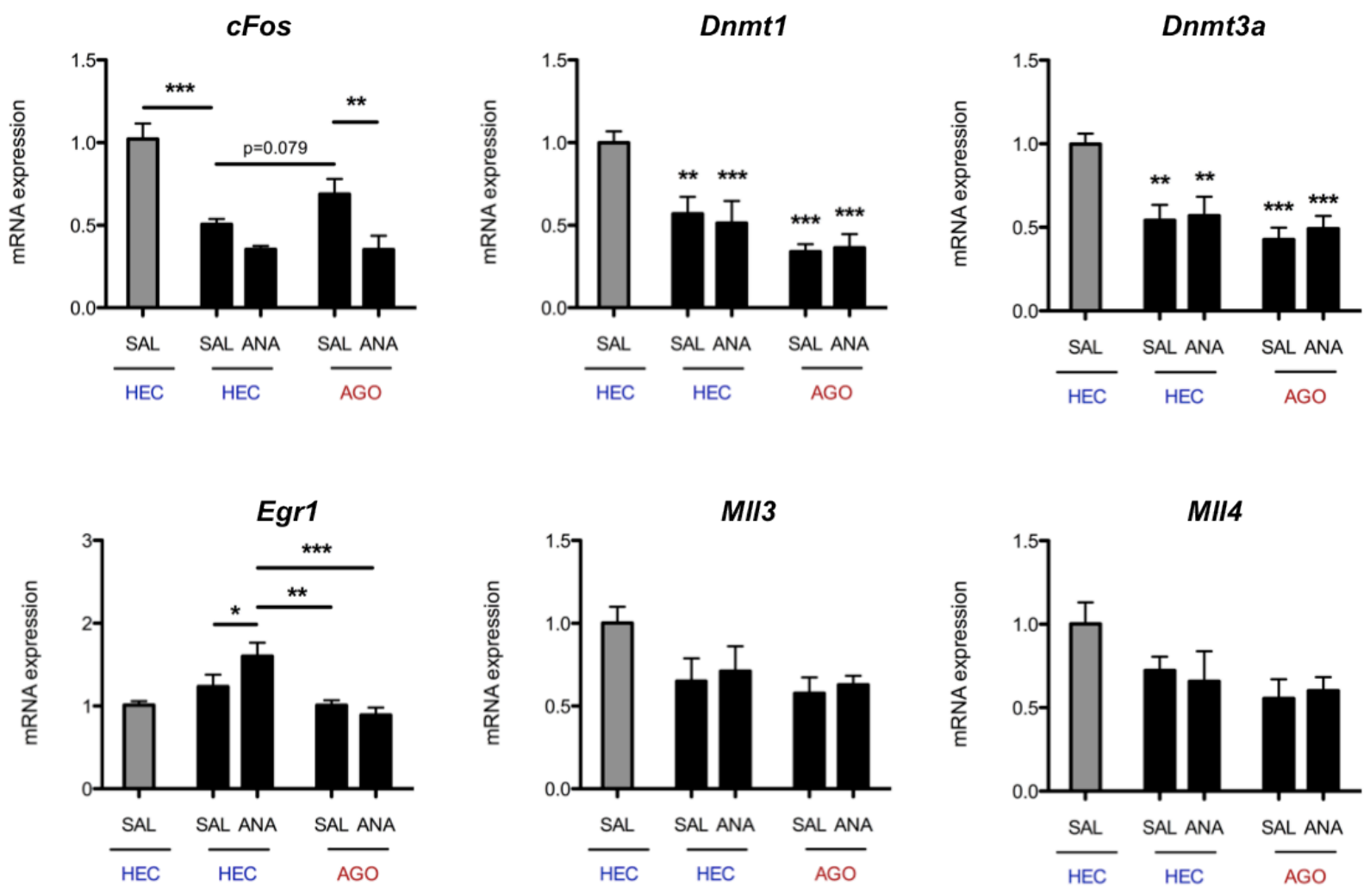

WT $\square$ GRi

Figure 6. Effects of chronic agomelatine treatment in combination with a TrkB inhibitor on the expression of transcription factors in the hippocampus

mRNA levels of genes encoding for transcription factors were measured in the hippocampus of mice by quantitative real-time RT-PCR, and are expressed as fold changes as compared to the WT mice treated with the two vehicles (WT HEC SAL). A one-way ANOVA indicated a significant interaction for $c F o s[F(4,30)=16.20$; $\mathrm{p}<0.001]$, Dnmt1 [F(4,29)=12.88; $<<0.001]$, Dnmt3a $[\mathrm{F}(4,29)=8.26 ; \mathrm{p}<0.001], \operatorname{Egrl}[\mathrm{F}(4,34)=6.81 ; \mathrm{p}<0.001]$, Mll3 $[\mathrm{F}(4,29)=2.39 ; \mathrm{p}=0.076]$ and Mll4 $[\mathrm{F}(1,29)=1.42 ; \mathrm{p}>0.05]$. In addition, the significant differences between each groups revealed by the LSD post hoc test are represented $(* p<0.05 ; * * p<0.01 ; * * * p<0.001)$. Of note, the twoway ANOVA between agomelatine and Ana12 factors in the GRi genotype indicated a significant effect of Ana12 on $c F O S[\mathrm{~F}(1,21)=15.02 ; \mathrm{p}<0.001]$, and a significant effect of agomelatine on $\operatorname{Egr} 1[\mathrm{~F}(1,22)=12.70 ; \mathrm{p}<0.01]$. Data are expressed as mean + S.E.M of $\mathrm{n}=5-9$ mice per group. 


\section{Supplementary data.}

\section{A Tail suspension test $B$ Splash test $\quad C$ Social interaction}
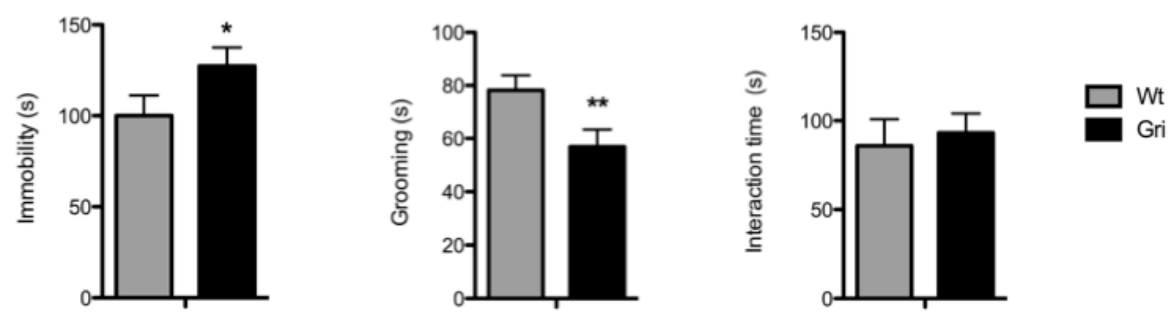

D

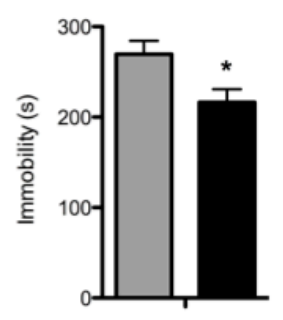

Forced swim test
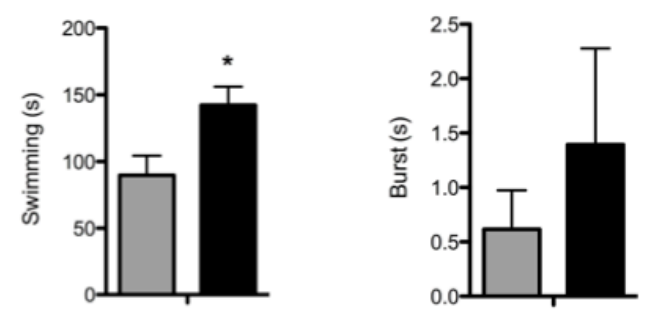

\section{Figure S1. Characterization of mood-related behaviors in GRi mice}

Mice were subjected to a battery of test routinely use to measure depressive-like behavior and response to antidepressant drugs. The difference between wild type (WT) and glucocorticoid receptor-impaired (GRi) mice in basal conditions was monitored. (A) The immobility time in the tail suspension test paradigm was measured, and a Student's t-test revealed a significant increase of immobility in GRi mice. (B) The time spent in grooming behavior over a total period of 5 minutes was measured in mice, and a Student's t-test revealed a significant decrease of the time spent in grooming behavior in GRi mice. (C) The time spent in active social interaction was measure over 10 minutes, and no significant difference was found in the Student's t-test analysis. (D) Mice were subjected to a forced swim test, and the time spent in immobility, swimming and high mobility (burst), over a 6-minute period, is represented. The Student's t-test revealed a significant increase in mobility, together with a decrease of immobility, in GRi mice as compared to their wild type littermates. Data are expressed as mean \pm S.E.M of $n=8-12$ mice per group. ${ }^{*} \mathrm{p}<0.05 ; * * \mathrm{p}<0.01 ; * * * \mathrm{p}<0.001$. 

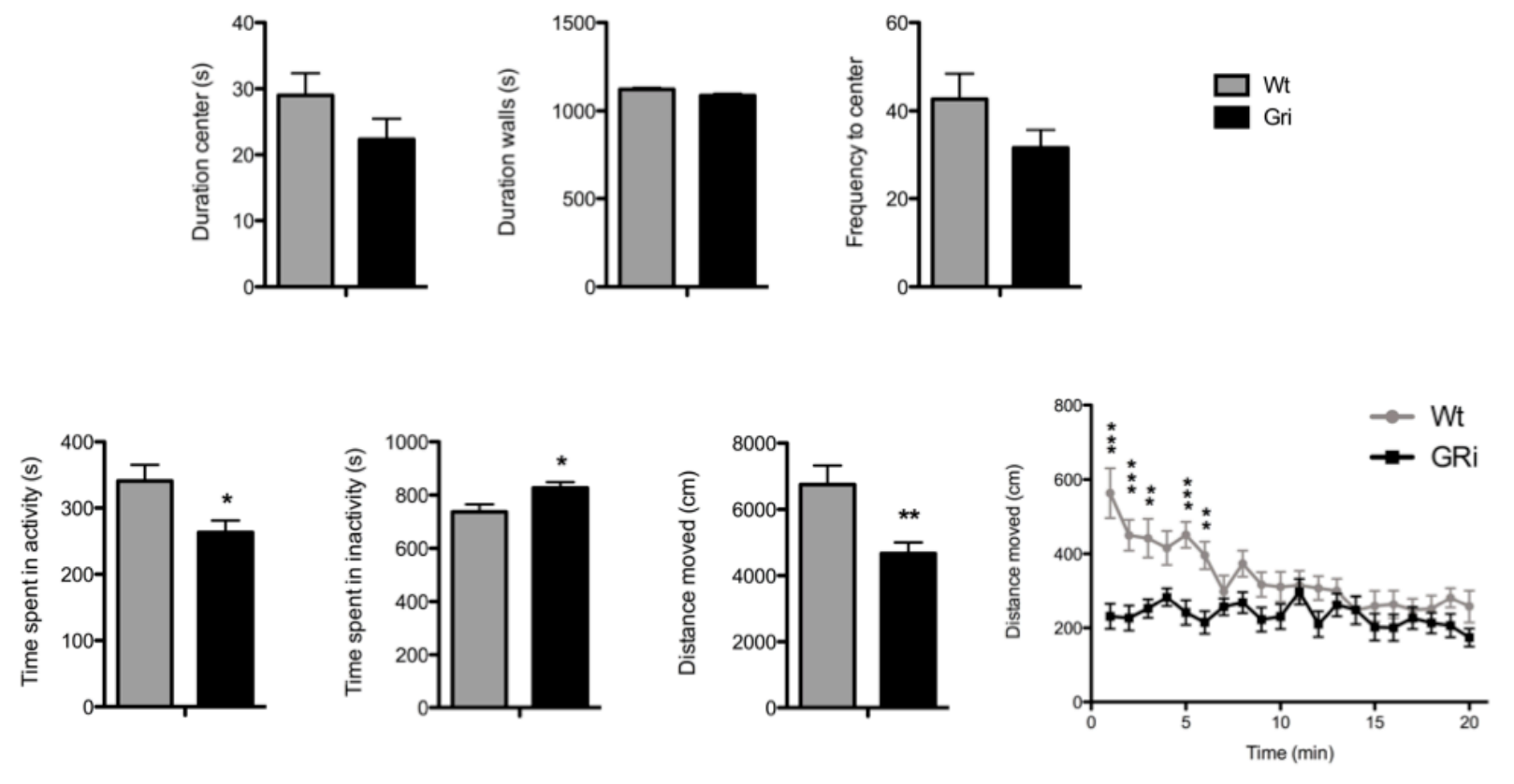

Figure S2. Characterization of anxiety-like behavior using the open field test in GRi mice

Mice were subjected to an open field test for 20 minutes. The difference between wild type (WT) and glucocorticoid receptor-impaired (GRi) mice in basal conditions was investigated. There was no difference in the tie spent in the periphery between WT and GRi mice. However, a trend was observed for the time spent in the center, as well as the number of entries in the central compartment, but did not reach statistical significance. Further, there was a significant difference in the motor behavior and exploration of GRi mice. The Student's t-test revealed that GRi mice spent more time in inactivity, and less time in small movement activity. Similarly, the distance covered by GRi mice was significantly decreased, especially during the first 6 minutes of the test, where a lower exploration was observed in GRi mice. Data are expressed as mean \pm S.E.M of $\mathrm{n}=8-12$ mice per group. $* \mathrm{p}<0.05 ; * * \mathrm{p}<0.01 ; * * * \mathrm{p}$ $<0.001$. 


\section{A Fear acquisition}
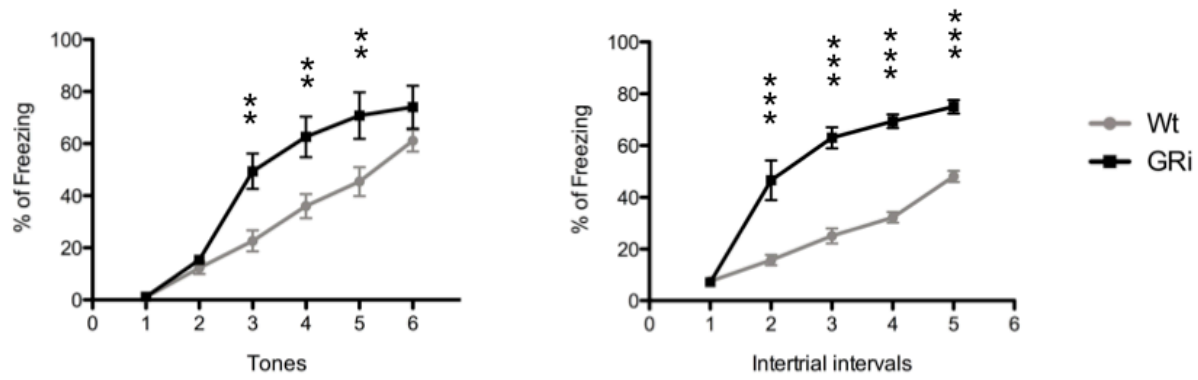

\section{B Contextual fear conditioning}

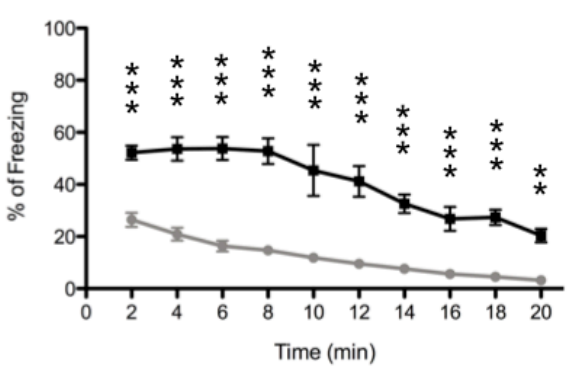

C Cued fear memory test
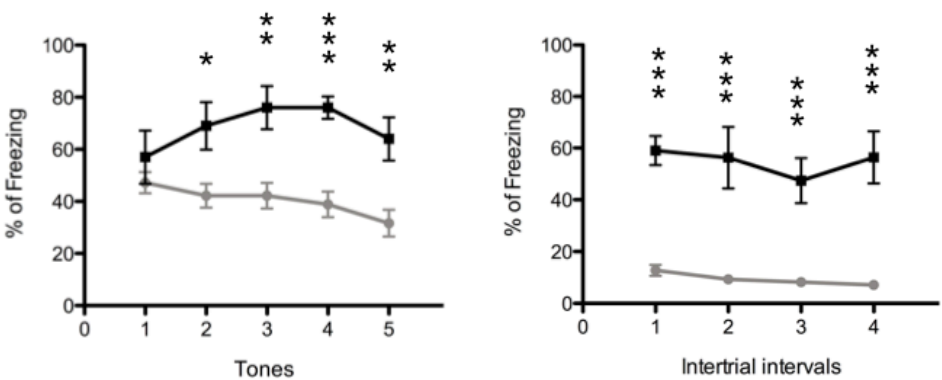

Figure S3. Characterization of fear response using the fear conditioning paradigm in GRi mice

Mice were tested in the fear conditioning paradigm, and the average freezing during the fear acquisition (A), the contextual fear conditioning (B) and the cued fear memory (C) is represented. A two-way ANOVA followed by a Bonferroni post hoc test revealed that GRi mice displayed significantly more freezing behaviors than WT. Data are expressed as mean \pm S.E.M of $\mathrm{n}=5-9$ mice per group. ${ }^{*} \mathrm{p}<0.05 ; * * \mathrm{p}<0.01 ; * * * \mathrm{p}<0.001$. 


\begin{tabular}{llll}
\hline Gene & Definition & Primer sense & Primer antisense \\
\hline Bcl2 & B-cell CLL/lymphoma 2 & ATGACTGAGTACCTGAACCG & ATGCTGGGGCCATATAGTTC \\
Bdnf4 & Brain derived neurotrophic factor exon 4 & AATCTCCCAGCCTCTGCCTA & CGAGTCTTTGGGGCCGATA \\
cFos & FBJ murine osteosarcoma viral oncogene homolog & AGGGAACGGAATAAGATGGC & TGCAACGCAGACTTCTCATC \\
Creb & cAMP responsive element binding protein 1 & GTTGTTATGGCGTCCTCCC & TACGACATTCTCTTGCTGCC \\
Crf & Corticotropin releasing factor & CCTTGAATTCTTGCAGCCG & GGACTTCTGTTGAGATTCCC \\
Dnmt1 & DNA methyltransferase (cytosine-5) 1 & AGCCGCTCAAAGCAAAAGTG & TGGGGTTCATCCACAGCATC \\
Dnmt3b & DNA methyltransferase (cytosine-5) $3 \mathrm{~b}$ & GATGAGGAGAGCCGAGAACG & CAGAGCCCACCCTCAAAGAG \\
Egr1 & Early growth response 1 & TCAATCCTCAAGGGGAGCC & ACTCGTCTCCACCATCGC \\
Gdnf & Glial derived neurotrophic factor & TGGGTTTGGGCTATGAAACC & AACATGCCTGGCCTACTTTG \\
Hprt & Hypoxanthine-guanine phosphoribosyltransferase & GATGATGAACCAGGTTATGAC & GTCCTTTCACCAGCAAGCTTG \\
Mll3 & Histone-lysine N-methyltransferase HRX 3 & TCCCGATAGTTTCGTCCCCT & AGAATGGGGATGATGGGGGA \\
Mll4 & Histone-lysine N-methyltransferase HRX 4 & CTCGCCACTGAGGATACGTC & CCCTGTAGACCCTGTAGGCT \\
Myst2 & MYST histone acetyltransferase 2 & GGTACTGCTCCGATACCTGC & TCTGAAGGGCTTGCAGAGTG \\
Ncoa6 & Nuclear receptor coactivator 6 & TCTACCCAGCATAGCCCCTT & AGTTTCTTCGGCTCGTCAGG \\
Vgf & VGF nerve growth factor inducible & TTGACACCCTTATCCAAGGC & ACCTGAGCTAATCCTTGCTG
\end{tabular}

Table S1. Primer sequences used in q RT-PCR experiments 
Chapter VII 


\section{CHAPTER VIII}

\section{Agomelatine normalizes hippocampal and behavioral dysfunction in a mouse model of environmental stress}

FABIEN BOULLE ${ }^{1,2}$, RENAUD MASSART ${ }^{1,3}$, LARA ZAIDAN ${ }^{2}$, SAMY MARDAY $^{2}$, CECILIA GABRIEL $^{4}$, ELISABETH MOCAER $^{4}$, MiCHEL HAMON ${ }^{1}$, LAURENCE LANFUMEY $^{1}$

${ }^{I}$ Centre de Psychiatrie et Neuroscience (INSERM U894), Universite Pierre et Marie Curie, Paris, France

${ }^{2}$ Department of Psychiatry and Neuropsychology, European Graduate School for Neuroscience (EURON), Maastricht University, Maastricht, The Netherlands

${ }^{3}$ Department of Pharmacology and Therapeutics, McGill University, Montreal, Quebec, Canada

${ }^{4}$ Institut de Recherche International Servier, Suresnes, France

In preparation 


\begin{abstract}
Stress-induced alterations in neuronal plasticity and associated hippocampal dysfunctions have been reported as a major culprit in the course and development of mood disorders. Here, we investigated the activation of intracellular signaling cascades, and the expression of epigenetic markers and plasticityrelated genes in the hippocampus of a mouse model of hyperactive and mixed affective disorders. Further, we analyzed the ability of agomelatine, a mixed MT1/MT2 melatonin receptor agonist $/ 5-\mathrm{HT}_{2 \mathrm{c}}$ receptor antagonist, to prevent stress-induced neurobiological and behavioral alterations. Adult male C57BL/6J mice were exposed to daily unpredictable socio-environmental stressors of mild intensity for a total period of 3 weeks. Behavioral investigations showed that stressed mice exhibited robust increase in emotional arousal, vigilance and motor activity, together with reduced anxiety as well as motivation and reward deficits. Neurobiological investigations showed an increased activation of Akt and Creb signaling pathways in the hippocampus of stressed mice. The decreased hippocampal levels of the repressive epigenetic marks HDAC2 and $\mathrm{H} 3 \mathrm{~K} 9 \mathrm{me} 2$, as well as the increased levels of the permissive mark H3K9/14ac suggested that chronic mild stress could be associated with increased gene transcription, and clear-cut evidence for such changes was found for neuroplasticity-related genes, including $A r c, B c l 2$, $B d n f$, Gdnf, Igfl and Neurod1. Altogether, the present data suggest that chronic ultra-mild stress can model the hyperactivity or psychomotor agitation, as well as mixed affective behaviors often observed in the manic state of bipolar disorders. Interestingly, agomelatine could normalize both behavioral and neurobiological alterations induced by stress, providing further molecular and behavioral evidence in the action of this new generation antidepressant.
\end{abstract}

Key words: Plasticity, hyperactivity, hippocampus, stress, mood, epigenetic 


\section{I - Introduction}

Stress is a predisposing factor for the course and development of a broad range of behavioral and pathophysiological disturbances, among which mood disorders have been abundantly reported (Gunnar and Quevedo, 2007). More specifically, the hippocampus - a key region in emotional and cognitive process - is known to be highly sensitive to glucocorticoid providing to this limbic structure an important role in the integration of stress response (McEwen et al., 1992; Sala et al., 2004). However, the exact mechanism by which stress, via glucocorticoid, modulates functional and structural plasticity in the brain remains largely unknown, and the timing and intensity of the stressors seem to be critical in the determination of the neuroendocrine and behavioral outcomes (McEwen et al., 2007). It is well accepted that severe and long-lasting traumatic stress might lead to neuronal loss and synaptic dysfunction in the hippocampus, generally associated with low mood, anxiety and impaired cognition, which constitute core symptoms of major depression (Apfel et al., 2011; Snyder et al., 2011, Stockmeier et al., 2004). Nevertheless, stressful life events, especially when disrupting circadian rhythms, can also be a precipitant of manic episodes of bipolar disorders including elevated mood, hyperactivity, impulsivity and increased vigilance (Malkoff-Schwartz et al., 1998; Proudfoot et al., 2011).

At the molecular level, the sustained elevation of glucocorticoids observed in stressful situations might interfere with various intracellular signaling and transcriptional processes. In particular, chromatin remodeling via histones modifications occurs in response to diverse environmental variations and represents a key regulator of nuclear integration to promote structural and functional adaptations underlying neuronal plasticity (Maze et al., 2013). Hence, during the past decade, epigenetic mechanisms have emerged as a key process by which environmental variations could leave persistent imprints on gene expression thereby increasing the risk for mood disorders (Boulle et al., 2012). In addition, antidepressants and mood stabilizers have been shown to mediate their therapeutic effects at least in part through epigenetic remodeling (Boulle et al., 2012; Vialou et al., 2012).

More recently, Agomelatine, a mixed melatonin receptor 1 (MT1) and 2 (MT2) agonist and serotonin 5$\mathrm{HT}_{2 \mathrm{C}}$ receptor antagonist, has been described as an emerging and efficient treatment for major depressive episodes (De Bodinat et al., 2010). Agomelatine is though to exert its effects via a re-synchronization of circadian rhythms (De Bodinat et al., 2010). Moreover, disruption of circadian periodicity has been proposed as a major player in the onset of bipolar disorders, and successful antidepressant treatment is associated with normalization of disturbed biological rhythms (Harvey AG, 2008; Lanfumey et al., 2013). Hence, the modulation of melatonin receptors may provide a specific an innovative way to treat bipolar disorders. 
Hence, in our experiments, we used a prolonged repetition of low-intensity stressors in adult mice, including social isolation, perturbations of circadian rhythms and daily life habits, in order to induce affective disorders. We previously reported that this chronic mild stress procedure was associated with reduced glucocorticoid receptor expression in the hippocampus and impulsive choice in the decision making task (Froger et al., 2004). In the present study, we aimed at further characterizing the manic-like phenotype of the mice, as well as exploring the intracellular signaling, epigenetic regulations and gene transcription profiles following stress exposure. In addition, we wanted to test the ability of the newgeneration antidepressant agomelatine to reverse the eventual cellular and molecular alterations and to restore a normal phenotype in stressed mice.

\section{II - Material and methods}

Animals: C57BL/6J male mice (Charles River Laboratories, 1'Arbresle, France) were used in the experiments. Upon arrival in the laboratory, the mice were housed in groups of four per cage under standard conditions $(22 \pm 21 \mathrm{C}, 60 \%$ humidity, 12-h light-dark cycle with lights on at $07 \mathrm{~h} 00$, food and water ad libitum) for 1 week before the beginning of experimental procedures. Experiments were performed using 10- to 12-week-old mice (25-30 g body weight). Procedures involving animals and their care were conducted in conformity with the institutional guidelines that are in compliance with national and international laws and policies (Council directive 87-848, October 19, 1987, Ministere de 1'Agriculture et de la Foret, Service Veterinaire de la Sante et de la Protection Animale; permissions 75116 to M.H. and 006269 to L.L.).

Stress and treatments: The chronic ultra mild stress procedure used in this study has been presented elsewhere (Froger et al., 2004), and is a modified version of the chronic mild stress protocol described by Willner in rats (Willner, 1992). Briefly, mice were subjected to daily socio-environmental stressors of low intensity, in an unpredictable manner (See supplementary table S1) during a 25-day period. Administration of compounds was initiated at the beginning of stress procedures, everyday at 6:00 $\mathrm{pm}$ (i.e. 1 hour before the onset of dark period), for a total period of 25 days. The doses used in the experiments have been chosen on the basis of previous studies performed in validated mice models of depression and anxiety (Paizanis et al., 2010). Agomelatine $(50 \mathrm{mg} / \mathrm{kg}$, Servier) or its vehicle (Hydroxyethylcellulose; HEC 1\%, Servier) was administrated via intraperitoneal injections.

Behavioral tests: The animals were tested for behavioral analysis after the fourth week of stress. The tests were performed at least 18 hours after the last stressor, so as to avoid an eventual effect of acute stress. The animals were kept in the testing room for more than 2 hours prior to the test so as to enable the mice to habituate to the new environment. 
The behavioral tests were adapted from existing protocols. Classical test for measuring depressed like behavior (TST, FST, splash test, saccharin intake) locomotor activity (OF, actimetry) and anxiety (EPM, OF) described in supplementary material, were performed between day 21 and day 25 .

Finally, the animals were sacrificed 18 hours after the last day of both stress and drug injection, and the brains were kept at $-80^{\circ} \mathrm{C}$ until use.

Quantitative reverse transcriptase PCR (qRT-PCR): Total mRNA extraction was performed using NucleoSpin RNA II kit (Macherey-Nagel, Hoerdt, France), after which the cDNA synthesis was performed using a High Capacity cDNA Reverse Transcription kit (Applied Biosystems, Courtaboeuf, France) according to the manufacturer's protocol. One part of the amplification was made with Absolute SYBR Green ROX Mix (Thermo Scientific, Illkirch, France) using the 7300 Real Time PCR System (Applied Biosystems, Courtaboeuf, France), and the other part of gene expression was measured using TaqMan (Applied Biosystems, Courtaboeuf, France) gene expression assays. The sequences of primers used are indicated in Table S2 and Table S3. The $2^{\Delta \Delta \mathrm{CT}}$ (Delta-Delta Comparative Threshold) method was used to normalize the fold change in gene expressions for both qPCR technologies.

Western blots: The hippocampus were lysed in ice-cold lysis buffer (1\% Triton X-100, $150 \mathrm{mM} \mathrm{NaCl}, 1$ mM EDTA, $10 \mathrm{mM}$ Tris, $\mathrm{pH}$ 8.0,10\%, $10 \mathrm{mM} \mathrm{NaF}, 1 \mathrm{mM}$ sodium orthovanadate and protease inhibitor cocktail) and protein extracts was loaded on a SDS-PAGE gel for electrophoresis migration and then transferred to a PVDF membrane for 7 min using the iBlot gel transfer system (Life technologies, St Aubin, France). Non-specific binding was blocked by incubating the membranes in a blocking buffer (PBS-Tween $0.01 \%$ supplemented with $5 \%$ of BSA) for $1 \mathrm{~h}$ at room temperature. The membranes were incubated with the primary antibody (see Table S4) overnight at $4^{\circ} \mathrm{C}$ in the same blocking buffer. Then, after extensive washing, the membranes were incubated with the appropriate fluorescent secondary antibodies (Alexa Fluor 488 goat anti-rabbit or Alexa Fluor 488 donkey anti-mouse; Molecular Probes, OR, USA) for $1 \mathrm{~h}$ at room temperature. Finally, the membranes were washed, dried and scanned using the Odyssey infrared imaging system (Westburg, Leusden, The Netherlands).

Immunohistochemistry: Coronal sections of $20 \mu \mathrm{m}$ were collected using a cryostat, after which sections were directly mounted on Superfrost Plus slides (Thermo Scientific, Illkirch, France) and stored at $-80^{\circ} \mathrm{C}$ until use. The sections were then fixed with $4 \%$ paraformaldehyde at $4{ }^{\circ} \mathrm{C}$ for $10 \mathrm{~min}$. After blocking nonspecific binding with $0.4 \%$ of BSA and $5 \%$ of appropriate serum, and permeabilizing the membranes with $0.05 \%$ of tween 20 , the sections were incubated overnight at $4{ }^{\circ} \mathrm{C}$ with the primary antibodies (see Table S4). The sections were then incubated for 1 hour at room temperature in presence of appropriated biotinylated secondary antobodies, and the reaction was amplified using the $\mathrm{ABC}$ staining system (Vectastain ABC Elite Kit, Vector Laboratories, Les Ullis, France) for one additional hour. Finally, the sections were treated with 3,3'-diaminobenzidine (Sigma FAST ${ }^{\mathrm{TM}}$, D4293, Sigma-Aldrich, Saint 
Quentin-Fallavier, France). After dehydrating the sections and mounting with cover slip, pictures were taken under optic microscope (Leica, zoom 2,5) and optical density was measured and then normalized by the background using Image J software.

Statistical analysis: Data are represented as mean \pm SEM and were analyzed using Student's t test for comparison between two groups (Prism 5.0, GraphPad software, USA). When more than two groups of data were compared, two-way ANOVA (Stress x Treatment) were used followed by Bonferroni post hoc test, or when necessary a planned pairwise comparison using Dunn's $t$-test. The level of significance was set as $P<0.05$.

\section{III - Results}

Agomelatine reverses stress-induced alterations in behavior: A battery of well-established behavioral tests usually employed to measure mood, emotions and motor performances in rodents were performed at the end of the stress period. Stressed animals displayed a pronounced hyperactivity, as shown by the increase exploration in the open field (OF) arena (Figure 1A, $+30 \pm 6.4 \%$ ), especially during the first minutes of the test (Figure 1A, upper panel). This increase in motor activity was confirmed by measuring spontaneous locomotion in actimetry boxes. The ambulation, corresponding either to the total number of square crossed (Figure S7) or the number of crossing in the center of the actimetry box (Figure 1B), was increased in stressed mice ( $+82 \pm 11.5 \%)$. The numbers of rearings, corresponding to a vertical activity where the mouse leaves the floor with the fore feet, was also increased after exposure to stress $(+95 \pm$ $12.5 \%$, Figure 1B). Similarly, the distance covered in the elevated plus maze (EPM) test was increased in mice subjected to chronic mild stress $(+20 \pm 7.6 \%$, Figure S6). However, the performance of motor activity in the rotarod test was altered in stressed mice. Mice exposed to stress displayed a decrease in the latency to fall ( $-39 \pm 9.5 \%$, Figure S6) indicating impairment of balance and movement coordination. Interestingly, the alterations in the distance covered in the OF, as well as the numbers of crossings and rearings in actimetry boxes could be significantly prevented by chronic administration of agomelatine (Figure 1A and 1B). Further, we assess the motivation and reward alterations, and measured the consumption of saccharin solution and the time spent in self-grooming. Data on Figure 2 indicate that chronic mild stress significantly decreased saccharin intake and grooming behavior $(-35 \pm 6.5 \%$ and $43 \pm 7.6 \%$ respectively, Figure $2 \mathrm{~A}$ and $2 \mathrm{~B}$ ). Agomelatine could normalize the alteration in both saccharin consumption and grooming behavior (Figure $2 \mathrm{~A}$ and $2 \mathrm{~B}$ ). We also performed some tests to measure the defense mechanisms and anxiety levels such as the tail suspension test (TST), the forced swim test (FST), the OF test and the EPM test (Figure 2, Figure S5, Figure S6 and Figure S7). Chronic mild stress significantly reduced the immobility time in the tail suspension test $(-52 \pm 11.7 \%$, Figure $2 \mathrm{D})$, which could be prevented by agomelatine treatment. There was no difference in the immobility time in the FST 
(Figure S5). However, a small increase in the number of burst (especially during the first 2 minutes, see Figure S5) and mobility was observed in the FST after stress exposure $(+16 \pm 7.2 \%$ and $+9 \pm 4.8 \%$ respectively, Figure $2 \mathrm{E}$ and $2 \mathrm{~F}$ ). The mobility time was significantly different between stressed mice treated with vehicle or agomelatine, indicating a preventive effect of agomelatine on escape-like behaviors in this paradigm (Figure 2F). In the OF, we observed a reduced anxiety as shown by the increased numbers of entries in the center $(+46 \pm 12.4 \%$, Figure $2 \mathrm{C})$, which could be corrected by agomelatine. Of note, the chronic mild stress procedure did not modify the water consumption and weight of the animals (Figure S4). Altogether, the behavioral analysis indicate that chronic ultra mild stress caused a marked hyperactivity, together with increase of defense mechanisms and decrease of motivation and reward. Those behavioral alterations could be prevented when mice were treated with agomelatine $(50 \mathrm{mg} / \mathrm{kg} / \mathrm{day})$ during the whole stress procedure.

Agomelatine reverses stress-induced alterations in intracellular signaling cascades: To further elucidate the cellular mechanisms underlying chronic ultra mild stress, the activation of hippocampal intracellular signaling pathways involved in survival, proliferation and differentiation was measured. As shown by western blots analyses (Figure 3), chronic ultra mild stress significantly impacted on hippocampal intracellular signaling cascades. The phosphorylation of the protein-kinase B (Akt), the extracellular signal-regulated kinase (Erk), the p-38 mitogen-activated protein kinase (p38), the cAMP response element-binding protein $(\mathrm{Creb})$, and the activating transcription factor 1 (Atf1) were increased after chronic ultra mild stress $(+17 \pm 6.2 \%,+42 \pm 10.5 \%,+22 \pm 8 \%,+55 \pm 14.8 \%$ and $+71 \pm 14.6$ $\%$ respectively, Figure 3), whereas no significant modulations were observed at TrkB phosphorylation. The increase of phospho-Akt, phospho-Erk, phospho-Creb and phospho-p38 induced by stress could be normalized by chronic agomelatine treatment (Figure 3). The western blot investigations suggest that specific effectors of the MAPK and PI3K pathways, involving Akt, Erk, p38, Creb and Atf1, were increased after chronic ultra mild stress, and that the administration of agomelatine could significantly prevent most of those alterations.

Agomelatine reverses stress-induced abnormal epigenetic regulation and gene expression: To further elucidate the molecular and transcriptional mechanisms underlying chronic ultra mild stress, the expression of various genes implicated in the regulation of transcription such as epigenetic regulators or transcription factors, as well as genes involved in neuronal plasticity was measured (Table S5, S6 and S7). First, qPCR screening (Table S5) revealed that chronic stress induced the hippocampal expression of many plasticity-related genes including the brain derived neurotrophic factor (Bdnf) gene (+ $28 \pm 7 \%)$, the neurogenic differentiation 1 (Neurodl) gene (+ $69 \pm 10 \%)$, the insulin growth factor 1 (Igfl) gene (+ $41 \pm 7 \%$ ), the activity-regulated cytoskeleton-associated protein (Arc) gene $(+56 \pm 10 \%)$, the expression the glial cell-derived neurotrophic factor $(G d n f)$ gene $(+58 \pm 15 \%)$ and the b-cell lymphoma $2(B c l 2)$ gene $(+46 \pm 9 \%)$. In addition, the expression of the nuclear receptor subfamily 1 , group D, member 2 
(Nrld2), known as a transcription activator was increased ( $+40 \pm 5 \%$, Table S6), and the expression of the nuclear receptor co-repressor 1 (Ncor 1$)$, known as a transcription repressor, was decreased (- $37 \pm 6$ $\%$, Table S6). A screening for modulations of epigenetic marks involved in synaptic plasticity including histone deacetylase, DNA methyltransferase, methyl binding domain protein and histone acetyltransferase was also investigated (Table S7). Among all the epigenetic regulators, a significant reduction of the epigenetic repressor Hdac2 (- $22 \pm 4 \%$, Table S7) - a key role player in hippocampal plasticity - was observed. Hence, we expressed further interest in the expression of epigenetic markers, and measured the expression of HDACs and post-translational modifications at histone tails (Figure S1, S2 and S3). As shown by immunostaining analyses, chronic mild stress decreased the HDAC2 protein levels in the CA1 and CA3 subfields of the hippocampus ( $-18 \pm 1.2 \%$ and $-14 \pm 4.3 \%$ respectively, Figure S1A), whereas the expression of HDAC1 was not modulated. The expression of histone 3 lysine 9 di-methylated (H3K9me2) was specifically decreased in the CA3 region (- $23 \pm 4.3 \%$, Figure S2A), whereas the expression of histone 3 lysine 9 and 14 acetylated (H3K9/14ac) was increased in the CA1 and CA3 subfields $(+63 \pm 12.5 \%$ and $+32 \pm 12.5 \%$ respectively, Figure S2B). The expression of histone 4 acetylated (H4ac) and histone 3 lysine 4 tri-methylated (H3K4me3) were not modulated by the stress (Figure S2C and S2D). Given the pronounced alterations of gene expression and epigenetic regulations, the ability of agomelatine to correct for these abnormal epigenetic modifications in the hippocampus was investigated. The figure 4 shows that chronic treatment with agomelatine could significantly prevent the stress-mediated decrease of HDAC2 and $\mathrm{H} 3 \mathrm{~K} 9 \mathrm{me} 2$, as well as the increase of $\mathrm{H} 3 \mathrm{~K} 9 / 14 \mathrm{ac}$ in the CA3 region of the hippocampus. The action of agomelatine was rather specific to the CA3 subfield, since no significant effects were observed in the CA1 and DG subfields (Figure S3). In a similar manner, some of the alteration in plasticity-related gene expression observed after chronic ultra mild stress exposure could be normalized by chronic agomelatine treatment (Figure 5). Agomelatine significantly restored the abnormal expression of the Bdnf gene, the Neurodl gene, the Igfl gene, the Arc gene, whereas the expression the $G d n f$ gene and the $B c l 2$ gene could not be normalized. All in all, these data indicate that chronic stress triggered a marked reorganization at histone post-translational modifications, pointing towards an open state of chromatin. Interestingly, this permissive state of chromatin observed after chonic ultra mild stress was associated with increased transcription of genes involved in neuroplasticity, and preventive administration of agomelatine could abolish these latter alterations.

\section{IV - Discussion}

Mounting evidences suggest that stressful life events might play a part in the development and course of mood disorders, and that successful antidepressant treatments might involve a normalization of stressrelated alterations in cortico-limbic structures (Calabrese et al., 2009; Touma C, 2011). In this context, the aim of the present study was to investigate the effect of prolonged socio-environmental stressors of low 
intensity on mood-related behaviors and hippocampal function in mice, and explore the biological mechanisms and therapeutic potentialities of the new generation agomelatine in this stress model.

Effect of stress on neuroplasticity and behavior: In the present study, we found that a chronic, unpredictable and ultra mild stress could induce a decrease in saccharin consumption and grooming behavior, reflecting motivation and reward deficits, two core symptoms generally related to depression like behavior and observed after chronic stress exposure (Willner P, 2005). We also found a robust decrease of immobility in the TST, an increased mobility and number of burst in the FST. These behavioral measures can be seen as the expression of defense mechanisms in reaction to innate fear stimuli. Hence, in our experiments, the chronic mild stress exposure facilitated flight response as shown by tonic/energetic agitation and escape-like behaviors, which might be interpreted as an excessive emotional arousal and high vigilance state. In addition, stressed mice displayed a reduced anxiety in the open field test. Further, we observed an increased locomotor and motor activity, reflecting a hyperactive state of mice after stress exposure. Some studies have reported such locomotor activity following chronic mild stress exposure in rodents and could be interpreted as a psychomotor agitation often seen in mood disorders (Gronli et al., 2005; Pardon et al., 2000; Negroni et al., 2004). Since many studies demonstrated that physical activity and exercise could significantly enhance hippocampal neurogenesis and plasticity (Van Praag et al., 1999; Fabel et al., 2008), the increased locomotor activity observed after chronic stress might explain, at least in part, the increased in hippocampal plasticity in our mice model. In addition, stressed mice displayed a pronounced impairment in motor coordination and balance, which can be related to the fact that mice subjected to stress had difficulty to learn the task and to keep focus on movement coordination. At the neurobiological level, chronic mild stress was shown to enhance hippocampal intracellular signaling pathways such as mitogen-activated protein kinases (MAPK) known to be involved in neuronal survival, differentiation and proliferation (Thomas et al., 2004). In addition, we found robust changes in epigenetic regulation and gene transcription. The increased in chromatin permissive state and plasticity-related gene expression might correspond to the nuclear integration of the observed increased in intracellular signaling cascades. Among all the epigenetic modifications, a significant decrease of the repressive mark HDAC2 was reported. The low levels of HDAC2 in the hippocampus were shown to strongly correlate with enhanced synaptic plasticity (Guan et al., 2009). In addition, stress and environmental adversity has been shown to impact on chromatin and histone regulations to generate an epigenetic reprogramming, possibly increasing the susceptibility for mood disorders (Roth et al., 2009; Tsankova et al., 2006; Weaver et al., 2004). Further, many genes including trophic factors (Bdnf, Gdnf, Igfl), pro-survival factor (Bcl2), differentiation factor (Neurodl) and cell/dendritic growth factor $(A r c)$, known to be critical in neuronal plasticity, were increased after chronic mild stress. Hence, the neurobiological investigations points towards drastic molecular and cellular changes underlying increased hippocampal plasticity. These results are rather provocative since it is well established that chronic stress paradigms in rodents are generally associated with impaired synaptic 
integrity, reduced dendritic arborization and decreased neurogenesis in the hippocampus, as well as depressive- and anxiety-like behaviors (Alonso et al., 2004; Goshen et al., 2008; Mineur et al., 2007). However, few studies reported that chronic stress could also enhance neurogenesis as well as dendritic spines and excrescence in CA3 neurons of the hippocampus (Parihar et al., 2011; Sunanda et al., 1995). In our protocol of chronic mild stress - in contrast to other protocols using longer or stronger stressors - we used a repetition of low-intensity socio-environmental stressors for a total period of 3 weeks suggesting that the timing, duration and intensity of the stressors might be critical in the determination of the neuroendocrine and behavioral outcomes. Further, we previously reported a reduced hippocampal expression of GR mRNA in stressed mice (Froger et al., 2004). Other reports showed that downregulation of GR in the hippocampus in rodents, either by genetic knockdown or by pharmacological blockade after exposure to chronic stress, could be associated with an increased synaptic plasticity (Avital et al., 2006; Fitzsimons et al., 2013; Krugers et al., 2006).

Effect of agomelatine treatment on stress-related alterations: Agomelatine is an atypical antidepressant that acts on the melatoninergic and the serotoninergic systems. Like many commonly used antidepressants, agomelatine was shown to positively modulate neurogenesis, hippocampal plasticity and neurotrophic signaling in rodent models of depression (Banasr et al., 2006; Soumier et al., 2009). In our experiments we did not observed any effects of chronic agomelatine treatment on hippocampal plasticity in non-stressed mice. Interestingly, agomelatine could specifically normalize the hippocampal alterations induced by chronic mild stress, indicating that this drug has a disease-dependent action on neuronal activity. MT2 receptors, one of the key players in agomelatine action, are abundantly expressed in various cell population of the hippocampus (Musshoff et al., 2002). Melatonin receptors are coupled to $\mathrm{G} \alpha_{\mathrm{i}}$ proteins resulting into an inhibition of cyclic AMP signaling (De Bodinat el al., 2010). Some studies showed that melatonin, most likely through the interaction via MT2 receptors, reduced neuronal firing and excitability, and inhibited long-term potentiation in mouse hippocampal slides (Hogan et al., 2001; Wang et al., 2005). This latter effect might explain the normalization of the increased intracellular signaling and associated epigenetic and neuroplastic changes observed after chronic mild stress. A previous study also showed that agomelatine could specifically normalize the increased hippocampal cFos levels, an indicator of increased neuronal activity, induced by prenatal stress in rat (Mairesse et al., 2013). At the behavioral level, chronic mild stress caused reward, motivation and attention deficit. These symptoms are known to be highly dependent on the mesolimbic dopaminergic system. The normalization of these behavioral alterations by agomelatine can be attributed to the inhibition of 5- $\mathrm{HT}_{2 \mathrm{C}}$ receptor, known to enhance dopamine released in several brain structures including the frontal cortex, striatum and nucleus accumbens (De Deurwaerdere et al., 2004; Di Matteo et al., 1999). In addition, our model of stress induced an overall increased in motor activity, which could be corrected by agomelatine. Previous studies also reported similar effects of agomelatine on hyperactivity in mice models of mood disorders (Mairesse et al., 2013; Norman et al., 2011), and systemic administration melatonin was also shown to 
reduce spontaneous locomotor activity in rats exposed to stress (Chuang et al., 1994). Finally, the emotional reactivity or vigilance is also known to be sensitive to melatonin receptor agonists, shifting the arousal state from hyperactive to sleep (Pandi-Perumal et al., 2007).

Conclusions and perspectives: In summary, the neurobiological and behavioral investigations provided clean-cut evidences that prolonged exposure to socio-environmental stressors of low intensity in C57B1/6 mice could induce drastic molecular and cellular changes leading to an increased hippocampal plasticity, together with marked hyperactivity, hyperarousal, reward and motivation deficits, distractibility and increased risk taking. Agomelatine could prevent both neurochemical and behavioral alterations triggered by stress, providing novel insights into the molecular, cellular and behavioral mechanisms of action of this atypical antidepressant in a rodent model of mood-related disorders. In addition, the altered epigenetic regulations in the hippocampus support the notion that chromatin remodeling via histone modifications can increase susceptibility for mood disorders, and that the reversal of such changes by antidepressants are required for their therapeutic action.

Finally, the abovementioned behavioral responses described in our stress model can be assimilated to common symptoms usually observed in mixed manic state of bipolar disorders (see Table S8). Although, no compelling evidences for hippocampal hyperactivity were shown in humans, validated models of manic-like behaviors showed similar neurochemical changes in the hippocampus, including upregulation of BDNF protein and increased PI3-K and MAPK signaling (Kirshenbaum et al., 2011; Prickaerts et al., 2006). In addition, both human and animal studies established a pivotal role for circadian rhythms and seasonal changes in the pathophysiology and treatment of bipolar disorders (Arey et al., 2013; Harvey A.G, 2008; Kirshenbaum et al., 2011). Hence, this model might be of particular interest to further investigate the causal relationship between stress, circadian rhythms and hippocampal dysfunction in the development and course of manic and bipolar disorders.

\section{V - References}

Alonso, R., Griebel, G., Pavone, G., Stemmelin, J., Le Fur, G. and Soubrie, P. (2004) Blockade of CRF(1) or V(1b) receptors reverses stress-induced suppression of neurogenesis in a mouse model of depression. Mol Psychiatry 9 , 278-286, 224.

Apfel, B. A., Ross, J., Hlavin, J., Meyerhoff, D. J., Metzler, T. J., Marmar, C. R., Weiner, M. W., Schuff, N. and Neylan, T. C. (2011) Hippocampal volume differences in Gulf War veterans with current versus lifetime posttraumatic stress disorder symptoms. Biol Psychiatry 69, 541-548.

Arey, R. N., Enwright, J. F., 3rd, Spencer, S. M., Falcon, E., Ozburn, A. R., Ghose, S., Tamminga, C. and McClung, C. A. (2013) An important role for Cholecystokinin, a CLOCK target gene, in the development and treatment of manic-like behaviors. Mol Psychiatry.

Avital, A., Segal, M. and Richter-Levin, G. (2006) Contrasting roles of corticosteroid receptors in hippocampal plasticity. J Neurosci 26, 9130-9134. 
Banasr, M., Soumier, A., Hery, M., Mocaer, E. and Daszuta, A. (2006) Agomelatine, a new antidepressant, induces regional changes in hippocampal neurogenesis. Biol Psychiatry 59, 1087-1096.

Boulle, F., van den Hove, D. L., Jakob, S. B., Rutten, B. P., Hamon, M., van Os, J., Lesch, K. P., Lanfumey, L., Steinbusch, H. W. and Kenis, G. (2012) Epigenetic regulation of the BDNF gene: implications for psychiatric disorders. Mol Psychiatry 17, 584-596.

Boulle, F., van den Hove, D. L., Jakob, S. B., Rutten, B. P., Hamon, M., van Os, J., Lesch, K. P., Lanfumey, L., Steinbusch, H. W. and Kenis, G. (2012) Epigenetic regulation of the BDNF gene: implications for psychiatric disorders. Mol Psychiatry 17, 584-596.

Calabrese, F., Molteni, R., Racagni, G. and Riva, M. A. (2009) Neuronal plasticity: a link between stress and mood disorders. Psychoneuroendocrinology 34 Suppl 1, S208-216.

Chuang, J. I. and Lin, M. T. (1994) Pharmacological effects of melatonin treatment on both locomotor activity and brain serotonin release in rats. J Pineal Res 17, 11-16.

de Bodinat, C., Guardiola-Lemaitre, B., Mocaer, E., Renard, P., Munoz, C. and Millan, M. J. (2010) Agomelatine, the first melatonergic antidepressant: discovery, characterization and development. Nat Rev Drug Discov 9, 628642 .

De Deurwaerdere, P., Navailles, S., Berg, K. A., Clarke, W. P. and Spampinato, U. (2004) Constitutive activity of the serotonin $2 \mathrm{C}$ receptor inhibits in vivo dopamine release in the rat striatum and nucleus accumbens. J Neurosci 24 , 3235-3241.

Di Matteo, V., Di Giovanni, G., Di Mascio, M. and Esposito, E. (1999) SB 242084, a selective serotonin2C receptor antagonist, increases dopaminergic transmission in the mesolimbic system. Neuropharmacology 38, 1195-1205.

Fabel, K. and Kempermann, G. (2008) Physical activity and the regulation of neurogenesis in the adult and aging brain. Neuromolecular Med 10, 59-66.

Fitzsimons, C. P., van Hooijdonk, L. W., Schouten, M., Zalachoras, I., Brinks, V., Zheng, T., Schouten, T. G., Saaltink, D. J., Dijkmans, T., Steindler, D. A., Verhaagen, J., Verbeek, F. J., Lucassen, P. J., de Kloet, E. R., Meijer, O. C., Karst, H., Joels, M., Oitzl, M. S. and Vreugdenhil, E. (2013) Knockdown of the glucocorticoid receptor alters functional integration of newborn neurons in the adult hippocampus and impairs fear-motivated behavior. Mol Psychiatry 18, 993-1005.

Froger, N., Palazzo, E., Boni, C., Hanoun, N., Saurini, F., Joubert, C., Dutriez-Casteloot, I., Enache, M., Maccari, S., Barden, N., Cohen-Salmon, C., Hamon, M. and Lanfumey, L. (2004) Neurochemical and behavioral alterations in glucocorticoid receptor-impaired transgenic mice after chronic mild stress. J Neurosci 24, 2787-2796.

Goshen, I., Kreisel, T., Ben-Menachem-Zidon, O., Licht, T., Weidenfeld, J., Ben-Hur, T. and Yirmiya, R. (2008) Brain interleukin-1 mediates chronic stress-induced depression in mice via adrenocortical activation and hippocampal neurogenesis suppression. Mol Psychiatry 13, 717-728.

Gronli, J., Murison, R., Fiske, E., Bjorvatn, B., Sorensen, E., Portas, C. M. and Ursin, R. (2005) Effects of chronic mild stress on sexual behavior, locomotor activity and consumption of sucrose and saccharine solutions. Physiol Behav 84, 571-577.

Guan, J. S., Haggarty, S. J., Giacometti, E., Dannenberg, J. H., Joseph, N., Gao, J., Nieland, T. J., Zhou, Y., Wang, X., Mazitschek, R., Bradner, J. E., DePinho, R. A., Jaenisch, R. and Tsai, L. H. (2009) HDAC2 negatively regulates memory formation and synaptic plasticity. Nature $459,55-60$.

Gunnar, M. and Quevedo, K. (2007) The neurobiology of stress and development. Annu Rev Psychol 58, $145-173$.

Harvey, A. G. (2008) Sleep and circadian rhythms in bipolar disorder: seeking synchrony, harmony, and regulation. Am J Psychiatry 165, 820-829.

Hogan, M. V., El-Sherif, Y. and Wieraszko, A. (2001) The modulation of neuronal activity by melatonin: in vitro studies on mouse hippocampal slices. J Pineal Res 30, 87-96. 
Kirshenbaum, G. S., Clapcote, S. J., Duffy, S., Burgess, C. R., Petersen, J., Jarowek, K. J., Yucel, Y. H., Cortez, M. A., Snead, O. C., 3rd, Vilsen, B., Peever, J. H., Ralph, M. R. and Roder, J. C. (2011) Mania-like behavior induced by genetic dysfunction of the neuron-specific $\mathrm{Na}+, \mathrm{K}+-$ ATPase alpha3 sodium pump. Proc Natl Acad Sci U S A 108 , 18144-18149.

Krugers, H. J., Goltstein, P. M., van der Linden, S. and Joels, M. (2006) Blockade of glucocorticoid receptors rapidly restores hippocampal CA1 synaptic plasticity after exposure to chronic stress. Eur J Neurosci 23, 3051-3055.

Lanfumey, L., Mongeau, R. and Hamon, M. (2013) Biological rhythms and melatonin in mood disorders and their treatments. Pharmacol Ther 138, 176-184.

Mairesse, J., Silletti, V., Laloux, C., Zuena, A. R., Giovine, A., Consolazione, M., van Camp, G., Malagodi, M., Gaetani, S., Cianci, S., Catalani, A., Mennuni, G., Mazzetta, A., van Reeth, O., Gabriel, C., Mocaer, E., Nicoletti, F., Morley-Fletcher, S. and Maccari, S. (2013) Chronic agomelatine treatment corrects the abnormalities in the circadian rhythm of motor activity and sleep/wake cycle induced by prenatal restraint stress in adult rats. Int $\mathrm{J}$ Neuropsychopharmacol 16, 323-338.

Malkoff-Schwartz, S., Frank, E., Anderson, B., Sherrill, J. T., Siegel, L., Patterson, D. and Kupfer, D. J. (1998) Stressful life events and social rhythm disruption in the onset of manic and depressive bipolar episodes: a preliminary investigation. Arch Gen Psychiatry 55, 702-707.

Maze, I., Noh, K. M. and Allis, C. D. (2013) Histone regulation in the CNS: basic principles of epigenetic plasticity. Neuropsychopharmacology 38, 3-22.

McEwen, B. S. (2007) Physiology and neurobiology of stress and adaptation: central role of the brain. Physiol Rev 87, 873-904.

McEwen, B. S., Gould, E. A. and Sakai, R. R. (1992) The vulnerability of the hippocampus to protective and destructive effects of glucocorticoids in relation to stress. Br J Psychiatry Suppl, 18-23.

Mineur, Y. S., Belzung, C. and Crusio, W. E. (2007) Functional implications of decreases in neurogenesis following chronic mild stress in mice. Neuroscience 150, 251-259.

Musshoff, U., Riewenherm, D., Berger, E., Fauteck, J. D. and Speckmann, E. J. (2002) Melatonin receptors in rat hippocampus: molecular and functional investigations. Hippocampus 12, 165-173.

Negroni, J., Venault, P., Pardon, M. C., Perez-Diaz, F., Chapouthier, G. and Cohen-Salmon, C. (2004) Chronic ultra-mild stress improves locomotor performance of B6D2F1 mice in a motor risk situation. Behav Brain Res 155 , 265-273.

Norman, T. R., Cranston, I., Irons, J. A., Gabriel, C., Dekeyne, A., Millan, M. J. and Mocaer, E. (2011) Agomelatine suppresses locomotor hyperactivity in olfactory bulbectomised rats: a comparison to melatonin and to the 5-HT(2c) antagonist, S32006. Eur J Pharmacol 674, 27-32.

Paizanis, E., Renoir, T., Lelievre, V., Saurini, F., Melfort, M., Gabriel, C., Barden, N., Mocaer, E., Hamon, M. and Lanfumey, L. (2010) Behavioural and neuroplastic effects of the new-generation antidepressant agomelatine compared to fluoxetine in glucocorticoid receptor-impaired mice. Int J Neuropsychopharmacol 13, 759-774.

Pandi-Perumal, S. R., Srinivasan, V., Spence, D. W. and Cardinali, D. P. (2007) Role of the melatonin system in the control of sleep: therapeutic implications. CNS Drugs 21, 995-1018.

Pardon, M. C., Perez-Diaz, F., Joubert, C. and Cohen-Salmon, C. (2000) Influence of a chronic ultramild stress procedure on decision-making in mice. J Psychiatry Neurosci 25, 167-177.

Parihar, V. K., Hattiangady, B., Kuruba, R., Shuai, B. and Shetty, A. K. (2011) Predictable chronic mild stress improves mood, hippocampal neurogenesis and memory. Mol Psychiatry 16, 171-183.

Prickaerts, J., Moechars, D., Cryns, K., Lenaerts, I., van Craenendonck, H., Goris, I., Daneels, G., Bouwknecht, J. A. and Steckler, T. (2006) Transgenic mice overexpressing glycogen synthase kinase 3beta: a putative model of hyperactivity and mania. J Neurosci 26, 9022-9029. 
Proudfoot, J., Doran, J., Manicavasagar, V. and Parker, G. (2011) The precipitants of manic/hypomanic episodes in the context of bipolar disorder: a review. J Affect Disord 133, 381-387.

Roth, T. L., Lubin, F. D., Funk, A. J. and Sweatt, J. D. (2009) Lasting epigenetic influence of early-life adversity on the BDNF gene. Biol Psychiatry 65, 760-769.

Sala, M., Perez, J., Soloff, P., Ucelli di Nemi, S., Caverzasi, E., Soares, J. C. and Brambilla, P. (2004) Stress and hippocampal abnormalities in psychiatric disorders. Eur Neuropsychopharmacol 14, 393-405.

Snyder, J. S., Soumier, A., Brewer, M., Pickel, J. and Cameron, H. A. (2011) Adult hippocampal neurogenesis buffers stress responses and depressive behaviour. Nature 476, 458-461.

Soumier, A., Banasr, M., Lortet, S., Masmejean, F., Bernard, N., Kerkerian-Le-Goff, L., Gabriel, C., Millan, M. J., Mocaer, E. and Daszuta, A. (2009) Mechanisms contributing to the phase-dependent regulation of neurogenesis by the novel antidepressant, agomelatine, in the adult rat hippocampus. Neuropsychopharmacology 34, 2390-2403.

Stockmeier, C. A., Mahajan, G. J., Konick, L. C., Overholser, J. C., Jurjus, G. J., Meltzer, H. Y., Uylings, H. B., Friedman, L. and Rajkowska, G. (2004) Cellular changes in the postmortem hippocampus in major depression. Biol Psychiatry 56, 640-650.

Sunanda, Rao, M. S. and Raju, T. R. (1995) Effect of chronic restraint stress on dendritic spines and excrescences of hippocampal CA3 pyramidal neurons--a quantitative study. Brain Res 694, 312-317.

Thomas, G. M. and Huganir, R. L. (2004) MAPK cascade signalling and synaptic plasticity. Nat Rev Neurosci 5, 173-183.

Touma, C. (2011) Stress and affective disorders: animal models elucidating the molecular basis of neuroendocrinebehavior interactions. Pharmacopsychiatry 44 Suppl 1, S15-26.

Tsankova, N. M., Berton, O., Renthal, W., Kumar, A., Neve, R. L. and Nestler, E. J. (2006) Sustained hippocampal chromatin regulation in a mouse model of depression and antidepressant action. Nat Neurosci 9, 519-525.

van Praag, H., Christie, B. R., Sejnowski, T. J. and Gage, F. H. (1999) Running enhances neurogenesis, learning, and long-term potentiation in mice. Proc Natl Acad Sci U S A 96, 13427-13431.

Vialou, V., Feng, J., Robison, A. J. and Nestler, E. J. (2013) Epigenetic mechanisms of depression and antidepressant action. Annu Rev Pharmacol Toxicol 53, 59-87.

Wang, L. M., Suthana, N. A., Chaudhury, D., Weaver, D. R. and Colwell, C. S. (2005) Melatonin inhibits hippocampal long-term potentiation. Eur J Neurosci 22, 2231-2237.

Weaver, I. C., Cervoni, N., Champagne, F. A., D'Alessio, A. C., Sharma, S., Seckl, J. R., Dymov, S., Szyf, M. and Meaney, M. J. (2004) Epigenetic programming by maternal behavior. Nat Neurosci 7, 847-854.

Willner, P. (2005) Chronic mild stress (CMS) revisited: consistency and behavioural-neurobiological concordance in the effects of CMS. Neuropsychobiology 52, 90-110. 


\section{Figures and legends}

A
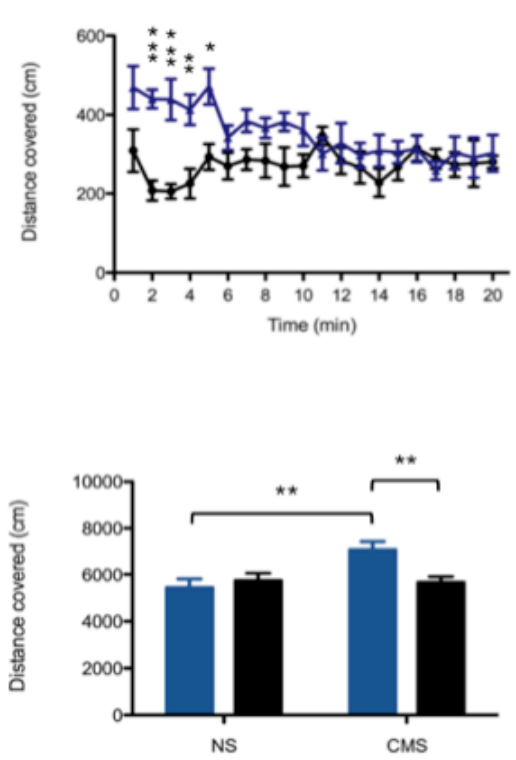

B
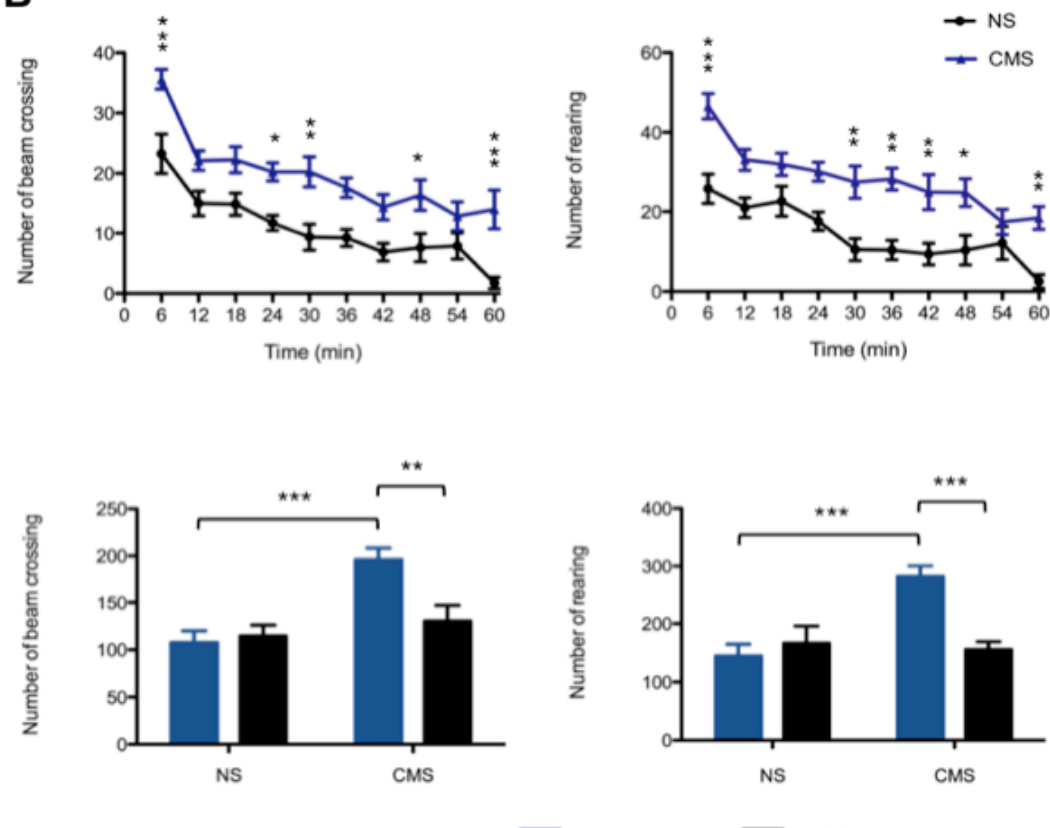

Figure 1. Effects of chronic agomelatine treatment on stress-induced locomotor dysfunction. (A) Mice were subjected to an open field test, and the distance covered in the arena was measured over the time (top panel). On the bottom panel, the total distance over a 20-minute period is represented. The two-way analysis of variance (ANOVA) indicated significant effect of Stress $[F(1,28)=5.78 ; p<0.05]$, but no effect of Treatment $[F(1,28)=2.95 ; p>0.05]$. However, the was a significant interaction between the Stress and the Treatment factors $[\mathrm{F}(1,28)=6.89 ; \mathrm{p}<0.05]$, and the Bonferroni post hoc test revealed a significant increase of the distance covered in stressed mice $(p<0.01)$, which could be prevented by agomelatine $(p<0.01)$. (B) Mice were placed in actimetry boxes and the numbers of crossings in the center of the apparatus, as well as the numbers of rearings were measured with an infrared dispositive over one hour (top panel). On the bottom panel, the total numbers of crossing and total numbers of rearings over a one-hour period are indicated. The two-way ANOVA indicated significant effect of Stress on crossing activity $[\mathrm{F}(1,28)=15.21 ; \mathrm{p}<0.01]$, and rearing activity $[\mathrm{F}(1,28)=9.12 ; \mathrm{p}<0.001]$. A significant interaction between the Stress and the Treatment factors on crossing $[\mathrm{F}(1,28)=7.30 ; \mathrm{p}<0.05]$ and rearing behaviors $[\mathrm{F}(1,28)=12.43 ; \mathrm{p}<0.01]$ was observed. Bonferroni post hoc test revealed a significant increase of the crossings and rearings in stressed mice $(\mathrm{p}<0.001)$, which could be prevented by agomelatine $\left(\mathrm{p}<0.01\right.$ and $\mathrm{p}<0.001$ respectively). Data are expressed as mean \pm S.E.M of $\mathrm{n}=8$ mice per group. ${ }^{* *} \mathrm{p}<$ 0.01 CMS HEC vs CMS AGO; ***p $<0.001$ CMS HEC vs CMS AGO. 
A

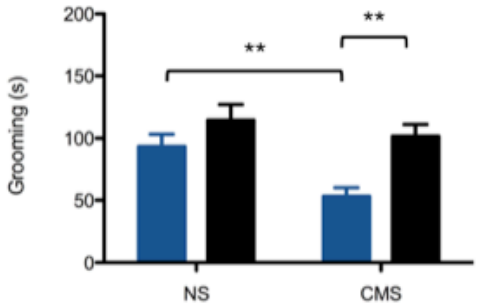

Tail suspension test

D

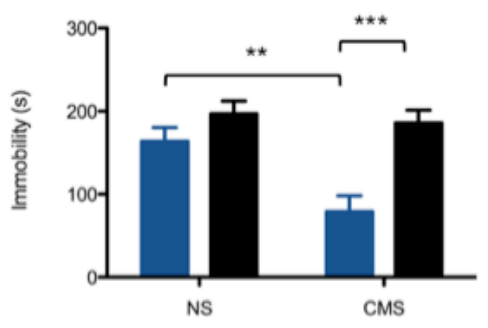

B

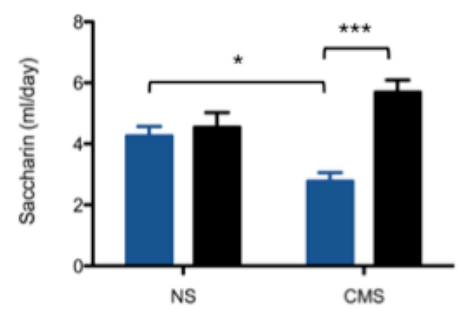

\section{C}

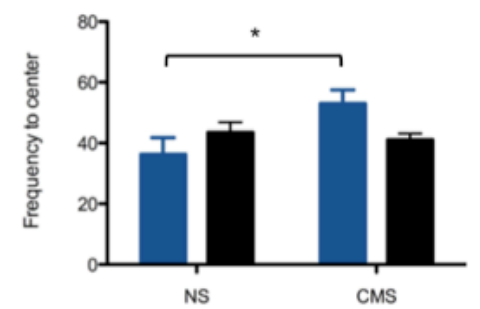

Open field
E

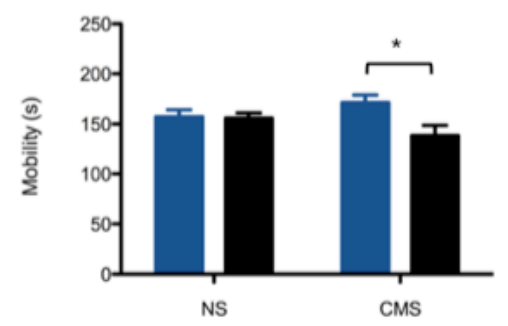

Forced swim test

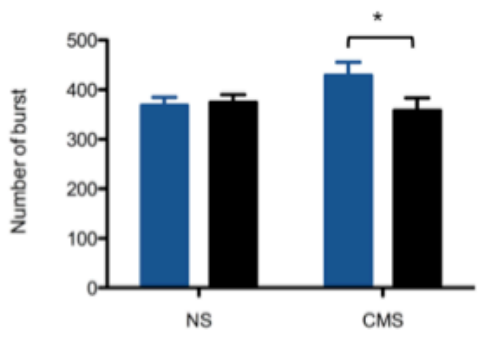

HEC
Open field

Figure 2. Effects of chronic agomelatine treatment on stress-induced affective behaviors. (A) The time spent in grooming behavior over a total period of 5 minutes was measured in mice. The two-way ANOVA indicated significant effect of Stress $[\mathrm{F}(1,70)=13.9 ; \mathrm{p}<0.01]$ as well as Treatment $[\mathrm{F}(1,70)=7.62 ; \mathrm{p}<0.05]$ on grooming behavior. Bonferroni post hoc test revealed a significant decreased in the self-grooming of stressed mice $(p<0.01)$, which could be prevented by agomelatine $(p<0.01)$. (B) The saccharin consumption was measured for an overnight period. There was a significant interaction between the Stress and the Treatment factors $[\mathrm{F}(1,39)=8.29 ; \mathrm{p}<0.01]$, and Bonferroni post hoc test revealed a significant decreased in the saccharin intake of stressed mice $(p<0.05)$, which could be prevented by agomelatine $(p<0.001)$. (C) Mice were subjected to an open field test, and the number of visit to the center of the arena was measured over a 20 -minute period. There was a significant interaction between the Stress and the Treatment $[\mathrm{F}(1,26)=5.94 ; \mathrm{p}<0.05]$, and Bonferroni post hoc test revealed a significant decreased in the number of entries in the center of the arena in stressed mice $(p<0.05)$. (D) The immobility time in the tail suspension test paradigm was measured after chronic mild stress. The two-way ANOVA indicated significant effect of Stress $[F(1,30)=7.69 ; p<0.01]$ as well as Treatment $[\mathrm{F}(1,30)=16.59 ; \mathrm{p}<0.001]$ on immobility time. There was a significant interaction between the Stress and the Treatment $[\mathrm{F}(1,30)=4.55 ; \mathrm{p}<0.05]$, and Bonferroni post hoc test revealed a significant decreased in the immobility time of stressed mice $(\mathrm{p}<0.01)$, which could be prevented by agomelatine $(\mathrm{p}<0.001)$. (E) Mice were subjected to the forced swim test, and the time spent in swimming activity (mobility) and the struggling activity (number of bursts), over a 6-minute period, are represented. There was a significant interaction between the Stress and the Treatment factors $[F(1,26)=4.25 ; p<0.05]$ for the mobility time, and the Bonferroni post hoc test revealed a significant decreased in the mobility time of stressed mice treated with vehicle as compared to stressed mice treated with agomelatine $(\mathrm{p}<0.05)$. A tendency towards an interaction for the number of burst $[\mathrm{F}(1,26)=3.12 ; \mathrm{p}=0.089]$ was observed, and a planned pairwise comparison using Dunn's t-test indicated a significant decreased in the number of bursts of stressed mice treated with vehicle as compared to stressed mice treated with agomelatine $(\mathrm{p}<0.05)$. Data are expressed as mean \pm S.E.M of $\mathrm{n}=7-12$ mice. ${ }^{*} \mathrm{p}<0.05 ; * * \mathrm{p}<0.01 ; * * \mathrm{p}<0.001$. 

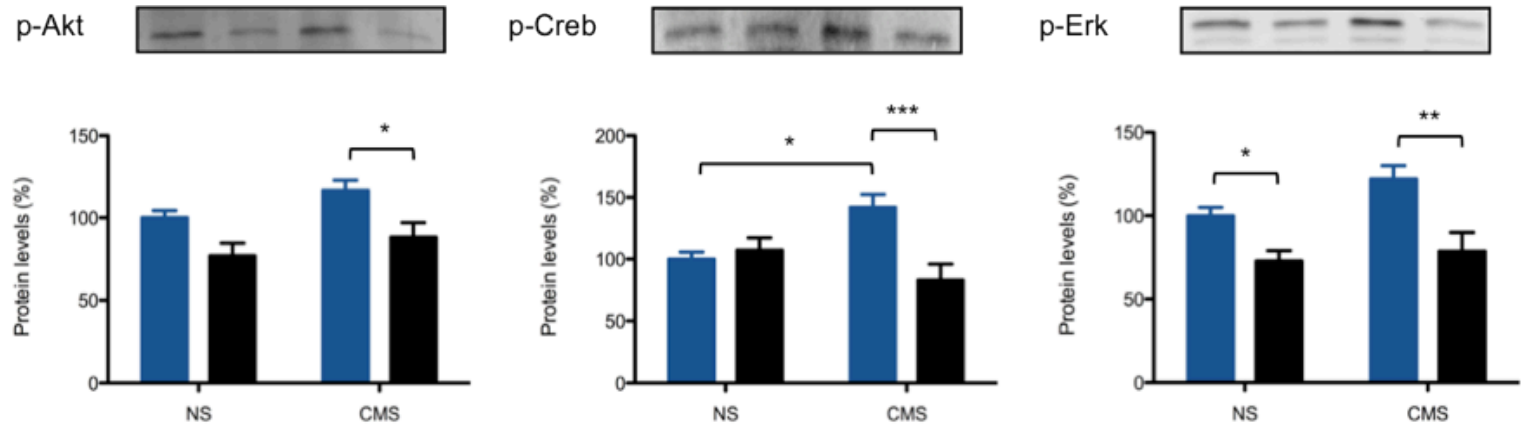

p-TrkB

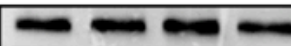

p-Atf1

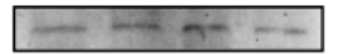

p-p38
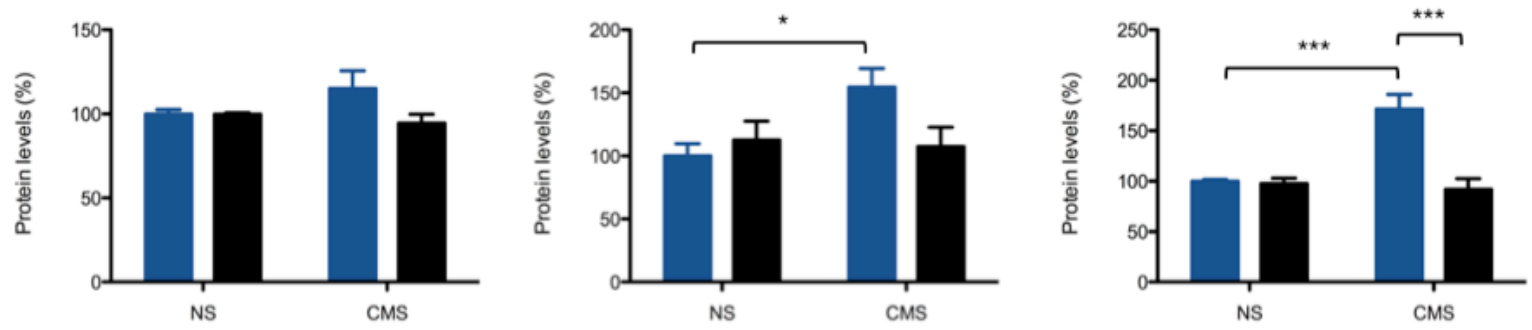

HEC

AGO

Figure 3. Effects of chronic agomelatine treatment on intracellular signaling in the hippocampus of stressed mice. Western blot analysis of phospho-Akt, phospho-Creb, phospho-Erk, phospho-TrkB, phospho-Atf1 and phospho-p38 were performed in the hippocampus of mice, and quantifications of optical density were monitored with ImageJ. A two-way ANOVA revealed a significant interaction between Stress and Treatment factors for $p-C r e b[F(1,28)=10.63 ; p<0.01], p-A t f 1[F(1,11)=5.19 ; p<0.05]$ and p-p38 $[F(1,12)=16.22 ; p<0.001]$. There was a significant effect of Treatment on p-Akt $[F(1,26)=13.72 ; p<0.001]$, $p$-Creb $[F(1,28)=6.49 ; p<0.05], p-E r k[F(1,14)=23.82 ; p<0.001]$ and $p-p 38[F(1,12)=18.35 ; p<0.01]$, and effect of Stress on $p$-p38 $[F(1,12)=11.77 ; p<0.01]$. Of note, a trend for a Stress effect was observed for $p$-Akt $[F(1,26)=4.09 ; p=0.053], p$-Erk $[\mathrm{F}(1,14)=4.55 ; \mathrm{p}=0.051]$ and $\mathrm{p}-\mathrm{Atf} 1[\mathrm{~F}(1,11)=3.55 ; \mathrm{p}=0.086]$. Bonferroni post hoc analyses revealed a significant increased between non-stressed mice treated (NS HEC) with vehicle and stressed mice treated with vehicle (CMS HEC) for p-Creb $(\mathrm{p}<0.05)$, p-Atf1 $(\mathrm{p}<0.05)$ and p-p38 $(\mathrm{p}<0.001)$. Agomelatine treatment $(50 \mathrm{mg} / \mathrm{kg} /$ day $)$ could prevent the phosphorylation of Creb $(\mathrm{p}<0.001)$ and p38 ( $<0001)$ induced by stress (CMS HEC v.s. CMS AGO). In addition, agomelatine could decrease p-Akt $(p<0.05)$ and $p$-Erk $(p<0.05)$ in stressed mice (CMS HEC v.s. CMS AGO). Data are represented as percentage of non-stressed mice treated with vehicle (NS HEC), and each bar represent the mean + S.E.M of $\left(\mathrm{n}=4-8\right.$ mice). ${ }^{*} \mathrm{p}<0.05, * * \mathrm{p}<0.01, * * * \mathrm{p}<$ 0.001 . 
A

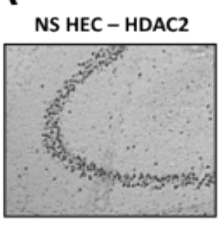

CMS HEC - HDAC2

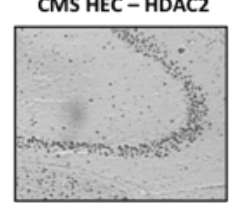

HDAC2

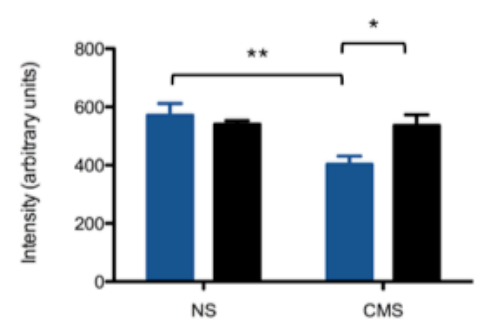

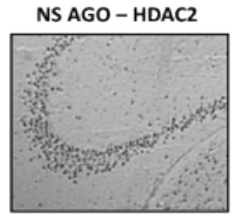

CMS AGO - HDAC2

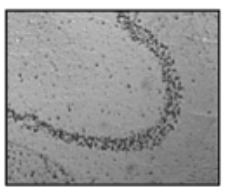

W.
B

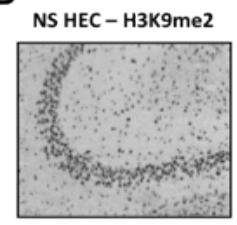

CMS HEC - H3K9me2

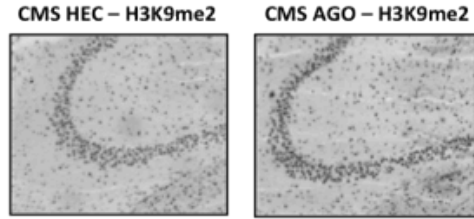

H3K9me2
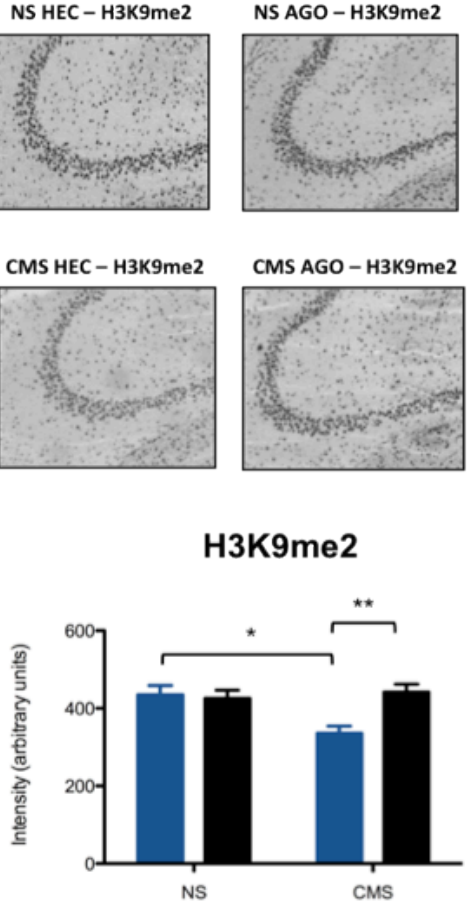

C
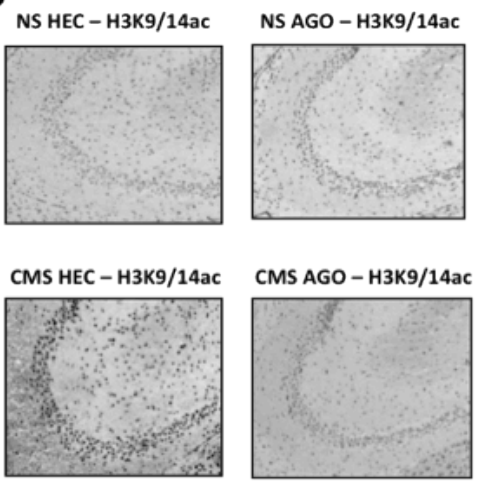

H3K9/14ac

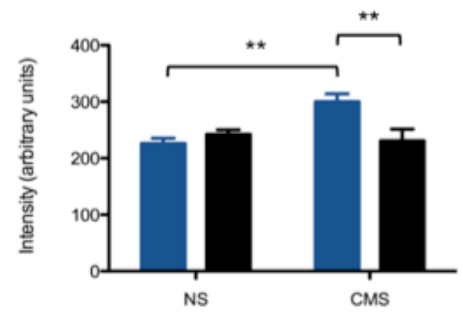

HEC

\section{Figure 4. Effects of chronic agomelatine treatment on epigenetic remodeling in the hippocampus of stressed mice} Representative photomicrographs of HDAC2 (A), H3K9me (B) and H3K9ac (C) immunolabelings in the CA3 subfield of the hippocampus (top panel) are shown, as well as the quantification of optical density (bottom panel). (A) The two-way ANOVA analysis indicated a significant effect of Stress $[F(1,16)=5.76 ; p<0.05]$, but no effect of Treatment $[F(1,16)=2.02 ; p>0.05]$ for the repressive mark HDAC2. There was a significant interaction between the Stress and the Treatment $[F(1,16)=5.17 ; p<0.05]$, and the Bonferroni post hoc test revealed a significant decreased HDAC2 in the CA3 subfield $(\mathrm{p}<0.01)$, which could be prevented by agomelatine $(\mathrm{p}<0.05)$. (B) The two-way ANOVA analysis indicated a significant effect of Treatment $[\mathrm{F}(1,17)=4.75 ; \mathrm{p}<0.05]$, but no effect of Stress $[F(1,17)=3.46 ; p>0.05]$ for the repressive mark H3K9me. There was a significant interaction between the Stress and the Treatment $[\mathrm{F}(1,17)=6.83 ; \mathrm{p}<0.05]$, and the Bonferroni post hoc test revealed a significant decreased H3K9me in the CA3 subfield $(p<0.05)$, which could be prevented by agomelatine $(p<0.01)$. (C) The two-way ANOVA analysis indicated a significant effect of Stress $[F(1,16)=5.25 ; p<0.05]$ and a tendency for an effect of Treatment $[F(1,16)=3.71 ; p=0.072]$ for the repressive mark H3K9ac. There was a significant interaction between the Stress and the Treatment $[F(1,16)=9.86 ; p<0.01]$, and the Bonferroni post hoc test revealed a significant decreased H3K9ac in the CA3 subfield ( $<0.01$ ), which could be prevented by agomelatine $(\mathrm{p}<0.01)$. Quantifications of immunolabelings are expressed as arbitrary units and each bar represent the mean + S.E.M of $\mathrm{n}=5$ (NS HEC), $\mathrm{n}=6$ (NS AGO), $\mathrm{n}=4$ (CMS HEC) and $\mathrm{n}=6$ (CMS AGO) mice. ${ }^{*} \mathrm{p}<0.05 ; * * \mathrm{p}<0.01$. 
Arc

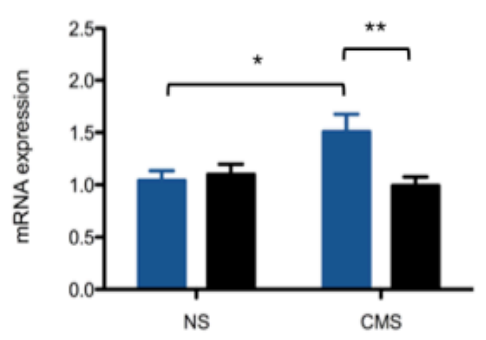

Gdnf

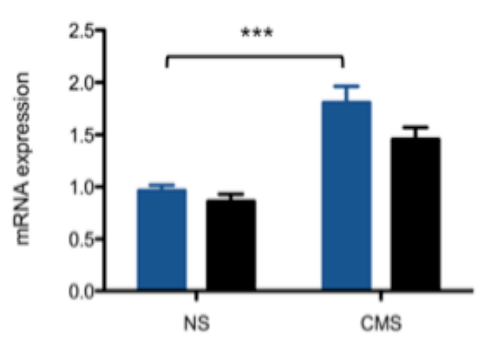

$B c / 2$

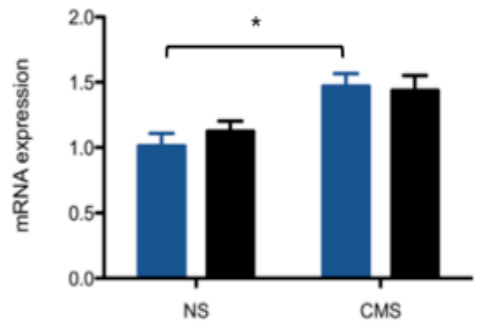

lgf1

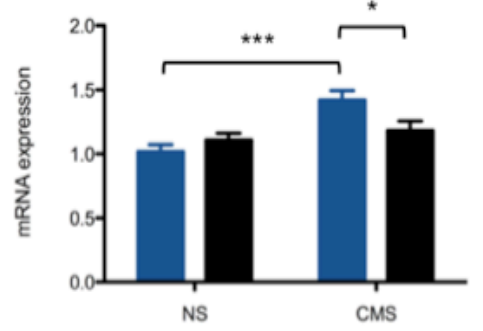

Bdnf

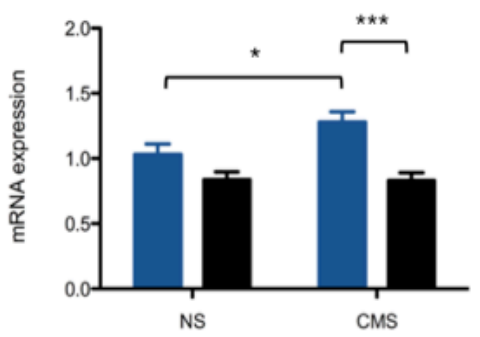

Neurod1

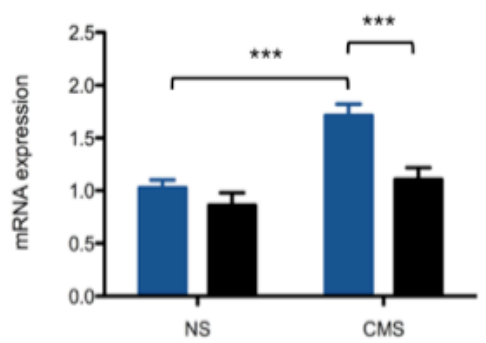

HEC

AGO

Figure 5. Effects of chronic agomelatine treatment on plasticity-related gene expression in the hippocampus of stressed mice. mRNA levels of plasticity-related genes in the hippocampus of mice were measured by quantitative real-time RT-PCR, and are expressed as fold changes as compared to the non-stressed mice treated with hydroxyethylcellulose (NS HEC). The two-way ANOVA indicated a significant interaction between Stress and Treatment factors for $\operatorname{Arc}[\mathrm{F}(1,29)=7.05 ; \mathrm{p}<0.05]$, Igfl $[\mathrm{F}(1,34)=6.15 ; \mathrm{p}<0.05]$ and Neurodl $[\mathrm{F}(1,32)=4.80 ; \mathrm{p}<0.05]$. In addition, there was also an effect of Stress on $B c l 2$ $[\mathrm{F}(1,26)=12.47 ; \mathrm{p}<0.01], \operatorname{Gdnf}[\mathrm{F}(1,25)=56.71 ; \mathrm{p}<0.001], \operatorname{Igf} 1[\mathrm{~F}(1,34)=13.30 ; \mathrm{p}<0.001]$ and Neurod1 $[\mathrm{F}(1,32)=14.41 ; \mathrm{p}<0.001]$, and a Treatment effect on $\operatorname{Arc}[\mathrm{F}(1,29)=4.50 ; \mathrm{p}<0.05], \operatorname{Bdnf}[\mathrm{F}(1,31)=17.16 ; \mathrm{p}<0.001], \operatorname{Gdnf}[\mathrm{F}(1,25)=5.57 ; \mathrm{p}<0.05]$ and Neurod1 $[\mathrm{F}(1,32)=21.05 ; \mathrm{p}<0.001]$. The Bonferroni post hoc tests indicated a significant increase of $\operatorname{Arc}(\mathrm{p}<0.05), B c l 2(\mathrm{p}<0.05), B d n f$ $(\mathrm{p}<0.05), \operatorname{Gdnf}(\mathrm{p}<0.001), \operatorname{Igf1}(\mathrm{p}<0.001)$ and Neurod1 $(\mathrm{p}<0.001)$, between non-stressed mice treated with vehicle (NS HEC) and stressed mice treated with vehicle (CMS HEC). Similarly, there was a significant difference between stressed mice treated with vehicle (CMS HEC) versus stressed mice treated with agomelatine (CMS AGO) for $\operatorname{Arc}(\mathrm{p}<0.01), B \operatorname{dnf}(\mathrm{p}<0.001), \operatorname{Igfl}(\mathrm{p}<0.05)$ and Neurod1 $(\mathrm{p}<0.001)$. Each bar represent the mean + S.E.M of $\mathrm{n}=7-12$ mice. $* \mathrm{p}<0.05 ; * * \mathrm{p}<0.01 ; * * \mathrm{p}<0.001$. 


\section{Supplementary methods.}

\section{Saccharin consumption test}

At the beginning of the test, plastic pipettes filled with tap water were proposed to the mice so as to measure the daily consumption of water using such kind of apparatus. Then, after habituation, two pipettes filled either with water or a $10 \%$ saccharin solution were assigned to every cage and the mice were able to freely choose between the two solutions. The pipettes were presented to the animals for an overnight period of 18 hours, after which they were removed from the cages.

\section{Tail suspension test}

The apparatus consists of three suspension units divided by walls (ID-Tech-Bioseb, Chaville, France). The mice were suspended by the tail, using an adhesive tape, and the duration of immobility was measured automatically by the software over a 6-minute period.

\section{Splash test}

The splash test, previously described by Surget et al., 2008, consists into spraying a $10 \%$ sucrose solution on the back of mice in their home cage. Because of its viscosity, the sucrose solution dirties the coat and induces grooming behavior. The total time of grooming over a 5-minute period was recorded in our experiments.

\section{Open field test}

The apparatus consisted of four open boxes of $40 \times 40 \mathrm{~cm}$ separated by white wood walls and equipped with an infrared floor for the measurement of motor activity. The arena was subdivided into a central and a peripheral zone. Mice were placed in the open field boxes for 20 min under normal light conditions, and the motor activity of the animals were automatically scored with a camera connected to a computerized system (Viewpoint, Lyon, France). The time spent in the different zones and the distance moved were scored.

\section{Forced swim test}

In the forced swimming test (FST), originally designed by Porsolt and colleagues (1977), mice were placed into plastic buckets $\left(19 \mathrm{~cm}\right.$ diameter, $23 \mathrm{~cm}$ deep, filled with $23^{\circ} \mathrm{C}-25^{\circ} \mathrm{C}$ water) under low light conditions and videotaped for 6 min (Viewpoint, Lyon, France). The different outcome measures were "immobility" reflecting no movement at all and/or minor movements necessary to keep the nose above the water; "mobility" reflecting medium activity such as swimming; and "bursts" reflecting strong mobility and struggling behaviors. 


\section{Rotarod test}

Motor coordination and balance were assessed with the rotarod test using an accelerating rotarod (Accelerating Rotarod, UGO Basile, Comerio, Italy). Mice were placed on rotating drums $(3 \mathrm{~cm}$ diameter), and the time that each animal maintained its balance on the rod was measured. The speed of the rotarod accelerated from 4-40 rpm over a 5-min period.

\section{Spontaneous locomotor activity}

Locomotor activity was measured using a computer-based photobeam apparatus. Actimeter box (area: $300 \times 150 \mathrm{~mm}^{2}$; height $180 \mathrm{~mm}$; with plexiglass wall and grid floor) detected mouse movements by means of two infrared light beams. Mice were placed in the testing apparatus for 1 hour. The ambulations corresponding to the number of squares crossed in periphery and centre during the observation period, and the rearings corresponding to the number of times the mouse stands on its hind feet (and leaves the floor with the fore feet) were measured.

\section{Elevated plus maze}

The elevated plus maze (EPM), as described previously by Narboux-Neme and colleagues (2011), consisted of a plus-shaped apparatus with two open and two closed arms. The apparatus was made from dark plastic material that was transparent for infrared light, and the walls of the closed compartment were covered with opaque scotch tape. For the test, the mouse was placed into one of the closed arm facing a closed part of the apparatus, and the movements of the animal were scored automatically under dark conditions with a computerized system using an infrared video camera (Viewpoint, Lyon, France). Percentage of time spent in the open and closed parts of the maze, numbers of entries to the open and closed arms, and total distance traveled were investigated.

\section{References:}

Surget, A., Saxe, M., Leman, S., Ibarguen-Vargas, Y., Chalon, S., Griebel, G., Hen, R. and Belzung, C. (2008) Drug-dependent requirement of hippocampal neurogenesis in a model of depression and of antidepressant reversal. Biol Psychiatry 64, 293-301.

Porsolt, R. D., Le Pichon, M. and Jalfre, M. (1977) Depression: a new animal model sensitive to antidepressant treatments. Nature 266, 730-732. 


\begin{tabular}{|c|c|c|c|}
\hline & Morning & Afternoon & Night \\
\hline Monday & & $30^{\circ}$ cage-tilt $(1 \mathrm{~h})$ & Difficult access to food \\
\hline Tuesday & Confinement $(1 \mathrm{~h})$ & Paired housing $(2 \mathrm{~h})$ & Overnight illumination \\
\hline Wednesday & $30^{\circ}$ cage-tilt $(1 \mathrm{~h})$ & Confinement $(2 \mathrm{~h})$ & $30^{\circ}$ cage-tilt $(1 \mathrm{~h})$ \\
\hline Thursday & Paired housing $(2 \mathrm{~h})$ & Confinement $(1 \mathrm{~h})$ & Soiled cage \\
\hline Friday & Confinement $(1 \mathrm{~h})$ & $30^{\circ}$ cage-tilt $(2 \mathrm{~h})$ & Reverse light/dark cycle \\
\hline Week-end & & Reverse light/dark cycle \\
\hline
\end{tabular}

Table S1. Procedures used for the chronic mild stress paradigm. The stressors consisted into repeated periods of $30^{\circ}$ cage tilt, confinement to small cages $(11 \times 8 \times 8 \mathrm{~cm})$, two 2 hour periods of paired housing, one overnight period of difficult access to food (without modifying the daily food ration), one period of continuous overnight illumination, and one overnight period in a soiled cage (50 $\mathrm{ml}$ of water/l of sawdust bedding). Animals were also placed on a reversed light/dark cycle from Friday evening to Monday morning. These stressors were scheduled over a 1-week period and repeated throughout a total period of 3 weeks. 


\begin{tabular}{ccc}
\hline Symbol & Sense & Anti-sense \\
\hline Arc & TCATTCAGTATGTGGTGGGC & \\
Akt1 & TATTGGCTACAAGGAACGGC & ATCCTGCACTTCCATACCC \\
Bdnf9 & AAAACCATAAGGACGCGGAC & TAGACATGTTTGCGGCATCC \\
Creb1 & GTTGTTATGGCGTCCTCCC & TACGACATTCTCTTGCTGCC \\
Crf & CCTTGAATTTCTTGCAGCCG & GGACTTCTGTTGAGATTCCCC \\
Mapk3 & TACGATCCGACAGATGAGCC & GAAGATCAACTCCTTCAGCCG \\
Gdnf & TGGGTTTGGGCTATGAAACC & AACATGCCTGGCCTACTTTG \\
Glur1 & TGTGACACCATGAAAGTGGG & AAAACCGCTAGGTTTACGGG \\
Igf1 & GACTGGAGATGTACTGTGCC & GTACTTCCTTCTGAGTCTTGGG \\
NeuroD1 & TGAAGCCATGAATGCAGAGG & TTTCTTTTTGGGACCCCGTC \\
Vgf & TTGACACCCTTATCCAAGGC & ACCTGAGCTAATCCTTGCTG \\
cfos & AGGGAACGGAATAAGATGGC & TGCAACGCAGACTTCTCATC \\
Egr1 & TCAATCCTCAAGGGGAGCC & ACTCGTCTCCACCATCGC \\
Bcl2 & ATGACTGAGTACCTGAACCG & ATGCTGGGGCCATATAGTTC
\end{tabular}

Table S2. Primers used for SybrGreen protocols. One part of the amplification was made with Absolute SYBR Green ROX Mix (Thermo Scientific, Illkirch, France) using the 7300 Real Time PCR System (Applied Biosystems, Courtaboeuf, France) and the sequences of primer sets are indicated. Gene expressions were normalized using Hprt as a reference gene and the conditions for the reaction included 35 cycles in a fixed sequence of $95^{\circ} \mathrm{C}$ for $20 \mathrm{~s}, 62^{\circ} \mathrm{C}$ for $30 \mathrm{~s}$, and $72^{\circ} \mathrm{C}$ for $30 \mathrm{~s}$. 


\begin{tabular}{cc}
\hline Symbol & Reference \\
\hline Bmal1 & Mm00500226_m1 \\
Cbp & Mm01342452_m1 \\
Id2 & Mm01293217_g1 \\
Nr1d2 & Mm00441730_m1 \\
Ncor1 & Mm00448681_m1 \\
Rpol1-2 & Mm00485813_m1 \\
Dnmt1 & Mm01151065_g1 \\
Hdac1 & Mm02745760_g1 \\
Hdac2 & Mm00515108_m1 \\
Hdac3 & Mm00515916_m1 \\
Hdac4 & Mm01299565_m1 \\
Hdac5 & Mm00515941_g1 \\
Hdac9 & Mm00458454_m1 \\
Mbd1 & Mm01262472_g1 \\
Mecp2 & Mm01193537_g1 \\
Myst2 & Mm01304323_m1 \\
Gapdh & Mm99999915_g1
\end{tabular}

Table S3. Primers used for Taqman protocols. The second part of gene expression was measured using TaqMan (Applied Biosystems, Courtaboeuf, France) gene expression assays, and the sequences of primer sets are indicated. Gene expressions were normalized using Gapdh as a reference gene and the conditions for the reaction were set as follow: $50^{\circ} \mathrm{C}, 2 \mathrm{~min} ; 95^{\circ} \mathrm{C}, 10 \mathrm{~min}$, and followed by 40 cycles at $95{ }^{\circ} \mathrm{C}, 15 \mathrm{~s} ; 60^{\circ} \mathrm{C}, 1 \mathrm{~min}$. 


\begin{tabular}{lll}
\hline Symbol & Name & Supplier \\
\hline p-Akt & Phospho-Akt (Ser473) (587F11) 4051 & Cell signaling \\
p-Creb & Phospho-CREB (Ser133) (87G3) 9198 & Cell signaling \\
p-Erk & Monoclonal Anti-MAP Kinase, Activated (Diphosphorylated ERK1\&2) M9692 & Sigma aldrich \\
p-p38 & Phospho-p38 MAPK (Thr180/Tyr182) (D3F9) 4511 & Cell signaling \\
p-TrkB & Trk B Phospho (pY817) (NTRK2) 2149-1 & Epitomics \\
H3K9me2 & Anti-Histone H3 (di methyl K9 [mAbcam 1220] ab1220 & Abcam \\
H3K4me3 & Anti-trimethyl-Histone H3 (Lys4) Antibody, clone MC315 & Millipore \\
H4ac & Anti-acetyl-Histone H4 Antibody 06-866 & Millipore \\
H3K9/14ac & H3K9/14ac polyclonal antibody pAb-005-044 & Diagenode \\
HDAC1 & Anti-HDAC1 antibody - ChIP Grade ab7028 & Abcam \\
HDAC2 & Anti-HDAC2 antibody - ChIP Grade ab7029 & Abcam
\end{tabular}

Table S4. List of antibodies used in the experiments. The names (including the reference) and suppliers for the antibodies used for western blots and immunohistochemistry are indicated. 


\begin{tabular}{cccccc}
\hline Symbol & Definition & NS & CMS & \% over NS & P value \\
\hline & & & & \\
Arc & Activity-regulated cytoskeleton-associated protein & $1.03 \pm 0.08$ & $1.59 \pm 0.10$ & $56 \%$ & $*$ \\
Akt1 & Thymoma viral proto-oncogene 1 & $1.01 \pm 0.04$ & $1.07 \pm 0.04$ & $6 \%$ & $\mathrm{~ns}$ \\
Bc12 & B cell lymphoma 2 & $1.01 \pm 0.09$ & $1.47 \pm 0.09$ & $46 \%$ & $* *$ \\
Bdnf9 & Brain-derived neurotrophic factor exon 9 & $1.00 \pm 0.08$ & $1.28 \pm 0.07$ & $28 \%$ & $*$ \\
Creb1 & cAMP responsive element binding protein 1 & $1.01 \pm 0.08$ & $1.17 \pm 0.07$ & $16 \%$ & ns \\
Crf & Corticotropin releasing factor & $1.02 \pm 0.07$ & $1.13 \pm 0.07$ & $11 \%$ & ns \\
Mapk3 & Mitogen-activated protein kinase 3 & $1.01 \pm 0.08$ & $0.87 \pm 0.05$ & $-14 \%$ & $\mathrm{~ns}$ \\
Gdnf & Glial-derived neurotrophic factor & $1.01 \pm 0.07$ & $1.59 \pm 0.15$ & $58 \%$ & $* * *$ \\
Glur1 & Glutamate receptor, ionotropic, AMPA1 & $1.01 \pm 0.10$ & $0.96 \pm 0.08$ & $-5 \%$ & $\mathrm{~ns}$ \\
Gpr88 & G-protein coupled receptor 88 & $0.99 \pm 0.17$ & $1.17 \pm 0.17$ & $18 \%$ & $\mathrm{~ns}$ \\
Igf1 & Insulin growth factor 1 & $1.01 \pm 0.05$ & $1.42 \pm 0.07$ & $41 \%$ & $* * *$ \\
NeuroD1 & Neurogenic differentiation 1 & $1.02 \pm 0.07$ & $1.71 \pm 0.10$ & $69 \%$ & $* *$ \\
Vgf & Nerve growth factor inducible & $1.04 \pm 0.10$ & $0.78 \pm 0.13$ & $-26 \%$ & $\mathrm{~ns}$
\end{tabular}

Table S5. Effect of chronic mild stress on hippocampal plasticity-related gene expression profiles. Diverse genes involved in neuroplasticity have been measured in the hippocampus of mice subjected or not to the chronic mild stress procedure. mRNA levels were quantified by quantitative real-time RT-PCR, and data were normalized to the house keeping gene Actb. Data are expressed as mean \pm S.E.M of arbitrary units representing the fold changes as compared to the non-stress (NS) condition. ns: non significant *p $<0.05$ vs. NS; **p $<0.01$ vs. NS; $* *$ p $<0.001$ vs. NS. Student's t test. 


\begin{tabular}{cccccc}
\hline Symbol & Definition & NS & CMS & \% over NS & P value \\
\hline \multirow{2}{*}{ Bmal1 } & Aryl hydrocarbon receptor nuclear translocator-like & $1.00 \pm 0.04$ & $0.91 \pm 0.04$ & $-9 \%$ & $\mathrm{~ns}$ \\
cfos & FBJ osteosarcoma oncogene & $1.05 \pm 0.18$ & $0.63 \pm 0.11$ & $-42 \%$ & $*$ \\
Cbp & Creb binding protein & $1.00 \pm 0.02$ & $1.01 \pm 0.04$ & $1 \%$ & $\mathrm{~ns}$ \\
Egr1 & Early growth response 1 & $1.00 \pm 0.08$ & $1.06 \pm 0.14$ & $6 \%$ & $\mathrm{~ns}$ \\
Id2 & Inhibitor of DNA binding 2 & $1.00 \pm 0.05$ & $0.89 \pm 0.05$ & $-11 \%$ & $\mathrm{~ns}$ \\
Nr1d2 & Nuclear receptor subfamily 1, group D, member 2 & $1.00 \pm 0.01$ & $1.40 \pm 0.05$ & $40 \%$ & $* * *$ \\
Ncor1 & Nuclear receptor co-repressor 1 & $1.00 \pm 0.05$ & $0.63 \pm 0.06$ & $-37 \%$ & $* *$ \\
Rpol1-2 & RNA polymerase 1 & $1.00 \pm 0.03$ & $0.96 \pm 0.12$ & $-4 \%$ & $\mathrm{~ns}$
\end{tabular}

Table S6. Effect of chronic mild stress on hippocampal transcription regulators. Diverse genes involved in the control of transcription have been measured in the hippocampus of mice subjected or not to the chronic mild stress procedure. mRNA levels were quantified by quantitative real-time RT-PCR, and data were normalized to the house keeping gene Actb. Data are expressed as mean \pm S.E.M of arbitrary units representing the fold changes as compared to the non stress (NS) condition. ns: non significant $* \mathrm{p}<0.05$ vs. NS; $* * p<0.01$ vs. NS; $* * * p<0.001$ vs. NS. Student's t test. 


\begin{tabular}{cccccc}
\hline Symbol & Definition & NS & CMS & \% over NS & P value \\
\hline & & & & & \\
Dnmt1 & DNA methyltransferase 1 & $1.00 \pm 0.02$ & $0.99 \pm 0.05$ & $-1 \%$ & $\mathrm{~ns}$ \\
Hdac1 & Histone deacetylase 1 & $1.00 \pm 0.02$ & $1.01 \pm 0.07$ & $1 \%$ & $\mathrm{~ns}$ \\
Hdac2 & Histone deacetylase 2 & $1.00 \pm 0.03$ & $0.78 \pm 0.04$ & $-22 \%$ & $* *$ \\
Hdac3 & Histone deacetylase 3 & $1.00 \pm 0.03$ & $1.01 \pm 0.03$ & $1 \%$ & $\mathrm{~ns}$ \\
Hdac4 & Histone deacetylase 4 & $1.00 \pm 0.02$ & $1.06 \pm 0.10$ & $6 \%$ & $\mathrm{~ns}$ \\
Hdac5 & Histone deacetylase 5 & $1.01 \pm 0.04$ & $1.03 \pm 0.06$ & $2 \%$ & $\mathrm{~ns}$ \\
Hdac9 & Histone deacetylase 9 & $1.00 \pm 0.02$ & $1.04 \pm 0.06$ & $4 \%$ & $\mathrm{~ns}$ \\
Mbd1 & Methyl binding domain 1 & $1.01 \pm 0.06$ & $1.00 \pm 0.04$ & $-1 \%$ & $\mathrm{~ns}$ \\
Mecp2 & Methyl CpG binding protein 2 & $1.00 \pm 0.03$ & $0.95 \pm 0.02$ & $-5 \%$ & $\mathrm{~ns}$ \\
Myst2 & MYST histone acetyltransferase 2 & $1.00 \pm 0.03$ & $0.99 \pm 0.02$ & $-1 \%$ & $\mathrm{~ns}$
\end{tabular}

Table S7. Effect of chronic mild stress on hippocampal expression of epigenetic regulators. Diverse genes involved in epigenetic repression or activation have been measured in the hippocampus of mice subjected or not to the chronic mild stress procedure. mRNA levels were quantified by quantitative real-time RT-PCR, and data were normalized to the house keeping gene Actb. Data are expressed as mean \pm S.E.M of arbitrary units representing the fold changes as compared to the non stress (NS) condition. ns: non significant *p $<0.05$ vs. NS; $*$ p $<0.01$ vs. NS; $* * * p<0.001$ vs. NS. Student's t test. 
A

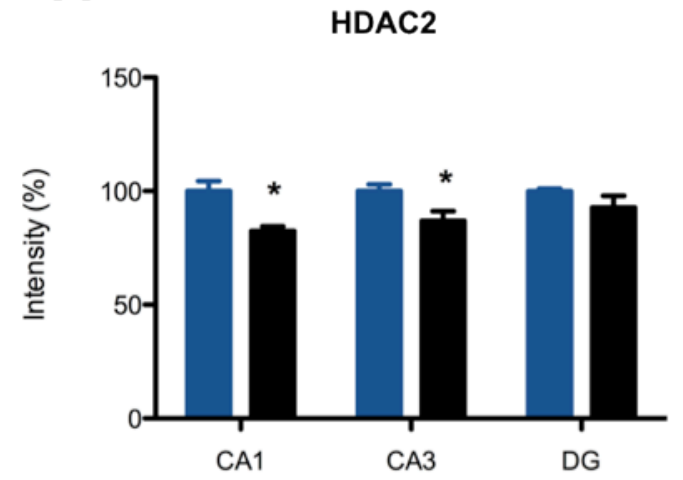

B

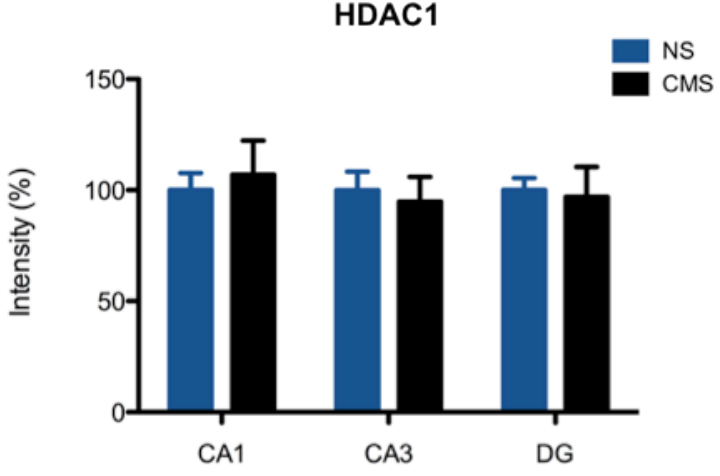

Figure S1. Effect of chronic mild stress on HDAC1 and HDAC2 expression in the hippocampus. The levels of HDAC2 (A) and HDAC 1 (B) in the hippocampus were measured by immunostaining, and the quantifications of optical density of the different hippocampal subfields are represented. Data are expressed as percentage of the nonstress (NS) condition and each bar represent the mean + S.E.M of $n=5$ (NS) and $n=6$ (CMS) mice. ${ }^{*} p<0.05$ vs. NS. Student's $t$ test. 


\section{A}

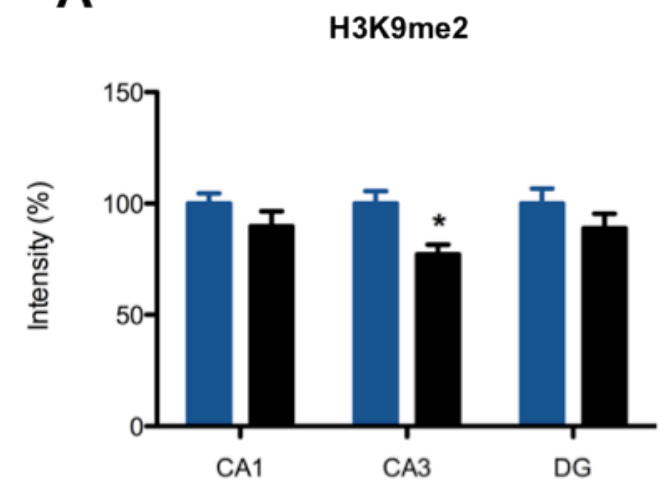

C

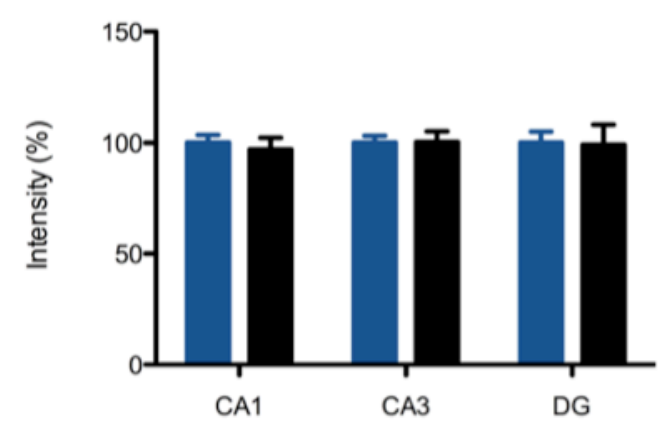

B

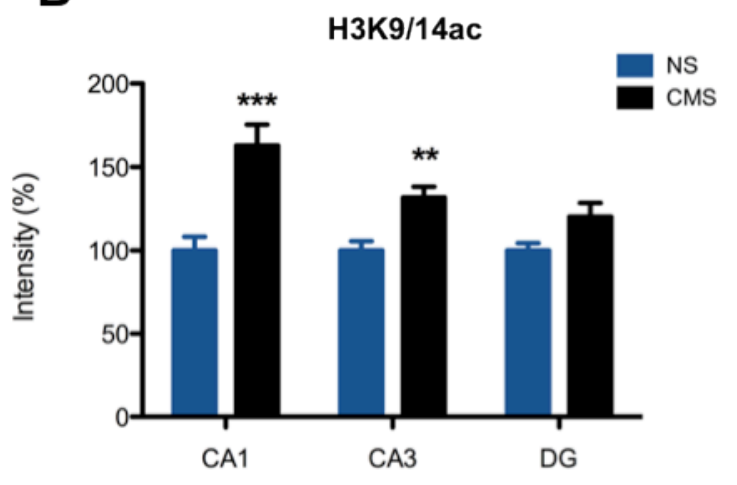

D

H3K4me3

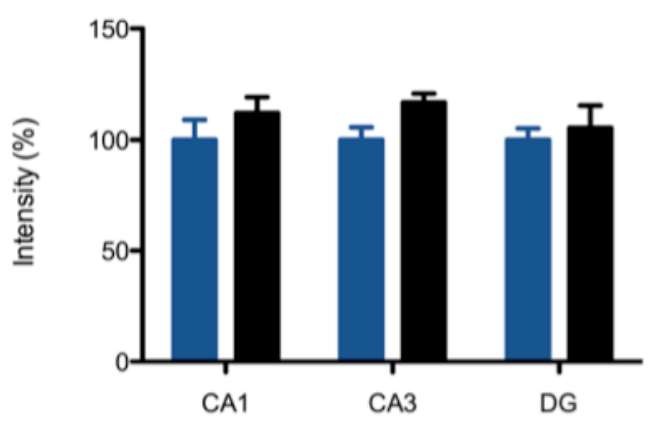

Figure S2. Effect of chronic mild stress on histone post-translational modifications in the hippocampus. The levels of H3K9me2 (A), H3K9/14ac (B), H4ac (C) and H3K4me3 (D) were measured by immunolabeling in the hippocampus, and the quantifications of optical density of the different hippocampal subfields are represented. (B) Data are expressed as percentage of the non-stress (NS) condition and each bar represent the mean + S.E.M of $n=5$ (NS) and $\mathrm{n}=6$ (CMS) mice. ${ }^{*} \mathrm{p}<0.05$ vs. NS; $* * \mathrm{p}<0.01$ vs. NS; ${ }^{* * *} \mathrm{p}<0.001$ vs. NS. Student's t test. 


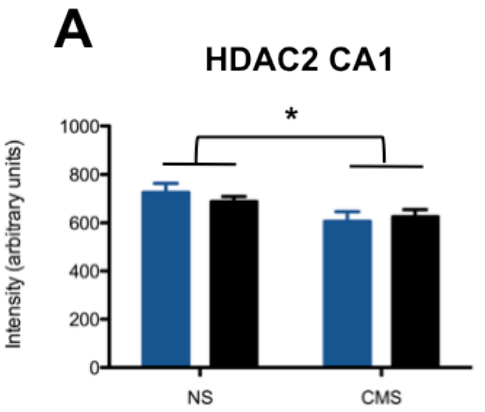

HDAC2 DG

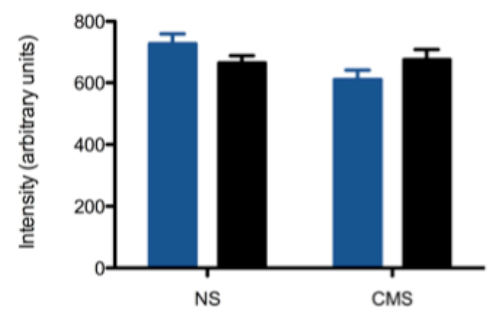

B

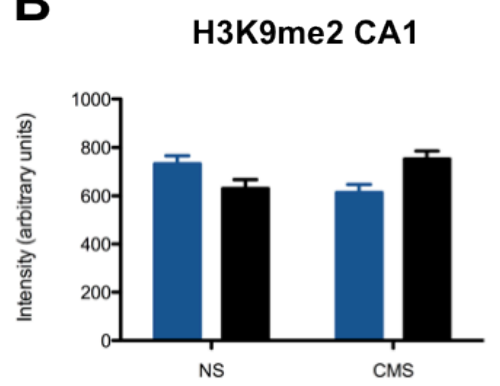

H3K9me2 DG

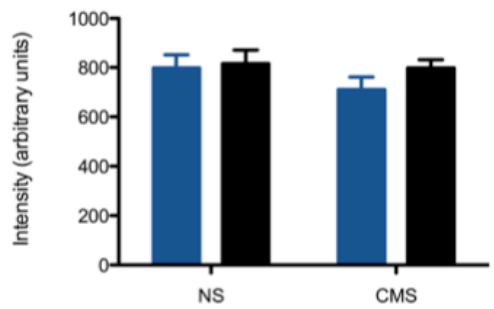

HEC
C

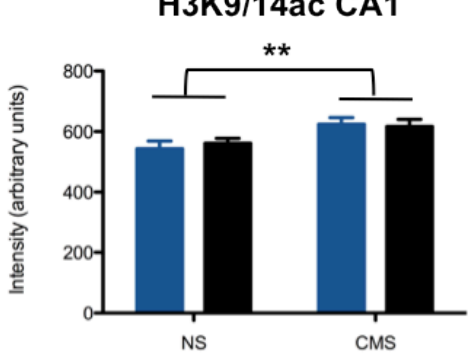

H3K9/14ac DG

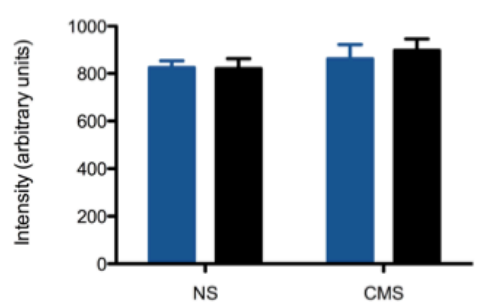

AGO

Figure S3. Effect of agomelatine on stress-induced epigenetic changes in the hippocampus. The levels of HDAC2 (A), H3K9me2 (B) and H3K9/14ac (C) were measured by immunolabeling in the hippocampus, and the quantifications of optical density of the CA1 (top panel) and the DG (bottom panel) are represented. The two-way ANOVA analysis indicated a significant effect of Stress on HDAC2 $[F(1,16)=7.03 ; p<0.05], H 3 \mathrm{~K} 9 / 14 \mathrm{ac}$ $[F(1,16)=8.89 ; \mathrm{p}<0.01]$, but not on H3K9me2 in the CA1 region. Further, the two-way ANOVA analysis indicated no significant effect of Stress on HDAC, H3K9me2 and H3K9/14ac in the DG. Quantifications of immunolabelings are expressed as arbitrary units and each bar represent the mean + S.E.M of $n=5$ (NS HEC), $n=6$ (NS AGO), $n=4$ (CMS HEC) and $\mathrm{n}=6$ (CMS AGO) mice. ${ }^{*} \mathrm{p}<0.05$ CMS HEC vs CMS AGO; **p $<0.01$ CMS HEC vs CMS AGO. 
A

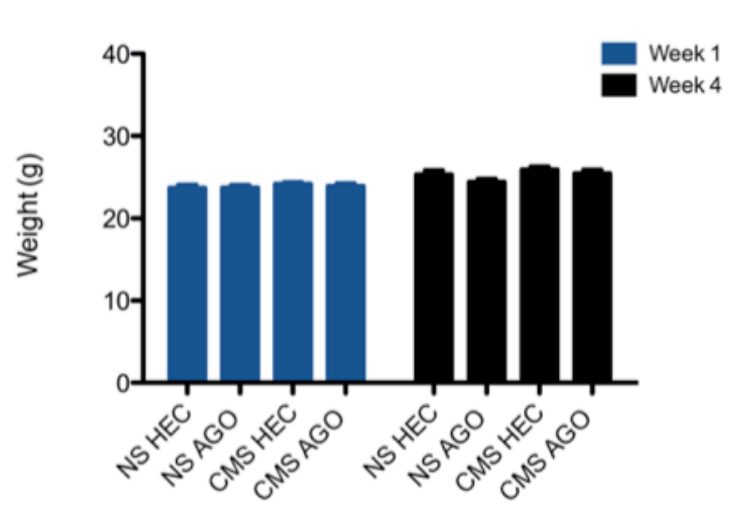

B

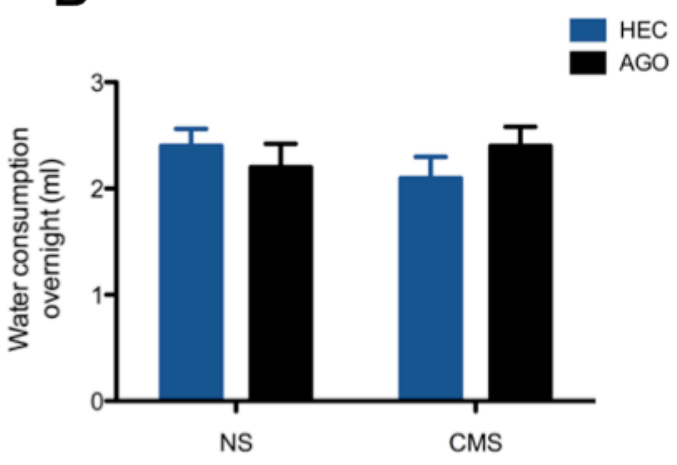

Figure S4. Water consumptions and weights. (A) The weight of mice was measure before and after the chronic mild stress procedure. (B) The consummation of water over the night is represented. Each bar represents the mean + S.E.M of $n=7-8$ animals per group. There were no significant modulations of the weights and water consumptions by stress or agomelatine treatment. 


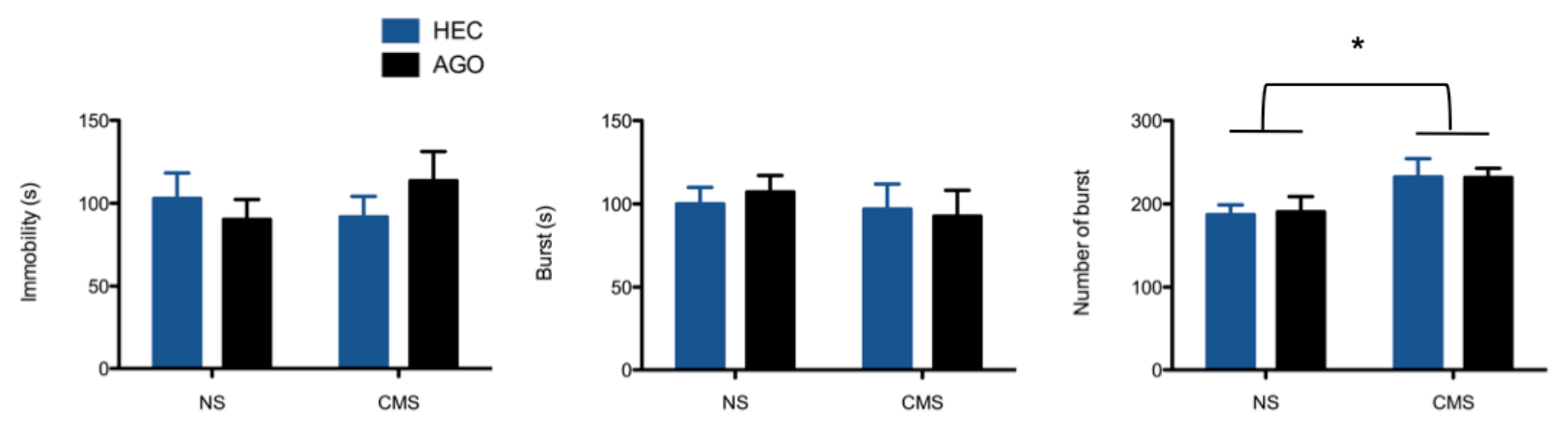

Figure S5. Effects of stress and agomelatine treatment in the FST. Mice were subjected to the forced swim test, and the time spent in immobility (right panel) and in burst activity (center panel) over a 6-minute period is represented. The numbers of bursts during the first 2 minutes is also represented (left panel). There was no significant modulation of the immobility and burst time by stress or agomelatine treatment. A two-way ANOVA indicated a significant effect of Stress factor on the numbers of bursts during the first 2 minutes $[F(1,28)=6.84$; $\mathrm{p}<0.05]$. Data are expressed as mean + S.E.M of $\mathrm{n}=7-8$ mice per group. ${ }^{*} \mathrm{p}<0.05$. 

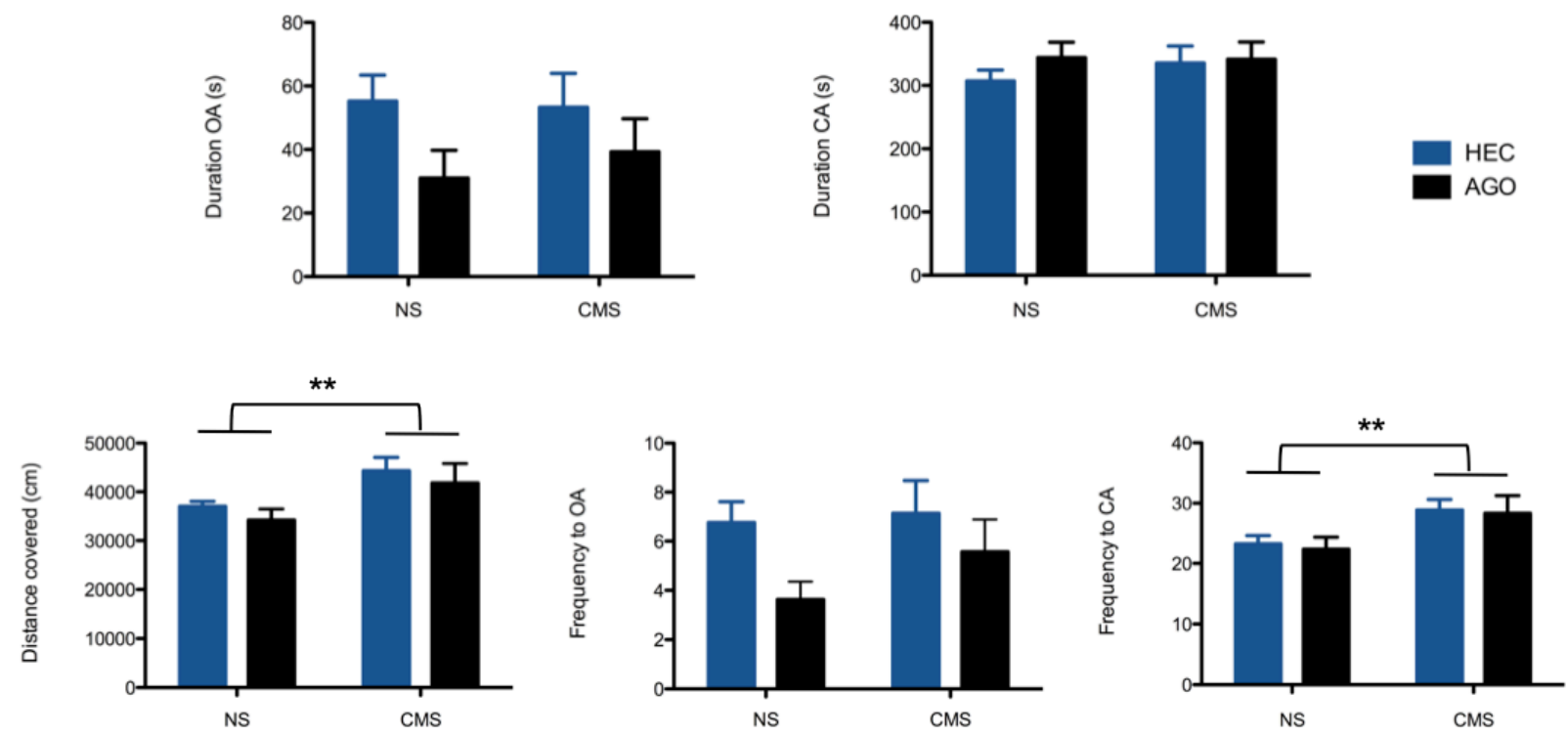

Figure S6. Effects of stress and agomelatine treatment in the EPM. Mice were subjected to the elevated plus maze test for 10 minutes. The two-way ANOVA indicated no significant difference of Stress or Treatment factors on the time spent in open arms or closed arms. However, there was a significant effect of Stress on the distance covered $[F(1,27)=7.85 ; p<0.01]$ and the frequency to closed arms $[F(1,27)=8.03 ; p<0.01]$. In addition, the two-way ANOVA indicated a significant effect of Treatment on the frequency to open arms $[F(1,27)=4.68 ; p<0.05]$. Data are expressed as mean + S.E.M of $\mathrm{n}=7-8$ mice per group. ${ }^{* *} \mathrm{p}<0.01$. 

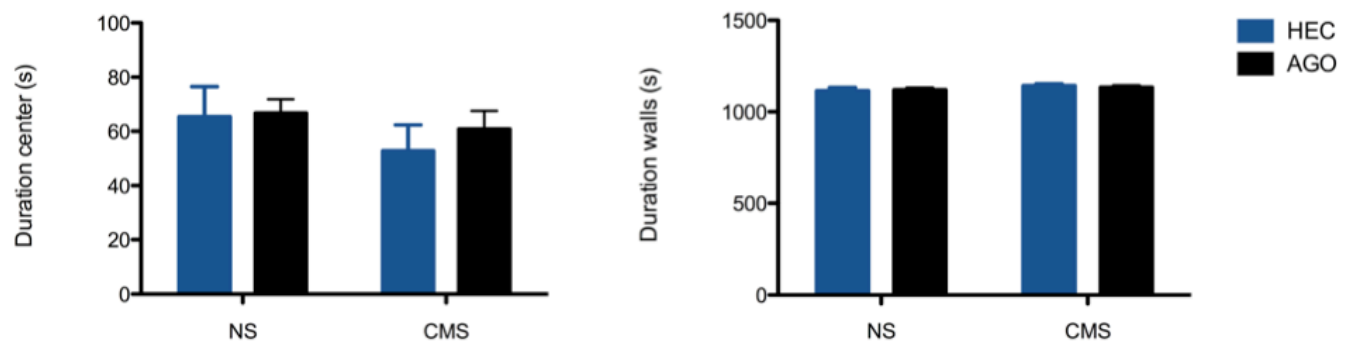

Figure S7. Effects of stress and agomelatine treatment in the OF. Mice were subjected to the open field test, and the time spent in the periphery (right panel) and the time spent in the center (left panel) of the arena over a 20minute period are represented. Data are expressed as mean + S.E.M of $n=7-8$ mice per group. There was no significant modulation of the time spent in the center or periphery by stress or agomelatine treatment. 
A

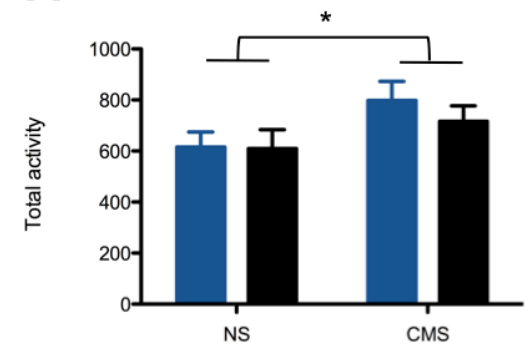

B

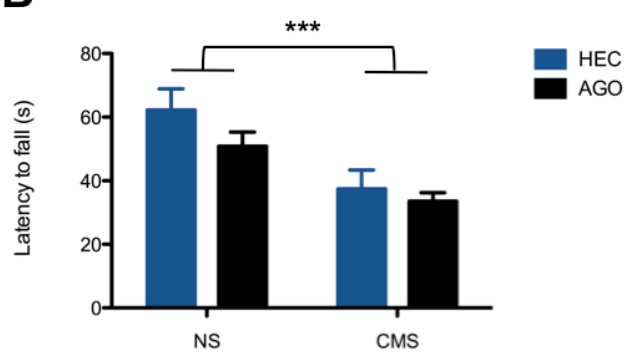

Figure S8. Effects of stress and agomelatine treatment on locomotor activity and movement coordination. (A) Mice were placed in actimetry boxes and the total locomotor activity during a 1-hour period was measured. Chronic mild stress significantly increased the locomotor activity $(\mathrm{p}=\ldots$... . (B) Mice were placed in a accelerating rotarod apparatus, and the latency to fall was measured. Chronic mild stress significantly altered the movement balance and coordination, which might be du to an increased distractibility $(\mathrm{p}=\ldots)$. Data are expressed as mean + S.E.M of $\mathrm{n}=7-8$ mice per group. 


\begin{tabular}{cc}
\hline Symptoms of mixed manic state & Chronic mild stress in C57Bl6 mice \\
\hline Disrupted circadian rhythms & \\
Increased risk taking & Inversion of light/dark cycles in stress procedures \\
Psychomotor agitation / hyperactivity & Reduced anxiety in the OF \\
Emotional arousal and vigilance & Increased locomotion and rearing \\
Impulsivity & Increased reactivity in the FST and TST \\
Self neglect & Facilitation of choice in the decision making task \\
Distractibility / decreased concentration & Decreased self grooming \\
Reward deficit & Inability to keep focussed in the rotarod test \\
High levels of energy & Impaired motor learning \\
\end{tabular}

Table S8. Comparison between clinical symptom of mania and behavioral response in mice exposed to chronic mild stress. 
Chapter VIII

216 


\section{CHAPTER IX}

\section{General Discussion}

Fabien BOULLE 
Mood disorders are among the major health problems worldwide due to the high prevalence and recurrence in the general population, and the significant burden for individual life quality and the repercussion on healthcare systems and society (WHO, 2001). Up to date, the etiology and biological mechanisms underlying mood disorders are still poorly understood. Mounting evidences suggest that a complex interaction between genes and the environment account for the development and course of major depression, i.e. one of the most prevalent affective disorders (Keers et al., 2012). Accordingly, complex epigenetic regulations - consisting of key mechanisms by which environmental factors induce enduring changes in gene expression without altering the DNA code - have been suspected to plays a pivotal role in the pathophysiology of depression (Tsankova et al., 2007). More specifically, epigenetic repression of the gene encoding for brain-derived neurotrophic factor (BDNF) - a small-secreted growth factor implicated in brain development and neuronal plasticity - may have a preponderant role in the onset of depression and other mood disorders (Boulle et al., 2012). In this context, the work presented in this thesis aimed at exploring the role of BDNF signaling and its downstream epigenetic regulation in the pathophysiology and treatment of mood disorders.

\section{I - BDNF/TrkB signaling in the pathophysiology of mood disorders}

Exon-specific regulation of the BDNF gene: BDNF has a complex gene structure, consisting of several untranslated 5' exons with independent promoters that can be connected to a 3' coding exon to form a bipartite or tripartite transcript yielding different splice variants of BDNF mRNA (Pruunsild et al., 2007). In Chapter 6, we investigated the expression of BDNF exon IV and exon IX in the hippocampus of rats exposed to fluoxetine during development in a model of maternal adversity. Male offspring exposed to prenatal stress showed a decrease in BDNF IV mRNA levels, while no changes were observed at BDNF IX mRNA expression. Among prenatally stressed female offspring, an increase in BDNF IV mRNA levels was observed, while expression of BDNF IX mRNA was unchanged. Maternal fluoxetine exposure on the other hand decreased BDNF IV mRNA levels in the hippocampus of female offspring, while no changes were observed at the BDNF IX exon, i.e. the coding exon. These observations are rather provocative since the BDNF IV transcript corresponds to an alternative splice variant that is not representative of the total BDNF protein level. Similarly, in Chapter 7, we showed that BDNF IV mRNA levels were decreased in the hippocampus of GR-i mice, further supporting the exon-specific involvement of BDNF in the stress response regulation and in mediating depressive-like behaviour. Accordingly, it has been suggested that the use of distinct BDNF mRNA splice variants differing either by the 5' or 3' extremity allows for temporal and spatial regulation of BDNF expression, which appears to be critical in the modulation of synaptic plasticity and spine development in dendrites (Baj et al., 2011). BDNF exon IV contains specific binding sites for the glucocorticoid receptor, making it a target of choice for stressrelated events (Suri et al., 2013). In addition, BDNF exon IV contains specific binding sites for the cyclic 
AMP response element binding protein (CREB) and methyl $\mathrm{CpG}$ binding protein 2 (MeCP2), making it a preferential epigenetic target (Dias et al., 2003; Martinowich et al., 2003). Accordingly, this exon has been shown to display a ubiquitous repartition in the brain and seems to play a key role in many processes related to mood, emotion, reward, learning and memory (see Chapter 2). Evidently, the exact role of the various BDNF transcripts and the complex regulation of BDNF mRNA and protein processing await further research.

Regulation of BDNF/TrkB signaling by stress and glucocorticoids: Stress has been proposed as a major risk factor in the development of affective disorders and the persistent elevation of glucocorticoids induced by chronic stress can significantly alter BDNF production and impact on structural and functional plasticity in the hippocampus (Berton et al., 2006; Suri et al., 2013). As such, in Chapters 6, 7 and 8, we investigated the hippocampal regulation of the BDNF gene in two different rodent models of stress, as well as in a transgenic mouse model displaying impaired glucocorticoid receptor (GR) signaling. Interestingly, the expression of BDNF exon IV mRNA was decreased in the hippocampus of GRimpaired (GR-i) mice. Previous experiments performed by our research group showed that GR-i mice displayed a deficit in the negative feedback regulation of the hypothalamo-pituitary-adrenal (HPA) axis under stressful conditions as well as in depressive-like behavior (Froger et al., 2004; Paizanis et al., 2010). Hence, the decrease in BDNF and downstream neuroplastic effectors in the hippocampus of this transgenic mouse model supports the notion that HPA axis impairment may play a part in the pathophysiology of major depression, and that the neuronal loss and synaptic dysfunction induced by prolonged stress exposure might involve alterations in neurotrophic signaling. In line with this hypothesis, we found that exposure to early-life (i.e. prenatal restraint) stress in Sprague-Dawley rats reduced the expression of BDNF mRNA in the hippocampus of adult male offspring, and was associated with increased depressive-like behavior (Chapter 6). However, the opposite effect on BDNF IV mRNA levels was observed in the hippocampus of female offspring prenatally exposed to maternal stress. This latter observation indicates a sex-specific regulation of the response and adaptation to stress, potentially leading to differential expression of the BDNF gene. In humans, a clear sex difference exists in the incidence and onset of stress-related diseases (Wang et al., 2007). In contrast, rodent models of psychiatric disorders, because of the estrus cycle and concomitant fluctuation in sex hormones in females, are based principally on male animals. However, recent studies have showed that sex hormones, especially estrogen, could induce the expression of BDNF (Scharfman et al., 2006; Solum et al., 2002). Clearly, the link between glucocorticoids, sex hormones and neurotrophic signaling should be addressed more thoroughly.

Further, exposure to repeated socio-environmental stressors of low intensity in adult C57B16J mice resulted in an increased BDNF IX mRNA expression and related plasticity pathways, in the hippocampus. Using this procedure, our research group previously reported a decrease hippocampal expression of GR mRNA in stressed mice (Froger et al., 2004). Endogenous decrease or pharmacological inactivation of 
GR was shown to correlate with enhanced synaptic plasticity (Avital et al., 2006; Krugers et al., 2006). In addition, the mineralocorticoid receptors (MR), which bind glucocorticoids with high affinity, are most densely localized in hippocampal neurons (De Kloet ER, 2000). MRs are activated at low doses of glucocorticoids and have been associated with enhanced cognitive function and hippocampal plasticity (Avital et al., 2006; Sousa et al., 2008). Hence, the levels of glucocorticoids, as well as the balance between MRs and GRs, might play a critical role in the molecular, neuroendocrine and behavioral determination of the stress response. Of note, at the transcriptional level, GRs can affect BDNF transcription either by binding to GR binding elements (GREs) present in the promoter areas and therefore inhibit transcription (Zanchi et al., 2010), or by interfering with the transcription factors that normally activate BDNF transcription (Kassel et al., 2007).

Altogether, the data presented in Chapters 6, 7 and $\mathbf{8}$ indicates that a clear link exists between stress, glucocorticoids and BDNF signaling, and suggest that the nature of the stressor (e.g. timing, duration, intensity), as well as genetic factors (e.g. GR polymorphism), are critically important in the determination of neuroplastic outcomes. This observation might explain, at least in part, the well-reported heterogeneity in stress responsivity and related pathologies.

Matching BDNF expression and neurocircuits to behavior: Among several growth factors, BDNF has been postulated as a key mediator of the synaptic dysfunction and neuronal atrophy often observed in the prefrontal cortex and hippocampus of mood disorder patients (Duman et al., 2012). A decrease of BDNF and its tropomyosin-related kinase receptor $(\operatorname{TrkB})$ were observed in the hippocampus of suicide completers and depressed patients (Autry et al., 2012; Dwivedi et al., 2003). In Chapters 6 and 7, we showed that the decrease of BDNF mRNA levels was associated with increased depressive-like behavior. According, male offspring that were subjected to prenatal stress exhibited decreased expression of the BDNF exon IV, concomitant with decreased swimming behavior in the forced swim test (FST). Similarly, female offspring that were exposed to maternal fluoxetine showed decreased expression of the BDNF exon IV and increased immobility in the FST. In GR-i mice, the decreased expression of the BDNF exon IV was associated with increased immobility in the tail suspension test (TST), decreased self-grooming, and increased fear and anxiety. Altogether, these findings suggest that BDNF/TrkB signaling and its associated plasticity are important in the regulation of mood.

Generally, impaired BDNF levels and plasticity (i.e. neurogenesis) in the hippocampus of rodents have been associated with increased depressive-like behavior (Castren et al., 2010; Jha et al., 2011; Mirescu et al., 2006). However, depression is a very complex disease and is difficult to model in rodents. Since animals might not be able to express the complete symptomatology of the disease, a rational approach should consist into matching symptom-related endophenotypes to hypothetically malfunctioning brain circuits. The hippocampus is a major component of the limbic system known to be highly vulnerable to 
stress and environmental variations, and is critically implicated in learning, memory and mood (see Chapter 3). However, in our experiments, stress or genetic variation may affect BDNF levels in various regions, and the observed changes in the hippocampus may not be solely attributed to the broad range of behavioral responses. Interestingly, approaches using region-specific knockdown or local infusion showed that BDNF-mediated plasticity in the hippocampus could be mostly associated with cognitive performance, fear memories and anxiety (Heldt et al., 2007; Quesseveur et al., 2013; Taliaz et al., 2010). Hence, it is possible that the observed decreased BDNF levels in the hippocampus are implicated predominantly in anxiety and in the cognitive symptoms of depression. In the hippocampus, BDNF/TrkB are abundantly expressed on neurons receiving serotonergic and glutamatergic afferences (Lessmann $\mathrm{V}$, 1998; Martinowich et al., 2008). Accordingly, the neuroplastic effects of BDNF on i.e. dendritic arborization, axonal growth, neuronal survival and neurotransmitter release might critically affect the development and functioning of specific neurotransmitter systems, which would explain at least in part some of the behavioral performances observed in our models.

In contrast, the findings presented in Chapters 7 bring some novel insights into the region-specific regulation of BDNF/TrkB signaling in the pathophysiology of depression. We confirmed that the chronic blockade of BDNF/TrkB signaling by peripheral administration of Ana12, a recently developed TrkB inhibitor, could result in antidepressant-like effects in GR-i mice. These findings are rather provocative because a growing body of literature indicated similar effects after administration of BDNF directly in the hippocampus, or peripheral administration of TrkB agonists (Liu et al., 2010; Shirayama et al., 2002). However, as recently described by Cazorla and colleagues, Ana12 diffused preferentially in the striatum to inhibit TrkB (Cazorla et al., 2011). Interestingly, clean-cut evidence from both rodent and human studies demonstrated that stress and/or major depression is associated with increased BDNF levels in the mesolimbic dopaminergic system i.e. the nucleus accumbens (Krishnan et al., 2007). The ventral striatum, including the nucleus accumbens, plays a major part in reward, pleasure, interest, impulsivity and fatigue/energy. Accordingly, BDNF-mediated plasticity in the nucleus accumbens might be implicated in the hedonic symptoms of depression (Martinowich et al., 2008; Krishnan et al., 2007).

Finally, in Chapter 8, we found that chronic exposure to low-intensity stress could be associated with hyperactivity. In this study, BDNF IX mRNA levels as well as neuroplasticity were increased in the hippocampus of mildly stressed mice. The relationship between hyperactivity and the hippocampus is not fully understood yet, but some evidence indicates that physical activity and exercise could significantly enhance hippocampal neurogenesis and plasticity (Van Praag et al., 1999; Fabel et al., 2008). In addition, a recent study provided evidence on the involvement of BDNF/TrkB signaling in enkephalinergic striatopallidal neurons in the control of locomotor behavior (Besusso et al., 2013). 
Altogether, our data point to a complex region-specific regulation of BDNF/TrkB signaling in the pathophysiology of depression. BDNF/TrkB signaling is critically important in regulating plasticity in cortico-limbic structures. Hence, dysregulation of this neuroplastic signaling may impact on neuronal connectivity and neurotransmission in diverse brain regions, leading to a broad range of behavioral disturbances.

\section{II - BDNF/TrkB signaling in the mechanism of action of antidepressants}

Putative mechanism of the adverse effects of fluoxetine during early development: Fluoxetine, an antidepressant belonging to the class of SSRIs, is widely used in the clinic for the treatment of mood disorders during pregnancy and the post-partum period (Cooper et al., 2007). There is growing evidence that the use of this antidepressant during development has negative consequence on brain development and adult psychopathology (Pawluski et al., 2009; Laine et al., 2003; Oberlander et al., 2009). In adulthood, it is well established that fluoxetine increases BDNF levels (including BDNF IV mRNA levels) in cortico-limbic structures to induce antidepressive and anxiolytic effects in rodents (Martinowich et al., 2007). However, in Chapter 6, we found that early-life exposure to fluoxetine led to decreased levels of BDNF IV mRNA in male and female offspring in adulthood. These observations are rather interesting, and suggest that the molecular mechanisms involved in early-life versus e.g. adulthood intervention with fluoxetine are distinct. Serotonin plays an important role in the development of the brain modulating neuronal differentiation, axon guidance or dendritic pruning (Gaspar et al., 2003; Homberg et al., 2010). The serotonergic system is complex, and involves at least fifteen identified receptors associated with different intracellular transduction cascades (Gaspar et al., 2003). Hence, the pattern of expression of serotonin receptor subtypes might be critical during development, and in the determination of fluoxetine effects. In addition, during postnatal development, certain populations of neurons express a transient serotonergic phenotype that no longer exists in adulthood, and the modulation of this partial serotonergic system might interfere with the fine-tuning process of neuronal networks (Cases et al., 1998; Gaspar et al., 2003). Moreover, fluoxetine was shown to interact with several targets including serotonin receptors (2A, 2C and 2B) and ion channels (Mostert et al., 2008), in addition to the serotonin transporter (5-HTT). The differential patterns of expression of these systems in early-life might also be determinant in the long-term biological action of developmental fluoxetine exposure.

Hence, future research should investigate the precise mechanisms of action of fluoxetine treatment during development in order to conclude whether the observed changes at BDNF signaling in adulthood are mediated via a direct effect of serotonin and its downstream signaling in developing neurons, via additional target systems of fluoxetine or via other compensatory mechanisms occurring later in life.

Mechanism of action of agomelatine in the treatment of in mood disorders: As mentioned above, conventional antidepressants, via the modulation of monoaminergic signaling, are known to enhance 
BDNF expression and neuroplasticity in cortico-limbic structures to exert their therapeutic effects (Castren et al., 2010). However, little is known about the neuroplastic mechanisms of action of the new generation antidepressant agomelatine. This atypical antidepressant acts as a mixed melatonin receptor 1 and 2 agonist and serotonin receptor 2C antagonist (De Bodinat et al., 2010). In Chapters 7 and 8, we particularly focused on the molecular and neurotrophic actions of agomelatine in two mouse models of affective disorders. In GR-i mice, the decreased BDNF IV mRNA levels and deficit in cell proliferation in the hippocampus could be reversed by chronic agomelatine treatment. In addition, the marked decrease of Bcl2 and cFos mRNA levels in GR-i mice could be restored by chronic agomelatine treatment. All this neurochemical changes correlated with the reversal of depressive- and anxiety- like behavior in GR-i mice. These findings support the notion that antidepressant medications, including agomelatine, require BDNF/TrkB signaling to rescue the impairment of hippocampal plasticity and exert their therapeutic effects. However, in our model of chronic mild stress, where BDNF IX mRNA levels and neuroplasticity were increased, we found that chronic administration of agomelatine could restore a normal hippocampal function by decreasing the levels of BDNF and associated signaling pathways. Of note, agomelatine did not produce such effects in naïve animals. This finding is of particular interest and indicates that agomelatine, rather than directly targeting the BDNF/TrkB system, acts as a normalizing drug, thereby restoring/rebalancing gene expression specifically in pathological conditions. Accordingly, agomelatine is though to exert its effects via a re-synchronization of circadian rhythms (De Bodinat et al., 2010). Disruption of circadian periodicity, as well as seasonal changes, have been proposed as a major player in the onset of various mood disturbances (i.e. bipolar disorders, mania), and successful antidepressant treatments have been associated with normalization of disturbed biological rhythms (Harvey AG, 2008; Lanfumey et al., 2013). Moreover, in our model of chronic mild stress, which appears to mimic common symptoms usually observed in the mixed manic state of bipolar disorder, and shows neurobiological changes observed in mouse models of mania (including increased hippocampal BDNF levels), agomelatine was efficient in rescuing both the neurochemical and behavioral alterations. Hence, we carefully suggest that the modulation of melatonin receptors, possibly with additional blockade of serotonin $2 \mathrm{c}$ receptors, may provide a specific and innovative way to treat bipolar disorders.

\section{III - Epigenetic regulation of BDNF/TrkB signaling in mood disorders}

BDNF/TrkB signaling and chromatin remodeling in neuronal plasticity: The interaction of BDNF with its receptor TrkB plays a preponderant role in the induction and maintenance of neuronal plasticity (Chao MV, 2003). The action of BDNF on neuronal architecture and networks is tightly regulated by epigenetic re-arrangements at the chromatin level (Karpova N, 2013). Accordingly, BDNF has a complex gene structure that has been reported to be highly sensitive to environmental variations and concomitant epigenetic modifications (Tsankova et al., 2007) underlying changes in expression of downstream target genes. In Chapter 5, we explored the role of epigenetic regulation downstream of BDNF/TrkB signaling 
using a pharmacological approach. We showed that chronic blockade of the BDNF receptor TrkB downregulates plasticity-related gene expression concomitant with epigenetic changes (e.g. posttranslational modifications at histone tails and $\mathrm{MeCP} 2$ binding) in cultured neuronal cells. These findings strongly suggest that TrkB signaling can underlie epigenetic remodeling at plasticity-related genes, and that its selective blockade is able to induce histone modifications in order to significantly alter neuronal plasticity. One might also suspect that the downregulation of BDNF/TrkB signaling observed in corticolimbic structures after severe or chronic stress might critically impact on the epigenetic program of neuronal cells, leading to reduced plasticity and thereby increasing the vulnerability towards mood disorders.

Early-life events, brain development and epigenetic imprints: The modulation of gene expression by epigenetic mechanisms is essential during development, where a "cellular memory" is created enabling an appropriate pattern of gene expression and a specific cellular phenotype (Probst et al., 2009). Hence, early-life events, behavioral experience or genetic variations can influence epigenetic remodeling, and modulate neuronal architecture and networks during development (Roth et al., 2011). In Chapter 6, we showed that early-life exposure to maternal fluoxetine is associated with persistent epigenetic changes, e.g. H3K27 tri-methylation at the BDNF promoter IV, concomitant with decreased expression at the corresponding BDNF mRNA, in the hippocampus of adult female offspring prenatally exposed to stress. Of note, this effect was observed only in female offspring prenatally exposed to stress, indicating that maternal adversity increased the vulnerability for fluoxetine-induced epigenetic reprogramming in the hippocampus in a sex-dependent manner. In Chapter 7, we explored epigenetic processes in the hippocampus of the GR-i transgenic mice, in which a transgene affecting the GR expression is present throughout the lifespan. We found a marked alteration in the machinery controlling histone posttranslational modifications and DNA methylation, including e.g. decreased expression of the DNA methyltransferase 1 (DNMT1) gene, the DNA methyltransferase 3a (DNMT3a) gene, the histone-lysine N-methyltransferase HRX 3 (MLL3) gene and the histone-lysine N-methyltransferase HRX 4 (MLL4) gene. In addition, GR-i mice showed deficits in neurogenesis and decreased BDNF-related signaling in the hippocampus in adulthood. Glucocorticoid-related signaling is critical during brain development, by remodeling axon and dendrite networks as well as modulating neuronal maturation and survival (Lupien et al., 2009). Hence, it is tempting to speculate that changes in the machinery controlling epigenetic regulation during development are responsible for an epigenetic reprogramming associated with the observed permanent deficit in functioning of the adult hippocampus. Altogether, the data presented in Chapter 6 and 7 provide further evidence that early-life events, including exposure to drugs or stressful situation, are critical for brain development, and can have negative consequences involving persistent epigenetic imprints up to adulthood, that most likely increase the susceptibility for mood disorders. 
Stress and epigenetic regulation in adulthood: Chromatin remodeling via histone modifications occurs in response to diverse environmental exposures, among which, stress insults have been most extensively described (Mifsud et al., 2011). At the molecular level, the sustained elevation of glucocorticoids observed in stressful situations might interfere with various intracellular signaling and transcriptional processes, and prolonged exposure to stress in adulthood have been shown to interact with the epigenome (Maze et al., 2013). In Chapter 8, we report that chronic exposure to a low-intensity socio-environmental stress could impact on chromatin regulation. We found that stress was associated with robust changes in epigenetic regulation and plasticity-related gene transcription. Chronic stress was associated with decreased HDAC2 and H3K27me3 levels in the hippocampus, while H3K9/14ac was increased in this same region. HDAC2 is a critical enzyme implicated in histone regulation, and low levels of this protein in the hippocampus have previously been shown to strongly correlate with enhanced synaptic plasticity (Guan et al., 2009). Further, in our model, there was also a robust increase in plasticity-related intracellular signaling pathways such as the mitogen-activated protein kinase (MAPK) cascade, after chronic exposure to stress. Hence, it remains speculative to conclude whether the changes in histone modifications correspond to the nuclear integration of the activated intracellular signaling cascades in response to stress, or whether stress directly affects histone-modifying enzymes, thereby inducing aberrant neuroplastic signaling. However, modifications at histone tails are considered as dynamic regulatory processes involved in gene transcription. Importantly, the alteration in the machinery controlling chromatin regulation and histone modifications, involving e.g. histone acetylating and methylating enzymes, might maintain stable patterns of gene expression and a persistent aberrant phenotype.

In conclusion, it remains difficult to determine whether stress-induced histone modifications in adulthood represent a cause or a consequence of the disease progression, but it appears to be well established that such kind of chromatin regulations forms a core are part of the neurobiological alterations observed in adult animal models of stress and related mood disorders. In this context, genetic association studies investigating the role of functional single nucleotide polymorphisms (SNPs) of genes involved in epigenetic regulations in mood disorder patients should be addressed.

\section{IV - Perspectives for the development of novel antidepressant drugs}

Targeting BDNF/TrkB signaling to modulate epigenetic-mediated neuroplasticity: As described above, $\mathrm{BDNF} / \mathrm{TrkB}$ signaling plays a critical role in neuronal plasticity, and appears to be required for the therapeutic action of antidepressants (Castren et al., 2010). However, the use of BDNF as a therapeutic treatment encounters many limitations, BDNF has a poor blood brain barrier penetration, low oral bioavailability and short half-life in plasma (Poduslo et al., 1996). In addition, the interaction of BDNF with pro-apoptotic p75 receptor might result in undesirable effects (Zhang et al., 2008). As such, the 
development of specific small-molecule TrkB ligands has recently emerged, and so far, only a limited amount of candidates have been identified and characterized (see Chapter 3). Peripheral administration of small synthetic TrkB agonists could induce neurogenesis and antidepressant-like properties in rodents (Liu et al., 2010). Nevertheless, we found that Ana12, a small non-peptidic, TrkB inhibitor could induce antidepressant effect in GR-i mice. These data are in accordance with a hypothetic region-specific regulation of BDNF in the pathophysiology of depression, and provide novel insights into the therapeutic role of TrkB inhibitors in mood disorders. However, the use of TrkB antagonists as a therapeutic treatment for mood disorders should be regarded with caution, since we also observed signs of increased anxiety after chronic treatment with Ana12 (Chapter 7).

Nevertheless, modulating the expression of specific BDNF exons in a targeted fashion may represent a promising strategy to restore enduring changes in gene expression induced by e.g. repeated environmental insults. In view of the region-specific distribution of BDNF transcripts in the brain and their functionally distinct roles, developing compounds that modulate the transcription of specific BDNF exons will provide considerable advantages and possibly avoid undesirable side effects. In this context, it was recently shown that a neutralizing inhibitor of miR-206, a small non-coding RNA regulating the expression of BDNF, could target specific BDNF transcripts to prevent detrimental effects of amyloid beta in a mouse model of Alzheimer disease (Lee et al., 2012). This finding should spur researchers to further investigate the possible role of such experimental strategies e.g. RNA interference therapy in the treatment of moodrelated disorders.

Since aberrant BDNF signaling might play a critical role in the pathophysiology and/or treatment of mood disorders, directly targeting epigenetic modifications at the BDNF gene promoters represents another promising strategy to enduringly reverse abnormal BDNF expression and engender long-lasting clinical benefits. Interestingly, in Chapters 5 we show that cyclotraxin-B, a specific TrkB inhibitor, induces a lasting downregulation of the expression of a subset of genes involved in neuroplasticity pathways, concomitant with post-translational modifications at histone tails as well as altered MeCP2 binding at those genes. Hence, our findings provide further insight into the neuroplastic and epigenetic effects of TrkB modulators, and point out that the ability of TrkB antagonists to reverse abnormal BDNF-mediated epigenetic remodeling in the dopaminergic system could bear therapeutic value.

Bcl2 as a promising therapeutic target for mood disorders: In the research work presented in this thesis, we studied BDNF/TrkB signaling and its downstream signaling pathways in various models, and using different approaches. It is interesting to note that, among all the TrkB target genes examined, the b-cell lymphoma 2 (Bcl2) gene was most consistently affected in our models. Accordingly, in Chapter 7, we found that GR impairment was associated with a robust decrease of Bcl2 mRNA levels in the hippocampus, and that this deficit was restored by chronic antidepressant treatment. Further, we found 
that the Bcl2 gene expression was decreased by pharmacological intervention aiming at blocking the TrkB receptor (Chapter 5 and 7). In addition, the chronic downregulation of BDNF/TrkB signaling was associated with lasting epigenetic remodeling at the $\mathrm{Bcl} 2$ gene promoter (Chapter 5). Bcl2 has been described as an important regulator of cell survival (Davies, 1995), and antidepressants and mood stabilizers have been shown to enhance the expression of Bcl2 in rodents (Hunsberger et al., 2009; Kosten et al., 2007). Hence, compounds that specifically increase Bcl2 levels in cortico-limbic areas might be a therapeutic strategy for the treatment of mood disorders.

Chromatin-modifving drugs in the treatment of mood disorders: As mentioned in the previous sections, our findings on epigenetic dysregulations in the hippocampus support the notion that chromatin remodeling via histone modifications can increase the susceptibility for mood disorders. In Chapter 7 and $\mathbf{8}$, we provide further insight into the epigenetic potential of antidepressants. We showed that the altered HDAC2 levels, as well as post-translational modifications at histone tails (e.g. H3K27me3 and $\mathrm{H} 3 \mathrm{~K} 9 / 14 \mathrm{ac}$ ) in adult mice subjected to prolonged exposure to stress can be restored by chronic treatment with agomelatine. The reversal of chromatin-related alterations correlated with behavioral remission indicating that epigenetic processes are required for the therapeutic action of antidepressants. In contrast, chronic agomelatine treatment could not restore the alterations of epigenetic regulation (e.g. DNMT1, DNMT3a, MLL3 and MLL4) in GR-i mice. Although these results are conflicting, other studies have reported that antidepressants require epigenetic regulation to mediate their neurochemical and behavioral effects. The positive effect of chromatin modifying drugs in animal models of mood disorders further support this hypothesis. In particular, HDAC inhibitors and DNMT inhibitors represent potentially powerful agents for the treatment of psychiatric disorders through regulation of plasticity-related gene expression (Sales et al., 2011; Covington et al., 2009). On the other hand, these molecular agents are expected to exert their effects on a substantial proportion of the genome, thereby most likely inducing numerous negative side effects. More specifically, inhibitors of DNA methylation have been suggested to promote cancer metastasis, systemic lupus erythematosus or other autoimmune diseases. Nevertheless, several epigenetic drugs targeting DNA methylation and histone deacetylation enzymes have recently been approved for clinical application in oncology, while some are still being tested in clinical trials (Arrowsmith et al., 2012). Hence, in a first step of research, future clinical studies should investigate whether such drugs exhibit better remission rates on depressed mood in cancer patients suffering from comorbid depression. This would provide a first line of clinical evidence for potential therapeutic effects of epigenetic drugs in the treatment of mood disorders. 


\section{IV - Concluding remarks}

In the present thesis, we have investigated the involvement of BDNF/TrkB signaling and its downstream epigenetic regulation in the pathophsyiology and treatment of mood disorders using different rodent models and approaches. Our findings indicate that epigenetic regulation at BDNF/TrkB signaling is critically important in the establishment and maintenance of neuronal plasticity. Moreover, adverse environmental exposures, especially when occurring during development, are able to induce stable and enduring epigenetic reprogramming involving aberrant BDNF/TrkB signaling and impaired neuroplasticity, thereby increasing the vulnerability to stress and related mood disorders. Interestingly, antidepressants require TrkB to exert some of their neurochemical and behavioral effects. Hence, targeting the BDNF receptor TrkB in order to restore plasticity-related gene expression and associated neuronal functioning appears to be a promising strategy for the treatment of mood disorders.

\section{V - References}

Arrowsmith, C. H., Bountra, C., Fish, P. V., Lee, K. and Schapira, M. (2012) Epigenetic protein families: a new frontier for drug discovery. Nat Rev Drug Discov 11, 384-400.

Autry, A. E. and Monteggia, L. M. (2012) Brain-derived neurotrophic factor and neuropsychiatric disorders. Pharmacol Rev 64, 238-258.

Avital, A., Segal, M. and Richter-Levin, G. (2006) Contrasting roles of corticosteroid receptors in hippocampal plasticity. J Neurosci 26, 9130-9134.

Baj, G., Leone, E., Chao, M. V. and Tongiorgi, E. (2011) Spatial segregation of BDNF transcripts enables BDNF to differentially shape distinct dendritic compartments. Proc Natl Acad Sci U S A 108, 16813-16818.

Berton, O. and Nestler, E. J. (2006) New approaches to antidepressant drug discovery: beyond monoamines. Nat Rev Neurosci 7, 137-151.

Besusso, D., Geibel, M., Kramer, D., Schneider, T., Pendolino, V., Picconi, B., Calabresi, P., Bannerman, D. M. and Minichiello, L. (2013) BDNF-TrkB signaling in striatopallidal neurons controls inhibition of locomotor behavior. Nat Commun 4, 2031.

Boulle, F., van den Hove, D. L., Jakob, S. B., Rutten, B. P., Hamon, M., van Os, J., Lesch, K. P., Lanfumey, L., Steinbusch, H. W. and Kenis, G. (2012) Epigenetic regulation of the BDNF gene: implications for psychiatric disorders. Mol Psychiatry 17, 584-596.

Cases, O., Lebrand, C., Giros, B., Vitalis, T., De Maeyer, E., Caron, M. G., Price, D. J., Gaspar, P. and Seif, I. (1998) Plasma membrane transporters of serotonin, dopamine, and norepinephrine mediate serotonin accumulation in atypical locations in the developing brain of monoamine oxidase A knock-outs. J Neurosci 18, 6914-6927.

Castren, E. and Rantamaki, T. (2010) Role of brain-derived neurotrophic factor in the aetiology of depression: implications for pharmacological treatment. CNS Drugs 24, 1-7.

Castren, E. and Rantamaki, T. (2010) The role of BDNF and its receptors in depression and antidepressant drug action: Reactivation of developmental plasticity. Dev Neurobiol 70, 289-297. 
Cazorla, M., Premont, J., Mann, A., Girard, N., Kellendonk, C. and Rognan, D. (2011) Identification of a lowmolecular weight TrkB antagonist with anxiolytic and antidepressant activity in mice. J Clin Invest 121, $1846-1857$.

Chao, M. V. (2003) Neurotrophins and their receptors: a convergence point for many signalling pathways. Nat Rev Neurosci 4, 299-309.

Cooper, W. O., Willy, M. E., Pont, S. J. and Ray, W. A. (2007) Increasing use of antidepressants in pregnancy. Am J Obstet Gynecol 196, 544 e541-545.

Covington, H. E., 3rd, Maze, I., LaPlant, Q. C., Vialou, V. F., Ohnishi, Y. N., Berton, O., Fass, D. M., Renthal, W., Rush, A. J., 3rd, Wu, E. Y., Ghose, S., Krishnan, V., Russo, S. J., Tamminga, C., Haggarty, S. J. and Nestler, E. J. (2009) Antidepressant actions of histone deacetylase inhibitors. J Neurosci 29, 11451-11460.

Davies, A. M. (1995) The Bcl-2 family of proteins, and the regulation of neuronal survival. Trends Neurosci 18, 355-358.

de Bodinat, C., Guardiola-Lemaitre, B., Mocaer, E., Renard, P., Munoz, C. and Millan, M. J. (2010) Agomelatine, the first melatonergic antidepressant: discovery, characterization and development. Nat Rev Drug Discov 9, 628642 .

de Kloet, E. R. (2000) Stress in the brain. Eur J Pharmacol 405, 187-198.

Dias, B. G., Banerjee, S. B., Duman, R. S. and Vaidya, V. A. (2003) Differential regulation of brain derived neurotrophic factor transcripts by antidepressant treatments in the adult rat brain. Neuropharmacology 45, 553-563.

Dietz, D. M., Laplant, Q., Watts, E. L., Hodes, G. E., Russo, S. J., Feng, J., Oosting, R. S., Vialou, V. and Nestler, E. J. (2011) Paternal transmission of stress-induced pathologies. Biol Psychiatry 70, 408-414.

Duman, R. S. and Aghajanian, G. K. (2012) Synaptic dysfunction in depression: potential therapeutic targets. Science $338,68-72$.

Dwivedi, Y. (2003) Involvement of brain-derived neurotrophic factor in late-life depression. Am J Geriatr Psychiatry 21, 433-449.

Fabel, K. and Kempermann, G. (2008) Physical activity and the regulation of neurogenesis in the adult and aging brain. Neuromolecular Med 10, 59-66.

Froger, N., Palazzo, E., Boni, C., Hanoun, N., Saurini, F., Joubert, C., Dutriez-Casteloot, I., Enache, M., Maccari, S., Barden, N., Cohen-Salmon, C., Hamon, M. and Lanfumey, L. (2004) Neurochemical and behavioral alterations in glucocorticoid receptor-impaired transgenic mice after chronic mild stress. J Neurosci 24, 2787-2796.

Gaspar, P., Cases, O. and Maroteaux, L. (2003) The developmental role of serotonin: news from mouse molecular genetics. Nat Rev Neurosci 4, 1002-1012.

Harvey, A. G. (2008) Sleep and circadian rhythms in bipolar disorder: seeking synchrony, harmony, and regulation. Am J Psychiatry 165, 820-829.

Heldt, S. A., Stanek, L., Chhatwal, J. P. and Ressler, K. J. (2007) Hippocampus-specific deletion of BDNF in adult mice impairs spatial memory and extinction of aversive memories. Mol Psychiatry 12, 656-670.

Homberg, J. R., Schubert, D. and Gaspar, P. (2010) New perspectives on the neurodevelopmental effects of SSRIs. Trends Pharmacol Sci 31, 60-65.

Hunsberger, J., Austin, D. R., Henter, I. D. and Chen, G. (2009) The neurotrophic and neuroprotective effects of psychotropic agents. Dialogues Clin Neurosci 11, 333-348.

Jha, S., Dong, B. and Sakata, K. (2011) Enriched environment treatment reverses depression-like behavior and restores reduced hippocampal neurogenesis and protein levels of brain-derived neurotrophic factor in mice lacking its expression through promoter IV. Transl Psychiatry 1, e40. 
Karpova, N. N. (2013) Role of BDNF epigenetics in activity-dependent neuronal plasticity. Neuropharmacology.

Kassel, O. and Herrlich, P. (2007) Crosstalk between the glucocorticoid receptor and other transcription factors: molecular aspects. Mol Cell Endocrinol 275, 13-29.

Keers, R. and Uher, R. (2012) Gene-environment interaction in major depression and antidepressant treatment response. Curr Psychiatry Rep 14, 129-137.

Kosten, T. A., Galloway, M. P., Duman, R. S., Russell, D. S. and D'Sa, C. (2008) Repeated unpredictable stress and antidepressants differentially regulate expression of the bcl-2 family of apoptotic genes in rat cortical, hippocampal, and limbic brain structures. Neuropsychopharmacology 33, 1545-1558.

Krishnan, V., Han, M. H., Graham, D. L., Berton, O., Renthal, W., Russo, S. J., Laplant, Q., Graham, A., Lutter, M., Lagace, D. C., Ghose, S., Reister, R., Tannous, P., Green, T. A., Neve, R. L., Chakravarty, S., Kumar, A., Eisch, A. J., Self, D. W., Lee, F. S., Tamminga, C. A., Cooper, D. C., Gershenfeld, H. K. and Nestler, E. J. (2007) Molecular adaptations underlying susceptibility and resistance to social defeat in brain reward regions. Cell 131, 391-404.

Krugers, H. J., Goltstein, P. M., van der Linden, S. and Joels, M. (2006) Blockade of glucocorticoid receptors rapidly restores hippocampal CA1 synaptic plasticity after exposure to chronic stress. Eur J Neurosci 23, 3051-3055.

Laine, K., Heikkinen, T., Ekblad, U. and Kero, P. (2003) Effects of exposure to selective serotonin reuptake inhibitors during pregnancy on serotonergic symptoms in newborns and cord blood monoamine and prolactin concentrations. Arch Gen Psychiatry 60, 720-726.

Lanfumey, L., Mongeau, R. and Hamon, M. (2013) Biological rhythms and melatonin in mood disorders and their treatments. Pharmacol Ther 138, 176-184.

Lee, S. T., Chu, K., Jung, K. H., Kim, J. H., Huh, J. Y., Yoon, H., Park, D. K., Lim, J. Y., Kim, J. M., Jeon, D., Ryu, H., Lee, S. K., Kim, M. and Roh, J. K. (2012) miR-206 regulates brain-derived neurotrophic factor in Alzheimer disease model. Ann Neurol 72, 269-277.

Lessmann, V. (1998) Neurotrophin-dependent modulation of glutamatergic synaptic transmission in the mammalian CNS. Gen Pharmacol 31, 667-674.

Liu, X., Chan, C. B., Jang, S. W., Pradoldej, S., Huang, J., He, K., Phun, L. H., France, S., Xiao, G., Jia, Y., Luo, H. R. and Ye, K. (2010) A Synthetic 7,8-Dihydroxyflavone Derivative Promotes Neurogenesis and Exhibits Potent Antidepressant Effect. J Med Chem.

Lupien, S. J., McEwen, B. S., Gunnar, M. R. and Heim, C. (2009) Effects of stress throughout the lifespan on the brain, behaviour and cognition. Nat Rev Neurosci 10, 434-445.

Martinowich, K., Hattori, D., Wu, H., Fouse, S., He, F., Hu, Y., Fan, G. and Sun, Y. E. (2003) DNA methylationrelated chromatin remodeling in activity-dependent BDNF gene regulation. Science 302, 890-893.

Martinowich, K. and Lu, B. (2008) Interaction between BDNF and serotonin: role in mood disorders. Neuropsychopharmacology 33, 73-83.

Martinowich, K., Manji, H. and Lu, B. (2007) New insights into BDNF function in depression and anxiety. Nat Neurosci 10, 1089-1093.

Maze, I., Noh, K. M. and Allis, C. D. (2013) Histone regulation in the CNS: basic principles of epigenetic plasticity. Neuropsychopharmacology 38, 3-22.

Mifsud, K. R., Gutierrez-Mecinas, M., Trollope, A. F., Collins, A., Saunderson, E. A. and Reul, J. M. (2011) Epigenetic mechanisms in stress and adaptation. Brain Behav Immun 25, 1305-1315.

Mirescu, C. and Gould, E. (2006) Stress and adult neurogenesis. Hippocampus 16, 233-238.

Mostert, J. P., Koch, M. W., Heerings, M., Heersema, D. J. and De Keyser, J. (2008) Therapeutic potential of fluoxetine in neurological disorders. CNS Neurosci Ther 14, 153-164. 
Oberlander, T. F., Gingrich, J. A. and Ansorge, M. S. (2009) Sustained neurobehavioral effects of exposure to SSRI antidepressants during development: molecular to clinical evidence. Clin Pharmacol Ther 86, 672-677.

Ochs, G., Penn, R. D., York, M., Giess, R., Beck, M., Tonn, J., Haigh, J., Malta, E., Traub, M., Sendtner, M. and Toyka, K. V. (2000) A phase I/II trial of recombinant methionyl human brain derived neurotrophic factor administered by intrathecal infusion to patients with amyotrophic lateral sclerosis. Amyotroph Lateral Scler Other Motor Neuron Disord 1, 201-206.

Paizanis, E., Renoir, T., Lelievre, V., Saurini, F., Melfort, M., Gabriel, C., Barden, N., Mocaer, E., Hamon, M. and Lanfumey, L. (2010) Behavioural and neuroplastic effects of the new-generation antidepressant agomelatine compared to fluoxetine in glucocorticoid receptor-impaired mice. Int J Neuropsychopharmacol 13, 759-774.

Pawluski, J. L., Galea, L. A., Brain, U., Papsdorf, M. and Oberlander, T. F. (2009) Neonatal S100B protein levels after prenatal exposure to selective serotonin reuptake inhibitors. Pediatrics 124, e662-670.

Poduslo, J. F. and Curran, G. L. (1996) Permeability at the blood-brain and blood-nerve barriers of the neurotrophic factors: NGF, CNTF, NT-3, BDNF. Brain Res Mol Brain Res 36, 280-286.

Probst, A. V., Dunleavy, E. and Almouzni, G. (2009) Epigenetic inheritance during the cell cycle. Nat Rev Mol Cell Biol 10, 192-206.

Pruunsild, P., Kazantseva, A., Aid, T., Palm, K. and Timmusk, T. (2007) Dissecting the human BDNF locus: bidirectional transcription, complex splicing, and multiple promoters. Genomics 90, 397-406.

Quesseveur, G., David, D. J., Gaillard, M. C., Pla, P., Wu, M. V., Nguyen, H. T., Nicolas, V., Auregan, G., David, I., Dranovsky, A., Hantraye, P., Hen, R., Gardier, A. M., Deglon, N. and Guiard, B. P. (2013) BDNF overexpression in mouse hippocampal astrocytes promotes local neurogenesis and elicits anxiolytic-like activities. Transl Psychiatry 3, e253.

Roth, T. L., Lubin, F. D., Funk, A. J. and Sweatt, J. D. (2009) Lasting epigenetic influence of early-life adversity on the BDNF gene. Biol Psychiatry 65, 760-769.

Roth, T. L. and Sweatt, J. D. (2011) Epigenetic marking of the BDNF gene by early-life adverse experiences. Horm Behav 59, 315-320.

Sales, A. J., Biojone, C., Terceti, M. S., Guimaraes, F. S., Gomes, M. V. and Joca, S. R. (2011) Antidepressant-like effect induced by systemic and intra-hippocampal administration of DNA methylation inhibitors. Br J Pharmacol 164, 1711-1721.

Scharfman, H. E. and MacLusky, N. J. (2006) Estrogen and brain-derived neurotrophic factor (BDNF) in hippocampus: complexity of steroid hormone-growth factor interactions in the adult CNS. Front Neuroendocrinol $27,415-435$.

Shirayama, Y., Chen, A. C., Nakagawa, S., Russell, D. S. and Duman, R. S. (2002) Brain-derived neurotrophic factor produces antidepressant effects in behavioral models of depression. J Neurosci 22, 3251-3261.

Solum, D. T. and Handa, R. J. (2002) Estrogen regulates the development of brain-derived neurotrophic factor mRNA and protein in the rat hippocampus. J Neurosci 22, 2650-2659.

Sousa, N., Cerqueira, J. J. and Almeida, O. F. (2008) Corticosteroid receptors and neuroplasticity. Brain Res Rev 57 , 561-570.

Suri, D. and Vaidya, V. A. (2013) Glucocorticoid regulation of brain-derived neurotrophic factor: relevance to hippocampal structural and functional plasticity. Neuroscience 239, 196-213.

Taliaz, D., Stall, N., Dar, D. E. and Zangen, A. (2010) Knockdown of brain-derived neurotrophic factor in specific brain sites precipitates behaviors associated with depression and reduces neurogenesis. Mol Psychiatry 15, 80-92.

Tsankova, N., Renthal, W., Kumar, A. and Nestler, E. J. (2007) Epigenetic regulation in psychiatric disorders. Nat Rev Neurosci 8, 355-367. 
Tsankova, N. M., Berton, O., Renthal, W., Kumar, A., Neve, R. L. and Nestler, E. J. (2006) Sustained hippocampal chromatin regulation in a mouse model of depression and antidepressant action. Nat Neurosci 9, 519-525.

van Praag, H., Kempermann, G. and Gage, F. H. (1999) Running increases cell proliferation and neurogenesis in the adult mouse dentate gyrus. Nat Neurosci 2, 266-270.

Wang, J., Korczykowski, M., Rao, H., Fan, Y., Pluta, J., Gur, R. C., McEwen, B. S. and Detre, J. A. (2007) Gender difference in neural response to psychological stress. Soc Cogn Affect Neurosci 2, 227-239.

World Health Organization (WHO). (2001). The world health report 2001. Mental health. New understanding. New hope. Geneva WHO.

Zanchi, N. E., Filho, M. A., Felitti, V., Nicastro, H., Lorenzeti, F. M. and Lancha, A. H., Jr. (2010) Glucocorticoids: extensive physiological actions modulated through multiple mechanisms of gene regulation. J Cell Physiol 224, 311315.

Zhang, Y. H., Chi, X. X. and Nicol, G. D. (2008) Brain-derived neurotrophic factor enhances the excitability of rat sensory neurons through activation of the p75 neurotrophin receptor and the sphingomyelin pathway. J Physiol 586, 3113-3127. 


\section{SUMMARY}

Mood disorders are among the major health problems worldwide due to the high prevalence and recurrence in the general population, and the significant burden for individual life quality and the repercussion on healthcare systems and society. Up to date, the etiology and biological mechanisms underlying mood disorders are still poorly understood. Mounting evidences suggest that a complex interaction between genes and environment might account in the development and course of major depression i.e. one of the most prevalent affective disorders. Accordingly, complex epigenetic regulations - consisting of key mechanisms by which environmental factors induce enduring changes in gene expression without altering the DNA code - have been suspected to plays a pivotal role in the pathophysiology of depression. More specifically, epigenetic repression of the gene encoding for brainderived neurotrophic factor (BDNF) - a small-secreted growth factor implicated in brain development and neuronal plasticity - may have a preponderant role in the onset of depression and other mood disorders.

In this context, the research presented in this thesis aimed at exploring the role of BDNF signaling and its downstream epigenetic regulations in the pathophysiology and treatment of mood disorders.

Our findings indicate that epigenetic regulation at BDNF/TrkB signaling is critically important in the establishment and maintenance of neuronal plasticity. Moreover, environmental variations, especially when occurring in development, are able to induce stable and enduring epigenetic reprogramming involving aberrant BDNF/TrkB signaling and impaired neuroplasticity, thereby increasing vulnerability to stress and mood disorders. Interestingly, antidepressants require TrkB to exert some of their neurochemical and behavioral effects. Hence, targeting the BDNF receptor TrkB to restore a normal epigenetic regulation and neuronal functioning appears to be a promising strategy for the treatment of mood disorders. 


\section{RESUME}

Les troubles de l'humeur font partie des problèmes de santé majeurs dans le monde, du fait de leur forte incidence et récurrence dans la population générale, de la nuisance pour la qualité de vie des patients ainsi que la répercussion majeure sur les systèmes de santé. A ce jour, l'étiologie ainsi que les mécanismes biologiques sous-jacents les troubles de l'humeur sous encore très mal connus. Un nombre grandissant de preuves suggère qu'une interaction complexe entre les gènes et l'environnement serait a l'origine de la mise en place et évolution des épisodes dépressifs majeurs - un des troubles de l'humeur les plus répandus. Par conséquent, des régulations épigénétiques complexes, qui consistent en des mécanismes clefs par lesquels l'environnement induit des changements persistant sur l'expression des gènes (sans modifier le code génétique), joueraient un rôle prépondérant dans la pathophysiologie de la dépression. De manière plus spécifique, la répression épigénétique du gène codant pour le brain-derived neurotrophic factor (BDNF) - un facteur de croissance impliqué dans la plasticité neuronale et développement du système nerveux central - serait un mécanisme clef dans la mise en place de la dépression et autres troubles de l'humeur.

Dans ce contexte, les travaux de recherche présentés dans cette thèse visent à explorer le rôle des régulations épigénétiques au niveau de la signalisation $\mathrm{BDNF} / \operatorname{TrkB}$ dans la physiopathologie et traitement des troubles de l'humeur.

Les résultats montrent que les régulations épigénétiques au niveau de la signalisation BDNF/TrkB sont fortement impliquées dans la mise en place et maintenance de la plasticité neuronale. De plus, les variations environnementales, particulièrement au cours du développement, sont capables d'induire une reprogrammation épigénétique stable et persistante au niveau du complexe BDNF/TrkB ainsi qu'une altération de la neuroplasticité, conduisant à une augmentation de la vulnérabilité au stress et troubles de l'humeur. De manière intéressante, la signalisation du récepteur TrkB est nécessaire pour les effets neurobiologiques et comportementaux des antidépresseurs. De ce fait, une approche pharmocologique ciblée sur le complexe BDNF/TrkB et ses régulations épigénétiques sous-jacentes apparaît comme stratégie thérapeutique prometteuse pour le traitement des troubles de l'humeur tel que la dépression. 


\section{ACKNOWLEDGEMENTS}

First of all, I would like to express my sincerest gratitude to Professor Harry Steinbusch and Professor Laurence Lanfumey for organizing this collaborative project. It was a real pleasure and a highly enriching experience to achieve this joint $\mathrm{PhD}$ program between the university of Maastricht and the university of Paris-Descartes. In particular, I would like to thank you Harry for giving me the opportunity to join your lab in Maastricht, and for setting up an exciting research project within the Translational NeuroPsychiatry (TNP) group. In addition, I greatly appreciated your continuous support and guidance throughout my whole PhD.

Dear Laurence, I also thank you for arranging this collaborative PhD project, and made your best to find solutions and funding in order to give me the opportunity to start a $\mathrm{PhD}$ program after my master internship. Thank you for all your availability, your trust and your energy during my PhD. It was really fruitful to have you as a scientific mentor, and also to benefit from your generosity, kindness and sympathy.

Further, I would like to warmly thank Professor Michel Hamon. Michel, I am very grateful for all your help and support in my $\mathrm{PhD}$ project. You always found time and energy to correct and improve scientific papers or give wise advises on research projects. Thank for sharing your passion for research, your scientific excellence and your vast knowledge in neuropharmacology.

Dear Daniel and Gunter, I would like to thank you for your precious supervision during these past years. You have contributed significantly to the improvement and the quality of my whole $\mathrm{PhD}$ project, and your continuous enthusiasm and endless motivation were really necessary to encourage me in my research. I think that your passion for science seriously impacted on the epigenetic reprogramming of my brain and helped me becoming a better scientist. I truly learned a lot by your side in Maastricht, and I am really grateful for this enriching experience.

I would like to thank all the members of the TNP group (i.e. Bart, Shahed, Julie, Mark, Rianne, Caroline, Nicole, Roy, Kostas, Bojan, Katia and many more...). It was a real pleasure to work with you, and share some common interests about translational research and epigenetics. To a larger extend, I would like to thank all the PhD students (and Jos) from the department of Psychiatry and Neuropsychology. Sven, Jochen, Annerieke, Evi, Eva, Tim, Jo, Alexandro and et al., I really enjoyed spending time with all of you 
at parties, BBQs or conferences. Pr. Chouliaras and Pr. Andrade thank you for being two real friends and colleagues, and living this fantastic adventure in Maastricht. Similarly, I would like to thank my paranymphs Ehsan and Paddy for arranging my PhD defense and for all the good moments we had in Maastricht. I would also like to thank Barbie and Andrea for their technical assistance and expert advises regarding ChIP experiments. Finally, I could not have accomplished this work without the help of many bachelor and master students: Henry, Pierre, Justina, Andro, Neha, Judith, Joost and Koen.

Evidently, I would like to warmly thank all my French family of La Pitie-Salpetriere. I have truly enjoyed working at the department of Neuropsychopharmacology, and will definitely keep some epic memories about my experience in this laboratory. I have found there a diversity of researchers sharing this common passion for science, but also a generous and friendly atmosphere making me feel home. In particular, I would like to thank Cedric, Sana, Said and Touf for their ability to gather people, to create a cozy environment in the lab and to contaminate people with their enthusiastic mood. I also found nice buddies including Emilien, Caro, Vincent, Alvarro, Boris, Elodie, Benoit, Florent, Anne, Adeline etc... who were always motivated to share some scientific ideas, experiences or gossips around a beer chez Jimmy. Samy, kan to le nou capav bwar ene ti rum et manj ene carry poul. Last but not least, I would like to thank all my students, Esther, Lara and Marion for helping me with experiments, and also for tolerating my strict supervision.

I am also very grateful to Nicole for her precious assistance in the organization of the double $\mathrm{PhD}$ degree. In addition, I would like to thank all the members of the reading committee i.e. Prof. Dr. De Baets, Prof. Dr. Lesch, Prof. Dr. Gorwood, Dr. Mongeau, Dr. Romano and Dr. Korosi for reviewing my thesis and giving your approval for the defense. I would also like to thank Prof. Dr. Tronche for being an external member of my corona.

Finally, I would like to address the warmest thanks to my family and girlfriend for supporting me during those past years. I am grateful to my parents Jean-Jacques and Micheline, and my brother Amaury for their mental support, even through the distance, during my PhD. In particular, I strongly appreciated the help and cheering on of my lovely Stephje. Thank you for tolerating my mood swings during the stressful moments of my PhD, and providing me even more energy to achieve my goal. You are the best 


\section{ABOUT THE AUTHOR}

Fabien Boulle was born on November $24^{\text {th }}, 1985$ in Curepipe (Republic of Mauritius). He attended the Lycee La Bourdonnais in Mauritius, where he completed a scientific Baccalaureate program.

In 2003, he started a Bachelor program in Cell Biology and Physiology at the University Paul Sabatier (Toulouse, France). Then, he specialized in the field of pharmacology at the Paris-Sud University (Paris, France) where he obtained his master degree in "Pharmacology, pharmacokinetics and pharmacogenetics" in 2009. During his master internship, he has investigated the pharmacological properties of newly developed TrkB ligands at the "Center for Psychiatry and Neuroscience - INSERM U894" (Paris, France) under the supervision of Dr. Joel Premont. In particular, he has been focusing on the (trans)activation of the TrkB receptor and the possible therapeutic value of compounds directly targeting the TrkB receptor.

In 2010, he officially started a collaborative $\mathrm{PhD}$ project initiated by the Paris-Descartes University (Center for Psychiatry and Neuroscience; Paris, France) and the University of Maastricht (Department of Psychiatry and Neuropsychology; Maastricht, The Netherlands) coordinated by Prof. Dr. Harry Steinbusch and Prof. Dr. Laurence Lanfumey. During his doctoral internship, he has been focusing on the epigenetic regulation of BDNF/TrkB signaling in the pathophysiology and treatment of mood disorders. In particular, he has been investigating the role of epigenetic regulation at BDNF/TrkB signaling in the development and maintenance of neuronal plasticity, under the supervision of Dr. Daniel van den Hove and Dr. Gunter Kenis at the department of Psychiatry and Neuropsychology (University of Maastricht). At the Center for Psychiatry and Neuroscience (Paris, France), he has been studying the role of $\mathrm{BDNF} / \mathrm{TrkB}$ signaling in the mechanism of action of antidepressants under the supervision of Prof. Dr. Laurence Lanfumey.

Since October 2013, he is actively involved in a MBA program at the IONIS School of Technology and Management (Paris, France). The MBA courses focus particularly on the management of biotechnology and pharmaceutical industry. 


\section{LIST OF PUBLICATIONS}

\section{Peer-reviewed international publications:}

Epigenetic regulation of the Bdnf gene: implications for psychiatric disorders.

Boulle F, Van den Hove DLA, Jakob S, Rutten BP, Lanfumey L, Hamon M, Steinbusch HW, Lesch KP, Kenis G.

Molecular Psychiatry, 17 (6): 584-96

TrkB inhibition as a therapeutic target for CNS-related disorders.

Boulle F, Kenis G, Cazorla M, Steinbusch HW, Lanfumey L, Van den Hove DLA.

Progress in Neurobiology, 98 (2): 197-206

\section{Submitted manuscripts:}

Blockade of the BDNF receptor TrkB downregulates the expression of plasticity genes concomitant with epigenetic changes in differentiated human neuroblastoma cells.

Boulle F, Van den Hove DLA, Machiels B, Goethals A, Pannaye P, Chinwang J, Romano A, Hamon M, Lanfumey L, Steinbusch HW, Kenis G.

Submitted; European Neuropsychopharmacology

Neuroplasticity induced by ethanol involves epigenetic regulation of BDNF in C57BL/6J mice.

Stragier E, Massart R, Salery M, Geny D, Boulle F, Hamon M, Lanfumey L.

Submitted; Molecular Psychiatry

\section{Manuscript in advanced preparation:}

Agomelatine normalizes hippocampal and behavioral dysfunction in a mouse model of environmental stress.

Boulle F, Massart R, Zaidan L, Marday S, Gabriel C, Mocaer E, Hamon M, Lanfumey L. 
Long-term behavioral and neurobiological consequences of developmental exposure to fluoxetine in a rodent model of maternal adversity.

Boulle F*, Pawluski J*, Machiels B, Kumar N, Homberg J, Kenis G, Steinbusch HW, Van den Hove DLA. (* joint first authors).

Behavioral and neurochemical characterization of TrkB-dependent mechanisms of agomelatine in glucocorticoid receptor-impaired mice.

Boulle F, Velthuis H, Kumar N, Koedam K, Van den Hove DLA, Kenis G, Steinbusch HW, Gabriel C, Mocaer E, Hamon M, Lanfumey L.

Growth factors and neuroplasticity pathways in the pathophysiology and treatment of mood disorders.

Boulle F, Van Haasteren J, Van den Hove DLA, Kenis G, Hamon M, Lanfumey L 